UNIVERSIDADE DE SÃO PAULO

FACULDADE DE MEDICINA

Estudo da associação dos polimorfismos da ECA e do AGT e fenótipos de risco cardiovascular em amostra feminina de Ouro Preto

RAIMUNDO MARQUES DO NASCIMENTO NETO

São Paulo

2007 
Raimundo Marques do Nascimento Neto

\title{
Estudo da associação dos polimorfismos da ECA e do AGT e fenótipos de risco cardiovascular em amostra feminina de Ouro Preto
}

\author{
Tese apresentado à Faculdade de \\ Medicina da Universidade de São Paulo \\ para obtenção do título de Doutor em \\ Cardiologia. \\ Área de concentração: Cardiologia \\ Orientador: Prof. Dr. José Eduardo Kreiger
}




\section{RESUMO}

Nascimento Neto, RM. Estudo da associação dos polimorfismos da ECA e do AGT e fenótipos de risco cardiovascular em amostra feminina de Ouro Preto. [tese]. São Paulo: Faculdade de Medicina, Universidade de São Paulo; 2007.

Estudamos a amostra das ouropretanas com prevalência de hipertensão arterial de (52,7\%). O objetivo foi descrever os fenótipos sistólico, diastólico e pressão de pulso e correlacionar as variantes genética da ECA e AGT. Os dados sugerem que a prevalência de hipertensão entre elas estão associadas a idade, classe social, escolaridade, hiperglicemia, circunferência da cintura abdominal, e perfil lipídico. $O$ alelo $T$ foi significante com glicemia $\{p<0,02(O R=2,2)\}$ e cor preta $\{p<0,002(O R=2,7)\}$ o alelo $D$ com idade $\{p<0,01(\mathrm{OR}=2,2)\}$ e HDL $\{p<0,0007(\mathrm{OR}=1,5)\}$. O genótipo DD com a idade $\{p<0,03(O R=0,7)\}$ e $H D L\{p<0,008(O R=2,0)\}$. A influência das variantes genéticas da ECA e do AGT tiveram pouco efeito sobre os fenótipos de pressão arterial, mas influenciaram os níveis de colesterol HDL e a glicemia, respectivamente. 


\begin{abstract}
Nascimento Neto, RM. Study of the associations of the ECA and AGT polymorphism and Cardiovascular Risk Phenotypes in a Female Sampling in Ouro Preto. [Thesis]. São Paulo: Faculdade de Medicina, Universidade de São Paulo; 2007.

We studied the sample of women from Ouro Preto with a prevalence of arterial hypertension of $(52,7 \%)$. The objective was to describe systolic, diastolic and pulse pressure phenotypes and correlate the ECA and AGT genetic variants. The data suggests that the prevalence of hypertension among them is related to age, social class, schooling, hyperglycemia, abdominal and lipidic profile. The $T$ allele showed significance with glycemia $\{p<0.02(O R=2.2)$ and color black $\{p<0.002(O R=2.7)\}$. The $D$ allele with age $\{p<0.01(\mathrm{OR}=2.2)\}$ and $\mathrm{HDL}\{\mathrm{p}<0.0007(\mathrm{OR}=1.5)\}$. The DD genotype with age $\{p<0.03(\mathrm{OR}=0.7)\}$ and $\mathrm{HDL}\{\mathrm{p}<0.008(\mathrm{OR}=2.0)\}$. Influence of the ECA and AGT genetic variants had little effect on arterial pressure phenotypes, but influenced the levels of HDL cholesterol and the hyperglycemia respectively.
\end{abstract}




\section{LISTA DE SIGLAS E ABREVIATURAS}

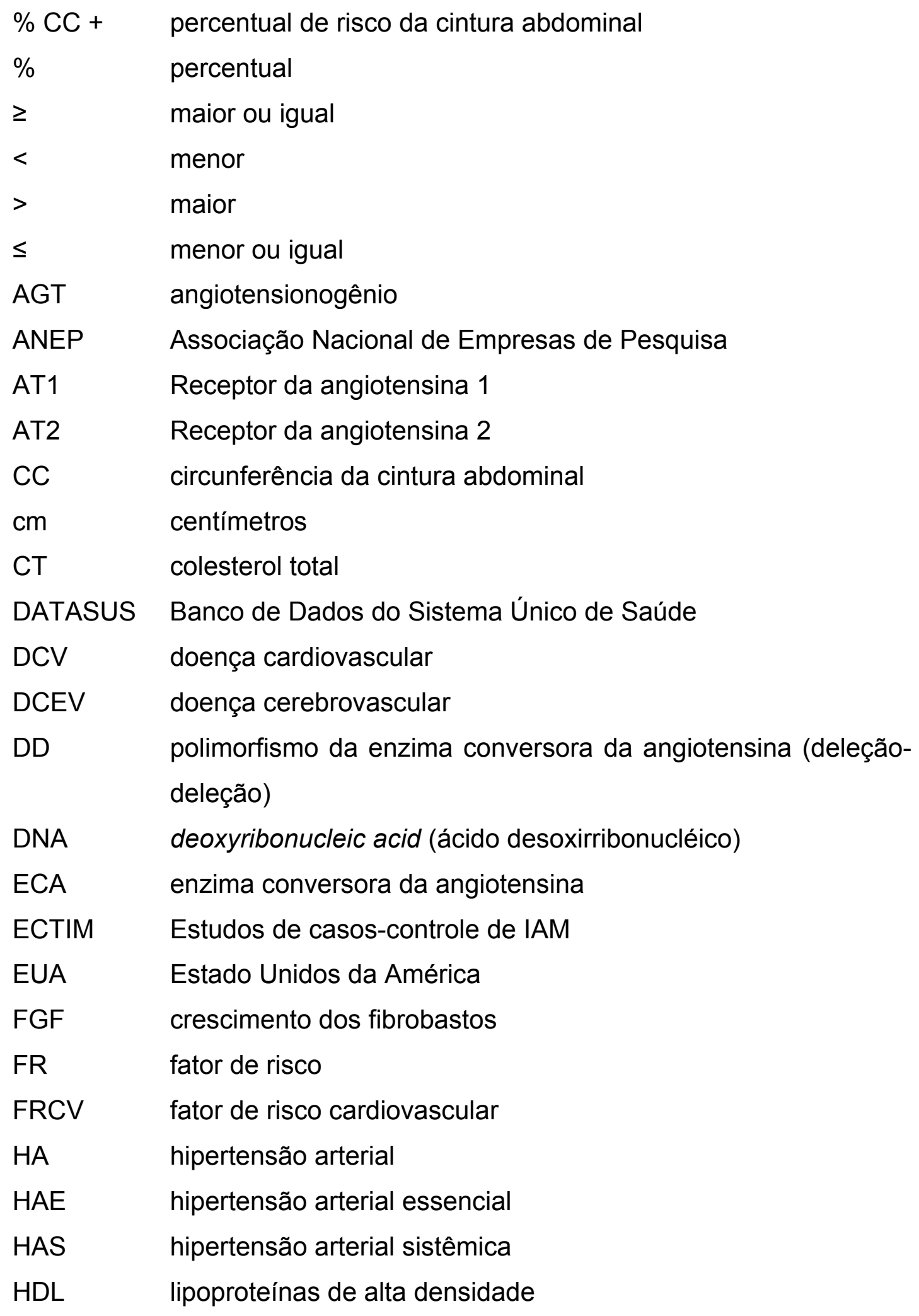




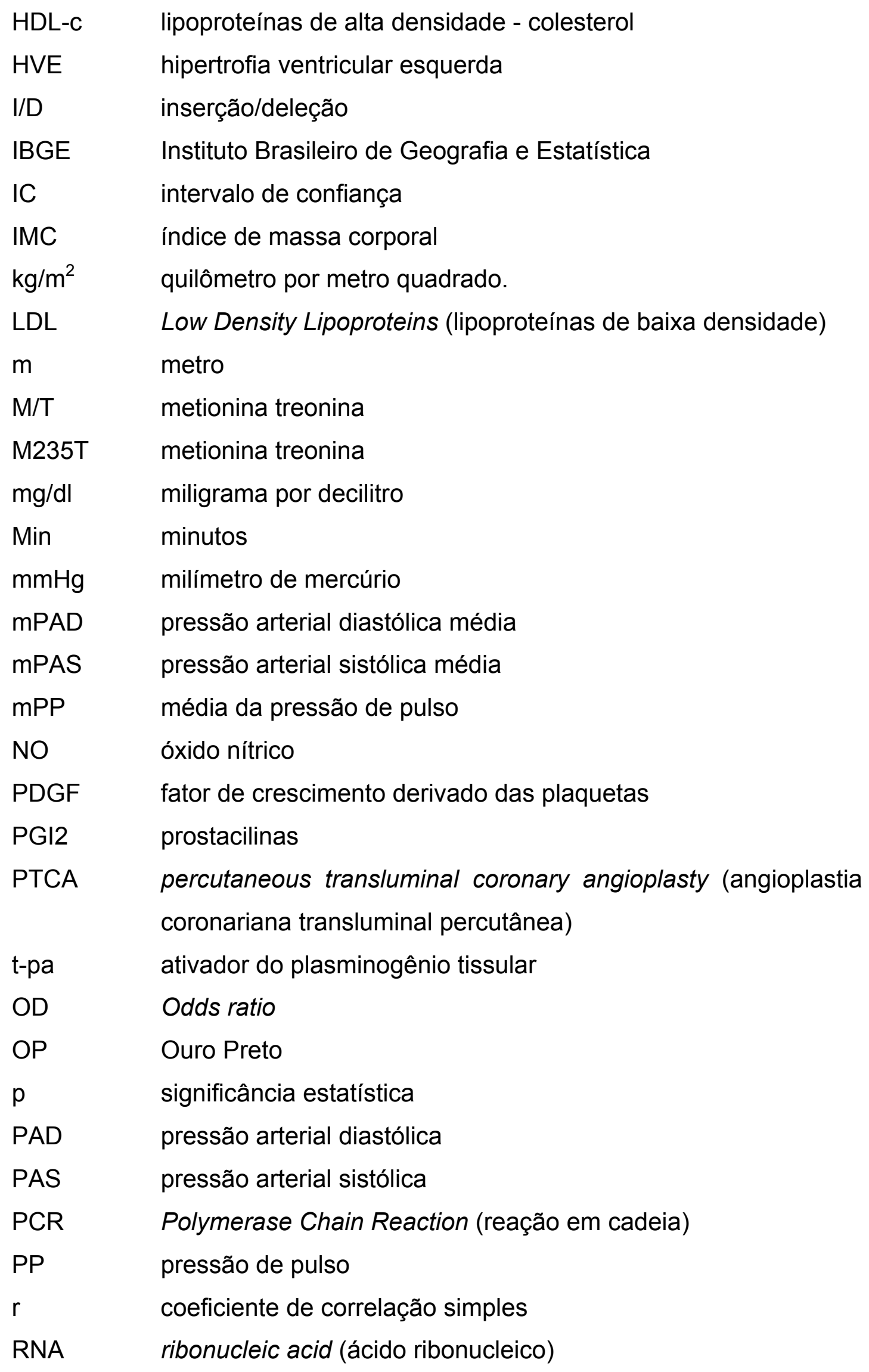


SPSS Statistical Package for the Social Sciences (pacote estatístico para as ciências sociais)

SRA sistema renina-angiotensina

UNESCO United Nations Education Science and Culture Organization (Organização das Nações Unidas para a Educação, a Ciência e a Cultura)

VII JNC VII Joint National Committee on Prevention, Detection, Evaluation, and Treatment of High Blood Pressure

VLDL very low density lipoproteins (lipoproteínas de muito baixa densidade)

$\gamma$-GT gama-glutamiltransferase 


\section{LISTA DE TABELAS}

Tabela 1 - Características demográficas socioeconômicas análises clínicas e antropométricas da amostra feminina projeto corações de Ouro Preto (MG) ................107

Tabela 2 - $\quad$ Características do fenótipo sistólico. ...............................108

Tabela 3 - $\quad$ Características do fenótipo diastólico...............................109

Tabela 4 - $\quad$ Características do fenótipo pressão de pulso....................110

Tabela 5 - Distribuição dos fenótipos da pressão arterial nas faixas etárias. .............................................................. 111

Tabela 6-A - Distribuição dos alelos do AGT e da ECA na amostra. ......112

Tabela 6-B - Distribuição dos polimorfismo do AGT e da ECA na amostra.

Tabela 7-A - Distribuição dos alelos (M e T) do AGT e do alelo (I e D) do alelo da ECA nos fenótipos faixa etária.

Tabela 7-B - Distribuição dos alelos (M e T) do AGT e do alelo (I e D) do alelo da ECA nos fenótipos cor de pele.

Tabela 8-A - Distribuição dos alelos (M e T) do AGT e (I e D) da ECA entre os fenótipos colesterol total

Tabela 8-B - Distribuição dos alelos (M e T) do AGT e (I e D) da ECA entre os fenótipos LDL colesterol.

Tabela 8-C - Distribuição dos alelos (M e T) do AGT e (I e D) da ECA entre os fenótipos HDL-colesterol.

Tabela 8-D - Distribuição dos alelos (M e T) do AGT e (I e D) da ECA entre os fenótipos triglicérides.

Tabela 9-A - Distribuição dos alelos ( $T$ e $M$ ) do AGT entre os fenótipos de índice de massa corporal.

Tabela 9-B - Distribuição dos alelos ( $T$ e $M$ ) do AGT entre os fenótipos de circunferência da cintura abdominal.

Tabela 9-C - Distribuição dos alelos ( $T$ e $M$ ) do AGT entre os fenótipos de hiperglicemia. 
Tabela 10 - Distribuição os polimorfismos do AGT e da ECA entre as faixas etárias.

Tabela 11 - Distribuição dos fenótipos sistólico, diastólico e pressão de pulso nos os polimorfismos do AGT e da ECA.

Tabela 12-A - Distribuição dos fenótipos circunferência da cintura abdominal e os polimorfismos do AGT e da ECA.

Tabela 12-B - Distribuição dos fenótipos da circunferência da cintura abdominal nos polimorfismos do AGT (MM x MT +TT) e da ECA (II x DI + DD).

Tabela 13-A - Distribuição dos fenótipos da glicemia e os polimorfismos do AGT e da ECA.

Tabela 13-B - Distribuição dos fenótipos da glicemia Nos polimorfismos do AGT (MM x MT +TT) e da ECA (II x DI + DD)

Tabela 14-A - Distribuição dos fenótipos do triglicérides nos polimorfismos do AGT e da ECA.

Tabela 14-B - Distribuição dos fenótipos do triglicérides Nos polimorfismos do AGT (MM X MT +TT) e da ECA (II x DI + DD)

Tabela 15-A - Distribuição dos fenótipos colesterol total e os polimorfismos do AGT e da ECA.

Tabela 15-B - Distribuição dos fenótipos colesterol total nos polimorfismos do AGT (MM x MT +TT) e da ECA (II x DI + DD)

Tabela 16-A - Distribuição dos fenótipos LDL colesterol os polimorfismos do AGT e da ECA.

Tabela 16-B - Distribuição dos fenótipos do LDL colesterol nos polimorfismos do AGT (MM x MT +TT) e da ECA (II x DI + DD)

Tabela 17-A - Distribuição dos fenótipos HDL-colesterol os polimorfismos do AGT e da ECA. 
Tabela 17-B - Distribuição dos fenótipos HDL-Colesterol nos polimorfismos do AGT (MM x MT +TT) e da ECA (II x $\mathrm{DI}+\mathrm{DD})$

Tabela 18 - Comparativa entre os dados da população feminina de Salvador (BA) e de Ouro Preto (MG).

Tabela 19 - Características demográficas socioeconômicas análises clínicas e antropométricas da amostra feminina projeto corações de Ouro Preto. 


\section{SUMÁRIO}

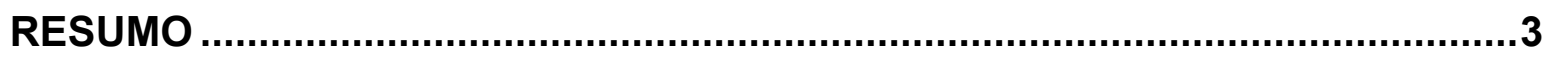

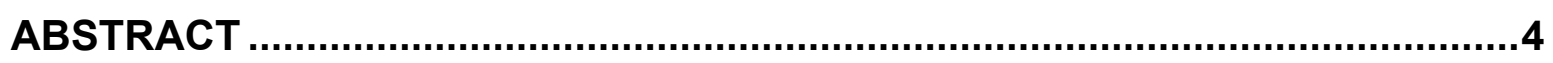

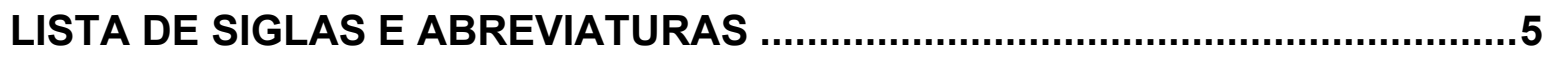

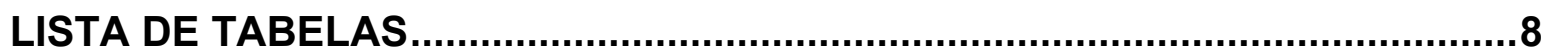

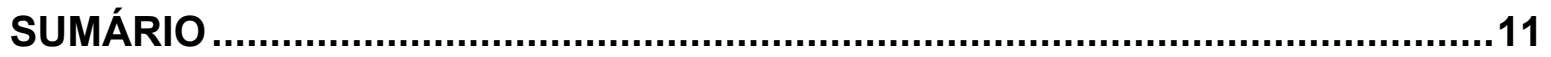

1 INTRODUÇÃO

1.1 Importância clínica e epidemiológica dos fenótipos da pressão arterial, dos fenótipos antropométricos e metabólicos............................16

1.2 Importância epidemiológica das doenças cardiovasculares na população feminina brasileira e mundial

1.3 Importância do risco nutricional e antropométrico na população

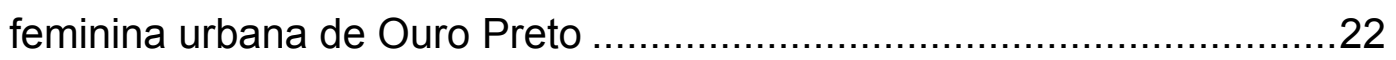

1.4 Importância do conhecimento fisiopatológico do sistema renina angiotensina nos fenótipos da pressão arterial e metabólicos

1.5 A prevalência dos alelos $D / l$ da enzima conversora da angiotensina (ECA) e seus polimorfismos, dos grupos populacionais que compuseram a população de Ouro Preto

1.6 Correlações entre os alelos e polimorfismos da ECA e do AGT com os fenótipos da pressão arterial e metabólicos

2 OBJETIVOS

3 JUSTIFICATIVAS DO ESTUDO

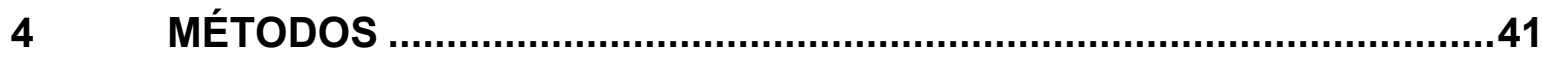

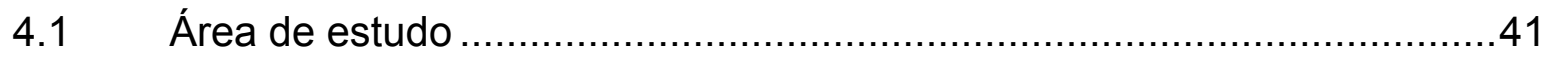

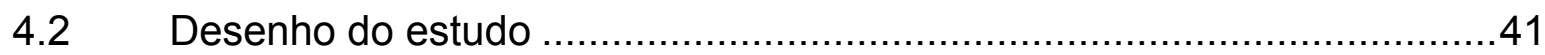

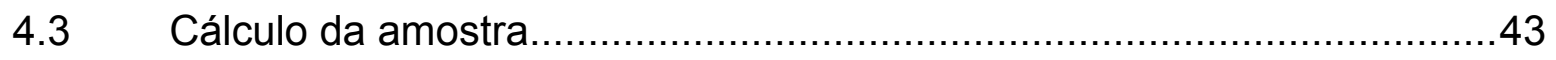

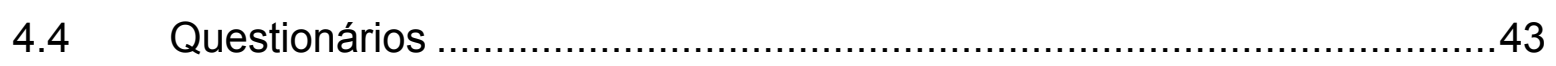

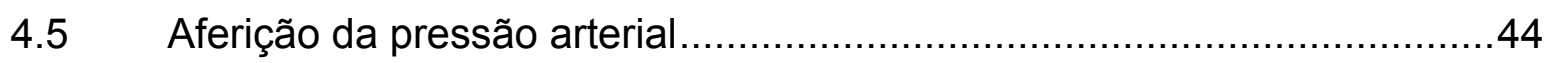


4.5.1 Recomendações sobre o procedimento de medida da pressão

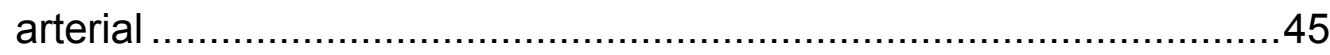

4.5.2 Procedimento de medida da pressão arterial ...............................45

4.6 Medidas antropométricas e coleta de material biológico .....................47

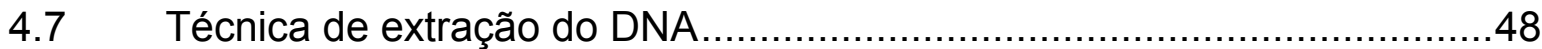

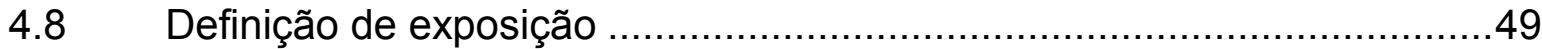

4.9 Critérios para estabelecimento dos fenótipos estudados .......................50

4.10 Processamento e análise dos dados .................................................51

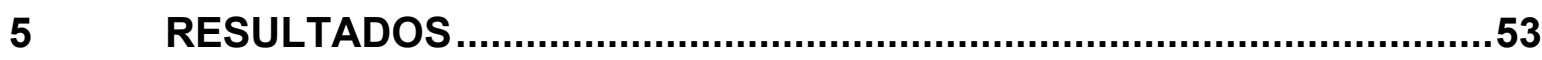

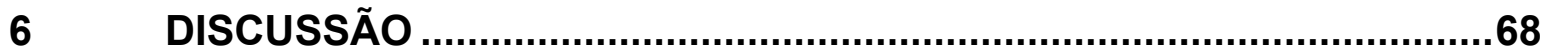

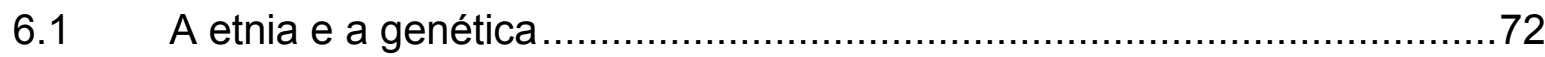

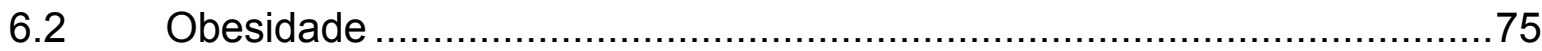

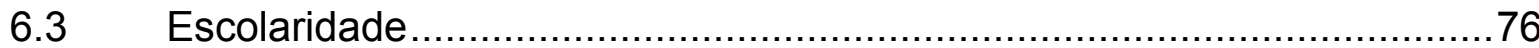

6.4 Polimorfismo do angiotensinogênio.............................................. 77

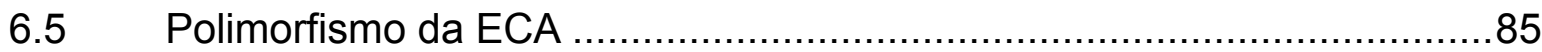

6.6 Percentuais dos genótipos entre as raças.......................................... 86

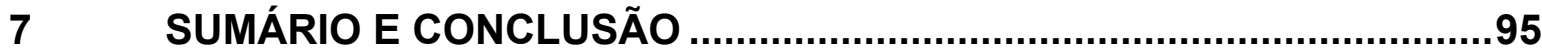

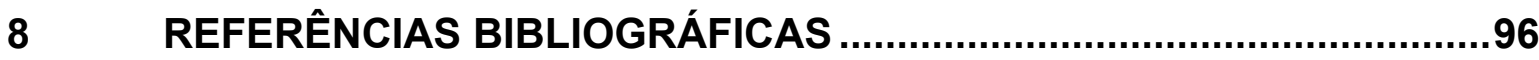

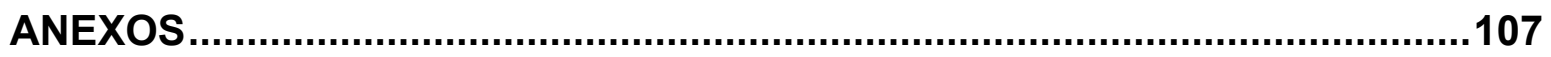

APÊNDICE I - Tabelas .......................................................................... 123

APÊNDICE II - Projeto “Corações de Ouro Preto” ........................................132

APÊNDICE III - Pesquisa .................................................................. 155 


\section{INTRODUÇÃO}

Este estudo descreve a associação dos alelos e os polimorfismos da enzima conversora da angiotensina e do angiotensinogênio, com os fenótipos de risco cardiovascular, na amostra feminina participantes do projeto "Corações de Ouro Preto". O principal objetivo desse projeto foi descrever a prevalência dos principais fatores de risco cardiovascular na população da cidade de Ouro Preto. Os objetivos secundários, os métodos e os resultados do projeto estão descritos na referência 27 .

A importância do problema é justificada por inúmeras publicações, entre elas, a da Organização Mundial da Saúde de 2003, na qual se relata que, do total de mortes de 56 milhões ocorridas no mundo, $47 \%$ ou 16 milhões resultaram de etiologia cardiovascular. ${ }^{1}$

No Brasil a estimativa do número de portadores de hipertensão arterial e diabetes é de 23 milhões. As doenças circulatórias são responsáveis por impacto expressivo na mortalidade da população brasileira, correspondendo a $32 \%$ dos óbitos em 2002, percentual equivalente a 267.496 mortes. $^{2}$

A importância social das doenças cardiovasculares é corroborada pelo fato de elas representarem a principal causa de aposentadorias, além de ser o segundo motivador de internações e o principal gerador de gastos com essas internações. ${ }^{3}$ 
O ritmo de crescimento das doenças cardiovasculares é bem maior nas economias em desenvolvimento do que nos países do primeiro mundo. Estima-se que, em 2020, haverá um aumento de $130 \%$ na incidência de cardiopatia isquêmica e $110 \%$ de doença cerebrovascular. ${ }^{1}$

Essas taxas tendem a aumentar nos próximos anos, não só pelo crescimento e envelhecimento da população, mas, sobretudo, pela persistência de hábitos inadequados de alimentação, tabagismo e atividade física. ${ }^{1,3}$

A acelerada urbanização promove a maciça transferência de grande número de pessoas das áreas rurais para as cidades, em busca de melhores condições de vida, o que faz disseminar um estilo de vida sedentário, aliado à globalização do padrão alimentar. A doença da urbanização, cujo conceito a relaciona com as doenças cardiovasculares, no Brasil, talvez tenha surgido em Minas Gerais na era colonial. ${ }^{4,18}$

A urbanização que floresceu nas cidades mineiras no século XVIII, tem Ouro Preto como seu exemplo maior. Essa urbanização, que foi marcada pela precocidade e intensidade da concentração de pessoas, merece atenção especial por estar na base da urbanidade brasileira. ${ }^{4,5,18,19,36}$

A antropologia da alimentação no Brasil tem como referencial as informações contidas nas obras de Gilberto Freyre. Em Casa Grande \& Senzala, Freyre, o sociólogo pernambucano, mostrou como a mistura de raças - a branca, a negra e a indígena - contribuiu para a formação dos hábitos da família brasileira. ${ }^{6,36}$ 
O padrão alimentar dos escravos e da população de Ouro Preto era constituído, fundamentalmente, de ingredientes nos quais o sal e a gordura saturada compunham parte fundamental, e eram usados para a conservação e acondicionamento dos alimentos devido à escassez dos produtos. Esse comportamento alimentar produzia uma dieta hipercalórica. ${ }^{6}$

A topografia, os aspectos geológicos da região de Ouro Preto e os interesses econômicos da época da fundação da cidade não estimulavam o desenvolvimento de uma agricultura que possibilitasse diversificação dos hábitos alimentares. O padrão cultural europeu associou ao comportamento dos escravos a ingestão de bebida alcoólica e o tabagismo. $\mathrm{O}$ hábito alimentar da atual população de Ouro Preto (MG) conserva, em grande parte, as características coloniais. ${ }^{6,7}$

A nutricionista Rosemeire Bertolini Lorime, em sua tese de doutorado, aborda a formação do homo brasiliensis sob um aspecto peculiar - a alimentação. Através desse estudo das raças e culturas que se entrecruzaram no país, dos séculos $\mathrm{XVI}$ ao $\mathrm{XVIII}$, a tese descreve as práticas alimentares do Brasil colonial, das quais algumas parecem perdurar até hoje. ${ }^{7}$

No anexo II encontra-se o relato mais detalhado sobre a antropologia urbanística e alimentar do período da fundação da cidade de Ouro Preto. 


\subsection{Importância clínica e epidemiológica dos fenótipos da pressão arterial, dos fenótipos antropométricos e metabólicos}

A pressão arterial é um dos fenótipos de risco para doença cardiovascular. Este fenótipo é a resultante do impacto das influências ambientais sobre a expressão de certos genes. A expressão gênica ocorre em nível subcelular e é progressivamente modificada sob outras influências, condicionadas pelo ambiente e/ou outros genes, em células, tecidos, órgãos e finalmente no organismo todo. ${ }^{8,9,20}$

A hipertensão arterial é uma doença crônico-degenerativa de natureza multifatorial. Na grande maioria dos casos é assintomática. Compromete fundamentalmente o equilíbrio dos sistemas vasodilatadores e vasoconstrictores, que mantêm o tônus vasomotor, levando a redução da luz dos vasos e a danos aos órgãos por eles irrigados. ${ }^{9,20}$

A hipertensão também pode ser conceituada como uma doença poligênica, que resulta de anormalidades dos mecanismos de controle da pressão arterial. Um grande número de substâncias biologicamente ativas, pode interagir com diferentes sistemas fisiológicos, de maneira complexa e com redundância para garantir a homeostasia cardiovascular. ${ }^{9,20}$

As relações de risco da pressão arterial sistólica (PAS) e diastólica (PAD) são consideradas contínuas, graduais, fortes e independentes de outros fatores de risco. Entretanto, as medidas da PAS e PAD estão associadas ao componente fixo do perfil da curva de pressão arterial. ${ }^{9,20}$ 
Não está claro ainda que tipo de pressão, isolada ou combinada, apresenta melhor correlação com eventos cardiovasculares. Em homens jovens (<60 anos) foi demonstrado recentemente, que as pressões sistólica, diastólica e média foram um potente preditor de doença cardiovascular, ao passo que a média de pressão sistólica ou pressão de pulso foi o preditor mais importante em homens mais velhos (> 60 anos). ${ }^{12}$

A pressão de pulso é a conseqüência do caráter episódico da contração cardíaca, bem como da estrutura e da função da circulação arterial. A pressão de pulso é influenciada pela fração de ejeção, rigidez das grandes artérias, redução precoce da onda de pulso e também pela freqüência cardíaca. ${ }^{12}$

Os fenótipos metabólicos envolvem uma constelação de fatores endógenos que estão associados com o aumento do risco cardiovascular e da diabetes tipo II. A definição clínica da síndrome metabólica necessita da presença de três dos cinco fatores de risco definido pela NCEP/ATP III. ${ }^{13}$

1. circunferência abdominal $>=102 \mathrm{~cm}$ para homens, $>88 \mathrm{~cm}$ para mulheres

2. valores de triglicérides $>150 \mathrm{mg} / \mathrm{dl}$

3. $\mathrm{HDL}<40 \mathrm{mg} / \mathrm{dl}$ para homens e $>50 \mathrm{mg} / \mathrm{dl}$ para mulheres

4. $P A S \geq 130 \mathrm{mmHg}$ ou $\mathrm{PAD} \geq 85 \mathrm{mmHg}$

5. glicemia $\geq 100 \mathrm{mg} / \mathrm{dl}$.

Hubert et al. Mostraram, no estudo de Framingham, que a obesidade é um fator de risco independente dos demais para a ocorrência 
de doença isquêmica coronariana e morte súbita, especialmente em indivíduos abaixo de 50 anos. $^{14}$

Dados do estudo de Framingham, publicados em 2002, sobre o risco cardiovascular em mulheres com sobrepeso mostraram que o risco relativo nelas foi maior do que nos homens (homens $R R, 1.46$; mulheres RR 1.75). Também entre os obesos o risco relativo foi maior entre as mulheres (homens RR 1.46; mulheres RR 1.64). A prevalência de hipertensão arterial para indivíduos com sobrepeso foi maior nas mulheres $28 \%$ do que nos homens $26 \% .^{14}$

Estudos sobre a prevalência da síndrome metabólica mostram uma variação com a etnia. A ocorrência entre as mulheres americanas foi de $31 \%$, entre as asiáticas de $26 \%$, de $22 \%$ entre as européias e de $11 \%$ entre as chinesas. ${ }^{15} \mathrm{~A}$ obesidade aumenta a prevalência da hipertensão arterial e o risco cardiovascular nas mulheres. ${ }^{14}$

Um estudo realizado em mulheres japonesas obesas mostrou que aquelas que eram hipertensas tinham alto índice de gordura intraabdominal/subcutânea e maior do que nas normotensas. ${ }^{16}$

mesmo estudo mostrou uma significativa e forte correlação entre o índice de gordura abdominal e a PAS $(r=0,62)$ e distólica $(r=0,63)$, independentemente da idade ou do índice de massa corporal. ${ }^{16}$ 


\subsection{Importância epidemiológica das doenças cardiovasculares na população feminina brasileira e mundial}

Em recente publicação da American Heart Association ${ }^{17}$ sobre as diretrizes para prevenção da doença cardiovascular em mulheres, ficou evidente a preocupação desta entidade com aumento da prevalência destas patologias no sexo feminino. ${ }^{16}$

Em todo o mundo, a doença cardiovascular (DCV) é a maior causa de morte entre mulheres e é responsável por um terço de todas as mortes. Em muitos países morrem mais mulheres do que homens por ano, devido à DCV. ${ }^{17}$ Não somente a mortalidade é importante, como também a morbidade. Hoje, nos Estados Unidos, vivem 38,2 milhões de mulheres (34\%) com doença cardiovascular, e uma grande percentagem está exposta a vários fatores de risco associados. Na China, na população de aproximadamente 1,3 bilhões, a prevalência entre as mulheres, ajustada para idade de 35 e 74 anos, da dislipidemia e da hipertensão arterial é de $53 \%$ e $25 \%$, respectivamente. A expectativa de vida vem crescendo muito em todo o mundo, desta forma, a prevalência da doença cardiovascular deverá crescer consideravelmente..$^{17,19}$

A prevalência da hipertensão arterial nas mulheres na América do Norte é de 24,8\%, nos Estados Unidos, 25,8\%, no Canadá, de $23,8 \%$. Na Europa estes percentuais são maiores: na Itália é de 30,6\%, na Finlândia, de 41,6\%, na Espanha, de 44,6\% e na Alemanha, de 50,3\%. ${ }^{16,69}$ 
Estudo comparativo entre as mulheres americanas, com mais de 40 anos, distribuídas pela etnia, mostrou que entre as afro-americanas e as de origem mexicana, a prevalência da hipertensão arterial foi sempre superior nelas do que nos homens da mesma faixa etária. Após os 60 anos, todas as compatriotas, independentemente da etnia, apresentaram maior prevalência de hipertensão arterial do que os homens. ${ }^{20}$

Publicações nacionais constatam resultados similares aos publicados para as mulheres americanas. Nos estudos realizados em Bambuí (MG) e de Catanduba (SP), a hipertensão arterial até a faixa etária dos 40-49 anos foi maior entre os homens. Depois dos 50 anos, a prevalência foi sempre maior nas mulheres do que nos homens. ${ }^{21,22}$

Seis estudos nacionais registraram uma predominância da hipertensão em mulheres. Desses estudos, dois são publicações sobre a população da cidade de Salvador (BA). Nos demais estudos epidemiológicos nacionais, a prevalência de hipertensão arterial é maior entre os homens. ${ }^{22,23}$ Análise comparativa entre os trabalhos publicados sobre a associação da hipertensão arterial com os fatores de risco cardiovascular, na população de Salvador (BA) e de Porto Alegre (RS), reforçou a conclusão de que a população da raça negra, a de baixa escolaridade e de baixo nível socioeconômico são descritos como os de elevado risco cardiovascular. ${ }^{23}$

No estudo da cidade de Vitória (ES) a prevalência de hipertensão arterial na população geral foi de $38,16 \%$, na população feminina foi de $22,1 \%$. Neste estudo, entre os hipertensos, registrou-se uma significância estatística na comparação com normotensos nas relações com o IMC 
$\left(\mathrm{kg} / \mathrm{m}^{2}\right)$ e CC $(\mathrm{cm})$, com médias de $28,0 \pm 4,9 \%(\mathrm{p}<0,01)$, e de $91,4 \pm$ $11,8 \mathrm{~cm}(p<0,01)$, respectivamente. ${ }^{24}$

Diversos índices antropométricos têm sido propostos para determinar a associação entre o excesso de peso e os fatores de risco cardiovascular. Estudos demonstraram que a medida da circunferência da cintura abdominal, maior que $88 \mathrm{~cm}$ para mulheres é capaz de identificar as pacientes com maior risco de $\mathrm{DCV} .{ }^{25}$

Vários estudos epidemiológicos sobre a população feminina têm mostrado a importância da correlação entre o sobrepeso e a obesidade com a hipertensão arterial e as doenças cardiovasculares. Entre estes, o estudo americano das enfermeiras (Nurse's Study) e no NHANES II (Segunda Pesquisa Nacional de Saúde e Nutrição). Nesse estudo, foram avaliadas americanas entre 20 e 75 anos. Nas com sobrepeso, o risco de hipertensão foi três vezes maior do que nas sem sobrepeso. Nas mais jovens, entre $20 \mathrm{e}$ 45 anos, o risco foi de seis vezes maior para hipertensão arterial, entre as com sobrepeso, do que nas com o peso normal. ${ }^{16,26}$

Vários estudos epidemiológicos sobre a hipertensão arterial no Brasil têm enfatizado diferentes aspectos, como os terapêuticos, sobre as prevalências, sobre o impacto social e econômico do problema, sobre os fatores de risco associados, bem como as suas relações com a doença cardiovascular. Poucos dados são descritos, no Brasil que correlacionem os fenótipos intermediários da hipertensão arterial e suas relações com o genótipo e a freqüência dos alelos e seus polimorfismos de genes candidatos. $^{21,22,23}$ 


\subsection{Importância do risco nutricional e antropométrico na população feminina urbana de Ouro Preto}

As desigualdades étnico-raciais vêm adquirindo relevância ainda maior na produção de diferentes fenótipos da doença cardiovascular. A escravidão e a colonização representaram o contexto em que se originaram essas desigualdades e condições desfavoráveis para determinados grupos populacionais. $\mathrm{O}$ impacto de barreiras sociais, econômicas e culturais nas condições de vida e da saúde de grupos étnico-raciais distintos deve, portanto, ter lugar destacado nos estudos epidemiológicos. ${ }^{6,7}$

A obesidade é uma doença crônica multifatorial caracterizada pelo excesso de tecido adiposo. Tem sido simultaneamente apontada com um fator de risco importante para a elevação da mortalidade e para a ocorrência de doenças crônicas degenerativas, entre elas, as doenças cardiovasculares. A distribuição da gordura corporal, do tipo central, é amplamente relacionada com o risco de diabetes, hipertensão arterial e síndrome metabólica. ${ }^{14,15,16}$

Em estudos epidemiológicos, o indicador de obesidade comumente utilizado é o índice de massa corporal (IMC) por apresentar boa correlação com a gordura corporal total e ter alta aplicabilidade e baixo custo. Entretanto, limitações desse índice na definição de sobrepeso/obesidade, são evidenciadas nas diferentes categorias: sexo, idade, raça e a prática de atividade física; e na avaliação do risco nutricional para co-morbidade, não conseguindo tampouco diferenciar e quantificar a distribuição de gordura. ${ }^{25,26,27}$ 
Recentemente, para a avaliação do risco nutricional de uma população, tem sido proposta a utilização conjunta do IMC e CC, por considerar que esse procedimento aumenta a acurácia do diagnóstico. Entretanto, deve-se ressaltar que o risco nutricional pode variar segundo características sociais, econômicas, demográficas e comportamentais dos diferentes grupos populacionais. Por esse motivo, o estudo "Corações de Ouro Preto" estimou a prevalência do risco nutricional combinado [índice de massa corporal (IMC) e circunferência da cintura (CC)], segundo as características sociodemográficas e sedentarismo da população urbana residente em Ouro Preto (MG). ${ }^{27,28}$

Nesse estudo, independentemente do indicador utilizado, foi observada alta prevalência de obesidade e sobrepeso na população. Entre mulheres o sobrepeso/obesidade e a circunferência da cintura foram de $48,2 \%$ e $54,2 \%$, respectivamente. Esses dados sugerem que, entre as mulheres com IMC normal ou com sobrepeso, podem apresentar obesidade central, indicando que características da distribuição da gordura corporal devem ser consideradas na avaliação do risco nutricional. ${ }^{27}$

Alguns estudos têm demonstrado que o IMC pode subestimar ou superestimar o sobrepeso e a obesidade, pois, apesar de estar correlacionado com excesso de gordura corporal, refletiria somente a proporção corporal, não estimando a adiposidade e distribuição de gordura corporal. Por outro lado, a CC tem sido recentemente utilizada como indicador de risco à saúde cardiovascular. ${ }^{25,26,27}$ 
A metodologia e os resultados detalhados do risco nutricional da população feminina do projeto de Ouro Preto na referencia.(27). Os principais resultados mostraram que o risco nutricional isolado esteve presente nas diferentes categorias de IMC nas mulheres, o qual é de 19,1\% para aquelas com o peso normal; $91,7 \%$, com sobrepeso e $98,5 \%$, com obesidade. As mulheres mais idosas (> 60 anos) apresentaram Odds Ratio (OR) de 9,94 quando estes comparados aos dos mais jovens. Para as mulheres com escolariade $\leq 4$ anos, o OD foi de 1,83 , quando comparada ao OD daquelas com mais de 4 anos. Os achados deste estudo mostraram o efeito independente da idade e escolaridade na probabilidade de ocorrência do risco nutricional combinado e a importância da análise conjunta do IMC e CC para a seleção de grupos em risco nutricional. ${ }^{26,27}$

Apesar da não existência, no Brasil, de dados nacionais sobre prevalência do sobrepeso central e de obesidade central, a sua relevância epidemiológica tem sido cada vez mais demonstrada na análise do risco nutricional para as doenças não transmissíveis em decorrência da boa correlação entre esses índices e os depósitos de gordura visceral. Ambos os indicadores têm sido apontados como adequados marcadores de complicações metabólicas, com base no conhecimento do metabolismo dos depósitos viscerais de triglicérides. ${ }^{26,2}$ 


\subsection{Importância do conhecimento fisiopatológico do sistema renina angiotensina nos fenótipos da pressão arterial e metabólicos}

A ativação do sistema renina-angiotensina-aldosterona (RAAS) constitui-se num fator de risco para eventos cardiovasculares. A angiotensina II age nos receptores AT1 e AT2. A estimulação dos receptores AT1 está associada à disfunção endotelial, principalmente a vasoconstrição, ativação plaquetária, maior liberação do fator inibidor da ativação do plasminogênio tipo 1. O papel do SRAA na regulação da pressão arterial torna esse sistema um importante candidato no papel da patogênese da hipertensão. Uma significativa percentagem de pacientes com hipertensão arterial essencial exibe níveis impropriamente elevados de renina. Foi, portanto, desenvolvida uma hipótese, de que uma variabilidade genética em um dos componentes do SRAA poderia explicar a variabilidade na pressão arterial ou a patogênese da hipertensão. A maior prevalência de hipertensão na obesidade é atribuída à hiperinsulenemia, decorrente da resistência à insulina, presente em indivíduos obesos, principalmente naqueles que apresentam excesso de gordura na região do tronco. ${ }^{26,29,30}$

A contribuição desses efeitos também é estuda com relação ao desenvolvimento e progressão da aterosclerose e no remodelamento ventricular na insuficiência cardíaca. ${ }^{39}$

Em humanos existem vários relatos do aumento da concentração circulante de AGT, renina, aldosterona e da atividade da enzima conversora da angiotensina em indivíduos hipertensos. ${ }^{30,31}$ 
Atualmente, as células adiposas não são vistas apenas como estruturas de proteção e sustentação, mas como um verdadeiro órgão dotado de intensa atividade endócrina e metabólica. Demonstrou-se que o angiotensinogênio tem seus níveis séricos elevados na obesidade, devido à sua maior síntese pelos adipócitos, o que geraria mais angiotensina II e elevação da pressão arterial, seja pelos efeitos diretos do peptídeo sobre o rim, ou pela ativação simpática. Também se constatou que a angiotensina dos adipócitos participa da regulação da neurotransmissão simpática envolvida no controle do metabolismo lipídico, regulando o volume dessas células, controlando as enzimas do metabolismo de ácidos graxos e agindo como agente modulador do peso corporal. A hipótese de que maior expressão do gene do angiotensinogênio em obesos contribua para os mecanismos que perpetuem o excesso de peso é bastante atraente, e necessita ainda de pesquisas clínicas e experimentais adicionais. ${ }^{32,35}$

A obesidade está associada aos níveis circulantes elevados do sistema SRRA (AGT, renina, aldosterona e ECA). Uma evidência da importância da relação entre o SRAA com a obesidade é relatada quando ocorre uma perda de $5 \%$ da massa corporal. Nesta situação registra-se uma redução significativa dos níveis dos elementos do sistema circulante. A regulação para baixo da expressão do AGT, no tecido adiposo, com a resposta de perda de peso, sustenta a suposição de os níveis plasmáticos de AGT podem ser responsáveis pela expressão do AGT no tecido adiposo. $^{32,35}$ 
Além disso, as reduções dessa expressão do AGT no tecido adiposo foram relacionados com a redução da pressão arterial sistólica. Esses dados sugerem que a redução da massa de gordura pode abaixar a atividade do sistema SRAA no plasma e no tecido adiposo e encontrar implicações terapêuticas. ${ }^{35}$

O AGT é muito abundante no tecido adiposo, e a síntese local dele poderia ser parte de um sistema parácrino que influencia a liberação de Ang II, nas vizinhanças das células musculares lisas vasculares. O estado nutricional de uma pessoa poderia influenciar o suprimento sanguíneo para o tecido adiposo nos indivíduos obesos. A concentração de AGT plasmática está, de fato, fortemente relacionada com a pressão arterial durante a perda de peso. Um estudo feito em 67 mulheres japonesas obesas mostrou que aquelas que eram hipertensas tinham maior índice de gordura intraabdominal/subcutânea do que as normotensas. ${ }^{15} \mathrm{O}$ mesmo estudo mostrou forte significância, entre esse índice de gordura e as pressões arteriais sistólica $(r=0,62)$ e diastólica $(r=0,63)$, independentemente da idade ou do índice de massa corporal. A associação entre o acúmulo de gordura intraabdominal e hipertensão aumenta a hipótese de que o AGT está envolvido na patogênese da hipertensão arterial em indivíduos obesos. Publicações descrevem níveis mais elevados de renina e de aldosterona em mulheres obesas. ${ }^{35,36}$ A concentração de AGT no plasma está, de fato, fortemente correlacionado com a pressão arterial durante a perda de peso. Essa situação confirma a tendência de sobrecarga salina e volume nas mulheres hipertensas e obesas. ${ }^{37}$ 
Os níveis do AGT, da renina, da aldosterona e a atividade elevada da ECA em mulheres obesas em menopausa, comparadas com as mulheres magras em menopausa, sugerem que o sistema renina angiotensina está mais ativado nas obesas. ${ }^{37}$

São desconhecidos os mecanismos que podem controlar a expressão do AGT nos obesos e a redução dessa expressão durante a

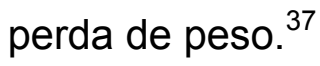

Estudos publicados por Stefan Engel e colaboradores ${ }^{38}$ mostraram que há uma significativa correlação entre a medida clínica da circunferência da cintura abdominal com os níveis plasmáticos de AGT e que existe uma correlação da redução da circunferência com a redução dos níveis plasmáticos de AGT. ${ }^{37}$

Os componentes do SRAA parecem desempenhar um papel na aterosclerose. Todos os componentes do SRAA estão presentes na parede dos vasos. O RNAm do AGT, por exemplo, está localizado no músculo liso, na gordura periadventicial e endotelial. A Ang II tem importantes efeitos locais sobre as células endoteliais e outras células implicadas na aterosclerose ou suas complicações e contribui para determinar a disfunção endotelial, supostamente, um significativo precursor da aterosclerose. ${ }^{39,40}$

A atividade da ECA foi inequivocamente descrita em células musculares lisas vasculares da íntima endotelial de lesões em desenvolvimento. Os achados de níveis aumentados de RNAm do AGT, ECA e AT1R e AT2R na neo-intima de vasos lesados apóiam a idéia de que 
as concentrações de Ang II desempenham um papel central no desenvolvimento de lesões da intima. ${ }^{39,40,41}$

Além de influenciar a pressão arterial, o sistema renina angiotensina é também um importante fator na etiologia da aterosclerose. Muitos estudos clínicos relatam a eficácia de agentes que inibem a atividade da ECA e de receptores da angiotensina II no tratamento da aterosclerose..$^{40,41}$

\subsection{A prevalência dos alelos $D / l$ da enzima conversora da angiotensina (ECA) e seus polimorfismos, dos grupos populacionais que compuseram a população de Ouro Preto}

A antropologia da população ouropretana, estimada no século XVIII, era composta de aproximadamente 21.789 habitantes, distribuídos em $33 \%$ a $50 \%$ de escravos. A distribuição dos escravos, pela sua origem, mostrava que $35,3 \%$ eram sudaneses e $64,7 \%$, bantos. Dados mais completos sobre a demografia da população de Ouro Preto (MG) estão descritos no anexo II.

A freqüência dos alelos $\mathrm{D}$ e I, os $\mathrm{M} \mathrm{e} \mathrm{T}$, os polimorfismo DD, DI e II e os MM, MT e TT, da ECA e do AGT, respectivamente, são relatados em vários estudos populacionais africanos e europeus. ${ }^{40}$

A freqüência dos alelos $D$, I e os polimorfismos $D D$, DI e II na população africana foi de $60 \%, 40 \%, 35 \%, 49 \%$ e $16 \%$, respectivamente..$^{36,42,43,44}$ 
A distribuição dos polimorfismos DD, DI e II na população africana hipertensa foi de $46 \%, 36 \%$ e $18 \%$. Já entre os europeus hipertensos, a freqüência foi de $32 \%, 49 \%$ e $19 \%$, respectivamente. ${ }^{42,43}$

A freqüência dos alelos $D$, I e os polimorfismos DD, DI e II na população européia foi de $57 \%, 43 \%, 32 \%, 49 \%$ e $19 \%$, respectivamente. A freqüência dos polimorfismos DD, DI e II, entre os europeus caucasianos hipertensos foi de $32 \%, 49 \%$ e $19 \%$, respectivamente. ${ }^{36,43,44,45,46,48}$

A freqüência do alelo $M$ foi de $9 \%, 19 \%, 58 \%, 17 \%$, e a do alelo $T$ foi de $91 \%, 81 \% 42 \%$ e $83 \%$ nos nigerianos, nos afro-caribenhos, nos caucasianos e afro-americanos, respectivamente..$^{36,43,44,45,46,48}$

Entre os caucasianos americanos, a freqüência do alelo $M$ foi de $62 \%$ e do alelo $\mathrm{T}$, de $28 \%$. Entre os afro-americanos e caucasianos europeus, a freqüência do alelo $\mathrm{M}$ foi de $13 \%$ e $55 \%$ e a do alelo $\mathrm{T}$, de $87 \%$ e $45 \%$, respectivamente, nessas populações. ${ }^{36,42,48}$

A hipertensão arterial da raça negra africana, em sua diáspora, foi avaliada em estudo cooperado. Analisaram os alelos de genes candidatos à hipertensão do sistema da renina-angiotensina em três populações da origem africana. O polimorfismo da inserção/deleção (I/D) da ECA e os variantes de M235T e de T174M do gene do angiotensinogêno (AGT) foram avaliados nos indivíduos da Nigéria, da Jamaica e dos Estados Unidos. ${ }^{36}$ Observou-se uma grande diferença na prevalência da hipertensão. Em aferições domiciliares, verificou-se prevalência de $16 \%$ nos Nigerianos, de $33 \%$ nos Estados Unidos. A freqüência do alelo $D$ foi similar em todos os grupos: 54\%, 59\%, e 63\% na Nigéria, na Jamaica e nos Estados Unidos, 
respectivamente. O alelo $235 \mathrm{~T}$ do gene AGT mostrou pequena variação de $81 \%$ nos estadunidenses e jamaicanos e de em $91 \%$ nos nigerianos. ${ }^{36,42}$

Esses resultados indicam que as exposições ambientais explicam, muito provavelmente, o grau de variabilidade na prevalência da hipertensão arterial na raça negra nas três regiões. Na população brasileira, a freqüência dos alelos e dos polimorfismos da ECA e do AGT foram descritos pelo estudo de Vitória. A freqüência dos alelos $D, I, M$ e T apresentaram as prevalências de $56,60 \%, 43,40 \%, 41,87 \%$ e 58,03\%. A prevalência dos polimorfismos MM, MT e TT do AGT foram de 19,84\%, 44,25\% e 35,90\%, respectivamente. $^{24,48}$

\subsection{Correlações entre os alelos e polimorfismos da ECA e do AGT com os fenótipos da pressão arterial e metabólicos}

O nível sorológico intra-individual da ECA é bastante estável. Todavia, a variação interindividual é alta, o que pode ser atribuído a variantes moleculares da ECA. Foi relatado que o nível da ECA no soro é determinado pelos polimorfismos ECA I/D na seguinte ordem: DD > ID > II. Além disso, o polimorfismo I/D pode explicar $47 \%$ da variância fenotípica total da ECA no soro. Esse resultado foi confirmado em diversas populações, incluindo-se centenários na França, índios Pima e brancos (mas não negros) dos USA. ${ }^{31,36,47}$ 
Numerosos estudos foram realizados num conjunto diverso de populações e etnias, a fim de investigar a relação entre o polimorfismo I/D e a pressão arterial. ${ }^{36,31}$

Zee et al. observaram que o polimorfismo ECA I/D estava associado com hipertensão arterial na população australiana. Todavia, nenhuma relação foi encontrada entre o polimorfismo da ECA e a hipertensão arterial em populações de outros países, incluindo Bélgica, Dinamarca e Grécia. Estudos em brancos e na população japonesa relatam evidência da ligação entre marcadores do lócus da ECA e a hipertensão em homens, mas não em mulheres. ${ }^{50,51}$

Barley et al. ${ }^{52}$ observaram que não havia associação significativa entre o genótipo de ECA e a elevação da pressão arterial em brancos do Reino Unido, mas entre os descendentes de afro-caribenhos, houve uma associação positiva entre a freqüência do alelo $D$ e a elevação da pressão arterial. Similarmente, foi encontrada uma associação positiva entre a freqüência do alelo $D$ e a pressão arterial elevada em dois estudos afroamericanos. Em pares de irmãos caucasianos em Utah, não foram encontradas evidências de associação do lócus da ECA e a hipertensão arterial.

Diferentes estudos relatam resultados discrepantes entre as relações da associação com o genótipo DD da ECA e a prevalência de hipertensão arterial, mas existe uma associação consistente em populações descendentes de africanos, e pode haver uma associação sexo-específica em brancos e asiáticos. ${ }^{52,53,54}$ 
As interações gene-gene poderiam ser um dos fatores que contribuem para a divergência nos dados, o que leva a especular se essas variantes moleculares teriam importância funcional e se suas freqüências variariam entre diferentes populações étnicas. Essa sugestão é reforçada pelo trabalho de Willians et al. que relataram interações genéticas entre múltiplos loci ao invés de variantes de um único gene, que sustentam a base genética da hipertensão nos indivíduos e nas suas etnias. ${ }^{55}$

Os estudos de Staessen e colaboradores ${ }^{57}$ foram os primeiros a demonstrar uma associação significativa do genótipo DD, do polimorfismo de inserção/deleção com a hipertensão arterial sistólica isolada em idosos. Nos estudos de Safar $^{56}$, o genótipo DD foi associado à maior rigidez arterial em pacientes diabéticos. Esses resultados foram mais significativos em pacientes com mais de 50 anos.

O estudo Olivetti (The Olivetti prospective Heart Study) ${ }^{58}$ realizado em 1.075 homens de 25 a 75 anos, analisou a variação genética do sistema renina angiotensina e suas correlações com gordura abdominal em homens. Os autores observaram que o polimorfismo da ECA I/D foi um preditor significativo em homens para gordura abdominal e sobrepeso. Os homens homozigotos DD tiveram uma significativa associação positiva com o peso corporal e a pressão arterial, em sujeitos com mais de 70 anos.

A relação do índice de massa corporal, a circunferência da cintura abdominal, a pressão arterial diastólica foram significativamente mais elevadas em pessoas com o genótipo do DD do que naqueles com o ID ou II genótipo. $^{58}$ 
O sobrepeso e a gordura abdominal foram mais freqüentes nos homens com o genótipo do DD, particularmente entre os mais velhos $(51,1 \%$ contra $36,5 \%$ e $33,1 \%$ contra $22,0 \%$, respectivamente). O OD foi de $1.82(\mathrm{Cl}$ de $95 \%, 1.16$ a 2.87$)$ para o sobrepeso, e de $1.76(\mathrm{Cl}, 1.06$ a 2.90$)$ para a gordura abdominal. ${ }^{58}$

Além de influenciar a pressão arterial, o sistema renina angiotensina é também um importante fator na etiologia da aterosclerose. Muitos estudos clínicos relataram a eficácia de agentes que inibem a atividade da ECA e de receptores da angiotensina II no tratamento da aterosclerose. ${ }^{59}$

O estudo de Rotterdamm ${ }^{60}$ avaliou a possível interação entre esses polimorfismos e o tabagismo com a morbidade e a mortalidade cardiovascular. Foram avaliados os polimorfismos de 6.714 fumantes e a incidência de eventos de infarto fatal e não fatal. Esse estudo mostrou que os polimorfismos da ECA I/D não apresentaram correlação como fator de risco para eventos isquêmicos, mas sua interação entre os fumantes pode determinar um fenótipo de risco para a mortalidade cardiovascular nos indivíduos mais novos portadores do genótipo DD.

Várias evidências indicam que a concentração de AGT no plasma está vinculada à pressão arterial. Uma alta correlação entre a concentração do substrato da renina e a pressão arterial elevada $(r=0,39, p<0,0001)$ foi primeiramente relatada em um grande estudo que envolveu 574 indivíduos. ${ }^{61,62,36}$

Existem evidências de que o polimorfismo do AGT, nos indivíduos portadores do alelo T235, tinham uma concentração plasmático de $20 \%$ 
mais elevada em mulheres e homens quando comparados com os portadores do alelo M235. ${ }^{36,61}$

As concentrações de AGT no plasma de crianças americanas brancas normotensas, portadoras dos genótipos 235TT, eram aproximadamente $13 \%$ mais elevadas do que naquelas com o genótipo 235MM. A importância do genótipo 235TT permaneceu, mesmo quando os resultados foram ajustados para o índice de massa corporal. Sabe-se que existe uma concentração mais elevada de AGT nos indivíduos com maior índice de massa corporal. ${ }^{36,61}$

Os mesmos autores observaram que a concentração média de AGT no plasma em crianças afro-americanas era $19 \%$ mais elevada que nas crianças caucasianas, mas essa associação com a pressão arterial não foi detectada, talvez porque a freqüência do alelo M235 era muito baixa para avaliar tal associação. ${ }^{36}$

As variações intra e interensaios clínicos, na avaliação da concentração de AGT, podem ser explicados, em parte, pela pequena elevação na concentração plasmática do AGT de $10 \%$ a $30 \%$ nos polimorfismos AGT 235T. Dessa forma, estudos definitivos para associações necessitam de uma grande amostra populacional a fim de se afirmarem ou refutarem-se tais associações. ${ }^{64}$

A freqüência do alelo AGT 235T (ou 174M) varia de um grupo étnico para outro. O alelo T235 do AGT foi descrito como responsável por uma associação significativa com a hipertensão arterial, em caucasianos com história familiar de hipertensão e, em duas publicações, em populações 
japonesas com probabilidade de 1,22 (IC 95\% 1,05 - 1,42) e 1,60 (IC 85\% 1,19 - 2,15). Em populações afro-caribenhas, porém, essa associação não foi encontrada. ${ }^{36,61}$

A freqüência do polimorfismo TT em populações japonesas é de 0,75\%; nos caucasianos, essa freqüência é de $0,35 \%$ e é predominante na população de origem africana: nos nigerianos, ela é de 0,93\%. Nas populações japonesas, os relatos da freqüência dos alelos T235 é, invariavelmente, alta, e os resultados são sempre uniformes, entre $0,65 \%$ a $0,75 \%$. As explicações para isso talvez sejam a menor variação fisiopatológica e ambiental e o fato de eles serem mais homogêneos geneticamente. $^{36,61}$

O alelo $235 T$ é bem mais freqüente nos africanos $(0,90)$ e nos afroamericanos $(0,80)$. Nos americanos de origem africana, a hipertensão arterial é mais prevalente e mais severa do que em caucasianos. Os fatores genéticos que contribuem para essa diferença étnica não são conhecidos. Essas populações hipertensas tendem a ser sensiveis ao sódio e têm baixas concentrações de renina circulante..$^{36,61}$

Os estudos iniciais de Jeunemaitre et al. mostram um elo entre parentes europeus do norte e do oeste com hipertensão arterial e o gene do AGT. A utilização de uma estratégia de avaliação em irmãos lhe permitiu descrever a etiologia multifatorial da hipertensão arterial. ${ }^{36}$

Uma série de polimorfismos na região 5 , exons e introns do AGT, foi descritas nos trabalhos iniciais de Jeunemaitre et al. Nesse estudo, relatouse que as duas variantes T134M e M235T, geralmente em desequilíbrio de 
ligação, estavam mais presentes em indivíduos com hipertensão arterial severa do que nos casos controle. ${ }^{36,65}$

Observou-se, também, que o AGT no plasma é elevado nos hipertensos e nos filhos de pais hipertensos, quando comparados com os normotensos. ${ }^{36,65}$

Num estudo planejado para avaliar os determinantes genéticos da pressão arterial, comparando os filhos de pais com pressões arteriais elevadas ou normais, Watt et al. ${ }^{66}$ observaram que os filhos de indivíduos hipertensos tinham níveis mais altos de AGT no plasma, quando comparados aos filhos de pais normotensos. Esses achados sugerem que um aumento do AGT no plasma poderia elevar a pressão arterial e contribuir para a hipertensão. ${ }^{67}$

Associação positiva também foi relatada em uma amostra do Estudo Framingham, em homens com hipertensão arterial severa, quando associados com mulheres, e também no estudo sobre o risco da aterosclerose (ARIC) quando a amostra foi ajustada para o índice de massa corporal e triglicérides. As proporções dos casos atribuíveis ao alelo 235T foram de $8 \%$ na população do ARIC e, de $20 \%$, na população de Framingham. Esse achado sugere que tanto a hipertensão arterial como a dislipidemia podem ser transmitidas, em associação. ${ }^{67}$ 


\section{OBJETIVOS}

- Descrever as características demográficas, antropométricas dos fenótipos da pressão arterial (pressão arterial sistólica, pressão arterial diastólica e pressão de pulso) da população feminina do projeto "Corações de Ouro Preto".

- Descrever a freqüência e as correlações dos alelos e dos polimorfismos da enzima conversora da angiotensina, do angiotensinogênio, com os fenótipos da pressão arterial sistólica, diastólica e pressão de pulso na população feminina do projeto "Corações de Ouro Preto".

Correlacionar os preditores genéticos com os fenótipos metabólicos - circunferência da cintura abdominal, glicemia, colesterol total, HDL-colesterol, LDL-colesterol e triglicérides na população feminina do projeto "Corações de Ouro Preto". 


\section{JUSTIFICATIVAS DO ESTUDO}

1. Os resultados na população feminina do projeto "Corações de Ouro Preto", mostraram uma alta prevalência de sobrepeso e obesidade. O critério utilizado de risco nutricional isolado ou combinado mostrou a possibilidade de estudo de novo fenótipo para a doença cardiovascular. A conclusão deste estudo mostrou um efeito independente da idade e da escolaridade na probabilidade de ocorrência do risco nutricional combinado e a importância da análise conjunta do IMC e CC para a seleção de grupos em risco nutricional.

2. Não existem dados nacionais sobre o impacto na prevalência dos fatores de risco cardiovascular associados ao risco nutricional combinado. A importância da prevalência de sobrepeso e obesidade central é demonstrada pela correlação desta com os depósitos de gordura visceral.

3. Estudos epidemiológicos brasileiros sobre hipertensão arterial têm enfatizado diferentes aspectos, como os terapêuticos, os descritivos sobre as prevalências, relatos do impacto socioeconômico do problema, descrições e correlações com os fatores de risco bem como os relativos à associação da $\mathrm{H}$ A com as doenças cardiovasculares. Poucos dados são descritos no Brasil que correlacionem os fenótipos intermediários da pressão arterial, tais como pressão arterial sistólica, diastólica e pressão de pulso como 
também os fenótipos antropométricos e suas relações com os genes candidatos do sistema renina angiotensina.

4. Várias publicações enfatizam a maior concentração do AGT no tecido adiposo. A concentração do AGT é relata em maior freqüência nos indivíduos com o polimorfismo 235TT do angiotensinogênio. Existem relatos significativos da relação de dados antropométricos com a concentração do AGT. Como na população feminina ouropretana os dados antropométricos registram percentuais elevados de sobrepeso, obesidade e circunferência da cintura abdominal, o estudo da correlação entre as freqüências dos alelos e do polimorfismo do AGT, nessa população, pode reforçar ou refutar essa associação.

5. Publicações internacionais relatam as correlações do sobrepeso, da obesidade e da circunferência da cintura abdominal com o polimorfismo da ECA em homens, mas poucos relatos são publicados sobre as mulheres.

6. As recentes publicações sobre a doença cardiovascular nas mulheres enfatizam o crescimento da prevalência dessas patologias no gênero feminino. Atualmente, em vários países, a mortalidade por fatores cardiovasculares em mulheres é superior à dos homens.

7. A prevalência de hipertensão arterial, de sobrepeso, obesidade, de risco nutricional isolado ou combinado, na população feminina ouropretana, é muito elevada, se comparada com registros nacionais e internacionais. 


\section{$4 \quad$ MÉTODOS}

As mulheres avaliadas assinaram o termo de consentimento livre e esclarecido, descrito no anexo III. O projeto foi aprovado pelo Comitê de Ética em Pesquisa da Universidade Federal de Ouro Preto, sob o número $2001 / 26$.

\section{1 Área de estudo}

O estudo foi realizado na cidade de Ouro Preto (MG), região sudeste do Brasil, localizada entre as coordenadas geodésicas $20^{\circ} 23^{\prime 2} 28^{\prime \prime}$ de latitude sul e 4330'20" de longitude oeste e altitude média de 1061 metros. Em 1996, a cidade era composta por 33 setores censitários e 9.287 domicílios, com uma população de 37.603 habitantes. Na população com mais de 15 anos, 52,6\% eram mulheres e, de acordo com a idade, 7,05\% eram adolescentes (15 a 19 anos); 24,0\%, adultos jovens (20 a 39); 14,3\%, adultos (40 a 59) e 6,8\% eram idosos (60 anos ou mais). ${ }^{27}$

\subsection{Desenho do estudo}

O desenho deste estudo foi o corte-transversal ou inquérito de prevalência dos FR para as DCV.

A partir da listagem de todos os endereços obtidos nos cadastros do IPTU e do Departamento de Assistência Social municipal, os 8.746 
domicílios foram ordenados segundo o setor, rua e número. Em cada setor os domicílios foram numerados em ordem crescente e a partir de listagens de números aleatórios para cada setor foram selecionados os domicílios participantes do estudo, através de uma amostra aleatória simples. O número de domicílios selecionados em cada setor censitário foi estratificado pela densidade domiciliar de cada setor. Quando o "domicílio" selecionado era um estabelecimento comercial, não habitado ou de recusa era imediatamente substituído pela próxima casa à direita. Através do processo amostral por conglomerados foi selecionado um indivíduo com 15 anos ou mais que apresentava a data de aniversário mais próxima da data da entrevista.

Os indivíduos selecionados foram avaliados em duas etapas diferentes. Inicialmente no domicílio foi realizada entrevista face a face de um questionário estruturado e avaliado em estudo piloto (ver anexo III), com duração média de 20 minutos. Foi realizada também aferição da pressão arterial, em duplicata, conforme método descrito no item 4.5.1, com intervalos de três minutos, de todos os membros da família e do indivíduo selecionado para o estudo. Posteriormente, na segunda fase, este foi convidado a comparecer na Escola de Farmácia da UFOP para realização da tomada das medidas antropométricas e coleta de sangue para análise bioquímica e genotipagem. Os métodos são descritos no item 4.6. e 4.7.

Este sub-projeto foi realizado apenas com a amostra das mulheres do Projeto "Corações de Ouro Preto" $(n=485) .{ }^{27}$ Foram excluídas as mulheres que não participaram das duas etapas anteriores ou que tinham 
menos de 18 anos, ou que, por qualquer motivo, o material biológico não foi colhido ou foi perdido. Considerando somente as mulheres com idade igual a 18 anos ou maior, a população que teve a sua genotipagem classificada foi constituída de $87,7 \%(n=386)$ da amostra do Projeto "Corações de Ouro Preto".

\subsection{Cálculo da amostra}

Para cumprir com os requisitos estatísticos mínimos para estimar a prevalência dos fatores de risco para as DCV nesta população, o tamanho da amostra foi calculado, no programa Epi-Info (Dean et al., 1994) versão 6.04 , tomando como base as seguintes premissas:

(1) Prevalência estimada da HAS igual a 25\%;

(2) Precisão desejada de $3 \%$;

(3) Nível de significância de 95\%.

Baseando nestas premissas a amostra de 800 indivíduos teria um poder de $99 \%$ para estimar a prevalência dos principais fatores de risco para as DCV. Esta amostra foi acrescida em $20 \%$ devido a possíveis perdas.

\subsection{Questionários}

As informações sociodemográficas e de sedentarismo foram obtidas por meio de entrevistas, face a face, utilizando-se questionário estruturado e pré-codificado. A escolaridade foi agrupada em baixa (analfabeto ao $1^{\circ} \mathrm{grau}$ incompleto), média ( $1^{\circ}$ grau completo a $2^{\circ}$ grau incompleto) e alta $\left(\geq 2^{\circ}\right.$ grau 
completo). A classe econômica foi definida pelos critérios propostos pela Associação Nacional de Pesquisa, de acordo com a contagem dos bens de consumo, empregados domésticos, número de banheiros no domicílio e nível de instrução do chefe da família. Para a análise, as classes socioeconômicas foram agrupadas em A e B (alta e média), C (média baixa), D e $E$ (baixa e muito baixa). A atividade ocupacional foi categorizada como: leve (atividades executadas em posição sentada e/ou de maneira fácil Exemplo: secretária); moderada (inclui trabalhos que implicavam caminhar e sentar. Exemplo: almoxarife) ou pesada (com trabalhos manuais pesados, tais como: operário da construção civil). O sedentarismo foi definido neste estudo a partir do agrupamento da atividade ocupacional com tempo de atividade física exercida na hora de lazer. Aqueles que exerciam atividade ocupacional leve ou moderada, tais como estudante, escriturário, professor, entre outras, e praticavam atividade física de lazer com tempo semanal inferior a 150 minutos foram classificados como sedentários.

\subsection{Aferição da pressão arterial}

A aferição da pressão arterial foi realizada por estudantes de Medicina, capacitados em curso teórico, aulas de vídeo, e praticas para o procedimento. O método utilizado foi o recomendado pelo VI Joint National Committee on Prevention, Detection, Evaluation, and Treatment of High Blood Pressure. Sixth Report of the Joint National Committee on Prevention, Detection, Evaluation, and Treatment of High Blood Pressure. 
O aparelho utilizado foi o esfigmomanômetro anaeróide, previamente calibrado. As medidas foram feitas em duplicata e com intervalos de três minutos após a mulher selecionada permanecer assentada por período mínimo de 20 minutos, tempo em que ela respondeu ao questionário protocolar.

\subsubsection{Recomendações sobre o procedimento de medida da pressão arterial}

1. Explicar o procedimento ao paciente.

2. Repousar pelo menos cinco minutos em ambiente calmo.

3. Evitar bexiga cheia.

4. Manter pernas descruzadas, pés apoiados no chão, dorso recostado na cadeira e relaxado.

5. Remover roupas do braço no qual será colocado o manguito.

6. Posicionar o braço na altura do coração (nível do ponto médio do esterno ou $4^{\circ}$ espaço intercostal), apoiado, com a palma da mão voltada para cima e o cotovelo ligeiramente fletido.

7. Solicitar que não se falasse durante a medição.

\subsubsection{Procedimento de medida da pressão arterial}

1. Colocar o manguito sem deixar folgas acima da fossa cubital, cerca de 2 a $3 \mathrm{~cm}$.

2. Centralizar o meio da parte compressiva do manguito sobre a artéria braquial. 
3. Estimar o nível da pressão sistólica (palpar o pulso radial e inflar o manguito até seu desaparecimento, desinflar rapidamente e aguardar um minuto antes da medida).

4. Palpar a artéria braquial na fossa cubital e colocar a campânula do estetoscópio sem compressão excessiva.

5. Inflar rapidamente até ultrapassar 20 a $30 \mathrm{mmHg}$ o nível estimado da pressão sistólica.

6. Proceder à deflação lentamente (velocidade de 2 a $4 \mathrm{mmHg}$ por segundo).

7. Determinar a pressão sistólica na ausculta do primeiro som (fase I de Korotkoff), que é um som fraco seguido de batidas regulares, e, após, aumentar ligeiramente a velocidade de deflação.

8. Determinar a pressão diastólica no desaparecimento do som (fase $V$ de Korotkoff).

9. Auscultar cerca de 20 a $30 \mathrm{mmHg}$ abaixo do último som para confirmar seu desaparecimento e depois proceder à deflação rápida e completa.

10. Determinar a pressão diastólica no abafamento dos sons (fase IV de Korotkoff) e anotar valores da sistólica/diastólica/zero, se os batimentos persistirem até o nível zero.

11. Esperar no mínimo três minutos antes de novas medidas.

12. Informar ao paciente os valores de pressão arterial obtidos.

13. Anotar os valores e o membro. 


\subsection{Medidas antropométricas e coleta de material biológico}

1. Classificação do índice de massa corporal (IMC):

Os indivíduos entrevistados foram agendados para uma segunda etapa que constava da realização de exame clínico e antropométrico, no horário de $7 \mathrm{~h}$ às $10 \mathrm{~h}$ da manhã, após um jejum de $12 \mathrm{~h}$. Para aferir o peso, utilizou-se a balança TANITA BF 542®, ajustada a cada medição, com capacidade de $136 \mathrm{~kg}$, variação de 0,2 kg, com os indivíduos vestindo um mínimo de roupas, sem jóias e/ou bijuterias, com a bexiga vazia e em jejum.

Para a medida da altura, utilizou-se o método preconizado por Frisancho, por meio de um antropômetro de campo.

2. A circunferência da cintura (CC):

Foi aferida no ponto médio entre o último arco costal e a crista ilíaca ou cintura natural com o indivíduo na posição supina.

3. Coleta do material biológico:

A coleta do material biológico foi realizada, com o sistema a vácuo, no Laboratório Piloto de Análises Clínicas (LAPAC) da Escola de Farmácia da Universidade Federal de Ouro Preto, de acordo com os seguintes procedimentos:

- rosquear a agulha no adaptador (canhão). Não remover a capa protetora de plástico da agulha;

- $\quad$ ajustar o garrote e escolha a veia; 
- fazer a anti-sepsia do local da coleta com algodão umedecido em álcool a $70 \%$ ou álcool iodado a $1 \%$ e não tocar mais no local desinfetado;

- $\quad$ remover o protetor plástico da agulha e fazer a punção;

- introduzir o tubo no suporte, pressionando-o até o limite;

- $\quad$ soltar o garrote assim que o sangue começar a fluir no tubo;

- separar a agulha do suporte com o auxílio de uma pinça e descartar a agulha em recipiente de boca larga, paredes rígidas e tampa, contendo hipoclorito de sódio a $2 \%$;

- orientar o paciente a pressionar com algodão a parte puncionada, mantendo o braço estendido, sem dobrá-lo;

- após coleta do sangue parte da amostra foi encaminhada para dosagem de lipídeos e glicose, e a outra parte foi encaminhada ao Laboratório de Biologia Molecular do INCOR para realização da genotipagem.

\subsection{Técnica de extração do DNA}

A avaliação do gene dos genótipos da enzima conversora da angiotensina e do angiotensinogênio e o polimorfismo I/D da ECA foi determinada pela média de três sistemas Primer: a variante M235T do gene do agiotensinogênio. 


\subsection{Definição de exposição}

1. A hipertensão arterial foi definida pelo critério do VI Joint: pressão arterial sistólica $>140 \mathrm{mmHg}$ e/ou pressão arterial diastólica $>90 \mathrm{mmHg}$, incluindo hipertensos em tratamento atual comprovado. Foi usada a média das duas medidas. ${ }^{8}$

A pressão sangüínea foi classificada de acordo com o critério da VI Joint; a glicose sangüínea, de acordo com o critério da Sociedade Brasileira de Diabetes, e os níveis de lipídeos sangüíneos, de acordo com o III Consenso Brasileiro de Dislipidemia. Foram considerados dislipidêmicos os indivíduos que apresentavam pelo menos uma alteração no perfil lipídico. ${ }^{8}$

2. A obesidade foi determinada pelo índice de massa corporal (IMC), de acordo com a classificação da OMS, como normal $\left(<25 \mathrm{~kg} / \mathrm{m}^{2}\right)$, sobrepeso $\left(25-29 \mathrm{~kg} / \mathrm{m}^{2}\right)$ e obesidade $\left(\geq 30 \mathrm{~kg} / \mathrm{m}^{2}\right)$. A obesidade abdominal foi avaliada pela circunferência de cintura (CC) e classificada como normal $(<80 \mathrm{~cm})$, sobrepeso $(80-87 \mathrm{~cm})$ e obesidade $(>88 \mathrm{~cm})$.

3. O sedentarismo foi definido pelo tempo de atividade física por semana e pela ocupação, de acordo com o critério do CDC. O indivíduo foi considerado sem risco quando sua ocupação era leve e atividade esportiva $>120$ minutos por semana, ou quando a ocupação era moderada ou pesada e tempo de atividade esportiva > 120 min; e como risco de sedentarismo, quando a ocupação era leve e tempo de atividade esportiva $\leq 120 \mathrm{~min}$. 
4. O tabagismo e hábito de beber foram definidos pelo tipo, freqüência e quantidade de consumo atual e passado. $\mathrm{O}$ hábito de beber foi classificado em: abstêmio (não consome), esporádico (consome bebida alcoólica de uma a três vezes por mês) e freqüente (consome mais de uma vez por semana). As informações sobre ingestão de bebida alcoólica foram comparadas com o nível de $\gamma$-GT sérico.

5. A escolaridade foi classificada em alta (ensino médio completo ou universidade), média (ensino fundamental completo ou ensino médio incompleto), baixa (ensino fundamental incompleto) ou muito baixa (analfabeto). A classe socioeconômica foi agrupada em alta (classes A e B), média (classe C) e baixa (classes D e E), de acordo com ANEP.

\subsection{Critérios para estabelecimento dos fenótipos estudados}

Os critérios utilizados foram os determinantes dos fenótipos intermediários da pressão arterial. Classificação dos fenótipos avaliados. ${ }^{8}$

1. Fenótipo Normotenso:mulheres com PA em qualquer idade $\leq 140 \mathrm{x}$ $90 \mathrm{mmHg}$.

2. Fenótipo Sistólico: mulheres com pressão arterial sistólica acima de $140 \mathrm{mmHg}$.

3. Fenótipo Diastólico: mulheres com a pressão arterial diastólica acima de $90 \mathrm{mmHg}$. 
4. Fenótipo Pressão de Pulso: mulheres com pressão de pulso acima de $60 \mathrm{mmHg}$.

5. Fenótipo Hipertenso: mulheres com a pressão arterial $\geq 140 \times$ $90 \mathrm{mmHg}$.

\subsection{Processamento e análise dos dados}

Todos os dados foram digitados no programa Epi Info, versão 6.04 (Dean et al., 1994). A análise de consistência foi realizada para detectar erros de digitação e informação, que depois de conferidos com os questionários originais foram corrigidos. A análise estatística foi realizada no programa SPSS versão 12 (SPSS Inc.).

O processamento envolveu a transformação de dados contínuos em categóricos através da classificação das variáveis genéticas e dos fatores sócio-demográficos, econômicos, clínicos e comportamentais, de acordo com parâmetros da literatura.

Primeiramente realizou-se uma análise descritiva (mediana, média, desvio padrão e proporção) das variáveis sóciodemográficas (sexo, idade, cor da pele, nível de escolaridade e classe econômica), clínicas (pressão arterial lipídeos, glicemia e antropometria) e comportamentais (tabagismo, etilismo e sedentarismo).

Para comparação das proporções ou médias das variáveis sociodemográficas e comportamentais segundo os fenótipos da pressão arterial foram utilizados, respectivamente, o teste do qui-quadrado de Pearson ou a prova exata de Fisher, quando necessário, e a análise de 
variância (ANOVA). O mesmo procedimento estatístico foi realizado para comparação destas variáveis em relação aos alelos e polimorfismos da ECA e AGT.

O intervalo de confiança de $95 \%$ foi utilizado para definição de diferença estatística. 


\section{RESULTADOS}

O atual estudo descreve as características sociodemográficas, étnicas, antropométricas e bioquímicas dos fenótipos (sistólico, diastólico e pressão de pulso) da pressão arterial das mulheres participantes do projeto Corações de Ouro Preto.

A amostra adulta feminina $(>18 \text { anos })^{27}$ foi de 468 participantes selecionada segundo os critérios de inclusão e exclusão descritos no anexo (A). Elas representam $87,7 \%(n=386)$ das participantes do projeto com mais de 18 anos. Ocorreu uma recusa de $17,5 \%$ após três convites. ${ }^{27}$

A participação por faixas etárias e das raças na amostra foram similares às informações estimadas pelo IBGE da população feminina da cidade de Ouro Preto. ${ }^{27}$

A idade média das participantes foi de $45,1 \pm 16,2$ (IC 95\%) (43,4 $46,7)$ anos. Entre as representantes do fenótipo sistólico a média foi de $56,4 \pm 13,3$ (IC 54,4 - 58,4) $(p<0,0001)$ anos. No fenótipo diastólico essa média foi de 52,8 $\pm 13,8$ (IC 50,2 - 54,4) $(p<0,0001)$ anos e no fenótipo pressão de pulso foi de 54,7 $\pm 15,2$ (IC 52,4 - 57,0) $(p<0,0001)$ anos (TAB. $1,2,3$ e 4$)$.

Entre as participantes $(n=112) 29,3 \%$ são da raça branca, $36,8 \%$ $(n=139)$ são morenas claras, $23,3 \%(n=89)$ morenas escuras $(n=38)$ e 9,9\% são da raça preta (TAB. 1). 
A distribuição pelo sentimento da cor da pele mostrou que as mulheres da raça preta foram mais prevalentes nos três fenótipos. A raça preta, comparativamente com a raça branca, mostrou prevalências de $60,0 \%$ contra $40,5 \%$ no fenótipo sistólico, $51,4 \%$ contra $36,1 \%$ no fenótipo diastólico e $60,0 \%$ contra 40,5\% no fenótipo pressão de pulso (TAB. 2, 3 e 4).

A possibilidade de as mulheres da raça preta pertencerem ao fenótipo sistólico foi de $(O R=2,19)$, ao diastólico, de $(O R=1,95)$ e ao da pressão de pulso, de $(O R=2,19)$, comparativamente, com as da raça branca (TAB. 2, 3 e 4).

Na análise univariada dos três fenótipos, não houve significância entre a cor da pele e o fenótipo sistólico $(p<0,2)$ e $(p<0,1)$ nos fenótipos diastólico e de pressão de pulso (TAB. 2, 3 e 4).

O tabagismo foi relatado por 88 mulheres, $22,7 \%$ das participantes (TAB. 1). Nos fenótipos sistólico, diastólico e pressão de pulso, a prevalência de tabagistas foi de $34,1 \%, 41,2 \%$ e $47,1 \%$, respectivamente. Entre os três fenótipos, somente nas participantes do fenótipo sistólico houve significância e risco associado ao tabagismo, $(p<0,001)$ e OR 1.41 IC 95\% $(1,02-1,93)$ (TAB. 1, 2, 3 e 4).

O sedentarismo está presente em $78,5 \%$ das mulheres avaliadas (TAB. 1). No fenótipo sistólico 45,8\% $(n=135)$ foram classificadas como sedentárias $(p<0,54)$ OR $=0,55\{\operatorname{IC~95\% ~}(0,7-1,9)\}$. No fenótipo diastólico $40,7 \%(n=120)$ são sedentárias $(p<0,20)$ OR $=1,12$ IIC 95\% $(0,8-1,4)\}$. As mulheres ( $n=145), 49,2 \%$ do fenótipo pressão de pulso são sedentárias $(p<0,12)$ OR $=1,48\{$ IC 95\% $(08-2,4)\}(T A B .2,3$ e 4). 
A estratificação da amostra pelos níveis de escolaridade, muito baixa, baixa, média e alta foi registrada em $25,7 \%, 32,2 \%, 19,7 \%$ e $31,2 \%$, respectivamente (TAB. 1).

A escolaridade mostrou significância $(p<0,0001)$ em todos os níveis de instrução nos três fenótipos estudados. A prevalência da participação nos fenótipos foi inversamente proporcional ao grau de escolaridade nos três fenótipos (TAB. 2, 3 e 4).

Das mulheres avaliadas $96(25,3 \%)$ possuem nível muito baixo de escolaridade. Entre elas $54,2 \%(n=69)$ participam do fenótipo sistólico; $54,2 \%(n=52)$, do fenótipo diastólico e $68,8 \%(n=66)$ apresentam o fenótipo pressão de pulso (TAB. 1, 2, 3 e 4).

As mulheres com grau de escolaridade muito baixo apresentaram 8,48 vezes a chance de pertencerem ao fenótipo sistólico, 3,10 de serem do fenótipo diastólico e 5,96 vezes do fenótipo pressão de pulso, quando comparadas com as participantes com alto grau de escolaridade (TAB. 2, $3 \mathrm{e}$ 4).

Das mulheres avaliadas, $115(23,5 \%)$ possuíam alto nível de escolaridade. Entre elas $23,5 \%(n=27)(p<0,0001)(O R=0.12)$ participam do fenótipo sistólico. No fenótipo diastólico, participam 25,2\% $\quad(n=29)$ $(p<0,0001)(O R=0.20)$. No fenótipo pressão de pulso $(n=31) 27,0 \%$ $(p<0,0001)(O R=0.16)$ possuem alta escolaridade $(T A B .2,3$ e 4).

A estratificação das mulheres da amostra, entre as classes socioeconômicas, mostrou que $11,0 \%(n=46)$ das participantes são da 
classe $A B, 37,0 \%(n=143)$ são da classe $C$ e $(n=187) 48,4 \%$ são das classes DE (TAB. 1).

Na estratificação dos fenótipos entre as classes sócio econômicas, observou-se um aumento da prevalência, nos três fenótipos, quanto menor era a condição socioeconômica (TAB. 2, 3 e 4).

Das mulheres pertencentes ao fenótipo sistólico $(n=167), 37,0 \%$ $(n=17)(n=17)$ são das classes $A B(p<0,01)(O R=0,99)$, na classe $C$ $(n=52)(p<0,01)(O R=1,99)$ e nas classes DE $(n=98) 53,6 \%(O R=2,19)$ (TAB. 2).

A classificação da amostra pelo risco nutricional mostrou que as médias de IMC e CC variaram significativamente com a idade e a escolaridade, e que essas médias são mais elevadas naquelas com idade de 60 anos ou mais e naquelas com baixa escolaridade. Não foram encontradas diferenças significativas com relação à classe econômica e sedentarismo. ${ }^{27}$

$\mathrm{Na}$ amostra, o sobrepeso, obesidade e circunferência da cintura abdominal foram de $31,0 \%, 17,2 \%$ e $54,2 \%$, respectivamente. Nas participantes com idade $\geq 60$ anos foi de $43,5 \%, 18,8 \%$ e $62,4 \%$ e naquelas com baixa escolaridade $35,8 \%, 15,2 \%$ e $61,4 \%$, respectivamente. ${ }^{27}$

O sobrepeso central esteve presente em $21,9 \%$, e a obesidade central, em 33,5\% Esses dois indicadores também foram maiores naquelas com idades $\geq 60$ anos. $^{27}$

As prevalências da circunferência da cintura abdominal aumentada foram de $43,1 \%, 43,6 \%$ e de $48,1 \%$ nos fenótipos sistólicos, diastólicos e 
pressão de pulso, respectivamente (TAB. 2, 3 e 4). Nessa mesma seqüência dos fenótipos, as médias foram de $89,2 \pm 14,2 \mathrm{~cm}$ (IC $87,0-91,0$ ) $(p<0,0001), \quad 90,0 \pm 13,1 \mathrm{~cm} \quad($ IC $87,9-92,1) \quad(p<0,0001) \quad$ e $\quad$ de $88,0 \pm 14,6 \mathrm{~cm}($ IC $85,7-90,2)(p<0,0001)$.

As mulheres com valores elevados da circunferência da cintura abdominal apresentaram chances de $(O R=1,38,1,92$ e 1,16) de pertencerem aos fenótipos sistólico, diastólico e pressão de pulso, em comparação àquelas com medidas normais (TAB. 2, 3 e 4).

$\mathrm{Na}$ avaliação sobre o perfil lipídico das mulheres do estudo, observou-se que $6,3 \%(n=24)$ apresentaram colesterol total aumentado, com média de 182,96 $\pm 3,9 \mathrm{mg} / \mathrm{dl}\{$ IC $95 \%(179,0-186,8) \mathrm{mg} / \mathrm{dl}\}$. Entre elas $37,5 \%(n=147)$ apresentaram HDL-colesterol baixo ou moderado com média de $65,14 \pm 27,1 \mathrm{mg} / \mathrm{dl}\{$ IC $95 \%(63,7-66,4) \mathrm{mg} / \mathrm{dl}\}$. As participantes com LDL-colesterol elevado $(n=43) \quad 11,3 \%$ com média de $95,88 \pm$ $27,4 \mathrm{mg} / \mathrm{dl}$ \{lC 95\% $(92,6-98,2) \mathrm{mg} / \mathrm{dl}\}$. Valores elevados de triglicérides foram observados em 8,8\% $(n=32)$ com média de $110,50 \pm 68,5 \mathrm{mg} / \mathrm{dl}$ $\{$ IC $95 \%(103,4-117,6) \mathrm{mg} / \mathrm{dl}\}$ (TAB. 1).

Nas mulheres pertencentes ao fenótipo sistólico, observou-se que ( $n=165) \quad 43,8 \%$ possuíam colesterol total elevado com média de $191,6 \pm 37,9 \mathrm{mg} / \mathrm{dl}\{\mathrm{IC} 95 \%(185,8-197,5)\}(p<0,0001)$ e $(O R=1,46)$. As com colesterol HDL alterado $(n=165) \quad 43,8 \%$ com média de $66,7 \pm 13,4 \mathrm{mg} / \mathrm{dl}\{\mathrm{IC} 95 \%(64,6-68,8)\}(p<0,02)$ e $(\mathrm{OR}=1,46) . \mathrm{O}$ LDLcolesterol aumentado foi registrado em $(n=163) 43,3 \%$ com média de $98,8 \pm 27,3 \mathrm{mg} / \mathrm{dl}\{(\mathrm{IC} 94,6-103,1)\}(p<0,02)$ e $(O R=1,44)$. Os níveis de 
triglicérides alterados foram observados em $(n=163) 43,3 \%$ com média de $127,7 \pm 65,9 \mathrm{mg} / \mathrm{dl}\{\mathrm{IC} 95 \%(116,5-136,9)\}(p<0,0001)$ e $(\mathrm{OR}=1,44)(T A B$. 2).

Nas mulheres pertencentes ao fenótipo diastólico, observou-se que ( $n=152) \quad 40,4 \%$ tinham colesterol total elevado com média de $191,5 \pm 36,5 \mathrm{mg} / \mathrm{dl}\{\operatorname{IC} 95 \%(185,6-197,4)\}(p<0,0001)$ e $(O R=1,95)$. As com colesterol HDL alterado $(n=152) 40,4 \%$, com média de $66,4 \pm$ $12,8 \mathrm{mg} / \mathrm{dl}\{\mathrm{IC} 95 \%(64,4-68,5)\}(p<0,08)$ e $(\mathrm{OR}=1,95)$. O LDL-colesterol aumentado foi registrado em $(n=151) 40,1 \%$, com média de $98,8 \pm$ $27,3 \mathrm{mg} / \mathrm{dl}\{\mathrm{IC} 95 \%(94,6-103,1)\}(p<0,02)$ e $(\mathrm{OR}=1,90)$. Os níveis de triglicérides alterados foram observados em $(n=151) 40,1 \%$, com média de $132,7 \pm 77,0 \mathrm{mg} / \mathrm{dl} \quad\{\mathrm{IC} 95 \% \quad(120,0-145,1)\} \quad(p<0,0001)$ e $(\mathrm{OR}=1,90)$ (TAB. 3).

Nas mulheres pertencentes ao fenótipo pressão de pulso, observouse que $(n=173) 47,5 \%$ estavam com colesterol total elevado, com média de média de 191,3 \pm 41,1 \{IC 95\% $(185,1-197,5)\}(p<0,0001)(O R=1,22)$. As com colesterol HDL alterado $(n=173) 47,5 \%$ com média de $66,9 \% \pm$ 13,2 mg/dl $\{$ IC 95\% $(64,9-68,9)\}(p<0,009)$ e $(O R=1,24)$. O LDL-colesterol aumentado foi registrado em $(n=170) \quad 47,3 \%$ com média de $99,2 \pm 29,1 \mathrm{mg} / \mathrm{dl}\{\operatorname{IC} 95 \%(94,2-103,6)\}(p<0,01)$ e $(\mathrm{OR}=1,24)$. Os níveis de triglicérides alterados foram observados em $(n=170) 47,0 \%$ com média de $119,7 \pm 65,7 \mathrm{mg} / \mathrm{dl}\{\mathrm{IC} 95 \%(109,7-129,6)\} \quad(p<0,01)$ e $(O R=1,24)$ (TAB. 4). 
A hiperglicemia foi registrada em 15,7\% $(n=60)$ das participantes com média de 99,01 $\pm 24,5 \mathrm{mg} / \mathrm{dl}\{\mathrm{IC} 95 \%(96,4-101,5)\}($ TAB. 1).

Nas mulheres pertencentes ao fenótipo sistólico, 23,5\% $(n=27)$ apresentaram hiperglicemia com média de 105,3 $\pm 26,8 \mathrm{mg} / \mathrm{dl}$ \{lC 95\% $(101,2-109,4) \mathrm{mg} / \mathrm{dl}\}(p<0,0001)(O R=1,43)(T A B .2)$.

Nas participantes do fenótipo diastólico, 40,6\% $\quad(n=153)$ apresentaram hiperglicemia com média de 106,0 $\pm 30,5 \mathrm{mg} / \mathrm{dl}$ \{ IC 95\% $(101,1-110,9)\}(p<0,0001)$ e $(O R=1,91)(T A B .3)$.

Entre as mulheres com fenótipo pressão de pulso, 47,8\% $(n=174)$ apresentaram hiperglicemia com média de $104,0 \pm 28,5 \mathrm{mg} / \mathrm{dl}$ \{IC 95\% $(99,7$ $-108,2)\}(p<0,0001)$ e $(O R=1,19)(T A B .4)$.

$\mathrm{Na}$ amostra, as médias da pressão arterial sistólica foi de 135,2 \pm 26,7 IC 95\% $(132,5-137,9) \mathrm{mmHg}$, da diastólica foi de $84,6 \pm 14,3$ IC $95 \%$ $(83,2$ - 86,0) $\mathrm{mmHg}$ e da pressão de pulso, foi de 50,5 \pm 18,7 IC 95\% (48,7 $52,4) \mathrm{mmHg}(\mathrm{TAB} .2)$.

A hipertensão arterial foi registrada em $52,7 \%$ das mulheres avaliadas (TAB. 5).

A prevalência de hipertensão arterial nas faixas etárias foi de 15-19 anos, 20-39 anos, 40-59 anos, e nas acima de 60 anos foi de 7,7\%, 18,7\%, $64,9 \%$ e 92,7\%, $(p<0,0001)$. A possibilidade $(O R=52,2)$ de as mulheres na faixa etária acima de 60 anos serem hipertensas, comparativamente com as da faixa etária de 20 a 39 anos, é de 52,2 vezes (TAB. 5).

As mulheres na faixa etária entre 20 a 39 anos apresentaram a prevalência de hipertensão arterial de 18,7\% ( $p<0,0001)$. Nessa faixa 
etária, a prevalência do fenótipo diastólico $(16,4 \%)$ é superior ao sistólico $(10,4 \%)(T A B .5)$

Na faixa etária entre 40 e 50 anos, 64,9\% das mulheres são hipertensas ( $p<0,0001)$. Nessa faixa etária, registraram-se as prevalências dos fenótipos sistólico $(54,5 \%)$ e diastólico $(57,3 \%)$ (TAB. 5).

Nas mulheres com mais de 60 anos, a prevalência de hipertensão arterial foi $92,7 \%(n=)$. Nos fenótipos, a prevalência do fenótipo sistólico foi de $(90,2 \%)$, do diastólico foi de $(59,2 \%)$ e da pressão de pulso, de $(91,5 \%)$ $(p<0,0001)($ TAB. 5).

As mulheres entre os 40 e 59 anos e as acima de 60 anos apresentam 10,2 e 80,0 vezes chances de serem pertencentes ao fenótipo sistólico do que as mulheres com idade entre 20 a 39 anos (TAB. 5).

A possibilidade de as mulheres com mais de 60 anos, comparativamente com as de 20 e 39 anos, é de terem 55 vezes maior propensão para hipertensão arterial, 80 vezes para o fenótipo sistólico, 50 vezes para o fenótipo diastólico e 49 vezes para apresentarem o fenótipo pressão de pulso (TAB. 5).

As freqüências na amostra dos alelos da ECA (D e I) foram de $57,8 \%(n=408)$ para o alelo $D$, e de $42,2 \%(n=208)$ para o alelo I (TAB. 6A).

A prevalência do alelo M do AGT foi de 39,8\% $(n=277)$ e do alelo T, de 59,3\% $(n=419)($ TAB. 6-A).

A distribuição dos genótipos da ECA registrou 18,1\% $(n=69)$ com o genótipo II, 46,2\% $(n=176)$ com o genótipo DI e 35,7\% $(n=136)$ com o 
genótipo DD. A distribuição do genótipo AGT mostrou que 16,5\% $(n=63)$ possuíam genótipo MM; 45,7\% ( $n=174)$, o genótipo MT e 36,5\% (139) eram do genótipo TT (TAB. 6-B).

A freqüência dos alelos do angiotensinogênio ( $M$ e $T$ ) não apresentou significância estatística na distribuição entre as faixas etárias $(p<0,50)$. Os alelos enzima conversora da angiotensina (I e D) mostraram significância em relação à distribuição das faixas etárias $(p<0,01)$ (TAB. 7A).

Ocorreu possibilidade de 2.2 vezes $(p<0,01)$ e $(O R=2,2)$, de as mulheres com mais de 60 anos apresentarem o alelo $D$ em relação ao alelo I, comparativamente com as mulheres entre 15 e 19 anos (TAB. 7-A).

A presença do alelo T do AGT foi significativa em relação ao quesito cor da pele $(p<0,002)(O R=2,2)$. As mulheres da raça negra mostram 2.2 vezes a chance de possuírem o alelo T. Não houve associação da cor da pele com o genótipo da ECA $(p<0,9)$ (TAB. 7-B).

Das mulheres portadoras do alelo $M(n=100), 30,1 \%$ e T $29,6 \%$ $(n=132)$ possuem níveis elevados de colesterol total, com $(p<0,50)$ e $(\mathrm{OR}=08)(\mathrm{TAB} .8-\mathrm{A})$.

As portadoras de LDL colesterol elevado possuem 43,9\% $(n=131)$ dos alelos $M$ e $(n=179) 40,8 \%$ do alelo $T(p<0,10)$ e $(O R=0.9)(T A B .8-B)$.

As participantes com colesterol HDL baixo e moderado possuem $43,4 \%(n=127)$ dos alelos $M$ e $56,6 \%(n=165)$ do alelo $T(p<0,30)$ e $(\mathrm{OR}=1,2)(\mathrm{TAB} .8-\mathrm{C})$. 
Entre as com o fenótipo triglicérides elevados, estão presentes $28,6 \%(n=67)$ dos alelo $M$ e 16,6\% $(n=73)$ possuem alelos T $(p<0,30)$ e $(O R=0.6)(T A B .8-D)$.

A análise dos percentuais dos alelos da AGT, presentes nos fenótipos sobrepeso e obesidade, mostrou o alelo $M$ com 52,3\% ( $n=156$ ) $(p<0,50)(O R=0,04)$ e alelo T com 56,2\% $(n=252)(p<0,50)(O R=0,04)$ (TAB. 9-A).

A prevalência dos alelos do AGT nas mulheres com fenótipo de hiperglicemia mostrou o alelo M com 13.9\% $(n=42)(p<0,02)(O R=2,2)$. O alelo T registrou 17,9\% $(n=78)(p<0,02)(O R=2,2)$. As mulheres com o alelo T mostraram que têm 2,2 vezes (OR 2,2) chances de apresentarem hiperglicemia (TAB. 9-C).

A participação dos alelos do AGT no fenótipo circunferência da cintura abdominal mostrou o alelo $M$ com 37,5\% $(n=111) \quad(p<0,70)$ $\{O R=1,02$ IC 95\%(0.7-1.4) $\} . O$ alelo T com 38,4\% $(n=167) \quad(p<0,70)$ $\{\mathrm{OR}=1,02 \mathrm{IC} \mathrm{95 \% (0.7-1.4) \}}(\mathrm{TAB} .9-\mathrm{B})$.

Das mulheres portadoras do alelo I $(n=94), 30,3 \%$ e D $32,0 \%$ $(n=142)$ possuem níveis elevados de colesterol total com $(p<0,50)$ e $(\mathrm{OR}=08)($ TAB. 8-A).

As portadoras de LDL colesterol elevado possuem $43,9 \%(n=131)$ dos alelos I e $(n=122) 39,3 \%$ do alelo $D(p<0,10)$ e $(O R=0.9)(T A B .8-B)$.

As participantes com o colesterol HDL baixo e moderado possuem $44,7 \%(n=140)$ dos alelos I e 34,7\% $(n=154)$ do alelo $D(p<0,007)$ e $(\mathrm{OR}=1,5)(\mathrm{TAB} \cdot \mathbf{8 - C})$ 
O fenótipo HDL-colesterol aumentado apresentou significância estatística em relação às mulheres com HDL-colesterol baixo ou moderado comparativamente às portadoras do alelo $\mathrm{D}$ em relação ao alelo I $(p<0,007)$. Esse comportamento não foi observado em relação aos alelos da AGT $(p<0,30)($ TAB. 8-C). Observou-se que as mulheres que possuem o alelo $D$ apresentam 1.5 vezes mais chances de ter o HDL colesterol elevado em comparação às portadoras do alelo I (TAB. 8-C).

Entre as com o fenótipo triglicérides elevado estão presentes $20,2 \%$ $(n=63)$ dos alelos I e 18,6\% ( $n=82)$ possuem alelos $T(p<0,30)$ e $(\mathrm{OR}=1,2)(\mathrm{TAB} .8-\mathrm{D})$.

A análise dos percentuais dos alelos da ECA, presentes nos fenótipos sobrepeso e obesidade, mostrou o alelo I com 55,2\% ( $n=174)$ $(p<0,90)(O R=0,90)$ e alelo $D$ com $54,8 \%(n=242)(p<0,90)(O R=0,90)$ (TAB. 9-A).

As mulheres que apresentaram valores elevados da glicemia $(<110 \mathrm{mg} / \mathrm{dl})$ mostraram significância estatística $(p<0,02)$ de possuírem o alelo $T$, em relação às mulheres não pertencentes a esse fenótipo. As mulheres com o alelo $T$ deram sinal de que têm 2,2 vezes $(O R 2,2)$ mais chances de apresentarem hiperglicemia (TAB. 9-C).

A prevalência dos alelos do ECA nas mulheres com fenótipo de hiperglicemia registrou o alelo I com 14,1\% $(n=44)(p<0,30)(O R=1,5)$. $O$ alelo $D$ registrou $17,0 \%(n=76)(p<0,30)(O R=1,5)(T A B .9-C)$.

A participação dos alelos da ECA no fenótipo circunferência da cintura abdominal mostrou o alelo I com 16,1\% ( $n=118) \quad(p<0,90)$ 
$\{\mathrm{OR}=0.91$ IC 95\% $(0.7-1.3)\}$. alelo D com 52,9\% $(n=164)(p<0,90)$ $\{\mathrm{OR}=0.91 \mathrm{IC} 95 \%(0.7-1.3)\}($ TAB. 9-B)

A tabela 6-B descreve as freqüências dos genótipos da ECA e AGT. Os genótipos (II, DI e DD) e (MM, MT e TT) foram de $\{18,1 \%$ ( $n=69), 46,2 \%$ $(n=176)$ e $35,7 \%(n=136)\}$ e $\{(16,5 \%(n=63), 45,7 \%(n=174)$ e $36,5 \%$ $(n=139)\}$, respectivamente.

A distribuição dos genótipos da ECA pela estratificação de faixa etária, análise comparativa entre as mulheres com mais de 60 anos e as com idade entre 20 e 39 anos, mostrou significância $(p<0,03)$. Na mesma análise dos genótipos do AGT não foi observada significância $(p<0,53)$ (TAB. 10).

A distribuição dos genótipos da ECA no fenótipo sistólico mostrou, no II 52,2\% ( $=36)$, no DI 42,7\% $(n=73)$ e DD 44,4\% $(n=60)(p>0,43)$ OR 0,73. Do genótipo do AGT foi de MM 43,5\% ( $n=27), M T, 44,8 \%(n=77)$ e TT, de 45,6\% $(n=62)(p<0,96)$ OR 1.08 (TAB. 11-A).

No fenótipo diastólico a distribuição do genótipo da ECA foi de II $40,6 \%(n=28)$, no $\mathrm{DI}$ de $41,5 \%(n=71)$ e no DD de $43,0 \% \quad(n=58)$ ( $p>0,94)$ OR 1,10. Do genótipo do AGT foi de MM 40,3\% ( $n=25)$, no MT de 39,5\% $(n=68)$ e no TT de 44,9\% $(n=61)(p<0,62)$ OR 1.20 (TAB. 11 B).

No fenótipo pressão de pulso, a distribuição dos genótipos da ECA e do AGT foi de II 50,7\% (n=35), no DI, de 40,9\% $(n=70)$ e no DD, de $53,3 \%(n=72)(p<0,007)$; no OR, de 1,10. No genótipo do AGT foi, no MM, 
de 40,3\% ( $n=25)$, no MT, de 39,5\% ( $n=68)$ e no TT, de 44,9\% ( $n=61)$ e $(p<0,62)$ OR 1.20 (TAB. 11-C).

A tabela 12 descreve as freqüências dos genótipos do AGT e da ECA no fenótipo circunferência da cintura abdominal. A prevalência dos genótipos nas participantes com a medida aumentada mostrou o genótipo MM, com 31,1\% ( $n=19)$. O genótipo MT com 37,3\% $(n=62)$ e o TT, com $34,6 \%(n=45)(p<0,80)(O R=1,17)$.

A prevalência dos genótipos da ECA nas participantes com a medida CC aumentada mostrou o genótipo II com 33,8\% ( $n=23)$. O genótipo DI com 36,9\% $(n=62)$ e o DD com 34,1\% $(n=43)(p<0,60)$ $(\mathrm{OR}=1,01)(T A B \cdot 12-A)$.

Na avaliação da freqüência dos genótipos do AGT e da ECA com as associações dos homozigotos para os alelos T e D mais os heterozigotos mostraram análises similares às anteriores (TAB. 12-B).

A tabela 13-A descreve as prevalências dos genótipos do AGT e da ECA no fenótipo hiperglicemia. Nas mulheres com hiperglicemia, o genótipo MM anotou 9,7\% $(n=6)$, no MT era de $17,8 \%(n=30)$ e no genótipo TT, $17,9 \%(n=24)(p<0,28)(O R=2,03)$.

O genótipo da ECA registrou, entre as mulheres com hiperglicemia, $11,8 \%$ ( $n=8)$; no genótipo II, $16,6 \% \quad(n=28)$; e no genótipo DI, $18,0 \%$ $(n=24)(p<0,50)(O R=1,65)(T A B \cdot 13-A)$.

As mulheres com hiperglicemia dos genótipos TT associada com MT registraram 63,9\% $(n=249)(p<0,11) \quad\{O R=2,02$ IC $95 \%(0,8-4,9)\}$ (TAB. 13-B). 
As participantes do fenótipo hipertrigliceridemia (limítrofe, alta e muito alta) mostraram a distribuição dos genótipos do AGT com 25,8\% $(n=16)$ no $M M, 20,1 \%(n=34)$ e $14,8 \%(n=20)(p<0,42)(T A B .14-A)$. Nesse fenótipo, a distribuição dos alelos da ECA registrou 20,6\% ( $n=14)$ no genótipo II; 19,6\% $(n=33)$ no DI e, no DD, 18,5\% $(n=24)(p<0,63)$ $(\mathrm{OR}=1,64)(\mathrm{TAB} \cdot 14-\mathrm{A})$

No fenótipo colesterol total elevado (limítrofe e alto), ocorreu, entre as participantes, a prevalência do MM de 30,7\% ( $n=19)$; do MT, 33,7\% $(n=57)$ e do TT, $27,6 \%(n=37)(p<0,80)(O R=0.77)$. No genótipo da ECA a distribuição foi de $26,1 \%(n=18)$; no II, no genótipo DI, $31,9 \%(n=54)$ e no DD, 32,6\% $(n=43)(p<0,60)(O R=0,7)(T A B .15-A)$.

As mulheres com o fenótipo colesterol LDL aumentado (desejável, limítrofe, moderado e alto) registraram, nos genótipos do AGT, as prevalências de 45,8 ( $n=28)$; no genótipo MM, 51,1\% ( $n=69)$; no MT e no TT, 41,2\% $(n=52)(p<0,10)(O R=0,42)$. A distribuição dos genótipos da ECA mostrou 27,6\% ( $n=21)$ no genótipo II; no genótipo DI, 44,7\% ( $n=75)$ e no $D D, 43,5 \%(n=57)(p<0,21)(O R=1,02)(T A B .16-A)$.

O grupo com fenótipo colesterol HDL (baixo e moderado) mostrou as prevalências de 41,9\% ( $n=26)$ no genótipo MM; no genótipo MT, 42,6\% $(N=72)$ e no genótipo TT, 32,8\% $(n=44)(p<0,30)(O R=0,6)$. No genótipo da ECA, a distribuição das prevalências foi de $44,9 \%(n=31)$ no genótipo II; no genótipo DI, $44,4 \%(n=75)$ e no DD, 38,7\% $(n=37)(p<0,008)(O R$ 2.01) (TAB. 17-A). 
A avaliação da associação dos genótipos DD e DI constatou uma prevalência de $37,2 \%(n=112)$ e no II, 44,9\% $(n=31)(p<0,06)(O R=0.72)$ (TAB. 17-B). 


\section{DISCUSSÃO}

O estudo descreve os fenótipos da pressão arterial, sistólico, diastólico e pressão de pulso e suas correlações com os principais fatores de risco cardiovascular. O objetivo do estudo foi evidenciar possíveis associações desses fenótipos com os polimorfismos de genes candidatos à hipertensão arterial. Os alelos e polimorfismos analisados foram da enzima conversora da angiotensina (D e I) e II, DI e DD e os do angiotensinogênio (T e D) e MM, MT e TT.

No presente estudo, a amostra seria isenta de criticas caso o desenho não fosse realizado em duas fases. Estudo epidemiológico, como o atual, realizado em duas fases, sendo a primeira desenvolvida no domicílio da mulher selecionada com a realização de entrevista e aferição da pressão arterial, e a segunda fase realizada em outro local, onde a coleta de material biológico e os dados antropométricos eram colhidos. Estudos com este formato apresentam perdas, como neste, em que ocorreu uma perda de $17,5 \%$ participantes, valor não menor do que os relatos em estudos internacionais com desenho parecido. ${ }^{69}$

A doença cardiovascular é a maior causa de mortalidade na população mundial. Dados publicados pela OMS responsabilizam as doenças cardiovasculares por 16 milhões de óbitos ao ano. ${ }^{1}$ No Brasil representa $32 \%$ da mortalidade total. Na população feminina, o percentual dos fatores de risco cardiovascular vem aumentado nas últimas décadas. ${ }^{20}$ 
Em muitos países, morrem mais mulheres do que homens por ano devido a DCV. ${ }^{16,70}$

A prevalência de hipertensão arterial na amostra feminina de Ouro Preto registrou o percentual de 52,7\% com pressão arterial superior ou igual a 140 x $90 \mathrm{mmHg}$ e com a idade média de 45,11 \pm 16,2 anos (TAB. 1 e 5).

A prevalência de hipertensão arterial varia entre $22,3 \%$ a 43,9\% na população urbana brasileira. Entre as mulheres, as variações das prevalências também são observadas. Esses percentuais oscilam, dependendo da região avaliada e do critério utilizado para o valor de normalidade da pressão arterial utilizado. Estudos brasileiros realizados na década de 90, que utilizaram valores 160 × $95 \mathrm{mmHg}$, a prevalência publicada entre as mulheres foi de $25,3 \%$ e $25,1 \%$ nas cidade de Araraquara (1991) e Pelotas (1994). O estudo que avaliou a prevalência de hipertensão arterial entre as mulheres com mais de 50 anos, na cidade de Araraquara (SP) foi de $54,6 \% .^{21,22}$

Quando o critério utilizado foi o de pressão arterial $\geq 140 \mathrm{x}$ $90 \mathrm{mmHg}$ para hipertensão, como por exemplo, o do Rio Grande do Sul, houve prevalência de $33,7 \%$ de hipertensos na população adulta. Com os mesmo critérios, entre as mulheres, registrou-se as prevalências de 22,1\%, $27,4 \%, 33,6 \%$ nas cidades de Vitória (ES), Salvador (BA) e Formiga (MG), respectivamente. ${ }^{22,23}$

A prevalência de hipertensão arterial nas mulheres de Ouro Preto (MG) apresentou maior similaridade com as freqüências descritas nas 
populações européias do que nas norte-americanas, canadenses e brasileiras. $^{69,70}$

A hipertensão arterial, nas mulheres norte americanas, canadenses, espanholas e alemãs, foi de $24,8 \%, 25,8 \%, 44,6 \%$ e $50,3 \%$, respectivamente. ${ }^{69,70}$

Nas mulheres portuguesas as prevalências foram de $12,5 \%$ nas com menos de 35 anos, e de 41,1\% nas com faixa etária entre 35 e 64 anos. $^{71}$

Fato epidemiológico atual, que merece atenção sobre a hipertensão arterial, é que, em alguns registros, a prevalência entre as mulheres é maior do que as registradas entre os homens. ${ }^{70}$

Seis estudos nacionais registraram uma predominância da hipertensão nas mulheres. Dois destes foram realizados na população da cidade de Salvador $(\mathrm{BA}){ }^{21,22}$

As análises sobre as prevalências dos fenótipos da pressão arterial devem levar em consideração as características da população estudada. Os percentuais entre as faixas etárias, freqüências das etnias, dos níveis de escolaridade e da renda familiar devem refletir a composição da população avaliada para ter validade interna e, ponderada, quando necessária para a validação externa. Dessa forma, análises comparativas entre os estudos de Ouro Preto e outros estudos são relatados abaixo (TAB. 2, 3 e 4).

No estudo de Ouro Preto (MG), a idade média foi de 45,1 $\pm 16,20$ anos $\{$ IC 95\% (43,4 - 46,7)\}. Em estudos brasileiros com os mesmos critérios de corte da pressão arterial $\geq 140 / 90 \mathrm{mmHg}$, a média das idades das 
mulheres estudas foi de $40,8 \pm 12,0$ anos, $41,9 \pm 14,6$ anos, $44,0 \pm 15,6$ anos, nas cidades de Pelotas (RS), Salvador (BA) e Rio Grande do Sul. As médias de idade desses estudos são muito similares às do estudo de Ouro Preto. $^{21,23}$

Estudo publicado sobre a prevalência de hipertensão arterial na população portuguesa mostra a importância da estratificação das faixas etárias para essa análise. Neste estudo, a prevalência na população geral mostrou valores de $49,5 \%$ entre os homens e de $38,9 \%$ entre as mulheres. No mesmo estudo, na população com mais de 64 anos, $78,7 \%$ dos homens e mulheres são hipertensos. ${ }^{71}$

Os fenótipos da hipertensão arterial mostraram valores muito elevados na população feminina de Ouro Preto quando comparados com os valores obtidos nos estudos epidemiológicos nacionais. ${ }^{21}$

Os valores da análise comparativa da composição etária do estudo de Ouro Preto com os nacionais não mostraram diferenças importantes para justificar as diferenças entre as prevalências. Observou-se uma similaridade entre os dados das mulheres de Ouro Preto e os das mulheres canadenses e das espanholas. ${ }^{69,70}$

A comparação das prevalências com a população portuguesa mostrou similaridade entre as ouropretanas e os homens portugueses $52,7 \%$ e 49,5\%, respectivamente. Entre as mulheres com idade acima de 60 anos, verificou-se aumento acentuado da prevalência entre as portuguesas $(78,8 \%)$ mas mesmo assim, as ouropretanas nessa faixa etária 
apresentaram percentuais mais elevados de $90,2 \%, 59,8 \%$ e $91,5 \%$ nos fenótipos sistólico, diastólico e pressão de pulso, respectivamente. ${ }^{69}$

\subsection{A etnia e a genética}

Vários estudos epidemiológicos indagam a dependência das patogêneses e das prevalências da hipertensão arterial influenciadas pelas etnias. $^{62}$

Publicações sobre as prevalências da hipertensão arterial, que analisaram as freqüências entre etnias, mostraram maior prevalência, morbidade e mortalidade entre os negros do que entre os brancos, asiáticos e outras etnias. ${ }^{62,69}$

Estudos ingleses e americanos publicaram uma faixa de mortalidade cardiovascular de 3,5 vezes maior em pessoas de origem afrocaribenha do que as médias nacionais devido à hipertensão arterial. ${ }^{19,70}$

O acidente vascular cerebral é mais comum em pessoas negras. As pessoas negras também apresentam maior incidência de insuficiência renal crônica do que as brancas. ${ }^{42}$

Estudos comparativos sobre a prevalência da hipertensão arterial na população da África meridional rural em 1990, utilizando critérios de 160/95 $\mathrm{mmHg}$, registraram freqüências de 5,9\%,5,7\% e 4,1\%, na Nigéria, Cameron e Gana, respectivamente. ${ }^{42,43,54}$

Dados colhidos em 2002, nas mesmas comunidades, utilizando aparelhos automáticos validados e critérios de 140/90 $\mathrm{mmHg}$, registraram as prevalências de $13 \%$ nos homens e $9 \%$ nas mulheres. ${ }^{42,43,54}$ 
Essas mesmas populações, avaliadas na região urbana, registraram valores médios de 19,1\%. Nos urbanos com mais de 65 anos, as prevalências ficaram entre $30 \%$ a $40 \%{ }^{42,43,54}$

As mulheres americanas de origem africana e mexicana, com mais de 40 anos, registram maior prevalência da hipertensão arterial do que nos homens. Quando a análise foi realizada na população com mais de 60 anos, em todas as etnias, a prevalência entre as mulheres foi maior. ${ }^{69,70}$

Entre os estudos brasileiros, o que mais se aproxima ao de Ouro Preto (MG) é o da cidade de Salvador (BA). Essa similaridade é conseqüência, principalmente, da forte miscigenação das populações das duas cidades. No estudo de Salvador $(B A)^{21}$, a prevalência da hipertensão arterial nas mulheres foi de $31,7 \%$, IC $(28,5-34,9)$, a idade média foi de 41,9 $\pm 14,6$ anos. No estudo de Ouro Preto (MG), a prevalência da hipertensão arterial foi de $52,7 \%$ idade média foi de $45,1 \pm 16,20$ anos $\{$ IC 95\% (43,4 46,7)\} (TAB. 18).

A freqüência das raças negra e branca em Ouro Preto (MG) foi de $9,9 \%$ e $29,6 \%$ e em Salvador (BA) de $28,1 \%$ e $24,8 \%$, respectivamente ${ }^{21}$ (TAB. 1).

Nas soteropolitanas, a hipertensão apresentou significância estatística em relação à cor de pele negra e parda. Quando comparadas às mulheres negras com as brancas, sobre a prevalência da hipertensão arterial, os valores foram de $41,1 \%$ e $21,1 \%$, respectivamente ${ }^{21}$ (TAB. 1 e 18). 
Nas ouropretanas, a maior prevalência, nos três fenótipos da pressão arterial, foi encontrada mais nas negras do que nas outras etnias. Mas, em nenhum dos fenótipos, houve significância estatística (TAB. 2, 3 e 4).

Na comparação entre as populações ouropretana e soteropolitana, observa-se mais similaridade entre as prevalências da hipertensão arterial nas duas comunidades pretas, $52,7 \%$ e $41,1 \%$, respectivamente. ${ }^{21}$

Nas ouropretanas, a prevalência do fenótipo sistólico foi de $\{n=21$ $60,0 \%(p<0,20)(O R=2,19)\} ;$ nas pretas e nas brancas $\{n=4540,5 \%$ $(p<0,20)(O R=0.41)\}$; no fenótipo diastólico, nas pretas foi $\{n=1851,4 \%$ $(p<0,12)(O R=1,00)\}$; nas brancas $\{n=3935,1 \%(p<0,12)(O R=0.50)\}$; no fenótipo pressão de pulso, nas negras foi de $\{n=2160,0 \%(p<0,10)$ $(O R=2,19)\}$; e nas brancas, de $\{n=4540,5 \%(p<0,12)(O R=0.45)\}(T A B$. 1, 2, 3 e 4).

Os comportamentos epidemiológicos dos fenótipos da pressão arterial entre as ouropretanas assemelham mais às soteropolitanas pretas ${ }^{21}$ (TAB. 18).

Nas análises dos estudos epidemiológicos, os critérios para padronização das etnias são debatidos e controversos. Apesar dessas dificuldades, o comportamento das ouropretanas mostrou equivalência com as publicações nacionais e internacionais, no que consiste à prevalência da hipertensão arterial na raça preta. Os dados somente divergem, juntamente com os internacionais, entre as prevalências da hipertensão arterial na raça 
negra africana e dos seus descendentes espalhados em todo o mundo. ${ }^{70,72,73}$

\subsection{Obesidade}

Os estudos que relacionam a hipertensão arterial com a obesidade, quando comparam suas influências entre os gêneros, mostraram maior relação de risco nas mulheres se estas forem comparadas aos homens, tanto para sobrepeso como para obesidade. ${ }^{15,16}$

Nas publicações do estudo de Framingham, quando os gêneros são comparados pelo índice de massa corporal, as mulheres com sobrepeso e obesidade apresentaram maior prevalência de hipertensão arterial e risco cardiovascular do que os homens pertencentes à mesma classificação. ${ }^{74}$

No estudo paulista publicado sobre a prevalência de hipertensão arterial em mulheres com sobrepeso e obesidade, os dados mostraram freqüências progressivas da hipertensão arterial. As prevalências foram de $15,7 \%, 24,9 \%$ e $39,1 \%$ para IMC $<25$, entre 25 e 30 e $>30 \mathrm{~kg} / \mathrm{m}^{2}$.

As mulheres no estudo de Salvador ${ }^{21}$ (BA) registram risco de OR 1,62 IC (1,02 - 2,58) na associação da obesidade com a hipertensão. O risco da obesidade abdominal foi de OR 2,05 IC $(1,31-3,21)$. No estudo do Rio Grande do Sul, o risco foi de (OR = 3,03). (TAB. 18)

Em relação à circunferência da cintura abdominal, o risco de associação com hipertensão arterial, nos estudos de Salvador (BA) e de São Paulo (SP), foi de OR = 2,05 e OR $=3,05^{21}$ (TAB. 18). 
No estudo de Ouro Preto (TAB. 9-B), observou-se significância estatística $(p<0,0001)$ nas mulheres com circunferência da cintura abdominal superior a $88 \mathrm{~cm}$, nos três fenótipos avaliados. A probabilidade de ocorrência foi de $\mathrm{OR}=1,38$, OR $=1,92$ e OR $=1,16$ nos fenótipos sistólico, diastólico e pressão de pulso, respectivamente.

\subsection{Escolaridade}

Entre as ouropretanas, o nível de escolaridade foi um dos critérios que maior significância estatística $(p<0,0001)$ mostrou em relação aos fenótipos da pressão arterial, na população de OP. As probabilidades de ocorrências foram muito elevadas nas mulheres com muito baixa escolaridade $\{(n=71,4 \%$ OR $=8,48\},\{(n=54,2 \%)$ OR $=5,92\}$ e $\{(n=68,8 \%$ $\mathrm{OR}=3,10\}$ nos fenótipos sistólico, diastólico e pressão de pulso, respectivamente (TAB. 2, 3 e 4).

Nas soteropolitanas, a hipertensão arterial esteve presente em $47,2 \%$ das mulheres com baixa escolaridade e 49,5\% das com média escolaridade.

As classes socioeconômicas mostraram significância estatística com relação aos três fenótipos entre as ouropretanas (TAB. 2, 3 e 4). As probabilidade de ocorrências foram de $\mathrm{OR}=2,19, \mathrm{OR}=3,50$ e $\mathrm{OR}=1,95$ para os fenótipos sistólico, diastólico e pressão de pulso, respectivamente.

Comportamento parecido ocorreu entre as soteropolitanas com uma freqüência de 59,3\% das mulheres da classe social baixa e com hipertensão arterial. 
A hiperglicemia foi estatisticamente significativa nos três fenótipos ( $p<0,0001$ ) (TAB. 2, 3 e 4) e apresentou probabilidades de ocorrências de $\mathrm{OR}=1,43, \quad \mathrm{OR}=1,91$ e $\mathrm{OR}=1,19$ nos fenótipos sistólico, diastólico e pressão de pulso, respectivamente. A hiperglicemia mostrou um risco de ocorrência de OR = 2,16 entre as hipertensas.

A dislipidemia, nas ouropretanas, foi estatisticamente significativa $(p<0,01)$ em todos os elementos avaliados, colesterol total, LDL e HDL colesterol e triglicérides (TAB. 8-A, 8-B, 8-C e 8-D) com risco de ocorrência de $(O R=1,90)(T A B .18)$

Nas soteropolitanas, não ocorreu significância com o colesterol total, LDL colesterol e triglicérides (TAB. 18).

Entre as duas populações femininas ocorreu significância estatística semelhante nos fenótipos idade, sobrepeso, obesidade, circunferência da cintura abdominal e hiperglicemia (TAB. 18).

Ocorreu significância estatística somente nas soteropolitanas de raça negra e parda.

No estudo de Ouro Preto não ocorreu significância entre os fenótipos da pressão arterial e as etnias (sentimento da cor da pele). No estudo de Salvador observou-se significância entre a hipertensão arterial e as etnias negra e parda.

\subsection{Polimorfismo do angiotensinogênio}

As pesquisas sobre a genética molecular humana da pressão arterial foram desenvolvidas com o objetivo de identificar os locus 
envolvidos, detectar variantes genéticas nos loci identificados, associá-los com fenótipos intermediários e, finalmente, estimar seus efeitos quantitativos sobre a pressão arterial e sua interação com os principais fatores ambientais. $^{65}$

Os genes do sistema renina-angiotensina foram extensamente estudados devido ao bem documentado papel desse sistema no controle da pressão arterial e na patogênese de várias formas de hipertensão.

Vários estudos iniciais mostraram uma correlação positiva entre níveis plasmáticos do AGT e a pressão arterial. Observou-se redução da pressão arterial com a administração do ANTIAGT, ou aumento da pressão arterial com a injeção de AGT, e, também a elevação da pressão arterial em animais transgênicos $A G T$, fatos que ofereceram atraentes evidências que vinculam o AGT à hipertensão arterial. $^{36}$

O primeiro e mais estimulador estudo correlacionando o polimorfismo do AGT com os fenótipos intermediários da pressão arterial foi o publicado pelo grupo do Jeunemaitre et al. ${ }^{36}$. O estudo foi realizado entre irmãos, o que facilitou os ajustes multifatoriais da hipertensão arterial. Nele são enfatizados os possíveis efeitos moduladores interativos de uma série de genes, entre eles os polimorfismos da ECA. Associados a essas interações gênicas, são citados fatores ambientais, tais como a ingestão de sódio e a obesidade. ${ }^{36}$

Uma das conclusões deste estudo foi de que os polimorfismos do AGT teriam um modesto efeito sobre a pressão arterial na população geral. Esses achados justificavam os resultados discrepantes, positivos e 
negativos, das associações entre os fenótipos intermediários da pressão arterial e o genótipo do AGT. ${ }^{36}$

Um grande estudo sobre a importância do polimorfismo do AGT na pressão arterial humana foi desenvolvido em duas grandes séries de irmãos em Salt Lake City e Paris. Os estudos foram desenvolvidos para avaliação de possíveis evidências da correlação dos polimorfismos genéticos, entre o AGT e os fenótipos intermediários da pressão arterial, em grupo familiar. Um excesso de $17 \%$ de alelos foi encontrado em pares de irmãos com hipertensão arterial grave, classificados como portadores de pressão arterial diastólica acima de $100 \mathrm{mmHg}$ ou utilizando dois fármacos antihipertensivos. ${ }^{36,61}$

A análise desses estudos mostra uma significativa associação entre o polimorfismo do AGT com os irmãos do sexo masculino, nos grupos de Utah e Paris, mas nenhuma associação foi observada nas comparações feitas entre as mulheres, que sugerissem influência de um fenômeno hormonal epistático. ${ }^{36,61}$

Várias linhas de evidências indicam que a concentração do AGT está vinculada à pressão arterial. Esses estudos podem mostrar que um aumento do AGT no plasma seria capaz de elevar a pressão arterial e contribuir para a hipertensão. Estudos também correlacionam o genótipo TT com a concentração do AGT no plasma. Tais observações foram relatadas após estudos em crianças normotensas, filhas de hipertensos. As filhas de hipertensos tinham $13 \%$ a mais da concentração do AGT do que as filhas de normotensos sem história familiar. $O$ estudo MONICA também publicou 
correlação entre as concentrações plasmáticas de AGT e o polimorfismo TT. ${ }^{36,61}$

Estudos que utilizaram avaliações de grandes metaanálises sugerem que, embora alguns estudos não tenham registrado a associação entre o polimorfismo do AGT e a hipertensão arterial, os indivíduos brancos e asiáticos homozigotos para o alelo 235T, parecem ter risco relativo de aumento para desenvolver os fenótipos da pressão arterial, quando comparados com os indivíduos homozigotos para o alelo M. As prevalências dos homozigotos TT nas etnias brancas são de 15\%, nos asiáticos; de $53,0 \%$ e de $67 \%$ entre os afro-caribenhos. Entre os africanos, apesar da maior prevalência dos homozigotos TT, o risco relativo não foi tão significativo como nas outras etnias. ${ }^{36,61}$

Os estudos de Caulfield e colaboradores ${ }^{75}$ mostraram forte ligação entre o genótipo AGT e a hipertensão arterial, numa série de 63 famílias britânicas. Essa associação foi observada no subgrupo de homens com o fenótipo diastólico, pressão diastólica acima de $100 \mathrm{mmHg}$, mas esta associação não foi registrada entre os pares de mulheres. Outro estudo observou associação entre o polimorfismo do AGT em pares de irmãos de origem afro-caribenha, sugerindo diferenças nas associações genótipofenótipo dependente da etnia avaliada. Dados de Cambiem $^{76}$, também avaliando as relações polimorfismo do AGT aos fenótipos da pressão arterial e etnias, descreveram correlações mais estabelecidas entre os asiáticos do que entre os caucasianos. 
Os dados do estudo de Framingham e o (ARIC) sobre o risco de aterosclerose, ajustados para idade e índice de massa corporal, mostraram maior correlação entre os homens do que entre as mulheres, nas associações dos fenótipos da pressão arterial e dos polimorfismos do AGT. ${ }^{67,77}$

Estudo publicado por Cambiem $^{76}$ descreveu forte associação estatística $(p<0,003)$ nos homens entre os fenótipos da pressão arterial e os polimorfismos do AGT. No mesmo estudo, entre as mulheres, a significância estatística somente foi evidenciada naquelas com mais de 45 anos de idade.

Estudos desenvolvidos em populações asiáticas, americanas e européias correlacionam o genótipo do AGT e os valores da pressão arterial em mulheres com pré-eclampsia. ${ }^{61}$

Avaliação comparativa da distribuição dos alelos do AGT do AGT (M e T), no atual estudo e em outras populações, mostrou os percentuais nas ouropretanas, nigerianos e caucasianos, do alelo $M(39,8 \%, 9,0 \%$ e $58,0 \%)$ e do alelo T $\left(60,2 \%, 91,0 \%\right.$ e $42,0 \%$ respectivamente). ${ }^{36,61}$

Os percentuais dos alelos $\mathrm{M}$ e $\mathrm{T}$ do AGT mostraram diferenças entre as ouropretanas, as africanas e as populações européias.

No atual estudo, a prevalência do alelo $T$ foi maior e mais significativa na raça negra, em comparação com a branca $(p<0,002)$ $(\mathrm{OR}=2,7)$. Esse comportamento aproxima mais as ouropretanas da população africana, na qual a prevalência do alelo T aponta uma freqüência de até $92 \% .^{36,61}$ 
O alelo T apresentou associação significativa com a hiperglicemia $(p<0,02)(O R=2,2)$. Os homozigotos TT não apresentaram significância estatística $(p<0,28)$ com o fenótipo hiperglicemia, mas observou-se a probabilidade de ocorrência de $(O R=2,03)$ em relação ao genótipo $M M$ (TAB. 9-C e TAB. 13-A).

As prevalências dos alelos AGT comparativamente entre as ouropretanas e a população do estudo de Vitória (ES) mostraram, M (39,8\% e $41,87 \%)$ e do alelo T $(60,2 \%$ e $58,03 \%)$ respectivamente. ${ }^{24}$

As prevalências dos genótipos do AGT na população de Ouro Preto (MG) e Vitória (ES) foram de MM (16,5\% e 19,8\%), de MT $(45,7 \%$ e $44,2 \%)$ e de TT $(36,5 \%$ e $35,9 \%)$. Portanto, as prevalências entre os alelos e os genótipos do AGT nas populações de Ouro Preto (MG) e de Vitória (ES) são muito similares. ${ }^{24}$

Pereira e colaboradores observaram uma correlação linear entre os alelos AGT 235T e o nível da pressão arterial. O risco foi maior na forma homozigótica do alelo T e na associação dos homozigotos TT com os heterozigotos $\mathrm{MT}^{24}$

A correlação linear foi verificada nos fenótipos sistólico com o genótipo (TT) $(p<0,0002)$, diastólico TT $(p<0,003)$ e pressão de pulso $(p<0,0003)$.

No atual estudo não ocorreu associação significativa do polimorfismo do AGT com os fenótipos sistólico $(p<0,90)$, diastólico $(p<0,62)$ e pressão de pulso $(p<0,62)$ tanto na análise de contingência, 
como também na avaliação linear $(p<0,39), \quad(p<0,30)$ e $(p<0,65)$ respectivamente (TAB. 11 A, 11-B e 11-C).

As prevalências da hipertensão arterial registradas nas cidades de Ouro Preto (MG) e Vitória (ES) foram muito diferentes. Na cidade de Vitória (ES), a prevalência foi de $38,2 \%$ (IC = 35,9\% - 40,5\%) na população geral e de $32,2 \%$ entre as mulheres. A prevalência da hipertensão arterial foi de $52,7 \%$ (TAB. 5) nas mulheres de Ouro Preto.

Vários estudos demonstram uma ampla variabilidade das prevalências da hipertensão arterial em populações com distribuição similar dos alelos e dos genótipos da ECA e do AGT.

Estudo sobre a hipertensão arterial na raça negra africana, em seu processo de diáspora, mostrou prevalências de $16,0 \%$ na Nigéria e de $35 \%$ entre os negros americanos. As prevalências dos alelos e genótipos da ECA e do AGT mostravam percentuais similares. ${ }^{42,54}$

A variabilidade nos valores das prevalências da hipertensão arterial entre as duas populações, com as mesmas etnias e freqüências similares dos genótipos do AGT, pode ser explicada, muito provavelmente, pelas exposições ambientais, tais com o consumo de sódio e a obesidade. ${ }^{77}$

As discordâncias entre o estudo de Ouro Preto e de Vitória, no que concerne às correlações entre o genótipo do AGT com os fenótipos sistólico, diastólico e pressão de pulso, devem ser analisadas.

O estudo de Ouro Preto foi desenvolvido somente no sexo feminino enquanto o de Vitória ${ }^{24}$ foi realizado nos dois gêneros. Várias publicações mostram diferenças nas correlações e significâncias da análise do 
polimorfismo do AGT entre os sexos. Os estudos dos grupos de Utah e Paris não mostraram significância entre o polimorfismo do AGT e os fenótipos intermediários da pressão arterial entre as mulheres.

O estudo de Caulfield ${ }^{75}$ e colaboradores mostrou correlação entre o polimorfismo do AGT e o fenótipo diastólico somente em homens.

Os estudos sobre os dados de Framingham e de ARIC mostraram maior prevalência e significância entre os homens do que entre as mulheres. ${ }^{67,77}$

O estudo de Cambiem mostrou significância entre o polimorfismo do AGT e os fenótipos da pressão arterial somente para as mulheres com menos de 45 anos.

Entre várias conjecturas para justificar as diferenças das prevalências e significâncias entre os dois estudos, Ouro Preto e Vitória, uma delas pode ser o efeito hormonal epistático. Este fenômeno explicaria as ações hormonais moduladoras sobre as expressões dos polimorfismos do AGT. Outros fatores ambientais associados a interações gene-gene, não avaliadas nos dois estudos, também podem influenciar na análise dos resultados. $^{36,61}$

Outras possibilidades que podem interferir nos resultados são os métodos de análise, independentemente dos utilizados para interpretar as associações. $^{36}$

Doenças muito freqüentes e que apresentem heterogeneidade genética, as freqüências dos alelos correlacionados com a doença podem produzir resultados falso - negativos, dependendo do tamanho da amostra. 
Por exemplo, estudos sobre as associações dos fenótipos da pressão arterial e os polimorfismos do AGT em populações negras e asiáticas, necessitam de uma grande amostra devido à alta prevalência do alelo $\mathrm{T}$ nessas comunidades. ${ }^{61}$

De maneira similar, as análises de doenças multigênicas e polimórficas, quando com pequenas significâncias estatísticas, são registradas e são utilizados múltiplos testes de genes envolvidos que podem levar aos resultados falso positivos. ${ }^{36}$

Em estudos que comparam as freqüências, utilizando análises de contingências para detectar uma associação entre o gene candidato e a doença, por exemplo, alelo $\mathrm{T}$ e os fenótipos da pressão arterial, fazem a análise depender da freqüência do alelo e da força de relação do alelo com a hipertensão arterial. $^{36,61}$

As limitações amostrais, os métodos utilizados, as influências ambientais especificas de cada região e os efeitos hormonais podem explicar, parcialmente, as diferenças associativas entre os estudos de Ouro Preto (MG) e de Vitória (ES).

\subsection{Polimorfismo da ECA}

O gene da ECA está vinculado à pressão arterial elevada em ratos espontaneamente hipertensos, expostos à sobrecarga de sódio e, por isso, mais propensos ao acidente vascular cerebral.

A freqüência do polimorfismo apresenta diferenças étnicas marcantes. Em populações brancas saudáveis ${ }^{31}$, a freqüência do alelo $D$ 
varia de 0,50 a 0,60 . Na população negra ${ }^{32}$, essa freqüência parece ser um pouco maior. Entre os japoneses e chineses, a freqüência do alelo $D$ varia de 0,27 a 0,40 .

\subsection{Percentuais dos genótipos entre as raças}

Distribuição do genótipo da ECA, em estudos nacionais correlacionados com a raça, mostrou a prevalência do polimorfismo DD $0,28 \%$ entre os indivíduos brancos, $0,34 \%$ nos mulatos e $0,43 \%$ entre os negros. $^{48}$

Os valores percentuais dos alelos da ECA entre as ouropretanas foram de D (57,80\%); do alelo I 42,20\%, Esses valores são muito similares aos descritos em populações africanas e caucasiana européia, do alelo D $60,0 \%$ e $57,0 \%$ e do alelo I, $40,0 \%$ e $43,0 \%$, respectivamente. ${ }^{52,53,54}$

Os genótipos da ECA, nas populações ouropretana, africana e européia, foram de DD 35,7\%, 35,0\% e 32,0\%, DI de $46,2 \%, 49,0 \%$ e $49,0 \%$ e de II $18,1 \%, 16,0 \%$ e $19,0 \%{ }^{52,53}$ (TAB. 6-A e 6-B)

O desenho do estudo de Vitória (ES), entre as publicações nacionais, é o que mais se assemelha ao de Ouro Preto (MG). A análise comparativa, entre as prevalências dos alelos da ECA nas populações ouropretana e de Vitória (ES), mostrou para o alelo D $(57,8 \%$ e \%56,6\%) e para o alelo I (42,2\% e 43,40\%). Os genótipos da ECA nas mulheres ouropretanas e de Vitória (ES) foram, respectivamente, de DD (35,7\% e $29,1 \%)$, DI $(46,2 \%$ e $54,9 \%)$ e II $(18,1 \% \text { e } 15,9 \%)^{24}$ (TAB. 6-A e $\left.6-B\right)$. 
A freqüência dos alelos (D e I) e dos polimorfismos (DD, DI e II) mostrou, no estudo atual e também de Vitória (ES), uma prevalência próxima aos achados em populações africanas e caucasianas. Isto parece ser compatível com a miscigenação étnica elevada na população brasileira ${ }^{64,24}$ (TAB. 6-B).

Estudos que descrevem as correlações, entre os alelos e genótipos da ECA com os fenótipos da pressão arterial, na literatura são muito discrepantes. $^{31,32}$

Alguns estudos epidemiológicos associam o alelo D com aumento de risco de doença cardiovascular. ${ }^{52,53,54,57}$

Estudos publicados por Rigat e colaboradores ${ }^{31}$ relatam que os indivíduos com um ou dois alelos D da ECA apresentam um aumento da atividade da ECA no plasma e nos tecidos de aproximadamente $25 \%$ a $50 \%$. Esses estudos postulam que os indivíduos portadores do genótipo DD apresentam maiores níveis de ECA tecidual e plasmático do que os indivíduos II. Assim, os indivíduos II teriam os menores níveis de ECA, enquanto os indivíduos ID teriam níveis intermediários dessa enzima. ${ }^{31}$

Van Kley at al. ${ }^{77}$ tentaram determinar o impacto funcional do polimorfismo da ECA em indivíduos saudáveis. Eles examinaram os efeitos da angiotensina I e II em 27 voluntários brancos saudáveis mantidos sob uma dieta controlada em sódio e potássio. Observou-se que os indivíduos DD apresentaram resposta aumentada das taxas de filtração glomerular, resistência vascular renal da aldosterona e da pressão arterial quando 
expostos a uma dose farmacológica de angiotensina I e que essa resposta não foi evidenciada com a infusão da angiotensina $1{ }^{77}$

Observou-se que nesses indivíduos saudáveis, mantidos por um período sob controle de redução de sódio, a resposta da angiotensina I foi enfraquecida no subgrupo com o genótipo DD, sugerindo que o impacto do genótipo pode ser modificado por fatores ambientais. ${ }^{77}$

Dois estudos com indivíduos normotensos saudáveis mostraram resultados conflitantes. No primeiro, realizado em população holandesa normotensa, indivíduos homozigotos DD apresentaram pressões sistólicas e diastólicas significativamente mais altas que a faixa da normalidade, mesmo após ajuste pelo índice de massa corporal e idade. Esse fato foi confirmado por regressão linear múltipla. ${ }^{73}$

Em um segundo estudo sobre o registro longitudinal de gêmeos suecos, avaliaram-se 298 pares de gêmeos do mesmo sexo. Não houve sinais de influências genéticas significativas entre os polimorfismos do sistema renina angiotensina e os fenótipos intermediários da pressão arterial. Na conclusão deste estudo, os autores excluem as possibilidades de viés de análise, porque os participantes eram do mesmo sexo e expostos a ambiente único: o norte europeu. ${ }^{31}$

$\mathrm{Na}$ população japonesa, Higashimori relatou que os indivíduos homozigotos DD, apresentaram um risco $79 \%$ maior de desenvolver hipertensão do que os genótipos II.

Zee e colaboradores ${ }^{78}$ observaram que o polimorfismo da ECA I/D estava associado com hipertensão arterial numa população australiana. 
Entretanto, em vários paises, entre eles a Bélgica, a Dinamarca, a Grécia e os Emirados Árabes, a associação relatada por Zee não foi observada.

Barley e colaboradores ${ }^{52}$, descrevendo seus trabalhos desenvolvidos no Reino Unido, observaram significância estatística na relação polimorfismo da ECA e os fenótipos da pressão arterial, entre os descendentes afro-caribenhos, mas não entre a população branca.

Estudos com associações negativas ${ }^{31}$ foram publicados em países tais como a Bélgica, a Dinamarca e em avaliações longitudinais em gêmeos do estudo Sueco.

As correlações e significâncias sobre as relações fenótipos da pressão arterial e os polimorfismos da ECA foram amplamente estudados e publicados. Dados discrepantes entre as associações são inúmeros. Entre todas as correlações avaliadas, as que mostraram maiores consistências foram sobre sexo-específica, sobre as etnias, homens brancos e descendentes africanos.

O conhecimento que está sedimentado sobre os polimorfismos da ECA é a correlação entre os alelos e os genótipos com as concentrações plasmáticas da ECA. O alelo D apresenta maior concentração do que o alelo I. Entre os genótipos correlacionados com a concentração, em ordem decrescente, estão o DD, o DI e o II. Estes achados foram constatados em diversos estudos, incluindo os centenários na França, os índios Pima e os brancos dos USA. ${ }^{47,49}$

Dados sobre os estudos de Framingham Heart Study, publicados por O'Donnell ${ }^{77}$ e o estudo The Suita Study ${ }^{44}$, publicado por Higaki, 
descreveram associação significativa somente entre os homens, com o fenótipo hipertensão arterial e o polimorfismo DD da ECA.

Os dados sobre as ouropretanas corroboram os achados de O'Donnell ${ }^{77}$ e Higaki ${ }^{44}$. Nas ouropretanas, não foi verificada associação entre o genótipo DD e os fenótipos sistólico $(p<0,73)$ e diastólico $(p<0,94)$.

O atual estudo não registrou associação significativa entre os fenótipos sistólico $\{n=60(44,4 \%)\}(p<0,40)$ e diastólico $\{n=58(43,0 \%)\}$ $(p<0,94)$ com os alelos e os genótipos da ECA (TAB. 11-A e 11-B). Estes dados corroboram relatos dos estudos de Vitória (ES). ${ }^{24}$

$\mathrm{Na}$ análise do fenótipo pressão de pulso entre as mulheres com mais de 60 anos, quando comparadas às participantes com idade entre 20 a 39 anos, foi registrada significância estatística $(p<0,01)(O R=2.2)$ com o alelo $D$ da ECA (TAB. 7-A).

Observou-se, nas ouropretanas, uma associação positiva entre o genótipo DD e as distribuições das faixas etárias $(p<0,03)$. A probabilidade de ocorrência do alelo DD entre as mulheres com mais de 60 anos foi de $\mathrm{OR}=5,53$ em comparação com as de 20 a 39 anos (TAB. 10).

No estudo de Ouro Preto (MG), observou-se uma tendência de associação $(p<0,07)(O R=1,10)$ entre $\circ$ fenótipo pressão de pulso e o genótipo DD (TAB. 11-C).

Achados sobre a associação entre o fenótipo pressão de pulso e o genótipo DD não foram observados nos estudos de Vitória $(E S)^{24}$, de Framingham Heart Study ${ }^{77}$ e no The Suita Study. ${ }^{44}$ 
A análise das associações do fenótipo da pressão de pulso das ouropretanas com mais 60 anos, com o alelo D e o genótipo DD da ECA, talvez possa ser explicada pela maior tendência da freqüência do alelo $D$ e do genótipo DD nessa faixa etária. Outra forma de análise e não excludente é que as mulheres com o alelo $D$ e o genótipo DD apresentam maior concentração da ECA do que as portadoras do alelo I e do genótipo II. Esse polimorfismo em mulheres com mais de 60 anos e com maior concentração de angiotensina II promoveria um aumento da resistência vascular periférica, elevando a prevalência do fenótipo pressão de pulso.

Os trabalhos publicados por Staessen ${ }^{53}$ e Safar $^{56}$ podem explicar esse achado entre as mulheres de Ouro Preto.

As publicações de Staessen ${ }^{53}$ demonstraram associação estatística entre o genótipo DD com o fenótipo pressão arterial sistólica isolada.

Os trabalhos de Safar ${ }^{56}$, que avaliam a rigidez vascular pela análise da velocidade da onda de pulso, ressaltam associação do genótipo DD com os indivíduos diabéticos com mais de 50 anos. Os dados de Safar descrevem a importância da avaliação do fenótipo pressão de pulso que refletiria a resistência vascular dos grandes arteriais.

Além da hipertensão arterial, outras patologias cardiovasculares, tais como a aterosclerose e a insuficiência coronariana são avaliadas nas suas correlações com os fenótipos e o polimorfismo da ECA. ${ }^{39,76}$

Várias publicações correlacionam os portadores do genótipo DD com maior risco para a doença arterial coronariana. ${ }^{70,40}$ 
Além de influenciar a pressão arterial, o sistema renina angiotensina é também um importante fator na etiologia da aterosclerose. Muitos estudos clínicos relataram a eficácia de agentes que inibem a atividade da ECA e de receptores da angiotensina II, no tratamento da aterosclerose. ${ }^{80,40}$

A ativação do sistema renina-angiotensina-aldosterona (SRAA) constitui-se num fator de risco para processos de desenvolvimento da aterosclerose. $^{80,40}$

A angiotensina II age nos receptores AT1 e AT2. A estimulação dos receptores AT1 está associada à disfunção endotelial, principalmente como conseqüência de um aumento na produção de espécies reativas de oxigênio, vasoconstrição, ativação plaquetária, maior liberação do fator inibidor da ativação do plasminogênio tipo 1 (PAl-1). A estimulação dos receptores AT2 pode atenuar os efeitos proliferativos da estimulação dos receptores AT1.

A contribuição desses efeitos tem sido estudada com relação ao desenvolvimento e progressão da aterosclerose e na reestenose, após a angioplastia. $^{76}$

A disfunção endotelial é um evento tardio, associado à aterosclerose, e mantém relação com futuros eventos cardiovasculares. A melhora da função endotelial é muito estudada com a utilização de estatinas. As pesquisas que avaliam essas relações observaram a identificação de um subconjunto de homozigotos DD da ECA. Esses relatos associam o alelo D com a disfunção endotelial. ${ }^{76}$ 
Existem controvérsias sobre a relação entre o genótipo DD com aumento do risco de IAM. Estudos sugeriram que o genótipo DD está associado à instabilidade da placa. ${ }^{70,76}$

Cambien et al. ${ }^{76}$ descreveram dados do estudo multicêntrico que avaliou 1300 indivíduos e os fatores genéticos que os predispunham ao aumento do infarto do miocárdio. Esses autores concluíram que os portadores do genótipo DD eram significativamente mais freqüentes entre os indivíduos com infarto agudo do miocárdio com uma razão de probabilidade (OD 1,3). A associação ficava mais evidente (OD 3,2) em indivíduos jovens com poucos fatores de risco cardiovasculares.

Evidência adicional, há no estudo de autopsia de casos fatais de infarto agudo, numa população do projeto MONICA de Belfast. ${ }^{84}$ Nessa população, uma elevada prevalência do genótipo DD foi demonstrada, quando comparada com os controles.

Os alelos e os genótipos da ECA não registraram significância estatística com os fenótipos colesterol total $(p<0,50)(O R=0,80)$, do LDLcolesterol $(p<0,10)(O R=0,9)$; triglicérides $(p<0,30)(O R=0,7)(T A B .14$, 15 e 16).

Os fenótipos colesterol alto e moderado e o fenótipo triglicérides muito alto e alto mostraram uma probabilidade de ocorrência de $\mathrm{OR}=1,3 \mathrm{e}$ $\mathrm{OR}=1,2$, respectivamente (TAB. 14 e 15).

Chamam atenção entre as ouropretanas, na análise dos fenótipos do perfil lipídico, as relações do HDL-colesterol e o polimorfismo da ECA. 
O fenótipo HDL-colesterol elevado mostrou significância estatística na avaliação do alelo $D(p<0,0007)$. As portadoras do genótipo DD mostraram uma probabilidade de ocorrência de OR = 1,5 (TAB. 8-C).

O fenótipo HDL-colesterol elevado mostrou significância estatística $(p<0,008)(O R=2,01)$ com o genótipo DD. A avaliação do fenótipo HDLcolesterol, correlacionado com a associação das portadoras dos genótipos DD e DI mostrou $(p<0,06)(\mathrm{OR}=0,72)(\mathrm{TAB} .17)$. 


\section{SUMÁRIO E CONCLUSÃO}

1) As prevalências dos fenótipos sistólico, diastólico e de pressão de pulso da pressão arterial, foram elevadas e fortemente associadas, com a idade, a classe social, a hiperglicemia e o perfil dos lipídios.

2) A distribuição do alelo $T$ foi mais prevalente nas ouropretanas da etnia negra.

3) Observou-se associação significativa entre o fenótipo hiperglicemia e o alelo T do AGT

4) Observou-se associação significativa entre o fenótipo colesterol HDL elevado, com o alelo D e o genótipo DD da ECA.

5) Observou-se associação significativa entre o alelo $D$ e o genótipo DD da ECA, nas ouropretanas com mais de 60 anos e tendência de associação com o fenótipo pressão de pulso.

Em conjunto, os dados sugerem que a prevalência de hipertensão entre as mulheres de ouropretenses é alta e associadas a idade, classe social, hiperglicemia e perfil lipídico. A influência das variantes genéticas da ECA e do angiotensinogênio tiveram pouco efeito sobre os fenótipos de pressão arterial, mas influenciaram os níveis de colesterol HDL e a hiperglicemia, respectivamente. 


\section{REFERÊNCIAS BIBLIOGRÁFICAS}

1- World Health Organization 2003. Available from: http://www.who.int/whr/media_centre /factsheet3.html.

2- DATASUS (2002). Disponível em: http://tabnet.datasus.gov.br/cgi/ deftohtm.exe? edb2002/cd8.def.

3- IBGE - Instituto Brasileiro de Geografia e Estatística. Contagem populacional 1996. Dados agregados por setores censitários.

4- BARKER, D.J.P. \& ROSE, G. Epidemiology in medical practice. Edinburgh, Churchill Livingstone, 1976

5- BENEVOLO, Leonardo. The History of the City. Cambridge: MIT Press, 1980.

6- Needell J. Identity, race, gender and modernity in the origins of Gilberto Freyre's Ouevre. American Historical Review 1995;100:51-77.

7- Castro, RCG. A formação da brasilidade alimentar. Jornal da USP, 2002; 09 junho de. Disponível em: <www.usp.br/jorusp/arquivo/2002/ jusp599/pag06.htm>.

8- Joint National Committee. The sixth report of the Joint National Committee on Prevention, Detection, Evaluation and Treatment of High Blood Pressure. Arch Intern Med. 1997;157:2413-2446.

9- Kaplan NM, Gidding SS, Pickering TG, Wright JT. Task Force 5: systemic hypertension. J Am Coll Cardiol. 2005;45(8):1346-1348.

10- Grundy SM, Balade GJ, Criqui MH, et al. Primary Prevention of coronary Heart Disease: Guidance from Framingham. Circulation. 1998;97:1876-1887. 
11- SBC - Sociedade Brasileira de Hipertensão. IV Diretrizes Brasileiras de Hipertensão Arterial. 1998. Disponível em: <http://departamentos. cardiol.br/ dha/publicacoes/ivdiretriz/Capitulo02.pdf>.

12- Smulyan H, Safar ME. The diastolic blood pressure in systolic hypertension. Ann Intern Med. 2000;132(3):233-237.

13- ATP III Update 2004: Implications of Recent Clinical Trials for the ATP III Guidelines JAMA. 2001;285:2486-2497 Available from: <http://www.nhlbi.nih.gov/ guidelines/cholesterol/atp3upd04.htm>.

14- Hubert HB, Feinleib M, McNamara PM, Castelli WP. Obesity as an independent risk factor for cardiovascular disease: a 26- year follow-up of participants in the Framingham Heart Study. Circulation. 1983;67(5):968-977.

15- Li TY, Rana JS, Manson JE, Willett WC, Stampfer MJ, Colditz GA, Rexrode KM, Hu FB. Obesity as compared with physical activity in predicting risk of coronary heart disease in women. Circulation. 2006;113(4):499-506.

16- Women. World Heart Federation Web site. Available at: http://www. worldheart.org/awareness-women.php. Accessed October 6, 2006.

17- Expert Panel/Writing Group. Evidence-based guidelines for cardiovascular disease prevention in women: 2007 update. Circulation. 2007;115(11):1481-1501.

18- Yusuf S, Hawken S, Ounpuu S, Bautista L, Franzosi MG, Commerford P, Lang CC, Rumboldt Z, Onen CL, Lisheng L, Tanomsup S, Wangai P, Razak F, Sharma AM, Anand SS; INTERHEART Study Investigators. Obesity and the risk of myocardial infarction in 27,000 participants from 52 countries: a case-control study. Lancet. 2005;366(9497):1640-9.

19- Yusuf S, Reddy S, Ounpuu S, Anand S. Global burden of cardiovascular diseases: part 1: general considerations, the epidemiologic transition, risk factors, and impact of urbanization. Circulation. 2001;104:2746-2753. 
19- Gu D, Gupta A, Muntner P, Hu S, Duan X, Chen J, Reynolds RF, Whelton PK, He J. Prevalence of cardiovascular disease risk factor clustering among the adult population of China: results from the International Collaborative Study of Cardiovascular Disease in Asia (InterAsia). Circulation. 2005;112:658-665.

20- Mosca L, Appel LJ, Benjamin EJ, Berra K, Chandra-Strobos N, Fabunmi RP, Grady D, Haan CK, Hayes SN, Judelson DR, Keenan NL, McBride P, Oparil S, Ouyang P, Oz MC, Mendelsohn ME, Pasternak RC, Pinn VW, Robertson RM, Schenck-Gustafsson K, Sila CA, Smith SC Jr, Sopko G, Taylor AL, Walsh BW, Wenger NK, Williams CL; American Heart Association. Evidence-based guidelines for cardiovascular disease prevention in women. Circulation. 2004;109:672-692.

21- Ínes Lessa; Lucélia Magalhães; Maria Jenny Araújo; Naomar de Almeida Filho; Estela Aquino; Mônica M. C. Oliveira Hipertensão arterial na população adulta de Salvador (BA) - Brasil Arq. Bras. Cardiol. vol.87 no.6 São Paulo Dec. 2006

22- Lessa I. Epidemiologia da hipertensão arterial sistêmica e da insuficiência cardíaca no Brasil. Rev Bras Hipertens. 2001;8(4):383-92.

23- Ducan BB, Schmidt MI, Polanczyk CA et al. Risk factors for noncominicable disease a metropolitan area in the south of Brasil: prevalence and simultanelty. Rev Saúde Públ 1993;27:43-48.

24- Pereira AC, Mota GF, Cunha RS, Herbenhoff FL, Mill JG, Krieger JE. Angiotensinogen 235T allele "dosage" is associated with blood pressure phenotypes. Hypertension 2003;41(1):25-30.

25- Misra A, Vikram NK. Clinical and pathophysiologial consequences of abdominal adiposity and abdominal adipose tissue depots. Nutrition. 2003; 19 (5): 457-66.

26- Li TY, Rana JS, Manson JE, Willett WC, Stampfer MJ, Colditz GA, Rexrode KM, Hu FB. Obesity as compared with physical activity in 
predicting risk of coronary heart disease in women. Circulation. 2006;113:499-506.

27- Freitas SN, Caiaffa WT, César CC, Faria VA, Nascimento Neto RM, Coelho GLLM. Risco Nutricional na População Urbana de Ouro Preto, Sudeste do Brasil: Estudo de Corações de Ouro Preto. Arq Bras Cardiol. 2007;88(2):191-199.

28- Cândido APC, Ferreira S, Limab AA, Nicolato RLC, Freitas SN, Brandão P, Pereira A, Krieger JE, Nascimento-Neto RM, Coelho GLLM.. Lipoprotein(a) as a risk factor associated with ischemic heart disease: Ouro Preto Study.

29- Despres JP. The insulin resistance-dyslipidemic syndrome of visceral obesity: effect on patients' risk. Obes Res. 1998;6:8-17.

30- Bader M, Paul M, Fernandez-Alfonso M, Kaling M, Ganten D. A molecular biology and biochemistry of the renin-angiotensin system. In: SWALES, J.D. (Ed). Textbook of hypertension. Oxford: Blackwell Scientific Publications, 1994.

31- Rigat B, Hubert C, Alhenc-Gelas F, Cambien F, Corvol P, Soubrier F. An insertion/deletion polymorphism in the angiotensin l-converting enzyme gene accounting for half the variance of serum enzyme levels. J Clin Invest. 1990;86:1343-1346.

32- Tiret L, Rigat B, Visvikis S, Breda C, Corvol P, Cambien F, Soubrier F: Evidence, from combined segregation and linkage analysis, that a variant of the angiotensin l-converting enzyme (ACE) gene controls plasma ACE levels. Am J Hum Genet. 51:197-205, 1992.

33- van Harmelen V, Ariapart P, Hoffstedt J, Lundkvist I, Bringman S, Arner P. Increased adipose angiotensinogen gene expression in human obesity. Obes Res. 2000;8:337-341.

34- Hopkins PN, Lifton RP, Hollenberg NK. Blunted renal vascular response to angiotensin $I I$ is associated with a common variant of the angiotensinogen gene and obesity. J Hypertens. 1996;14:199-207. 
35- Cooper R, McFarlane-Anderson N, Bennett FI, Wilks R, Puras A, Tewksbury D, Ward R, Forrester T. ACE, angiotensinogen and obesity: a potential pathway leading to hypertension. J Hum Hypertens. 1997;11(2):107-11.

36- Jeunemaitre $X$, Soubrier F, Kotelevtsev YV, Lifton RP, Williams CS, Charru A, Hunt SC, Hopkins PN, Williams RR, Lalouel JM, et al. Molecular basis of human hyperpertension: role of angiotensinogen. Cell. 1992;71(1):169-80.

37- Tick M, et al. The effect of weight reduction on blood pressure, plasma renin activity, and plasma aldosterone levels in obese patients $N$ Engl $J$ Med. 1981; 304 930-933.

38- The association of human adipose angiotensinogen gene expression with abdominal fat obesity. Campbell K, Engel H, Timperio A, Cooper C, Crawford Current Opinion in Endocrinology \& Diabetes. 8(5):B113B142, October 2001.

39- Fox CS, Polak JF, Chazaro I, et al. Genetic and environment contributions to atherosclerosis phenotypes in men and women: heritability of carotid intimamedia thickness in the FraminghamHeart Study. Stroke 2003;34:397-401.

40- Jeunemaitre X, Ledru F, Battaglia S, Guillanneuf MT, Courbon D, Dumont $\mathrm{C}$, et al. Genetic polymorfisms of the renin-angiotensin system and angiographic extent and severity of coronary artery disease: the CORGENE study. Hum Genet 1997;99:66-73

41- Golomb BA, Ritchie JB, Criqui MH, Dimsdale JE. Statins lower blood pressure: results from the USCD Statin Study. Circulation. 2004;110:III402.

42- Cooper RS, et al. Heritability of angiotensin-converting enzyme and angiotensinogen: A comparison of US blacks and Nigerians. Hypertension. 2000;35(5):1141-7. 
43- Jain S, Li Y, Patil S, Kumar A. A single-nucleotide polymorphism in human angiotensinogen gene is associated with essential hypertension and affects glucocorticoid induced promoter activity. $J$ Mol Med. 2005;83(2):121-31.

44- Higaki J, Baba S, Katsuya T, Sato N, Ishikawa K, Mannami T, Ogata J, Ogihara T. Deletion allele of angiotensin-converting enzyme gene increases risk of essential hypertension in Japanese men: the Suita Study. Circulation. 2000;101(17):2060-2065.

45- Gu XX, Spaepen M, Guo C, Fagard R, Amery A, Lijnen P, et al. Lack of association between the I/D polymorphism of the angiotensin-converting enzyme gene and essential hypertension in a Belgian population. $J$ Hum Hypertens. 1994;8:683-685.

46- Jeunemaitre X, Lifton RP, Hunt SC, Williams RR, Lalouel JM. Absence of linkage between the angiotensin converting enzyme locus and human essential hypertension. Nat Genet. 1992;1:72-75.

47- Faure-Delanef L, Baudin B, Bénéteau-Burnat $B$, Beaudoin JC, Giboudeau J, Cohen D. Plasma concentration, kinetic constants, and gene polymorphism of angiotensin-converting enzyme in centenarians. Clin Chem. 1998;44(10):2083-7.

48- Pereira AC, Mota GA, Benseñor I, Lotufo PA, Krieger JE. Effect of race, genetic population structure, and genetic models in two-locus association studies: clustering of functional renin-angiotensin system gene variants in hypertension association studies. Braz J Med Biol Res, 2001;34(11): 1421-1428.

49- Foy CA, McCormack LJ, Knowler WC, Barrett JH, Catto A, Grant PJ. The angiotensin-I converting enzyme (ACE) gene I/D polymorphism and ACE levels in Pima Indians. J Med Genet. 1996;33(4):336-337.

50- Zee RY, Lou YK, Griffiths LR, Morris BJ. Association of a polymorphism of the angiotensin l-converting enzyme gene with essential hypertension. Biochem Biophys Res Commun. 1992;184:9-15. 
51- O'Donnell CJ, Lindpaintner K, Larson MG, Rao VS, Ordovas JM, Schaefer $\mathrm{E}$, et al. Evidence for association and genetic linkage of the angiotensin-converting enzyme locus with hypertension and blood pressure in men but not women in the Framingham Heart Study. Circulation. 1998;97:1766-1772.

52- Barley J, Blackwood A, Carter N, Crews D, Cruickshank K, Jeffery S, Ogulesi A, Sagnella G. Angiotensin converting enzyme insertion/deletion polymorphism: association with ethnic origin. $J$ Hypertens. 1994;12:955-957.

53. Staessen JA, Wang JG, Ginocchio G, Petrov V, Saavedra AP, Soubrier F, Vlietinck R, Fagard R. The deletion/insertion polymorphism of the angiotensin converting enzyme gene and cardiovascular-renal risk. J. Hypertens. 1997,15:1579-1592.

54- Kamdar S, Daniel H, Fogarty P, Lawson M, Munroe P, Caulfield M. ACE insertion/deletion polymorphism in Vincentian African Caribbeans with essential hypertension. J Hum Hypertens. 1994;8:611.

55- Williams SM, Addy JH, Phillips JA 3rd, Dai M, Kpodonu J, Afful J, et al. Combinations of variations in multiple genes are associated with hypertension. Hypertension. 2000;36:2-6.

56- Safar ME, Lajemi M, Rudnichi A, Asmar R, Benetos A. Angiotensinconverting enzyme $D / /$ gene polymorphism and age-related changes in pulse pressure in subjects with hypertension. Arterioscler Thromb Vasc Biol. 2004; 24: 782-6.

57- Staessen JA, Wang JG, Brand E et al. Effects of three candidate genes on prevalence and incidence of hypertension in a Caucasian population. J Hypertens. 2001; 19: 1349-58.

58- Pasquale Strazzullo, MD; Roberto lacone; Licia lacoviello, MD, PhD; Ornella Russo; Gianvincenzo Barba, MD; Paola Russo, BS; Andria D'Orazio; Antonio Barbato, MD; Francesco Paolo Cappuccio, MD, FRCP; Eduardo Farinaro, MD; and Alfonso Siani, MD Genetic Variation 
in the Renin-Angiotensin System and Abdominal Adiposity in Men: The Olivetti Prospective Heart Study. Ann Intern Med. 2003;138:17-23.

59- Mulder HJGH, van Geel PP, Schalij MJ, van Gilst WH, Zwinderman AH, Bruschke AVG. DD ACE gene polymorphism is associated with increased coronary artery endothelial dysfunction: the PREFACE trial. Heart. 2003;89:557-558.

60- Sayed-Tabatabaei FA, Schut AF, Vasquez AA, Bertoli-Avella AM, Hofman A, Witteman JC, van Duijn CM. Angiotensin converting enzyme gene polymorphism and cardiovascular morbidity and mortality: the Rotterdam Study. J Med Genet. 2005;42(1):26-30.

61- Matthew E. Dickson, Curt D. Sigmund. Genetic Basis of Hypertension Revisiting Angiotensinogen. Hypertension. 2006;48:14-20.

62- Marteau JB, Zaiou M, Siest G, Visvikis-Siest S. Genetic determinants of blood pressure regulation. J Hypertens. 2005;23(12):2127-43.

63- Amar A. Sethi; Børge G. Nordestgaard; Birgit Agerholm-Larsen; Erik Frandsen; Gorm Jensen; Anne Tybjærg-Hansen -Angiotensinogen Polymorphisms and Elevated Blood Pressure in the General Population The Copenhagen City Heart Study. Hypertension. 2001;37:875.

64- Van Harmelen, M Elizalde, P Ariapart, S Bergstedt-Lindqvist, S Reynisdottir, J Hoffstedt, I Lundkvist, S Bringman and P Arner The association of human adipose angiotensinogen gene expression with abdominal fat distribution in obesity. International Journal of Obesity (2000) 24, 673-678.

65- Jeunemaitre X. Genetic polymorphisms in the renin-angiotensin system. Therapie. 1998;53:271-277.

66- Watt GC, Harrap SB, Foy CJ, Holton DW, Edwards HV, Davidson HR, et al. Abnormalities of glucocorticoid metabolism and the reninangiotensin system: a four-corners approach to the identification of genetic determinants of blood pressure. Hypertens. 1992;10:473-82. 
67- Province MA, Ludwig EH, Ellison RC, Folsom AR, Heiss G, Lalouel JM, Higgins M, Rao D.C Associations of Candidate Loci Angiotensinogen and Angiotensin-Converting Enzyme with Severe Hypertension: The NHLBI Family Heart Study. Annals of Epidemiology. 1997;9:13-21.

68- ANEP - Associação Nacional de Empresas de Pesquisas. Critério de classificação econômica Brasil. Disponível em: www.anep.org.br.

69- Wolf-Maier K, Cooper RS, Banegas JR, Giampaoli S, Hense HW, Joffres $\mathrm{M}$, et al. Hypertension prevalence and blood pressure levels in 6 European countries, Canada, and the United States. JAMA. 2003 $14 ; 289(18): 2363-9$.

70- Lori Mosca MD, Group Evidence-Based Guidelines for Cardiovascular Disease Prevention in Women: 2007 Update. Circulation $2007 ; 115: 1481$.

71- Macedo ME, Lima MJ, Silva AO, Alcantara P, Ramalhinho V, Carmona J. Prevalence, awareness, treatment and control of hypertension in Portugal: the PAP study. J Hypertens. 2005;23(9):1661-6.

72- Cooper R, Rotimi C, Ataman S, McGee D, Osotimehin B, Kadiri S, Muna W, Kingue S, Fraser H, Forrester T, Bennett F, Wilks R. The prevalence of hypertension in seven populations of West African origin. Am J Public Health. 1997;87:160-168.

73- van Rooyen JM, Huisman HW, Eloff FC, Laubscher PJ, Malan L, Steyn HS, Malan NT. Cardiovascular reactivity in Black South-African males of different age groups: the influence of urbanization. Ethn Dis. 2002;12:69-75.

74- D Levy, AL DeStefano, MG Larson, CJ O'Donnell, RP Lifton, H Gavras, LA Cupples, RH Myers. Evidence for a gene influencing blood pressure on chromosome 17. Genome scan linkage results for longitudinal blood pressure phenotypes in subjects from the framingham heart study. Hypertension. 2000;36 (4):477-83 11040222. 
75- Caulfield M, Munroe P, Pembroke J, Samani N, Dominiczak A, Brown M, Benjamin N, Webster J, Ratcliffe P, O'Shea S, Papp J, Taylor E, Dobson R, Knight J, Newhouse S, Hooper J, Lee W, Brain N, Clayton D, Lathrop GM, Farrall M, Connell J; MRC British Genetics of Hypertension Study. Genome-wide mapping of human loci for essential hypertension. Lancet. 2003;361(9375):2118-23.

76- Cambien F, Poirier O, Lecerf L, et al. Deletion polymorphism in the gene for angiotensin-converting enzyme is a potent risk factor for myocardial infarction. Nature. 359:641-644, 1992.

77- Topol EJ, McCarthy J, Gabriel S, Moliterno DJ, Rogers WJ, Newby LK, Freedman M, Metivier J, Cannata R, O'Donnell CJ, Kottke-Marchant K, Murugesan G, Plow EF, Stenina O, Daley GQ. Single nucleotide polymorphisms in multiple novel thrombospondin genes may be associated with familial premature myocardial infarction. Circulation. 2001;104 (22):2641-4 11723011.

77- van Der Kleij FGH, De Jong PE, Henning $\mathrm{RH}$, et al. Enhanced responses of blood pressure, renal function, and aldosterone to angiotensin I in the DD genotype are blunted by low sodium intake. J Am Soc Nephrol. 2002; 13:1025-1033.

78- Higashimori K, Zhao Y, Kamitami A, Katsuya T, Nakura J, Mikami H, Ogihara T. Association analysis of a polymorphism of the angiotensin converting enzyme gene with essential hypertension in the Japanese population. Biochem Biophys Res Commun. 1993;191:399-404.

79- Keaveney B, Mczenzie C, Parish S, Palmer A, Clark S, Youngman L, Délepine $M$, Lathrop $M$, Peto $R$, Collins $R$. Large-scale test of hypothesized associations between the angiotensin-converting enzyme insertion/deletion polymorphism and myocardial infarction in about 5000 cases and 6000 controls. International Studies of Infarction Survival Collaborators. Lancet, 2000;355:434-442.

80- Tanriverdi H, Evrengul H, Mergen H, Acar C, Seleci D, Kuru O, Tanriverdi S, Kaftan A. Early sign of atherosclerosis in slow coronary 
flow and relationship with angiotensin-converting enzyme I/D polymorphism. Heart \& Vessels. 22(1):1-8, 2007 Jan.

81- Agerholm-Larsen B, Nordestgaard BG, Steffensen R, Sørensen TI, Jensen G, Tybjaerg-Hansen A. ACE gene polymorphism: ischemic heart disease and longevity in 10,150 individuals. A case-referent and retrospective cohort study based on the Copenhagen City Heart Study. Circulation. 1997 May 20;95(10):2358-2367.

82- Evans AE, Poirier O, Kee F, Lecerf L, McCrum E, Falconer T, Crane J, O'Rourke DF, Cambien F. Polymorphisms of the angiotensinconverting-enzyme gene in subjects who die from coronary heart disease. Q J Med. 1994;87(4):211-214. 


\section{ANEXOS}

Tabela 1 - Características demográficas socioeconômicas análises clinícas e antropométricas da amostra feminina projeto corações de Ouro Preto (MG).

\begin{tabular}{|c|c|c|c|c|}
\hline Características & $\mathrm{n}$ & Percentual & $\begin{array}{l}\text { Média e desvio- } \\
\text { padrão }\end{array}$ & $\begin{array}{l}\text { IC (95\% Int. } \\
\text { médias) }\end{array}$ \\
\hline Tabagismo & 88 & $22,7 \%$ & & \\
\hline Sedentarismo & 300 & $78,5 \%$ & & \\
\hline Brancas & 112 & $29,3 \%$ & & \\
\hline Morenas claras & 139 & $36,8 \%$ & & \\
\hline Morenas escuras & 89 & $23,3 \%$ & & \\
\hline Pretas & 38 & $9,9 \%$ & & \\
\hline Classe social $A B$ & 46 & $11,0 \%$ & & \\
\hline Classe social C & 143 & $37,0 \%$ & & \\
\hline Classe social DE & 187 & $48,4 \%$ & & \\
\hline Escolaridade muito baixa & 98 & $25,3 \%$ & & \\
\hline Escolaridade baixa & 123 & $31,8 \%$ & & \\
\hline Escolaridade média & 41 & $10,6 \%$ & & \\
\hline Escolaridade alta & 119 & $30,8 \%$ & & \\
\hline Glicemia > 110 mg/dl & 60 & $15,7 \%$ & $99,01 \pm 24,5$ & $(96,4-101,5)$ \\
\hline Colesterol total > $200 \mathrm{mg} / \mathrm{dl}$ & 24 & $6,3 \%$ & $182,96 \pm 37,9$ & $(179,0-186,8)$ \\
\hline Colesterol HDL $<40 \mathrm{mg} / \mathrm{dl}$ & 147 & $37,5 \%$ & $65,14 \pm 12,5$ & $(63,7-66,4)$ \\
\hline Colesterol LDL > 130 mg/dl & 43 & $11,3 \%$ & $95,88 \pm 27,4$ & $(92,6-98,2)$ \\
\hline Triglicérides > $150 \mathrm{mg} / \mathrm{dl}$ & 32 & $8,8 \%$ & $110,50 \pm 68,5$ & $(103,4-117,6)$ \\
\hline Idade & 386 & $100 \%$ & $45,11 \pm 16,20$ & $(43,4-46,7)$ \\
\hline Índice de massa corporal > 25 kg/m² & 208 & $53,5 \%$ & $26,0 \pm 5,3$ & $(25,5-26,6)$ \\
\hline Circunferência da cintura abdominal $>88 \mathrm{~cm}$ & 127 & $33,5 \%$ & $87,1 \pm 10,7$ & $(83,1-86,0)$ \\
\hline Pressão arterial sistólica média & 386 & $100 \%$ & $135,21 \pm 26,7$ & $(132,5-137,9)$ \\
\hline Pressão arterial diastólica média & 386 & $100 \%$ & $84,69 \pm 14,3$ & $(83,2-86,0)$ \\
\hline Pressão de pulso média & 386 & $100 \%$ & $50,55 \pm 17,7$ & $(48,7-52,4)$ \\
\hline
\end{tabular}

FONTE: Dados compilados pelo autor. 
Tabela 2 - Características do fenótipo sistólico.

\begin{tabular}{|c|c|c|c|c|c|c|}
\hline Características & $\mathrm{n}$ & $\%$ & $\begin{array}{l}\text { Média e } \\
\text { desvio- } \\
\text { padrão }\end{array}$ & $\begin{array}{l}\text { IC (95\% Int. } \\
\text { médias) }\end{array}$ & $\mathbf{P}$ & OR (95\% Int.médias) \\
\hline Tabagismo (+) & 29 & $34,1 \%$ & & & 0,026 & 0,55 IC 0,3- 0,9 \\
\hline sedentarismo & 135 & $45,8 \%$ & & & 0,6 & 1.16 IC $(0,7-1,9)$ \\
\hline Brancos & 45 & $40,5 \%$ & & & & 1 \\
\hline Moreno claro & 63 & $45,7 \%$ & & & \multirow{3}{*}{0,20} & 1,21 IC $(0,72-2,1)$ \\
\hline Moreno escuro & 38 & $42,7 \%$ & & & & 1.09 \\
\hline Pretos & 21 & $60,0 \%$ & & & & $2.19 \mathrm{IC}(0,6-2,0)$ \\
\hline Classe social $A B$ & 17 & $37,0 \%$ & & & \multirow{3}{*}{0.006} & 1 \\
\hline Classe social C & 52 & $36,9 \%$ & & & & $1.0 \mathrm{IC}(0,8-2,1)$ \\
\hline Classe social DE & 98 & $53,6 \%$ & & & & $2.10 \mathrm{IC}(0,9-4,0)$ \\
\hline Escolaridade muito baixa & 69 & $71,9 \%$ & & & 0.000 & 8.48 \\
\hline Escolaridade baixa & 61 & $49,6 \%$ & & & 0.000 & 3.20 \\
\hline Escolaridade média & 12 & $29,3 \%$ & & & 0.000 & 1.34 \\
\hline Escolaridade alta & 27 & $23,5 \%$ & & & 1 & 1 \\
\hline Glicemia > 110 mg/dl & 166 & $44,1 \%$ & $105,3 \pm 26,8$ & $101,2-109,4$ & 0,0001 & 3,8 IC $(2,1-5,8)$ \\
\hline Colesterol total > $200 \mathrm{mg} / \mathrm{dl}$ & 165 & $43,8 \%$ & $191,6 \pm 37,9$ & $185,8-197,5$ & 0,0001 & $2,1 \mathrm{IC}(0,9-4,9)$ \\
\hline Colesterol HDL < 40 mg/dl & 165 & $43,8 \%$ & $66,7 \pm 13,4$ & $66,4-68,8$ & 0,02 & 1.6 IC $(1,1-2,5)$ \\
\hline Colesterol LDL > $130 \mathrm{mg} / \mathrm{dl}$ & 163 & $43,3 \%$ & $98,8 \pm 27,3$ & $94,6-103,1$ & 0.02 & $1,5 \mathrm{IC}(0,8-2,8)$ \\
\hline Triglicérides > 150 mg/dl & 163 & $43,3 \%$ & $127,7 \pm 65,9$ & $116,5-136,9$ & 0,0001 & 2,2 IC $(1,0-4,6)$ \\
\hline Idade & 169 & $44,9 \%$ & $56,5 \pm 13,3$ & $(54,4-58,4)$ & 0,0001 & \\
\hline $\begin{array}{l}\text { Circunferência da cintura } \\
\text { abdominal }>88 \mathrm{~cm}\end{array}$ & 164 & $43,1 \%$ & $89,2 \pm 14,2$ & $87,0-91,0$ & 0.0001 & 3,3 IC $(2,2-5,2)$ \\
\hline
\end{tabular}

FONTE: Dados compilados pelo autor. 
Tabela 3 - Características do fenótipo diastólico.

\begin{tabular}{|c|c|c|c|c|c|c|}
\hline Características & $\mathrm{n}$ & $\%$ & $\begin{array}{l}\text { Média e desvio- } \\
\text { padrão }\end{array}$ & $\begin{array}{l}\text { IC ( }(95 \% \text { Int. } \\
\text { médias) }\end{array}$ & $\mathbf{P}$ & $\begin{array}{l}\text { OR (95\% Int. } \\
\text { médias) }\end{array}$ \\
\hline Tabagismo & 35 & $41,2 \%$ & & & 0,9 & $\begin{array}{l}0.95 \mathrm{IC}(0,5- \\
1,56)\end{array}$ \\
\hline Sedentarismo & 120 & $40,7 \%$ & & & 0,5 & $\begin{array}{l}1.121 \mathrm{IC}(0,8- \\
1,4)\end{array}$ \\
\hline Brancos & 39 & $35,1 \%$ & & & & 1 \\
\hline Moreno claro & 65 & $47,1 \%$ & & & \multirow{3}{*}{0,123} & 1,6 IC $(0,9-2,8)$ \\
\hline Moreno escuro & 33 & $37,1 \%$ & & & & 1,0 IC $(0,5-2,0)$ \\
\hline Pretos & 18 & $51,4 \%$ & & & & 2,0 IC $(0,8-4,5)$ \\
\hline Classe social $A B$ & 15 & $32,6 \%$ & & & & 1 \\
\hline Classe social C & 53 & $37,6 \%$ & & & \multirow[t]{2}{*}{0,096} & $\begin{array}{l}1,83 \text { IC }(0,6- \\
2,7)\end{array}$ \\
\hline Classe social DE & 86 & $47,0 \%$ & & & & $1,8 \mathrm{IC}(0,9-3,8)$ \\
\hline Escolaridade muito baixa & 52 & $54,2 \%$ & & & \multirow{3}{*}{0,000} & $\begin{array}{l}3,10 \text { IC }(1,9- \\
6,3)\end{array}$ \\
\hline Escolaridade baixa & 60 & $48,8 \%$ & & & & 1,9 \\
\hline Escolaridade média & 16 & $39,0 \%$ & & & & $2.8 \mathrm{IC}(1,6-5,1)$ \\
\hline Escolaridade alta & 29 & $25,2 \%$ & & & & 1 \\
\hline Glicemia > 110 mg/dl & 153 & $40,6 \%$ & $106,0 \pm 30,5$ & $101,1-110,9$ & 0,000 & 2,9 IC $(1,6-5,2)$ \\
\hline Colesterol total $>200 \mathrm{mg} / \mathrm{dl}$ & 152 & $40,4 \%$ & $191,5 \pm 36,5$ & $185,6-197,4$ & 0,000 & 0,8 IC $(0,4-1,9)$ \\
\hline Colesterol HDL $<40 \mathrm{mg} / \mathrm{dl}$ & 152 & $40,4 \%$ & $66,4 \pm 12,8$ & $64,4-68,5$ & 0,083 & $\begin{array}{l}1.95 \mathrm{IC}(1,0- \\
2,4)\end{array}$ \\
\hline Colesterol LDL > 130 mg/dl & 151 & $40,1 \%$ & $98,4 \pm 26,9$ & $94,0-102,7$ & 0,075 & $1,1 \mathrm{IC}(0,6-2,1)$ \\
\hline Triglicérides > $150 \mathrm{mg} / \mathrm{dl}$ & 151 & $40,1 \%$ & $132,7 \pm 77.0$ & $120,0-145,1$ & 0,000 & 4,0 IC $(1.8-8,9)$ \\
\hline Idade & 157 & $41,4 \%$ & $52,8 \pm 13,8$ & $50,2-54,4$ & 0,0001 & \\
\hline $\begin{array}{l}\text { Circunferência da cintura } \\
\text { abdominal }>88 \mathrm{~cm}\end{array}$ & 151 & $43,61 \%$ & $90,0 \pm 13,1$ & $87,9-92,1$ & 0,000 & 4,4 IC $(2,8-6,9)$ \\
\hline
\end{tabular}

FONTE: Dados compilados pelo autor. 
Tabela 4 - Características do fenótipo pressão de pulso.

\begin{tabular}{|c|c|c|c|c|c|c|}
\hline Características & n & $\%$ & $\begin{array}{l}\text { Média e } \\
\text { desvio- } \\
\text { padrão }\end{array}$ & $\begin{array}{l}\text { IC (95\% Int. } \\
\text { médias) }\end{array}$ & $\mathbf{P}$ & $\begin{array}{l}\text { OR (95\% Int. } \\
\text { médias) }\end{array}$ \\
\hline Tabagismo & 40 & $47,1 \%$ & & & 1,0 & $1.0 \mathrm{IC}(0,6-1,6)$ \\
\hline Sedentarismo & 145 & $49,2 \%$ & & & 0,13 & $1.48(0,8-2,4)$ \\
\hline Brancos & 45 & $40,5 \%$ & & & & 1 \\
\hline Moreno claro & 62 & $44,9 \%$ & & & \multirow{3}{*}{0,12} & $1.19 \mathrm{IC}(0,7-2,0)$ \\
\hline Moreno escuro & 47 & $52,8 \%$ & & & & $1.65 \mathrm{IC}(0,9-3,0)$ \\
\hline Pretos & 21 & $60,0 \%$ & & & & $2.19 \mathrm{IC}(0,9-5,1)$ \\
\hline Classe social $A B$ & 18 & $39,1 \%$ & & & & 1 \\
\hline Classe social C & 55 & $39,0 \%$ & & & \multirow{2}{*}{0,006} & 1.0 \\
\hline Classe social DE & 102 & $55,7 \%$ & & & & 1.9 IC $(0,9-4,0)$ \\
\hline Escolaridade muito baixa & 66 & $68,8 \%$ & & & \multirow{3}{*}{0,000} & 5,96 \\
\hline Escolaridade baixa & 65 & $52,8 \%$ & & & & 1.12 IC $(3,1-11,4)$ \\
\hline Escolaridade média & 15 & $36,6 \%$ & & & & 3,0 IC $(1,7-5,4)$ \\
\hline Escolaridade alta & 31 & $27,0 \%$ & & & 1 & 1 \\
\hline Glicemia > 110 mg/dl & 174 & $47,8 \%$ & $104,0 \pm 28,5$ & $99,7-108,2$ &, 000 & $3,1 \mathrm{IC}(1,7-58)$ \\
\hline Colesterol total $>200 \mathrm{mg} / \mathrm{dl}$ & 173 & $47,5 \%$ & $191,3 \pm 41,1$ & $185,1-187,5$ &, 000 & 3,6 IC $(1,8-9,2)$ \\
\hline Colesterol HDL $<40 \mathrm{mg} / \mathrm{dl}$ & 173 & $47,5 \%$ & $66,9 \pm 13,2$ & $64,9-68,9$ &, 000 & 2,0 IC $(1,3-3,1)$ \\
\hline Colesterol LDL > 130 mg/dl & 170 & $47,3 \%$ & $99,2 \pm 29,1$ & $94,2-103,6$ & 009 & 1,7 IC $(0,9-3,2)$ \\
\hline Triglicérides > $150 \mathrm{mg} / \mathrm{dl}$ & 170 & $47,0 \%$ & $119,7 \pm 65,7$ & $109,7-129,6$ &, 010 & 1,7 IC $(0,8-3,6)$ \\
\hline Idade & 177 & $52,9 \%$ & $54,7 \pm 15,2$ & $52,4-57,0$ & 0,0001 & \\
\hline $\begin{array}{l}\text { Circunferência da cintura } \\
\text { abdominal }>88 \mathrm{~cm}\end{array}$ & 172 & $48,1 \%$ & $88,0 \pm 14,6$ & $85,7-90,2$ & 0,0001 & $2,3 \mathrm{IC}(1,5-3,6)$ \\
\hline
\end{tabular}

FONTE: Dados compilados pelo autor. 
Tabela 5 - Distribuição dos fenótipos da pressão arterial nas faixas etárias.

\begin{tabular}{|c|c|c|c|c|c|}
\hline \multicolumn{2}{|c|}{ Idade } & Fenótipo normotensão & $\begin{array}{l}\text { fenótipo hipertensão arterial } \\
\qquad(\geq 140 \times 90 \mathrm{mmHg})\end{array}$ & $\mathbf{P}$ & OR \\
\hline $15-19$ & $\mathrm{~N}$ & 12 & 1 & \multirow{10}{*}{0,0001} & \multirow{10}{*}{$\begin{array}{l}\text { EX } \\
1 \\
8,0 \text { IC }(4,5-14,5) \\
55,2 \text { IC }(20,1-159,6)\end{array}$} \\
\hline $15-19$ & $\%$ & 92,3 & 7,7 & & \\
\hline \multirow{2}{*}{$20-39$} & $\mathrm{~N}$ & 109 & 25 & & \\
\hline & $\%$ & 81,3 & 18,7 & & \\
\hline \multirow{2}{*}{$40-59$} & $\mathrm{~N}$ & 54 & 100 & & \\
\hline & $\%$ & 35,1 & 64,9 & & \\
\hline \multirow{2}{*}{$\geq 60$} & $\mathrm{~N}$ & 6 & 76 & & \\
\hline & $\%$ & 7,3 & 92,7 & & \\
\hline \multirow{2}{*}{ Total } & $\mathrm{N}$ & 181 & 202 & & \\
\hline & $\%$ & 47.3 & 52,7 & & \\
\hline \multicolumn{2}{|c|}{ Sistólico } & Fenótipo normotensão & $\begin{array}{c}\text { Fenótipo pressão sistólica } \\
\text { aumentada }\end{array}$ & $\mathbf{P}$ & OR \\
\hline \multirow{2}{*}{$15-19$} & $\mathrm{~N}$ & 13 & 0 & \multirow{10}{*}{0,0001} & \multirow{10}{*}{10,2 IC $(5,2-20,5)$} \\
\hline & $\%$ & 100 & 0 & & \\
\hline \multirow{2}{*}{$20-39$} & $\mathrm{~N}$ & 120 & 14 & & \\
\hline & $\%$ & 89,6 & 10,4 & & \\
\hline \multirow{2}{*}{$40-59$} & $\mathrm{~N}$ & 70 & 84 & & \\
\hline & $\%$ & 45,5 & 54,5 & & \\
\hline \multirow{2}{*}{$\geq 60$} & $\mathrm{~N}$ & 8 & 74 & & \\
\hline & $\%$ & 9,8 & 90,2 & & \\
\hline \multirow{2}{*}{ Total } & $\mathrm{N}$ & 211 & 172 & & \\
\hline & $\%$ & 55,1 & 44,9 & & \\
\hline \multicolumn{2}{|c|}{ Diastólico } & Fenótipo normotensão & Fenótipo diastólica elevada & $\mathbf{P}$ & OR \\
\hline \multirow{2}{*}{$15-19$} & $\mathrm{~N}$ & 12 & 1 & \multirow{10}{*}{0,0001} & \multirow{10}{*}{7,5 IC $(3,8-15,0)$} \\
\hline & $\%$ & 92,3 & 7,7 & & \\
\hline \multirow{2}{*}{$20-39$} & $\mathrm{~N}$ & 112 & 22 & & \\
\hline & $\%$ & 83,6 & 16,4 & & \\
\hline \multirow{2}{*}{$40-59$} & $\mathrm{~N}$ & 66 & 88 & & \\
\hline & $\%$ & 42,9 & 57,1 & & \\
\hline \multirow{2}{*}{$\geq 60$} & $\mathrm{~N}$ & 33 & 49 & & \\
\hline & $\%$ & 40,2 & 59,8 & & \\
\hline \multirow{2}{*}{ Total } & $\mathrm{N}$ & 223 & 160 & & \\
\hline & $\%$ & 58,2 & 41,8 & & \\
\hline P. pulso & & Fenótipo normotensão & Fenótipo diastólica elevada & $\mathbf{P}$ & OR \\
\hline \multirow{2}{*}{$15-19$} & $\mathrm{~N}$ & 10 & 3 & & \\
\hline & $\%$ & 76,9 & 23,1 & & \\
\hline & $\mathrm{N}$ & 110 & 24 & & EX \\
\hline $20-39$ & $\%$ & 82,1 & 17,9 & & \\
\hline $40-59$ & $\mathrm{~N}$ & 75 & 79 & & 1 \\
\hline $40-59$ & $\%$ & 48,7 & 51,3 & 0,0001 & 18310127861 \\
\hline & $\mathrm{N}$ & 7 & 75 & & $4,83 \operatorname{IC}(2,1-8,6)$ \\
\hline$\geq 60$ & $\%$ & 8,5 & 91,5 & & $491 \mathrm{IC}(18.8-1337)$ \\
\hline & $\mathrm{N}$ & 202 & 181 & & \\
\hline Iotal & $\%$ & 52,7 & 47,3 & & \\
\hline
\end{tabular}

FONTE: Dados compilados pelo autor. 
Tabela 6-A - Distribuição dos alelos do AGT e da ECA na amostra.

\begin{tabular}{l|l|l|l|l|l}
\hline \multicolumn{1}{c|}{ Alelos AGT } & \multicolumn{1}{|c|}{ N } & \multicolumn{1}{|c|}{$\%$} & \multicolumn{1}{|c|}{ Alelos ECA } & \multicolumn{1}{c|}{ N } & \multicolumn{1}{c}{$\%$} \\
\hline $\mathrm{M}$ & 277 & 39,2 & $\mathrm{I}$ & 298 & 42,2 \\
\hline $\mathrm{T}$ & 419 & 59,3 & $\mathrm{D}$ & 408 & 57,8 \\
\hline Total & 696 & $98,5 \%$ & & 706 & 100 \\
\hline
\end{tabular}

LEGENDA: $\mathrm{M}$ e $\mathrm{T}$ = alelos do AGT; I e $\mathrm{D}=$ alelos da ECA.

FONTE: Dados compilados pelo autor.

Tabela 6-B - Distribuição dos polimorfismo do AGT e da ECA na amostra.

\begin{tabular}{l|l|l|l|l|l}
\hline \multicolumn{1}{c|}{ Polimorfismo AGT } & \multicolumn{1}{|c|}{$\mathbf{N}$} & \multicolumn{1}{c|}{$\%$} & \multicolumn{1}{c|}{ Polimorfismo ECA } & \multicolumn{1}{c}{ N } & \multicolumn{1}{c}{$\%$} \\
\hline MM & 63 & 16,5 & II & 69 & 18,1 \\
\hline MT & 174 & 45,7 & DI & 176 & 46,2 \\
\hline TT & 139 & 36,5 & DD & 136 & 35,7 \\
\hline Total & 381 & 100,0 & Total & 381 & 100,0 \\
\hline
\end{tabular}

LEGENDA: MM, MT e TT = Polimorfismo do AGT; II, DI e DD = Polimorfismo da ECA.

FONTE: Dados compilados pelo autor.

Tabela 7-A - Distribuição dos alelos (M e T) do AGT e do alelo (I e D) do alelo da ECA nos fenótipos faixa etária.

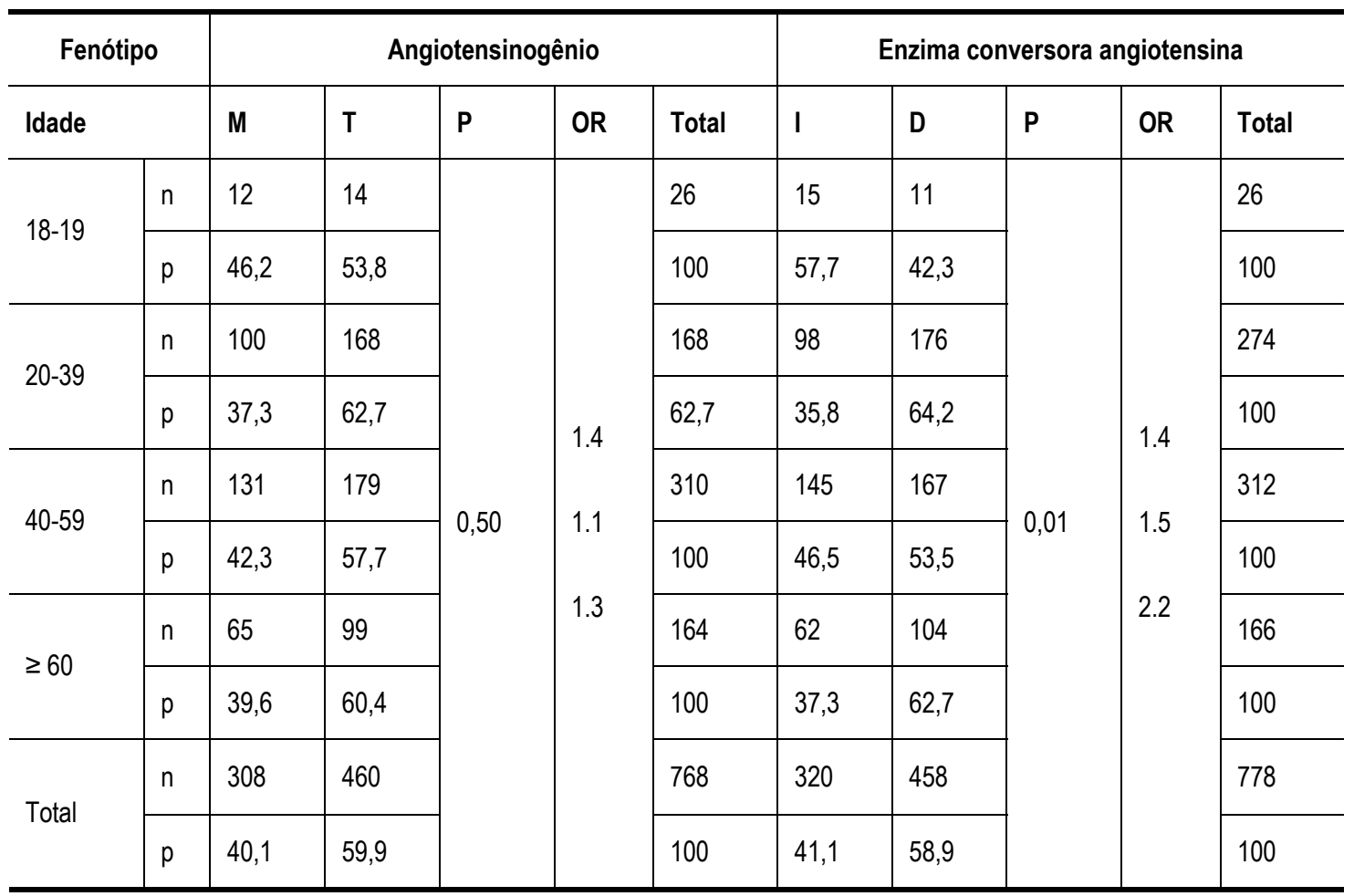

FONTE: Dados compilados pelo autor. 
Tabela 7-B - Distribuição dos alelos (M e T) do AGT e do alelo (I e D) do alelo da ECA nos fenótipos cor de pele.

\begin{tabular}{|c|c|c|c|c|c|c|c|c|c|c|c|}
\hline \multirow{2}{*}{\multicolumn{2}{|c|}{$\begin{aligned} \text { Fenótipo } \\
\text { Cor da pele }\end{aligned}$}} & \multicolumn{5}{|c|}{ Angiotensinogênio } & \multicolumn{5}{|c|}{ Enzima conversora angiotensina } \\
\hline & & M & T & $P$ & OR & Total & I & D & $P$ & OR & Total \\
\hline \multirow{2}{*}{ Branco } & $\mathrm{n}$ & 111 & 113 & \multirow{10}{*}{0,002} & \multirow{10}{*}{1.6} & 224 & 97 & 131 & \multirow{10}{*}{0,91} & \multirow{10}{*}{0.9} & 228 \\
\hline & $\mathrm{p}$ & 49,6 & 50,4 & & & 100,0 & 42,5 & 57,5 & & & 100 \\
\hline \multirow{2}{*}{ Morena clara } & $\mathrm{n}$ & 108 & 174 & & & 282 & 115 & 173 & & & 288 \\
\hline & $\mathrm{p}$ & 38,3 & 61,7 & & & 100 & 39,9 & 60,1 & & & 100 \\
\hline \multirow{2}{*}{ Morena escura } & $\mathrm{n}$ & 66 & 112 & & & 178 & 73 & 105 & & & 178 \\
\hline & $\mathrm{p}$ & 37,1 & 62,9 & & & 100 & 41,0 & 59,0 & & & 100 \\
\hline \multirow{2}{*}{ Preta } & $\mathrm{n}$ & 20 & 56 & & & 76 & 33 & 43 & & & 76 \\
\hline & $\mathrm{p}$ & 26,3 & 73,7 & & & 100 & 43,4 & 56,6 & & & 100 \\
\hline \multirow{2}{*}{ Total } & $\mathrm{n}$ & 305 & 455 & & & 760 & 318 & 452 & & & 770 \\
\hline & $\mathrm{p}$ & 40,1 & 59,9 & & & 100 & 41,3 & 58,7 & & & 100 \\
\hline
\end{tabular}

FONTE: Dados compilados pelo autor.

Tabela 8-A - Distribuição dos alelos (M e T) do AGT e (I e D) da ECA entre os fenótipos colesterol total.

\begin{tabular}{|c|c|c|c|c|c|c|c|c|c|c|c|}
\hline \multicolumn{2}{|l|}{ Perfil lipídico } & \multicolumn{5}{|c|}{ Angiotensinogênio } & \multicolumn{5}{|c|}{$\begin{array}{l}\text { Enzima conversora da } \\
\text { angiotensina }\end{array}$} \\
\hline \multicolumn{2}{|l|}{ Colesterol T } & M & $\mathrm{T}$ & $P$ & OR & Total & I & D & $P$ & OR & Total \\
\hline \multirow{2}{*}{ Ótimo fenótipo colesterol total normal } & $\mathrm{N}$ & 201 & 313 & \multirow{8}{*}{0,50} & & 514 & 219 & 301 & \multirow{8}{*}{0,50} & & 520 \\
\hline & $\%$ & 39,1 & 60,9 & & & 100 & 42,1 & 57,9 & & & 100 \\
\hline \multirow{2}{*}{$\begin{array}{l}\text { Limítrofe fenotipo colesterol total } \\
\text { limítrofe }\end{array}$} & $\mathrm{N}$ & 79 & 105 & & & 184 & 72 & 116 & & & 188 \\
\hline & $\%$ & 42,9 & 57,1 & & & 100, & 38,3 & 61,7 & & & 100 \\
\hline \multirow{2}{*}{ Alto fenotipo colesterol alto } & $\mathrm{N}$ & 21 & 27 & & & 48 & 22 & 26 & & & 48 \\
\hline & $\%$ & 43,8 & 56,3 & & & 100, & 45,8 & 54,2 & & & 100 \\
\hline \multirow{2}{*}{ Total } & $\mathrm{N}$ & 301 & 445 & & & 746 & 313 & 443 & & & 756 \\
\hline & $\%$ & 40,3 & 59,7 & & & 100 & 41,4 & 58,6 & & & 100 \\
\hline
\end{tabular}

FONTE: Dados compilados pelo autor. 
Tabela 8-B - Distribuição dos alelos (M e T) do AGT e (I e D) da ECA entre os fenótipos LDL colesterol.

\begin{tabular}{|c|c|c|c|c|c|c|c|c|c|c|c|}
\hline \multicolumn{2}{|l|}{ Perfil lipídico } & \multicolumn{5}{|c|}{ Angiotensinogênio } & \multicolumn{5}{|c|}{$\begin{array}{c}\text { Enzima conversora da } \\
\text { angiotensina }\end{array}$} \\
\hline \multicolumn{2}{|l|}{ LDL } & M & $\mathrm{T}$ & $\mathrm{P}$ & OR & Total & I & $\mathrm{D}$ & $P$ & OR & Total \\
\hline \multirow{2}{*}{ Ótimo fenótipo colesterol LDL normal } & $\mathrm{N}$ & 167 & 259 & \multirow{8}{*}{0,10} & & 426 & 188 & 244 & \multirow{8}{*}{0,10} & & 432 \\
\hline & $\%$ & 39,2 & 60,8 & & & 100 & 43,5 & 56,5 & & & 100 \\
\hline \multirow{2}{*}{$\begin{array}{l}\text { Desejável fenótipo colesterol LDL } \\
\text { desejável }\end{array}$} & $\mathrm{N}$ & 90 & 138 & & & 228 & 84 & 146 & & & 230 \\
\hline & $\%$ & 39,5 & 60,5 & & & 100 & 36,5 & 63,5 & & & 100 \\
\hline \multirow{2}{*}{$\begin{array}{l}\text { Fenótipo colesterol LDL limítrofe, } \\
\text { moderado e alto }\end{array}$} & $\mathrm{N}$ & 41 & 41 & & & 82 & 38 & 46 & & & 84 \\
\hline & $\%$ & 50,0 & 50,0 & & & 100 & 45,2 & 54,8 & & & 100 \\
\hline \multirow{2}{*}{ TOTAL } & $\mathrm{N}$ & 298 & 438 & & & 736 & 310 & 436 & & & 746 \\
\hline & $\%$ & 40,5 & 59,5 & & & 100,0 & 41,6 & 58,4 & & & 100 \\
\hline
\end{tabular}

FONTE: Dados compilados pelo autor.

Tabela 8-C - Distribuição dos alelos (M e T) do AGT e (I e D) da ECA entre os fenótipos HDL-colesterol.

\begin{tabular}{|c|c|c|c|c|c|c|c|c|c|c|c|}
\hline \multicolumn{2}{|l|}{ Perfil lipídico } & \multicolumn{5}{|c|}{ Angiotensinogênio } & \multicolumn{5}{|c|}{ Enzima conversora da angiotensina } \\
\hline \multicolumn{2}{|l|}{ HDL } & M & $\mathrm{T}$ & $P$ & OR & Total & I & $\mathrm{D}$ & $\mathrm{P}$ & OR & Total \\
\hline \multirow{2}{*}{$\begin{array}{l}\text { Fenótipo colesterol } \\
\text { HDL baixo e } \\
\text { moderado }\end{array}$} & $\mathrm{N}$ & 127 & 165 & \multirow{6}{*}{0,30} & & 292 & 140 & 154 & \multirow{6}{*}{0,007} & \multirow{6}{*}{0,6 IC $(0,5-0,9)$} & 294 \\
\hline & $\%$ & 43,4 & 56,6 & & & 100,0 & 47,3 & 52,7 & & & 100,0 \\
\hline \multirow{2}{*}{ Alto } & $\mathrm{N}$ & 174 & 280 & & & 454 & 173 & 289 & & & 462 \\
\hline & $\%$ & 38,3 & 61,7 & & & 100 & 37,4 & 62,6 & & & 100,0 \\
\hline \multirow{2}{*}{ Total } & $\mathrm{N}$ & 301 & 445 & & & 746 & 313 & 443 & & & 756 \\
\hline & $\%$ & 40,3 & 59,7 & & & 100,0 & 41,4 & 58,6 & & & 100 \\
\hline
\end{tabular}

FONTE: Dados compilados pelo autor.

Tabela 8-D - Distribuição dos alelos (M e T) do AGT e (I e D) da ECA entre os fenótipos triglicérides.

\begin{tabular}{|c|c|c|c|c|c|c|c|c|c|c|c|}
\hline \multirow{2}{*}{\multicolumn{2}{|c|}{$\begin{array}{c}\text { Perfil lipídico } \\
\text { Triglicérides }\end{array}$}} & \multicolumn{5}{|c|}{ Angiotensinogênio } & \multicolumn{5}{|c|}{ Enzima conversora da angiotensina } \\
\hline & & \multirow{2}{*}{$\frac{M}{234}$} & \multirow{2}{*}{$\frac{T}{366}$} & $\mathbf{P}$ & OR & Total & I & D & $\mathbf{P}$ & OR & Total \\
\hline Ótimo fenótipo colesterol & $\mathrm{N}$ & & & \multirow{8}{*}{0,30} & & 600 & 249 & 357 & \multirow{8}{*}{0,30} & \multirow{8}{*}{$\begin{array}{l}0,6 \\
\text { IC }(0,5-0,9)\end{array}$} & 606 \\
\hline total normal & $\%$ & 39,0 & 61,0 & & & 100 & 41,1 & 58,9 & & & 100 \\
\hline \multirow{2}{*}{$\begin{array}{l}\text { Limítrofe fenótipo } \\
\text { colesterol LDL desejável }\end{array}$} & $\mathrm{N}$ & 33 & 41 & & & 74 & 37 & 39 & & & 76 \\
\hline & $\%$ & 44,6 & 55,4 & & & 100 & 48,7 & 51,3 & & & 100 \\
\hline \multirow{2}{*}{$\begin{array}{l}\text { Fenótipo triglicérides alto } \\
\text { e muito alto }\end{array}$} & $\mathrm{N}$ & 34 & 32 & & & 66 & 25 & 43 & & & 68 \\
\hline & $\%$ & 51,6 & 48,4 & & & 100 & 37,9 & 62,1 & & & 100 \\
\hline \multirow{2}{*}{ Total } & $\mathrm{N}$ & 301 & 439 & & & 740 & 311 & 439 & & & 750 \\
\hline & $\%$ & 40,7 & 59,3 & & & 100 & 41,5 & 58,5 & & & 100 \\
\hline
\end{tabular}

FONTE: Dados compilados pelo autor. 
Tabela 9-A - Distribuição dos alelos (T e M) do AGT entre os fenótipos de índice de massa corporal.

\begin{tabular}{|c|c|c|c|c|c|c|c|c|c|c|c|}
\hline \multirow{2}{*}{\multicolumn{2}{|c|}{$\begin{array}{c}\text { Fenótipo } \\
\text { Índice de massa corporal }\end{array}$}} & \multicolumn{5}{|c|}{ Angiotensinogênio } & \multicolumn{5}{|c|}{ Enzima conversora angiotensina } \\
\hline & & \multirow{2}{*}{$\frac{M}{15}$} & \multirow{2}{*}{$\frac{T}{23}$} & $p$ & OR & Total & I & D & $p$ & OR & Total \\
\hline Baixo peso & $\mathrm{N}$ & & & \multirow{10}{*}{0,50} & & 38 & 15 & 23 & \multirow{10}{*}{0,90} & & 38 \\
\hline & $\%$ & $39,5 \%$ & $60,5 \%$ & & & $100,0 \%$ & $39,5 \%$ & $60,5 \%$ & & & $100,0 \%$ \\
\hline \multirow[t]{2}{*}{ Normal } & $\mathrm{N}$ & 127 & 173 & & & 300 & 126 & 176 & & & 302 \\
\hline & $\%$ & $42,3 \%$ & $57,7 \%$ & & & $100,0 \%$ & $41,7 \%$ & $58,3 \%$ & & & $100,0 \%$ \\
\hline \multirow[t]{2}{*}{ Sobrepeso } & $\mathrm{N}$ & 97 & 169 & & & 266 & 113 & 157 & & & 270 \\
\hline & $\%$ & $36,5 \%$ & $63,5 \%$ & & & $100,0 \%$ & $41,9 \%$ & $58,1 \%$ & & & $100,0 \%$ \\
\hline \multirow[t]{2}{*}{ Obesidade } & $\mathrm{N}$ & 59 & 83 & & & 142 & 61 & 85 & & & 146 \\
\hline & $\%$ & $41,5 \%$ & $58,5 \%$ & & & $100,0 \%$ & $41,8 \%$ & $58,2 \%$ & & & $100,0 \%$ \\
\hline \multirow[t]{2}{*}{ Total } & $\mathrm{N}$ & 298 & 448 & & & 746 & 315 & 441 & & & 756 \\
\hline & $\%$ & $39,9 \%$ & $60,1 \%$ & & & $100,0 \%$ & $41,7 \%$ & $58,3 \%$ & & & $100,0 \%$ \\
\hline
\end{tabular}

FONTE: Dados compilados pelo autor.

Tabela 9-B - Distribuição dos alelos (T e M) do AGT entre os fenótipos de circunferência da cintura abdominal.

\begin{tabular}{|c|c|c|c|c|c|c|c|c|c|c|c|}
\hline \multirow{2}{*}{\multicolumn{2}{|c|}{$\begin{array}{c}\text { Fenótipo } \\
\begin{array}{c}\text { Circunferência da cintura } \\
\text { abdominal }\end{array}\end{array}$}} & \multicolumn{5}{|c|}{ Angiotensinogênio } & \multicolumn{5}{|c|}{ Enzima conversora angiotensina } \\
\hline & & \multirow{2}{*}{$\begin{array}{r}\text { M } \\
185\end{array}$} & \multirow{2}{*}{$\begin{array}{r}\mathbf{T} \\
267\end{array}$} & \multirow{5}{*}{$\begin{array}{c}\mathbf{p} \\
0,70\end{array}$} & OR & \multirow{2}{*}{$\begin{array}{l}\text { Total } \\
452\end{array}$} & \multirow{2}{*}{$\begin{array}{c}\text { I } \\
192\end{array}$} & \multirow{2}{*}{$\begin{array}{r}\text { D } \\
266\end{array}$} & \multirow{5}{*}{$\begin{array}{c}\mathbf{p} \\
0,90\end{array}$} & \multirow[t]{2}{*}{ OR } & \multirow{2}{*}{$\begin{array}{l}\text { Total } \\
458\end{array}$} \\
\hline \multirow{2}{*}{$<88 \mathrm{~cm}$} & $\mathrm{~N}$ & & & & & & & & & & \\
\hline & $\%$ & $40,9 \%$ & $59,1 \%$ & & & $100,0 \%$ & $41,9 \%$ & $58,1 \%$ & & & $100,0 \%$ \\
\hline \multirow{2}{*}{$\geq 88 \mathrm{~cm}$} & $\mathrm{~N}$ & 111 & 167 & & & 278 & 118 & 164 & & & 282 \\
\hline & $\%$ & $39,9 \%$ & $60,1 \%$ & & & $100,0 \%$ & $41,8 \%$ & $58,2 \%$ & & & $100,0 \%$ \\
\hline \multirow{2}{*}{ Total } & $\mathrm{N}$ & 296 & 434 & & & 434 & 730 & 310 & & & 740 \\
\hline & $\%$ & $40,5 \%$ & $59,5 \%$ & & & $59,5 \%$ & $100,0 \%$ & $41,9 \%$ & & & $100,0 \%$ \\
\hline
\end{tabular}

FONTE: Dados compilados pelo autor.

Tabela 9-C - Distribuição dos alelos (T e M) do AGT entre os fenótipos de hiperglicemia

\begin{tabular}{|c|c|c|c|c|c|c|c|c|c|c|c|}
\hline \multirow{2}{*}{\multicolumn{2}{|c|}{$\begin{array}{c}\text { Fenótipo } \\
\text { Glicemia }\end{array}$}} & \multicolumn{5}{|c|}{ Angiotensinogênio } & \multicolumn{5}{|c|}{ Enzima conversora angiotensina } \\
\hline & & \multirow{2}{*}{$\frac{M}{259}$} & \multirow{2}{*}{$\begin{array}{l}\mathbf{T} \\
367\end{array}$} & $\mathbf{P}$ & OR & Total & I & D & $p$ & OR & Total \\
\hline $100 \mathrm{maldl}$ & $\mathrm{N}$ & & & \multirow{8}{*}{0,02} & \multirow{5}{*}{$\begin{array}{l}2, .2 \\
\text { IC }(1,2-4,3)\end{array}$} & 626 & 267 & 369 & \multirow{8}{*}{0,3} & & 636 \\
\hline - & $\%$ & $41,4 \%$ & $58,6 \%$ & & & $100,0 \%$ & $42,0 \%$ & $58,0 \%$ & & & $100,0 \%$ \\
\hline \multirow{2}{*}{$>100 \leq 110 \mathrm{mg} / \mathrm{dl}$} & $\mathrm{N}$ & 14 & 44 & & & 58 & 24 & 34 & & & 58 \\
\hline & $\%$ & $24,1 \%$ & $75,9 \%$ & & & $100,0 \%$ & $41,4 \%$ & $58,6 \%$ & & & $100,0 \%$ \\
\hline \multirow{2}{*}{$>110 \mathrm{mg} / \mathrm{dl}$} & $\mathrm{N}$ & 28 & 34 & & & 62 & 20 & 42 & & & 62 \\
\hline & $\%$ & $45,2 \%$ & $54,8 \%$ & & \multirow{3}{*}{$\begin{array}{l}0,8 \\
\text { IC }(0,5-1,5)\end{array}$} & $100,0 \%$ & $32,3 \%$ & $67,7 \%$ & & & $100,0 \%$ \\
\hline \multirow{2}{*}{ Total } & $\mathrm{N}$ & 301 & 445 & & & 746 & 311 & 445 & & & 756 \\
\hline & $\%$ & $40,3 \%$ & $59,7 \%$ & & & $100,0 \%$ & $41,1 \%$ & $58,9 \%$ & & & $100,0 \%$ \\
\hline
\end{tabular}

FONTE: Dados compilados pelo autor. 
Tabela 10 - Distribuição os polimorfismos do AGT e da ECA entre as faixas etárias.

\begin{tabular}{|c|c|c|c|c|c|c|c|c|c|c|c|c|c|c|}
\hline \multirow{2}{*}{\multicolumn{3}{|c|}{ Fenótipo }} & \multicolumn{6}{|c|}{ Angiotensinogênio } & \multicolumn{6}{|c|}{ Enzima Conversora angiotensina } \\
\hline & & & MM & MT & TT & $\mathbf{P}$ & OR & Total & II & DI & DD & $\mathbf{P}$ & OR & Total \\
\hline \multirow{8}{*}{$\begin{array}{l}\text { Faixa } \\
\text { etária }\end{array}$} & \multirow{2}{*}{$15-19$} & $\mathrm{~N}$ & 3 & 6 & 4 & \multirow{10}{*}{0,53} & & 13 & 4 & 7 & 2 & \multirow{10}{*}{0,03} & & 13 \\
\hline & & $\%$ & 23,1 & 46,2 & 30,8 & & & 100 & 30,8 & 53,8 & 15,4 & & & 100 \\
\hline & \multirow{2}{*}{$20-39$} & $\mathrm{~N}$ & 23 & 54 & 57 & & & 134 & 15 & 68 & 54 & & & 137 \\
\hline & & $\%$ & 17,2 & 40,3 & 42,5 & & & 100 & 10,9 & 49,6 & 39,4 & & & 100 \\
\hline & \multirow{2}{*}{$40-50$} & $\mathrm{~N}$ & 25 & 81 & 49 & & & 135 & 39 & 67 & 50 & & & 156 \\
\hline & & $\%$ & 16,1 & 52,3 & 31,6 & & & 100 & 25,0 & 42,9 & 32,1 & & & 100 \\
\hline & \multirow{2}{*}{$>60$} & $\mathrm{~N}$ & 14 & 37 & 31 & & & 82 & 12 & 38 & 33 & & & 83 \\
\hline & & $\%$ & 17,1 & 45,1 & 37,8 & & & 100 & 14,5 & 45,8 & 39,8 & & & 100 \\
\hline \multirow{2}{*}{ TOTAL } & & $\mathrm{N}$ & 65 & 178 & 141 & & & 384 & 70 & 180 & 139 & & & 389 \\
\hline & & $\%$ & 16,9 & 46,4 & 36,7 & & & 100 & 18,0 & 46,3 & 35,7 & & & 100 \\
\hline
\end{tabular}

FONTE: Dados compilados pelo autor.

Tabela 11 - Distribuição dos fenótipos sistólico, diastólico e pressão de pulso nos os polimorfismos do AGT e da ECA.

\begin{tabular}{|c|c|c|c|c|c|c|c|c|c|c|c|c|c|c|}
\hline \multirow{2}{*}{\multicolumn{3}{|c|}{ Fenótipo }} & \multicolumn{6}{|c|}{ Angiotensinogênio } & \multicolumn{6}{|c|}{ Enzima conversora angiotensina } \\
\hline & & & MM & MT & TT & $\mathbf{P}$ & OR & Total & II & DI & DD & $\mathbf{P}$ & OR & Total \\
\hline \multirow{4}{*}{ Sistólico } & \multirow{2}{*}{ FN } & $\mathrm{N}$ & 35 & 95 & 74 & \multirow{6}{*}{0,96} & & 204 & 33 & 98 & 75 & \multirow{6}{*}{0,43} & & 54,9 \\
\hline & & $\%$ & 56,5 & 55,2 & 54,4 & & & 55.1 & 47,8 & 57,3 & 55,6 & & & 169 \\
\hline & \multirow{2}{*}{ FS } & $\mathrm{N}$ & 27 & 77 & 62 & & & 166 & 36 & 73 & 60 & & & 45,1 \\
\hline & & $\%$ & 43,5 & 44,8 & 45,6 & & & 44,9 & 52.2 & 42,7 & 44.4 & & & 54,9 \\
\hline \multirow{2}{*}{\multicolumn{2}{|c|}{ Total }} & $\mathrm{N}$ & 62 & 172 & 136 & & & 370 & 69 & 171 & 135 & & & 375 \\
\hline & & $\%$ & 100 & 100 & 100 & & & 100 & 100 & 100 & 100 & & & 100 \\
\hline \multirow{2}{*}{\multicolumn{3}{|c|}{ Fenótipo }} & \multicolumn{6}{|c|}{ Angiotensinogênio } & \multicolumn{6}{|c|}{ Enzima conversora angiotensina } \\
\hline & & & MM & MT & TT & $\mathbf{P}$ & OR & Total & II & DI & DD & $p$ & OR & Total \\
\hline \multirow{4}{*}{ Diastólico } & \multirow{2}{*}{ FN } & $\mathrm{N}$ & 37 & 104 & 75 & \multirow{6}{*}{0,62} & & 218 & 41 & 100 & 77 & \multirow{6}{*}{0,94} & & 216 \\
\hline & & $\%$ & 59,7 & 60,5 & 55,1 & & & 58,1 & 59,4 & 58,5 & 57,0 & & & 58,4 \\
\hline & 50 & $\mathrm{~N}$ & 25 & 68 & 61 & & & 157 & 28 & 71 & 58 & & & 154 \\
\hline & 10 & $\%$ & 40,3 & 39,5 & 44,9 & & & 41,9 & 40,65 & 41,5 & 43,0 & & & 41,6 \\
\hline \multirow{2}{*}{\multicolumn{2}{|c|}{ Total }} & $\mathrm{N}$ & 62 & 172 & 136 & & & 375 & 69 & 171 & 135 & & & 135 \\
\hline & & $\%$ & 100 & 100 & 100 & & & 100 & 100 & 100 & 100 & & & 100 \\
\hline \multirow{2}{*}{\multicolumn{3}{|c|}{ Fenótipo }} & \multicolumn{6}{|c|}{ Angiotensinogênio } & \multicolumn{6}{|c|}{ Enzima conversora angiotensina } \\
\hline & & & MM & MT & TT & $\mathbf{P}$ & OR & Total & II & DI & DD & $\mathrm{p}$ & OR & Total \\
\hline \multirow{4}{*}{ P. pulso } & \multirow{2}{*}{ FN } & $\mathrm{N}$ & 37 & 104 & 75 & \multirow{6}{*}{0,62} & & 216 & 34 & 101 & 63 & \multirow{6}{*}{0,07} & & 75 \\
\hline & & $\%$ & 59,7 & 60,5 & 55,1 & & & 58,4 & 49,3 & 59,1 & 46,7 & & & 55,1 \\
\hline & ᄃc & $\mathrm{N}$ & 25 & 68 & 61 & & & 154 & 35 & 70 & 72 & & & 61 \\
\hline & 10 & $\%$ & 40,3 & 39,5 & 44,9 & & & 41,6 & 50,7 & 40,9 & 53,3 & & & 44,9 \\
\hline \multirow{2}{*}{ Total } & & $\mathrm{N}$ & 62 & 172 & 136 & & & 370 & 62 & 172 & 136 & & & 135 \\
\hline & & $\%$ & 100 & 100 & 100 & & & 100 & 100 & 100 & 100 & & & 100 \\
\hline
\end{tabular}

LEGENDA: FN = fenótipo da pressão arterial normal; FS = fenótipo sistólico aumentado; FD = fenótipo diastólico aumentado FPP = fenótipo pressão de pulso aumentado.

FONTE: Dados compilados pelo autor. 
Tabela 12-A - Distribuição dos fenótipos circunferência da cintura abdominal e os polimorfismos do AGT e da ECA.

\begin{tabular}{|c|c|c|c|c|c|c|c|c|c|c|c|c|c|c|}
\hline \multirow{2}{*}{\multicolumn{3}{|c|}{ Fenótipos }} & \multicolumn{6}{|c|}{ Angiotensinogênio } & \multicolumn{6}{|c|}{ Enzima conversora } \\
\hline & & & MM & MT & TT & $\mathrm{p}$ & OR & Total & II & DI & DD & $\mathrm{p}$ & OR & total \\
\hline \multirow{6}{*}{$\begin{array}{l}\text { Circunferência } \\
\text { da cintura } \\
\text { abdominal }\end{array}$} & \multirow{2}{*}{$<88 \mathrm{~cm}$} & $\mathrm{~N}$ & 42 & 104 & 85 & \multirow{6}{*}{0,8} & \multirow{6}{*}{1,17} & 23 & 45 & 106 & 83 & \multirow{6}{*}{0,60} & \multirow{6}{*}{1,01} & 234 \\
\hline & & $\%$ & 68,9 & 62,7 & 65,4 & & & 33,8 & 66,2 & 63,1 & 65,9 & & & 64,6 \\
\hline & \multirow{2}{*}{$\begin{array}{l}\geq 88 \\
\mathrm{~cm}\end{array}$} & $\mathrm{~N}$ & 19 & 62 & 45 & & & 23 & 23 & 62 & 43 & & & 128 \\
\hline & & $\%$ & 31,1 & 37,3 & 34,6 & & & 33,8 & 33,8 & 36,9 & 34,1 & & & 35,4 \\
\hline & \multirow{2}{*}{ Total } & $\mathrm{N}$ & 61 & 166 & 130 & & & 357 & 68 & 168 & 126 & & & 362 \\
\hline & & $\%$ & 100 & 100 & 100 & & & 100 & 100 & 100 & 100 & & & 100 \\
\hline
\end{tabular}

FONTE: Dados compilados pelo autor.

Tabela 12-B - Distribuição dos fenótipos da circunferência da cintura abdominal nos polimorfismos do AGT (MM x MT +TT) e da ECA (II $\times$ DI + DD).

\begin{tabular}{|c|c|c|c|c|c|c|c|c|c|c|c|c|}
\hline \multirow{2}{*}{\multicolumn{3}{|c|}{ Fenótipos }} & \multicolumn{5}{|c|}{ Angiotensinogênio } & \multicolumn{5}{|c|}{ Enzima conversora } \\
\hline & & & MM & $\mathrm{MT}+\mathrm{TT}$ & $\mathrm{p}$ & OR & Total & II & $D I+D D$ & p & OR & total \\
\hline \multirow{6}{*}{$\begin{array}{l}\text { Circunferência } \\
\text { da cintura } \\
\text { abdominal }\end{array}$} & \multirow{2}{*}{$<88 \mathrm{~cm}$} & $\mathrm{~N}$ & 42 & 189 & \multirow{6}{*}{0,4} & & 231 & 45 & 189 & \multirow{6}{*}{0,76} & & 234 \\
\hline & & $\%$ & 68,9 & 63,9 & & & 64,7 & 66,2 & 64,3 & & & 64,6 \\
\hline & \multirow{2}{*}{$\geq 88 \mathrm{~cm}$} & $\mathrm{~N}$ & 19 & 107 & & & 126 & 23 & 105 & & & 128 \\
\hline & & $\%$ & 31,1 & 36,1 & & & 35,3 & 33,8 & 35,7 & & & 35,4 \\
\hline & \multirow{2}{*}{ Total } & $\mathrm{N}$ & 61 & 296 & & & 357 & 68 & 294 & & & 362 \\
\hline & & $\%$ & 100 & 100 & & & 100 & 100 & 100 & & & 100 \\
\hline
\end{tabular}

FONTE: Dados compilados pelo autor.

Tabela 13-A - Distribuição dos fenótipos da glicemia e os polimorfismos do AGT e da ECA.

\begin{tabular}{|c|c|c|c|c|c|c|c|c|c|c|c|c|c|c|}
\hline \multirow{2}{*}{\multicolumn{3}{|c|}{ Fenótipos }} & \multicolumn{6}{|c|}{ Angiotensinogênio } & \multicolumn{6}{|c|}{ Enzima conversora } \\
\hline & & & MM & MT & TT & $p$ & OR & Total & II & DI & DD & $p$ & OR & total \\
\hline \multirow{6}{*}{ Glicemia } & \multirow{2}{*}{$<110 \mathrm{mg} / \mathrm{dl}$} & $\mathrm{N}$ & 56 & 139 & 110 & \multirow{6}{*}{0,28} & & 305 & 60 & 141 & 109 & \multirow{6}{*}{0,5} & & 310 \\
\hline & & $\%$ & 90,3 & 82,2 & 82,1 & & & 83,6 & 88,2 & 83,4 & 83.8 & & & 83,8 \\
\hline & \multirow{2}{*}{$\geq 110 \mathrm{mg} / \mathrm{dl}$} & $\mathrm{N}$ & 6 & 30 & 24 & & & 60 & 8 & 28 & 24 & & & 60 \\
\hline & & $\%$ & 9,7 & 17,8 & 17,9 & & & 16,4 & 11,8 & 16,6 & 18,0 & & & 310 \\
\hline & \multirow{2}{*}{ Total } & $\mathrm{N}$ & 62 & 169 & 134 & & & 365 & 68 & 169 & 133 & & & 370 \\
\hline & & $\%$ & 100 & 100 & 100 & & & 100 & 100 & 100 & 100 & & & 100 \\
\hline
\end{tabular}

FONTE: Dados compilados pelo autor. 
Tabela 13-B - Distribuição dos fenótipos da glicemia Nos polimorfismos do AGT (MM x MT +TT) e da ECA (II x DI + DD).

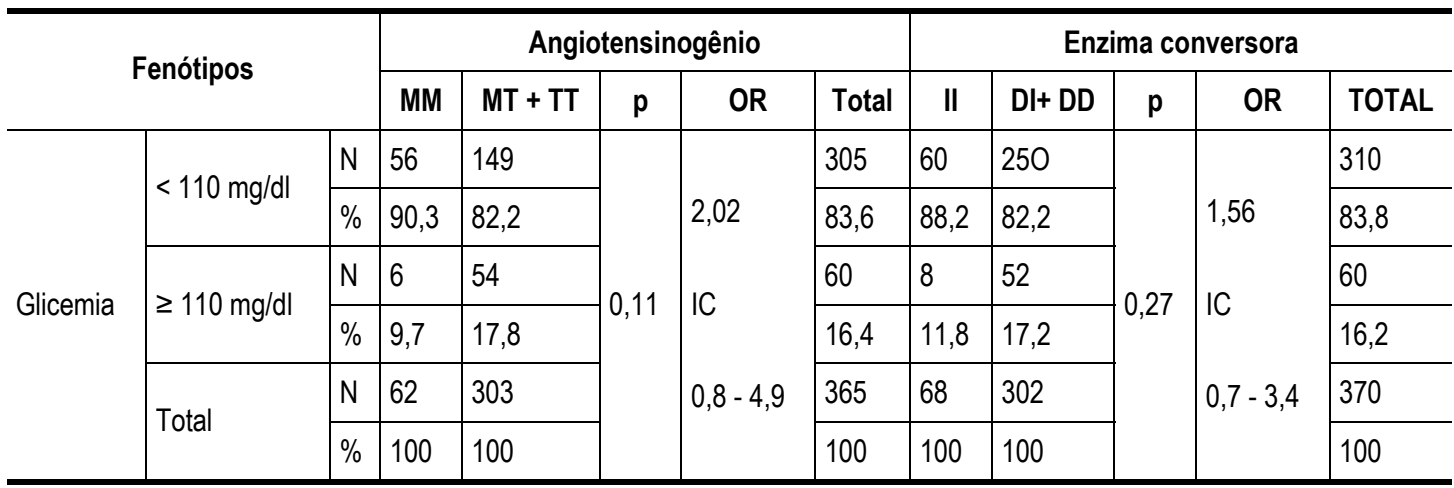

FONTE: Dados compilados pelo autor.

Tabela 14-A - Distribuição dos fenótipos do triglicérides nos polimorfismos do AGT e da ECA.

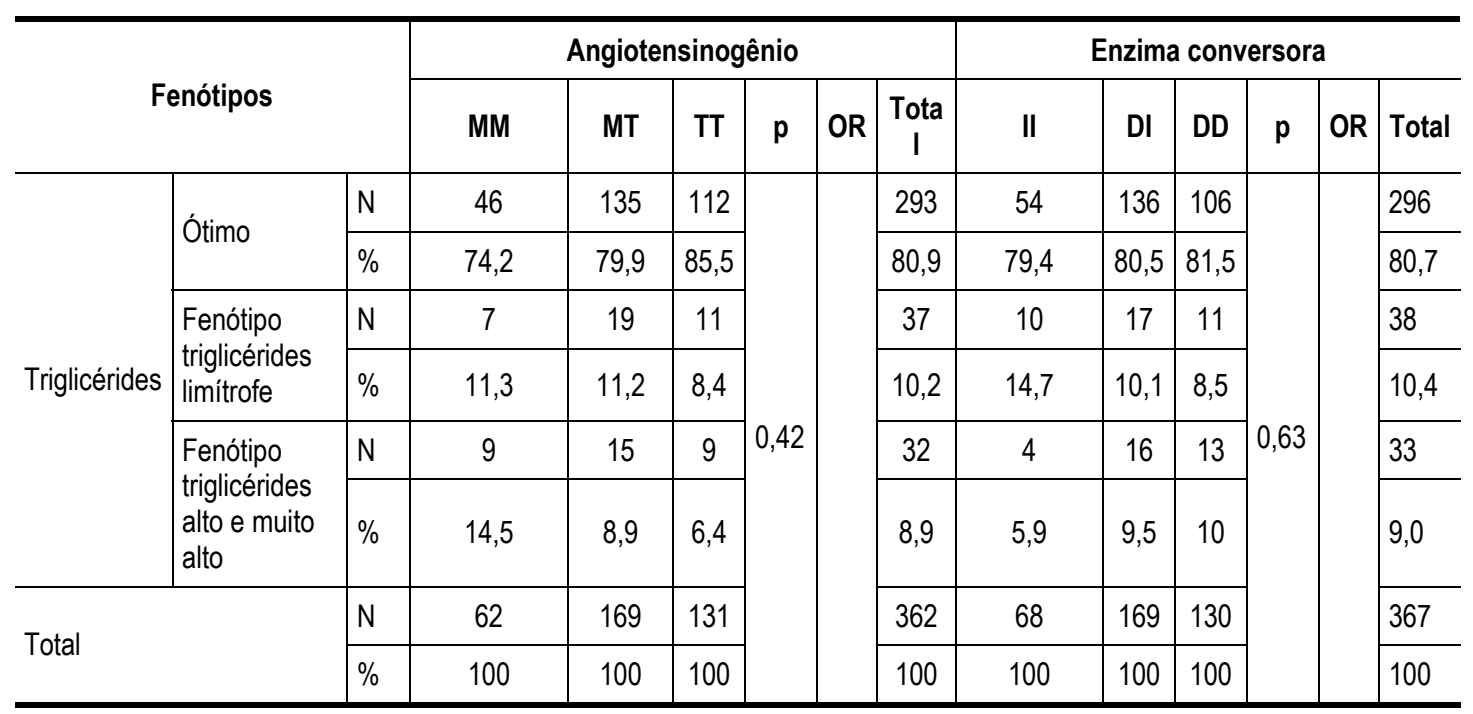

FONTE: Dados compilados pelo autor. 
Tabela 14-B - Distribuição dos fenótipos do triglicérides Nos polimorfismos do AGT (MM X MT +TT) e da ECA (II x DI + DD).

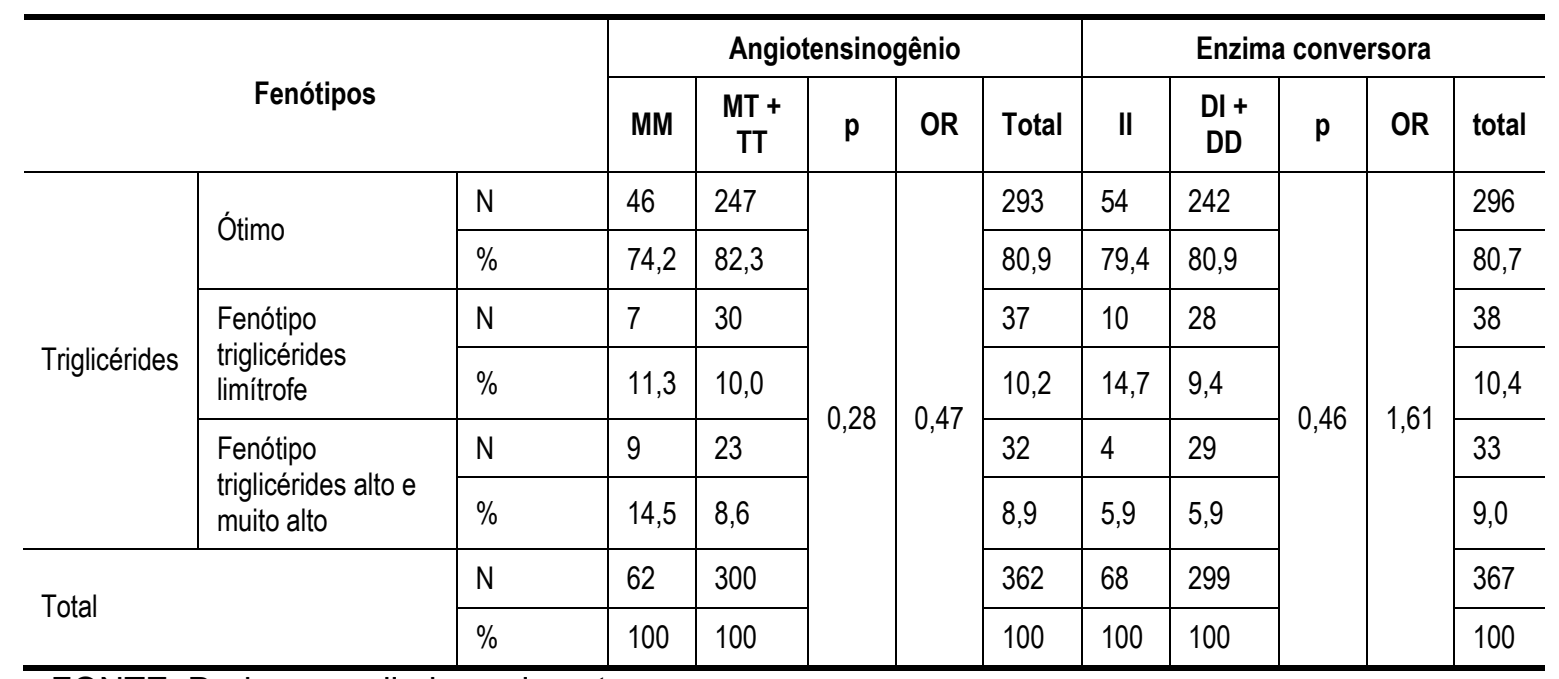

FONTE: Dados compilados pelo autor.

Tabela 15-A - Distribuição dos fenótipos colesterol total e os polimorfismos do AGT e da ECA.

\begin{tabular}{|c|c|c|c|c|c|c|c|c|c|c|c|c|c|c|}
\hline \multirow{2}{*}{\multicolumn{3}{|c|}{ Fenótipos }} & \multicolumn{6}{|c|}{ Angiotensinogênio } & \multicolumn{5}{|c|}{ Enzima conversora } & \multirow[b]{2}{*}{ total } \\
\hline & & & MM & MT & TT & $p$ & OR & Total & II & DI & DD & $p$ & OR & \\
\hline \multirow{6}{*}{$\begin{array}{l}\text { Colesterol } \\
\text { total }\end{array}$} & \multirow{2}{*}{ Ótimo } & $\mathrm{N}$ & 43 & 112 & 97 & \multirow{8}{*}{0,80} & & 252 & 51 & 115 & 89 & \multirow{8}{*}{0,60} & & 225 \\
\hline & & $\%$ & 69,4 & 66,3 & 72,4 & & & 69,0 & 73,9 & 68,0 & 67,4 & & & 68,9 \\
\hline & \multirow{2}{*}{$\begin{array}{l}\text { Fenótipo } \\
\text { triglicérides } \\
\text { limítrofe }\end{array}$} & $\mathrm{N}$ & 15 & 44 & 30 & & & 89 & 12 & 44 & 35 & & & 91 \\
\hline & & $\%$ & 24,2 & 26,0 & 22,4 & & & 24,4 & 17,4 & 26,0 & 26,5 & & & 24,6 \\
\hline & \multirow{2}{*}{$\begin{array}{l}\text { Fenótipo } \\
\text { triglicérides } \\
\text { alto e muito } \\
\text { alto }\end{array}$} & $\mathrm{N}$ & 4 & 13 & 7 & & & 24 & 6 & 10 & 8 & & & 24 \\
\hline & & $\%$ & 6,5 & 7,7 & 5,2 & & & 6,6 & 8,7 & 5,9 & 6,1 & & & 6,5 \\
\hline \multirow{2}{*}{ Total } & & $\mathrm{N}$ & 62 & 169 & 169 & & & 365 & 69 & 169 & 132 & & & 370 \\
\hline & & $\%$ & 100 & 100 & 100 & & & 100 & 100 & 100 & 100 & & & 100 \\
\hline
\end{tabular}

FONTE: Dados compilados pelo autor. 
Tabela 15-B - Distribuição dos fenótipos colesterol total nos polimorfismos do AGT (MM x MT +TT) e da ECA (II x DI + DD).

\begin{tabular}{|c|c|c|c|c|c|c|c|c|c|c|c|c|}
\hline \multirow{2}{*}{\multicolumn{3}{|c|}{ Fenótipos }} & \multicolumn{5}{|c|}{ Angiotensinogênio } & \multicolumn{5}{|c|}{ Enzima conversora } \\
\hline & & & \multirow{2}{*}{$\begin{array}{l}\text { MM } \\
43\end{array}$} & \multirow{2}{*}{$\begin{array}{l}\text { MT + TT } \\
209\end{array}$} & \multirow{2}{*}{$p$} & \multirow{2}{*}{ OR } & \multirow{2}{*}{$\begin{array}{l}\text { Total } \\
252\end{array}$} & \multirow{2}{*}{$\begin{array}{r}\text { II } \\
51\end{array}$} & \multirow{2}{*}{$\begin{array}{c}\text { DI + } \\
\text { DD } \\
204\end{array}$} & \multirow{2}{*}{$p$} & \multirow{2}{*}{ OR } & \multirow{2}{*}{$\begin{array}{l}\text { Total } \\
204\end{array}$} \\
\hline \multirow{6}{*}{$\begin{array}{l}\text { Colesterol } \\
\text { total }\end{array}$} & \multirow{2}{*}{ Ótimo } & $\mathrm{N}$ & & & & & & & & & & \\
\hline & & $\%$ & 69,4 & 69,0 & \multirow{7}{*}{0,99} & & 69,0 & 73,9 & 67,8 & \multirow{7}{*}{0,25} & \multirow{7}{*}{0,70} & 67,8 \\
\hline & Fenótipo & $\mathrm{N}$ & 15 & 74 & & & 89 & 12 & 79 & & & 79 \\
\hline & limítrofe & $\%$ & 24,2 & 24,4 & & 10 & 24,4 & 17,4 & 26,2 & & & 26,2 \\
\hline & (14 & $\mathrm{N}$ & 4 & 20 & & & 24 & 6 & 18 & & & 18 \\
\hline & & $\%$ & 6,5 & 6,5 & & & 6,6 & 8,7 & 6,0 & & & 6,0 \\
\hline \multirow{2}{*}{\multicolumn{2}{|c|}{ Total }} & $\mathrm{N}$ & 62 & 303 & & & 365 & 69 & 301 & & & 301 \\
\hline & & $\%$ & 100 & 100 & & & 100 & 100 & 100 & & & 100 \\
\hline
\end{tabular}

FONTE: Dados compilados pelo autor.

Tabela 16-A - Distribuição dos fenótipos LDL colesterol os polimorfismos do AGT e da ECA.

\begin{tabular}{|c|c|c|c|c|c|c|c|c|c|c|c|c|c|c|}
\hline \multirow{2}{*}{\multicolumn{3}{|c|}{ Fenótipos }} & \multicolumn{6}{|c|}{ Angiotensinogênio } & \multicolumn{6}{|c|}{ Enzima conversora } \\
\hline & & & MM & MT & TT & $p$ & OR & Total & II & DI & DD & $p$ & OR & Total \\
\hline \multirow{6}{*}{$\begin{array}{l}\text { Colesterol } \\
\text { LDL }\end{array}$} & \multirow{2}{*}{ Ótimo } & $\mathrm{N}$ & 33 & 99 & 77 & \multirow{8}{*}{0,10} & & 209 & 47 & 93 & 72 & \multirow{8}{*}{0,21} & & 212 \\
\hline & & $\%$ & 54,1 & 58,9 & 58,8 & & & 58,1 & 69,1 & 55,4 & 55,8 & & & 58,1 \\
\hline & \multirow{2}{*}{$\begin{array}{l}\text { Fenótipo } \\
\text { colesterol } \\
\text { LDL } \\
\text { desejável }\end{array}$} & $\mathrm{N}$ & 20 & 44 & 46 & & & 110 & 14 & 51 & 46 & & & 111 \\
\hline & & $\%$ & 32,8 & 26,2 & 35,1 & & & 30,6 & 20,6 & 30,4 & 35,7 & & & 30,4 \\
\hline & Fenótipos & $\mathrm{N}$ & 8 & 25 & 8 & & & 41 & 7 & 24 & 11 & & & 42 \\
\hline & $\begin{array}{l}\text { LDL limítrofe, } \\
\text { moderado e } \\
\text { alto }\end{array}$ & $\%$ & 13,0 & 14,9 & 6,1 & & & 11,4 & 10,3 & 14,3 & 7,8 & & & 11,5 \\
\hline \multirow{2}{*}{ Total } & & $\mathrm{N}$ & 61 & 168 & 131 & & & 360 & 1 & 1 & 1 & & & 365 \\
\hline & & $\%$ & 100 & 100 & 100 & & & 100 & ,3 & ,3 & ,3 & & & 100 \\
\hline
\end{tabular}

FONTE: Dados compilados pelo autor. 
Tabela 16-B - Distribuição dos fenótipos do LDL colesterol nos polimorfismos do AGT (MM x MT +TT) e da ECA (II x DI + DD).

\begin{tabular}{|c|c|c|c|c|c|c|c|c|c|c|c|c|}
\hline \multirow{2}{*}{\multicolumn{3}{|c|}{ Fenótipos }} & \multicolumn{5}{|c|}{ Angiotensinogênio } & \multicolumn{5}{|c|}{ Enzima conversora } \\
\hline & & & \multirow{2}{*}{$\begin{array}{l}\text { MM } \\
33\end{array}$} & \multirow{2}{*}{$\begin{array}{c}\text { MT+ } \\
\text { TT } \\
176\end{array}$} & \multirow{2}{*}{$\mathbf{P}$} & OR & \multirow{2}{*}{$\begin{array}{l}\text { Total } \\
209\end{array}$} & \multirow{2}{*}{$\begin{array}{c}\text { II } \\
47\end{array}$} & \multirow{2}{*}{$\begin{array}{c}\mathrm{DI}+ \\
\mathrm{DD} \\
165\end{array}$} & \multirow{2}{*}{$\mathbf{P}$} & \multirow{2}{*}{ OR } & \multirow{2}{*}{$\begin{array}{l}\text { total } \\
212\end{array}$} \\
\hline \multirow{6}{*}{$\begin{array}{l}\text { Colesterol } \\
\text { LDL }\end{array}$} & Ótimn & $\mathrm{N}$ & & & & \multirow{8}{*}{0,77} & & & & & & \\
\hline & 2) & $\%$ & 54,1 & 58,9 & \multirow{7}{*}{0,21} & & 58,1 & 69,1 & 55,6 & \multirow{7}{*}{0,21} & \multirow{7}{*}{1.43} & 58,1 \\
\hline & Fenótipo colesterol LDL & $\mathrm{N}$ & 20 & 90 & & & 110 & 14 & 97 & & & 111 \\
\hline & desejável & $\%$ & 38,2 & 30,1 & & & 30,6 & 20,6 & 32,7 & & & 30,4 \\
\hline & Fenótipos colesterol & $\mathrm{N}$ & 8 & 33 & & & 41 & 7 & 35 & & & 42 \\
\hline & $\begin{array}{l}\text { LUL IImitroie, moderado } \\
\text { e alto }\end{array}$ & $\%$ & 13,0 & 10,5 & & & 11,4 & 10,2 & 11,0 & & & 11,5 \\
\hline \multirow{2}{*}{\multicolumn{2}{|c|}{ Total }} & $\mathrm{N}$ & 61 & 239 & & & 360 & 68 & 297 & & & 365 \\
\hline & & $\%$ & 100 & 100 & & & 100 & 100 & 100 & & & 100 \\
\hline
\end{tabular}

FONTE: Dados compilados pelo autor.

Tabela 17-A - Distribuição dos fenótipos HDL-colesterol os polimorfismos do AGT e da ECA.

\begin{tabular}{|c|c|c|c|c|c|c|c|c|c|c|c|c|c|c|}
\hline \multirow{2}{*}{\multicolumn{3}{|c|}{ Fenótipos }} & \multicolumn{6}{|c|}{ Angiotensinogênio } & \multicolumn{6}{|c|}{ Enzima conversora } \\
\hline & & & MM & MT & TT & $p$ & OR & Total & II & DI & DD & $p$ & OR & total \\
\hline \multirow{4}{*}{$\begin{array}{l}\text { Colesterol } \\
\text { HDL }\end{array}$} & \multirow{2}{*}{$\begin{array}{l}\text { Baixo e } \\
\text { moderado }\end{array}$} & $\mathrm{N}$ & 26 & 72 & 44 & \multirow{6}{*}{0,30} & & 142 & 31 & 75 & 37 & \multirow{6}{*}{0,008} & & 143 \\
\hline & & P & 41,9 & 42,6 & 32,8 & & & 38,9 & 44,9 & 44,4 & 38,7 & & & 38,7 \\
\hline & \multirow{2}{*}{ Alto } & $\mathrm{N}$ & 36 & 97 & 90 & & & 223 & 38 & 94 & 95 & & & 227 \\
\hline & & $\%$ & 58,1 & 57,4 & 67,2 & & & 61,1 & 55,1 & 55,6 & 61,4 & & & 61,4 \\
\hline \multirow{2}{*}{\multicolumn{2}{|c|}{ Total }} & $\mathrm{N}$ & 62 & 169 & 134 & & & 365 & 69 & 169 & 370 & & & 370 \\
\hline & & $\%$ & 100 & 100 & 100 & & & 100 & 100 & 100 & 100 & & & 100 \\
\hline
\end{tabular}

FONTE: Dados compilados pelo autor.

Tabela 17-B - Distribuição dos fenótipos HDL-Colesterol nos polimorfismos do AGT (MM x MT +TT) e da ECA (II x DI + DD)

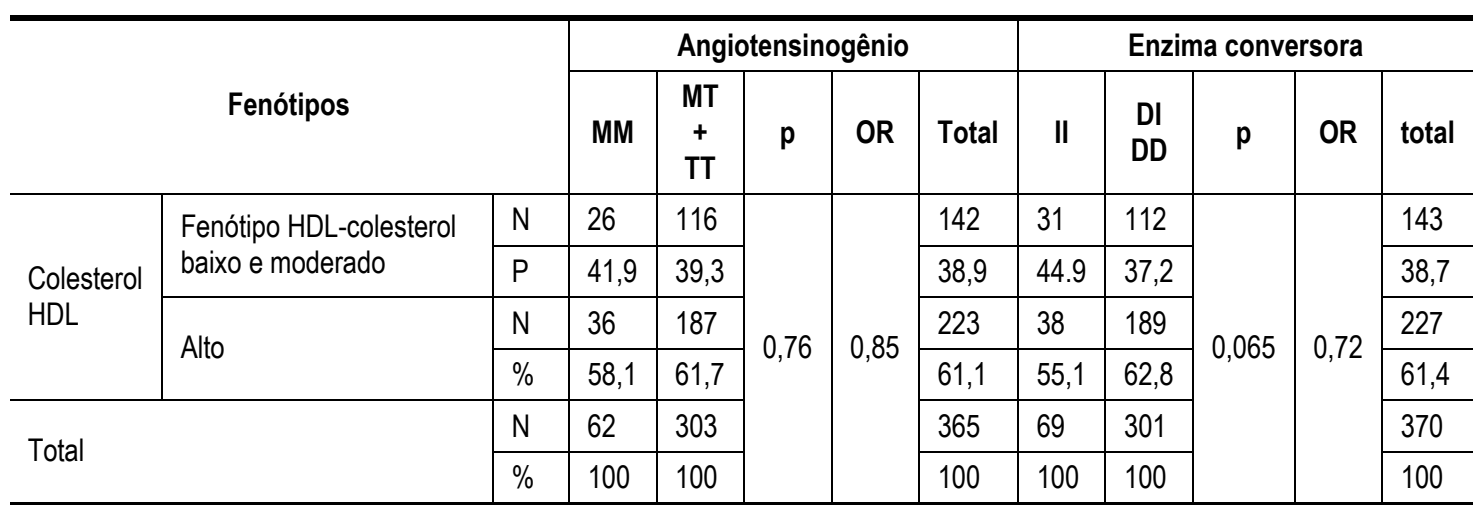

FONTE: Dados compilados pelo autor. 
Tabela 18 - Comparativa entre os dados da população feminina de Salvador (BA) e de Ouro Preto (MG).

\begin{tabular}{|c|c|c|c|c|c|c|c|c|c|c|c|}
\hline \multirow{2}{*}{$\begin{array}{r}\text { ESTUDO } \\
\text { Característica }\end{array}$} & \multicolumn{2}{|c|}{ SALVADOR } & \multicolumn{3}{|c|}{ FSop } & \multicolumn{3}{|c|}{ FDop } & \multicolumn{3}{|c|}{ FPPop } \\
\hline & $S$ & OR & $\%$ & $S$ & OR & $\%$ & $S$ & OR & $\%$ & $S$ & OR \\
\hline Idade anos & & & & & & & & & & & \\
\hline Média & $S$ & 9,8 & 44,9 & $S$ & & 41,4 & $S$ & & 52,9 & $S$ & \\
\hline \multirow{2}{*}{\multicolumn{12}{|c|}{ Raça }} \\
\hline & & & & & & & & & & & \\
\hline Branca & 1,0 & & 40,5 & 1,0 & & 35,1 & 1,0 & & 40,5 & 1,0 & \\
\hline $\mathrm{P} / \mathrm{M}$ & $S$ & 2,00 & 45,7 & NS & 1,20 & 47,1 & NS & 2.10 & 44,9 & NS & 1,10 \\
\hline Preta/negra & $S$ & 2.93 & 60,0 & NS & 2.19 & 51,4 & NS & 2.20 & 60,0 & NS & 2.19 \\
\hline \multicolumn{12}{|l|}{ Escolaridade } \\
\hline Baixa/MB & NS & 4,22 & 71,9 & $S$ & 8,48 & 54,2 & $S$ & 3.10 & 68,8 & S & 5,96 \\
\hline Média & EX & 1,78 & 29,3 & $S$ & 1,34 & 48,8 & $\mathrm{~S}$ & 1,90 & 34,6 & $S$ & 1.54 \\
\hline Alta & 1.0 & & & 1.0 & & & 1.0 & & & 1.0 & \\
\hline \multicolumn{12}{|l|}{ Classe social } \\
\hline Baixa/DE & EX & 1,18 & 53,6 & $S$ & 2.19 & 47,0 & $S$ & 3,50 & 55,7 & $S$ & 1,96 \\
\hline Média/ C & $E X$ & 1.01 & 36,9 & $S$ & 1.97 & 37,6 & $S$ & 1,83 & 39,0 & $S$ & 1,95 \\
\hline Alta / A & 1,0 & & & 1,0 & & & 1,0 & & & 1,0 & \\
\hline \multicolumn{12}{|l|}{ Tabagismo } \\
\hline Sim & EX & & 34,1 & $S$ & 0,5 & 41,2 & SN & 1.0 & 47,1 & NS & 0,9 \\
\hline \multicolumn{12}{|l|}{ Ativi.fisica } \\
\hline Sedentária & NS & 1.5 & 45,8 & NS & 1,1 & 40,7 & SN & 1.2 & 47,2 & NS & 1.0 \\
\hline \multicolumn{12}{|l|}{ SB/Obesidade } \\
\hline $\mid \mathrm{MC}>25$ & $S$ & 3,37 & & & & & & & & & \\
\hline \multicolumn{12}{|l|}{$\mathrm{CC}$ abd } \\
\hline $\operatorname{sim}$ & $S$ & 4,39 & 43,1 & $S$ & 1.38 & 43,6 & $S$ & 1,92 & 48,1 & $S$ & 1,94 \\
\hline \multicolumn{12}{|l|}{ Colesterol } \\
\hline$>240 \mathrm{mg} / \mathrm{dl}$ & NS & NS & 43,8 & $S$ & 1.48 & 40,4 & $S$ & 1,91 & 47,5 & $S$ & 1,22 \\
\hline \multicolumn{12}{|l|}{ LDL-C } \\
\hline$>160 \mathrm{mg} / \mathrm{dl}$ & NS & NS & 43,3 & $S$ & 1,44 & 40,1 & $S$ & 1.90 & 47,3 & $S$ & 1.24 \\
\hline \multicolumn{12}{|l|}{$\mathrm{HDL}-\mathrm{C}$} \\
\hline$\geq 40 \mathrm{mg} / \mathrm{dl}$ & EX & $E X$ & 43,8 & $S$ & 1.46 & 40.4 & $S$ & 1.95 & 47,5 & $S$ & 1.22 \\
\hline \multicolumn{12}{|l|}{ Triglicérides } \\
\hline$\geq 200 \mathrm{mg} / \mathrm{dl}$ & NS & NS & 43,3 & $S$ & 1.44 & 40,1 & $S$ & 1,90 & 47,0 & $S$ & 1,24 \\
\hline \multicolumn{12}{|l|}{ Hiperglicemia } \\
\hline $\operatorname{sim}$ & $S$ & 2,16 & 44,1 & $S$ & 1.43 & 40,6 & $S$ & 1,91 & 47,8 & $S$ & 1,19 \\
\hline
\end{tabular}

LEGENDA: FSop = fenótipo da pressão sistólica aumentada amostra de Ouro Preto; FDop = fenótipo da pressão diastólica aumentada amostra de Ouro Preto; FPPop = fenótipo da pressão de pulso aumentada amostra de Ouro Preto; $\mathrm{P} / \mathrm{M}=$ etnias e cor de pele parda e morena; Preta/negra = etnias e cor de pele preta-negra; Baixa /MB = escolaridade baixa e muito baixa; Baixa/DE= classe social baixa/ e classes sociais DE; Média/C = classe social; Alta/A classe social; SB/OBESIDADE = sobrepeso e obesidade; IMC = índice de massa corporal; CCabd = circunferência da cintura abdominal; LDL-C = colesterol LDL; HDL-C = colesterol HDL; $S=$ significância estatística $(p<0,05)$; NS = não significante EX = excluído.

FONTE: Dados compilados pelo autor e referência 22. 
Tabela 19 - Características demográficas socioeconômicas análises clinícas e antropométricas da amostra feminina projeto corações de Ouro Preto.

\begin{tabular}{|c|c|c|c|c|}
\hline Características & $\mathrm{n}$ & percentual & Média e desvio-padrão & IC (95\% Int. médias) \\
\hline Tabagismo & 88 & $22,7 \%$ & & \\
\hline Sedentarismo & 300 & $78,5 \%$ & & \\
\hline Brancas & 112 & $29,3 \%$ & & \\
\hline Morenas claras & 139 & $36,8 \%$ & & \\
\hline Morenas escuras & 89 & $23,3 \%$ & & \\
\hline Pretas & 38 & $9,9 \%$ & & \\
\hline Classe social $A B$ & 46 & $11,0 \%$ & & \\
\hline Classe social C & 143 & $37,0 \%$ & & \\
\hline Classe social DE & 187 & $48,4 \%$ & & \\
\hline Escolaridade muito baixa & 98 & $25,3 \%$ & & \\
\hline Escolaridade baixa & 123 & $31,8 \%$ & & \\
\hline Escolaridade média & 41 & $10,6 \%$ & & \\
\hline Escolaridade alta & 119 & $30,8 \%$ & & \\
\hline Glicemia > 110 mg/dl & 60 & $15,7 \%$ & $99,01 \pm 24,5$ & $(96,4-101,5)$ \\
\hline Colesterol total $>200 \mathrm{mg} / \mathrm{dl}$ & 24 & $6,3 \%$ & $182,96 \pm 37,9$ & $(179,0-186,8)$ \\
\hline Colesterol HDL $<40 \mathrm{mg} / \mathrm{dl}$ & 147 & $37,5 \%$ & $65,14 \pm 12,5$ & $(63,7-66,4)$ \\
\hline Colesterol LDL > 130 mg/dl & 43 & $11,3 \%$ & $95,88 \pm 27,4$ & $(92,6-98,2)$ \\
\hline Triglicérides > 150 mg/dl & 32 & $8,8 \%$ & $110,50 \pm 68,5$ & $(103,4-117,6)$ \\
\hline Idade & 386 & $100 \%$ & $45,11 \pm 16,20$ & $(43,4-46,7)$ \\
\hline Índice de massa corporal >25 kg/m² & 208 & $53,5 \%$ & $26,0 \pm 5,3$ & $(25,5-26,6)$ \\
\hline Circunferência da cintura abdominal $>88 \mathrm{~cm}$ & 127 & $33,5 \%$ & $87,1 \pm 10,7$ & $(83,1-86,0)$ \\
\hline Pressão arterial sistólica média & 386 & $100 \%$ & $135,21 \pm 26,7$ & $(132,5-137,9)$ \\
\hline Pressão arterial diastólica média & 386 & $100 \%$ & $84,69 \pm 14,3$ & $(83,2-86,0)$ \\
\hline Pressão de pulso média pressão de pulso média & 386 & $100 \%$ & $50,55 \pm 17,7$ & $(48,7-52,4)$ \\
\hline
\end{tabular}

FONTE: Dados compilados pelo autor. 


\section{APÊNDICE I - Tabelas}

\section{Oneway - TABELA FENÓTIPO DIASTÓLICO}

\begin{tabular}{|c|c|c|c|c|c|c|c|c|}
\hline & & \multirow[t]{2}{*}{ N } & \multirow[t]{2}{*}{ Mean } & \multirow{2}{*}{$\begin{array}{c}\text { Std. } \\
\text { Deviation }\end{array}$} & \multicolumn{2}{|c|}{$\begin{array}{l}95 \% \text { Confidence Interval } \\
\text { for Mean }\end{array}$} & \multirow[t]{2}{*}{ Minimum } & \multirow[t]{2}{*}{ Maximum } \\
\hline & & & & & Lower Bound & Upper Bound & & \\
\hline \multirow{3}{*}{ idade } & normotenso & 219 & 39,9361 & 16,11756 & 37,7895 & 42,0826 & 18,00 & 82,00 \\
\hline & hipertensão diastólica & 157 & 52,3885 & 13,37844 & 50,2795 & 54,4976 & 18,00 & 94,00 \\
\hline & Total & 376 & 45,1356 & 16,22608 & 43,4902 & 46,7810 & 18,00 & 94,00 \\
\hline \multirow{3}{*}{$\begin{array}{l}\text { Circunferência da } \\
\text { cintura } \\
\text { (abdominal) }\end{array}$} & normotenso & 206 & 80,619 & 13,4918 & 78,766 & 82,472 & 54,0 & 133,0 \\
\hline & hipertensão diastólica & 151 & 90,046 & 13,1154 & 87,937 & 92,155 & 55,0 & 140,0 \\
\hline & Total & 357 & 84,606 & 14,1085 & 83,138 & 86,075 & 54,0 & 140,0 \\
\hline \multirow{3}{*}{ Glicose Metodo: } & normotenso & 211 & 93,89 & 17,439 & 91,52 & 96,26 & 62 & 228 \\
\hline & hipertensão diastólica & 153 & 106,08 & 30,578 & 101,19 & 110,96 & 77 & 297 \\
\hline & Total & 364 & 99,01 & 24,572 & 96,48 & 101,55 & 62 & 297 \\
\hline \multirow{3}{*}{ coltot } & normotenso & 212 & 176,82 & 37,753 & 171,70 & 181,93 & 103 & 319 \\
\hline & hipertensão diastólica & 152 & 191,54 & 36,564 & 185,68 & 197,40 & 109 & 328 \\
\hline & Total & 364 & 182,96 & 37,914 & 179,06 & 186,87 & 103 & 328 \\
\hline \multirow{3}{*}{ hdl } & normotenso & 212 & 64,18 & 12,210 & 62,53 & 65,83 & 41 & 129 \\
\hline & hipertensão diastólica & 152 & 66,49 & 12,862 & 64,43 & 68,55 & 17 & 123 \\
\hline & Total & 364 & 65,14 & 12,521 & 63,85 & 66,43 & 17 & 129 \\
\hline \multirow{3}{*}{ Idl } & normotenso & 208 & 93,24 & 27,065 & 89,54 & 96,94 & 46 & 215 \\
\hline & hipertensão diastólica & 151 & 98,40 & 26,984 & 94,06 & 102,74 & 17 & 178 \\
\hline & Total & 359 & 95,41 & 27,114 & 92,60 & 98,22 & 17 & 215 \\
\hline \multirow{3}{*}{ trig } & normotenso & 210 & 94,48 & 56,684 & 86,77 & 102,19 & 26 & 555 \\
\hline & hipertensão diastólica & 151 & 132,79 & 77,082 & 120,40 & 145,19 & 35 & 395 \\
\hline & Total & 361 & 110,50 & 68,551 & 103,41 & 117,60 & 26 & 555 \\
\hline
\end{tabular}

Test of Homogeneity of Variances

\begin{tabular}{|l|l|l||l|l|}
\hline & \multicolumn{1}{|c|}{ Levene Statistic } & df1 & \multicolumn{1}{c|}{ df2 } & Sig. \\
\hline idade & 5,277 & 1 & 374 &, 022 \\
\hline Circunferência da cintura (abdominal) &, 023 & 1 & 355 &, 879 \\
\hline Glicose Metodo: & 14,006 & 1 & 362 &, 000 \\
\hline coltot &, 169 & 1 & 362 &, 681 \\
\hline hdl &, 095 & 1 & 362 &, 758 \\
\hline Idl &, 006 & 1 & 357 &, 940 \\
\hline trig & 17,639 & 1 & 359 &, 000 \\
\hline
\end{tabular}




\begin{tabular}{|c|c|c|c|c|c|c|}
\hline \multicolumn{7}{|l|}{ ANOVA } \\
\hline & & Sum of Squares & df & Mean Square & $\mathrm{F}$ & Sig. \\
\hline \multirow{3}{*}{ idade } & Between Groups & 14179,678 & 1 & 14179,678 & 62,721 & ,000 \\
\hline & Within Groups & 84552,404 & 374 & 226,076 & & \\
\hline & Total & 98732,082 & 375 & & & \\
\hline \multirow{3}{*}{ Circunferencia da cintura (abdominal) } & Between Groups & 7743,944 & 1 & 7743,944 & 43,555 & ,000 \\
\hline & Within Groups & 63118,012 & 355 & 177,797 & & \\
\hline & Total & 70861,955 & 356 & & & \\
\hline \multirow{3}{*}{ Glicose Metodo: } & Between Groups & 13173,380 & 1 & 13173,380 & 23,150 & ,000 \\
\hline & Within Groups & 205991,552 & 362 & 569,037 & & \\
\hline & Total & 219164,931 & 363 & & & \\
\hline \multirow{3}{*}{ coltot } & Between Groups & 19190,947 & 1 & 19190,947 & 13,822 & ,000 \\
\hline & Within Groups & 502621,589 & 362 & 1388,457 & & \\
\hline & Total & 521812,536 & 363 & & & \\
\hline \multirow{3}{*}{ hdl } & Between Groups & 471,409 & 1 & 471,409 & 3,024 & ,083 \\
\hline & Within Groups & 56435,162 & 362 & 155,898 & & \\
\hline & Total & 56906,571 & 363 & & & \\
\hline \multirow{3}{*}{ Idl } & Between Groups & 2336,993 & 1 & 2336,993 & 3,198 & 075 \\
\hline & Within Groups & 260855,814 & 357 & 730,689 & & \\
\hline & Total & 263192,808 & 358 & & & \\
\hline \multirow{3}{*}{ trig } & Between Groups & 128975,227 & 1 & 128975,227 & 29,628 & ,000 \\
\hline & Within Groups & 1562767,017 & 359 & 4353,111 & & \\
\hline & Total & 1691742,244 & 360 & & & \\
\hline
\end{tabular}




\section{Oneway - TABELA UNIVARIADA DO FENÓTIPO SISTÓLICO}

\begin{tabular}{|c|c|c|c|c|c|c|c|c|}
\hline & & \multirow{2}{*}{$\mathbf{N}$} & \multirow{2}{*}{ Mean } & \multirow{2}{*}{$\begin{array}{r}\text { Std. } \\
\text { Deviation }\end{array}$} & \multicolumn{2}{|c|}{$\begin{array}{l}95 \% \text { Confidence } \\
\text { Interval for Mean }\end{array}$} & \multirow{2}{*}{ Minimum } & \multirow{2}{*}{ Maximum } \\
\hline & & & & & $\begin{array}{l}\text { Lower } \\
\text { Bound }\end{array}$ & $\begin{array}{l}\text { Upper } \\
\text { Bound }\end{array}$ & & \\
\hline \multirow{3}{*}{ idade } & normotenso & 207 & 35,8841 & 11,93128 & 34,2491 & 37,5190 & 18,00 & 79,00 \\
\hline & hipertensão sistólica & 169 & 56,4675 & 13,36041 & 54,4385 & 58,4964 & 20,00 & 94,00 \\
\hline & Total & 376 & 45,1356 & 16,22608 & 43,4902 & 46,7810 & 18,00 & 94,00 \\
\hline \multirow{3}{*}{$\begin{array}{l}\text { Circunferência da } \\
\text { cintura } \\
\text { (abdominal) }\end{array}$} & normotenso & 193 & 80,676 & 12,8025 & 78,859 & 82,494 & 57,0 & 125,0 \\
\hline & hipertensão sistólica & 164 & 89,232 & 14,2076 & 87,041 & 91,422 & 54,0 & 140,0 \\
\hline & Total & 357 & 84,606 & 14,1085 & 83,138 & 86,075 & 54,0 & 140,0 \\
\hline \multirow{3}{*}{ Glicose Metodo: } & normotenso & 198 & 93,68 & 21,152 & 90,71 & 96,64 & 62 & 281 \\
\hline & hipertensão sistólica & 166 & 105,38 & 26,817 & 101,27 & 109,49 & 67 & 297 \\
\hline & Total & 364 & 99,01 & 24,572 & 96,48 & 101,55 & 62 & 297 \\
\hline \multirow{3}{*}{ coltot } & normotenso & 199 & 175,73 & 36,437 & 170,64 & 180,83 & 103 & 328 \\
\hline & hipertensão sistólica & 165 & 191,68 & 37,933 & 185,85 & 197,52 & 109 & 311 \\
\hline & Total & 364 & 182,96 & 37,914 & 179,06 & 186,87 & 103 & 328 \\
\hline \multirow{3}{*}{ hdl } & normotenso & 199 & 63,81 & 11,520 & 62,20 & 65,42 & 41 & 113 \\
\hline & hipertensão sistólica & 165 & 66,75 & 13,490 & 64,68 & 68,83 & 17 & 129 \\
\hline & Total & 364 & 65,14 & 12,521 & 63,85 & 66,43 & 17 & 129 \\
\hline \multirow{3}{*}{ Idl } & normotenso & 196 & 92,53 & 26,676 & 88,77 & 96,28 & 46 & 215 \\
\hline & hipertensão sistólica & 163 & 98,88 & 27,311 & 94,65 & 103,10 & 17 & 178 \\
\hline & Total & 359 & 95,41 & 27,114 & 92,60 & 98,22 & 17 & 215 \\
\hline \multirow{3}{*}{ trig } & normotenso & 198 & 97,12 & 67,884 & 87,60 & 106,63 & 26 & 555 \\
\hline & hipertensão sistólica & 163 & 126,77 & 65,984 & 116,56 & 136,97 & 35 & 395 \\
\hline & Total & 361 & 110,50 & 68,551 & 103,41 & 117,60 & 26 & 555 \\
\hline
\end{tabular}

\begin{tabular}{|c|c|c|c|c|}
\hline \multicolumn{5}{|l|}{ Test of Homogeneity of Variances } \\
\hline & Levene Statistic & df1 & df2 & Sig. \\
\hline idade & 3,215 & 1 & 374 & ,074 \\
\hline Circunferência da cintura (abdominal) & 2,079 & 1 & 355 & ,150 \\
\hline Glicose Metodo: & 8,162 & 1 & 362 & ,005 \\
\hline coltot & 1,084 & 1 & 362 & ,298 \\
\hline hdl & ,927 & 1 & 362 &, 336 \\
\hline Idl & 144 & 1 & 357 & ,705 \\
\hline trig & ,984 & 1 & 359 & ,322 \\
\hline
\end{tabular}




\begin{tabular}{|c|c|c|c|c|c|c|}
\hline \multicolumn{7}{|l|}{ ANOVA } \\
\hline & & Sum of Squares & df & $\begin{array}{l}\text { Mean } \\
\text { Square }\end{array}$ & $F$ & Sig. \\
\hline \multirow{3}{*}{ idade } & Between Groups & 39418,794 & 1 & 39418,794 & 248,555 & ,000 \\
\hline & Within Groups & 59313,288 & 374 & 158,592 & & \\
\hline & Total & 98732,082 & 375 & & & \\
\hline \multirow{3}{*}{$\begin{array}{l}\text { Circunferencia da cintura } \\
\text { (abdominal) }\end{array}$} & Between Groups & 6489,750 & 1 & 6489,750 & 35,790 & ,000 \\
\hline & Within Groups & 64372,205 & 355 & 181,330 & & \\
\hline & Total & 70861,955 & 356 & & & \\
\hline \multirow{3}{*}{ Glicose Metodo: } & Between Groups & 12366,528 & 1 & 12366,528 & 21,648 & ,000 \\
\hline & Within Groups & 206798,403 & 362 & 571,266 & & \\
\hline & Total & 219164,931 & 363 & & & \\
\hline \multirow{3}{*}{ coltot } & Between Groups & 22952,039 & 1 & 22952,039 & 16,655 &, 000 \\
\hline & Within Groups & 498860,497 & 362 & 1378,068 & & \\
\hline & Total & 521812,536 & 363 & & & \\
\hline \multirow{3}{*}{ hdl } & Between Groups & 781,016 & 1 & 781,016 & 5,037 & ,025 \\
\hline & Within Groups & 56125,556 & 362 & 155,043 & & \\
\hline & Total & 56906,571 & 363 & & & \\
\hline \multirow{3}{*}{$|d|$} & Between Groups & 3590,389 & 1 & 3590,389 & 4,937 & ,027 \\
\hline & Within Groups & 259602,418 & 357 & 727,178 & & \\
\hline & Total & 263192,808 & 358 & & & \\
\hline \multirow{3}{*}{ trig } & Between Groups & 78598,774 & 1 & 78598,774 & 17,492 &, 000 \\
\hline & Within Groups & 1613143,469 & 359 & 4493,436 & & \\
\hline & Total & 1691742,244 & 360 & & & \\
\hline
\end{tabular}




\section{Oneway - FENÓTIPO PRESSÃO DE PULSO}

\begin{tabular}{|c|c|c|c|c|c|c|c|c|c|}
\hline \multicolumn{10}{|l|}{ Descriptives } \\
\hline & & \multirow{2}{*}{$\mathbf{N}$} & \multirow{2}{*}{ Mean } & \multirow{2}{*}{$\begin{array}{c}\text { Std. } \\
\text { Deviation }\end{array}$} & \multirow{2}{*}{$\begin{array}{l}\text { Std. } \\
\text { Error }\end{array}$} & \multicolumn{2}{|c|}{$\begin{array}{l}95 \% \text { Confidence Interval } \\
\text { for Mean }\end{array}$} & \multirow{2}{*}{ Minimum } & \multirow{2}{*}{ Maximum } \\
\hline & & & & & & $\begin{array}{l}\text { Lower } \\
\text { Bound }\end{array}$ & $\begin{array}{l}\text { Upper } \\
\text { Bound }\end{array}$ & & \\
\hline \multirow{3}{*}{ idade } & normal & 199 & 36,5477 & 11,61793 & ,82357 & 34,9236 & 38,1718 & 18,00 & 73,00 \\
\hline & aumentada & 177 & 54,7910 & 15,23104 & 1,14483 & 52,5316 & 57,0503 & 18,00 & 94,00 \\
\hline & Total & 376 & 45,1356 & 16,22608 & ,83680 & 43,4902 & 46,7810 & 18,00 & 94,00 \\
\hline \multirow{3}{*}{$\begin{array}{l}\text { Circunferência } \\
\text { da cintura } \\
\text { (abdominal) }\end{array}$} & normal & 185 & 81,446 & 12,8159 & ,9422 & 79,587 & 83,305 & 55,0 & 125,0 \\
\hline & aumentada & 172 & 88,006 & 14,6709 & 1,1186 & 85,798 & 90,214 & 54,0 & 140,0 \\
\hline & Total & 357 & 84,606 & 14,1085 & ,7467 & 83,138 & 86,075 & 54,0 & 140,0 \\
\hline \multirow{3}{*}{ Glicose Metodo: } & normal & 190 & 94,42 & 19,279 & 1,399 & 91,66 & 97,18 & 68 & 281 \\
\hline & aumentada & 174 & 104,03 & 28,501 & 2,161 & 99,76 & 108,29 & 62 & 297 \\
\hline & Total & 364 & 99,01 & 24,572 & 1,288 & 96,48 & 101,55 & 62 & 297 \\
\hline \multirow{3}{*}{ coltot } & normal & 191 & 175,38 & 33,031 & 2,390 & 170,66 & 180,09 & 103 & 328 \\
\hline & aumentada & 173 & 191,34 & 41,159 & 3,129 & 185,16 & 197,52 & 109 & 319 \\
\hline & Total & 364 & 182,96 & 37,914 & 1,987 & 179,06 & 186,87 & 103 & 328 \\
\hline \multirow{3}{*}{ hdl } & normal & 191 & 63,51 & 11,616 & 841 & 61,85 & 65,17 & 41 & 113 \\
\hline & aumentada & 173 & 66,95 & 13,250 & 1,007 & 64,96 & 68,94 & 17 & 129 \\
\hline & Total & 364 & 65,14 & 12,521 & ,656 & 63,85 & 66,43 & 17 & 129 \\
\hline \multirow{3}{*}{$|d|$} & normal & 189 & 91,94 & 24,695 & 1,796 & 88,39 & 95,48 & 46 & 167 \\
\hline & aumentada & 170 & 99,27 & 29,162 & 2,237 & 94,86 & 103,69 & 17 & 215 \\
\hline & Total & 359 & 95,41 & 27,114 & 1,431 & 92,60 & 98,22 & 17 & 215 \\
\hline \multirow{3}{*}{ trig } & normal & 191 & 102,31 & 70,098 & 5,072 & 92,31 & 112,32 & 26 & 555 \\
\hline & aumentada & 170 & 119,71 & 65,765 & 5,044 & 109,75 & 129,66 & 35 & 395 \\
\hline & Total & 361 & 110,50 & 68,551 & 3,608 & 103,41 & 117,60 & 26 & 555 \\
\hline
\end{tabular}

Test of Homogeneity of Variances

\begin{tabular}{|l|l|l|l|l|}
\hline & \multicolumn{1}{|c|}{ Levene Statistic } & df1 & df2 & Sig. \\
\hline idade & 13,880 & 1 & 374 &, 000 \\
\hline Circunferência da cintura (abdominal) & 3,455 & 1 & 355 &, 064 \\
\hline Glicose Metodo: & 12,358 & 1 & 362 &, 000 \\
\hline coltot & 9,986 & 1 & 362 &, 002 \\
\hline hdl &, 407 & 1 & 362 &, 524 \\
\hline Idl & 3,134 & 1 & 357 &, 078 \\
\hline trig &, 216 & 1 & 359 &, 642 \\
\hline
\end{tabular}




\begin{tabular}{|c|c|c|c|c|c|c|}
\hline \multicolumn{7}{|l|}{ ANOVA } \\
\hline & & Sum of Squares & df & Mean Square & $\mathbf{F}$ & Sig. \\
\hline \multirow{3}{*}{ idade } & Between Groups & 31177,520 & 1 & 31177,520 & 172,607 &, 000 \\
\hline & Within Groups & 67554,562 & 374 & 180,627 & & \\
\hline & Total & 98732,082 & 375 & & & \\
\hline \multirow{3}{*}{ Circunferencia da cintura (abdominal) } & Between Groups & 3835,502 & 1 & 3835,502 & 20,314 &, 000 \\
\hline & Within Groups & 67026,454 & 355 & 188,807 & & \\
\hline & Total & 70861,955 & 356 & & & \\
\hline \multirow{3}{*}{ Glicose Metodo: } & Between Groups & 8383,759 & 1 & 8383,759 & 14,398 & 000 \\
\hline & Within Groups & 210781,172 & 362 & 582,268 & & \\
\hline & Total & 219164,931 & 363 & & & \\
\hline \multirow{3}{*}{ coltot } & Between Groups & 23134,798 & 1 & 23134,798 & 16,794 &, 000 \\
\hline & Within Groups & 498677,737 & 362 & 1377,563 & & \\
\hline & Total & 521812,536 & 363 & & & \\
\hline \multirow{3}{*}{ hdl } & Between Groups & 1074,301 & 1 & 1074,301 & 6,965 & ,009 \\
\hline & Within Groups & 55832,270 & 362 & 154,233 & & \\
\hline & Total & 56906,571 & 363 & & & \\
\hline \multirow{3}{*}{$|d|$} & Between Groups & 4814,017 & 1 & 4814,017 & 6,651 & ,010 \\
\hline & Within Groups & 258378,791 & 357 & 723,750 & & \\
\hline & Total & 263192,808 & 358 & & & \\
\hline \multirow{3}{*}{ trig } & Between Groups & 27205,798 & 1 & 27205,798 & 5,868 & , 016 \\
\hline & Within Groups & 1664536,446 & 359 & 4636,592 & & \\
\hline & Total & 1691742,244 & 360 & & & \\
\hline
\end{tabular}


Distribuição dos alelos (M e T) do AGT e (D e I) da ECA nos

fenótipos sistólico, diastólico e pressão de pulso.

\begin{tabular}{|c|c|c|c|c|c|c|c|c|c|c|c|}
\hline \multirow{2}{*}{\multicolumn{2}{|c|}{$\begin{array}{c}\text { Pressão arterial } \\
\text { Fenótipo }\end{array}$}} & \multicolumn{5}{|c|}{ AGT } & \multicolumn{5}{|c|}{ ECA } \\
\hline & & M & $\mathbf{T}$ & $\mathbf{P}$ & OR & Total & I & D & $\mathbf{P}$ & OR & Total \\
\hline \multirow{2}{*}{ Sistólico normal } & $\mathrm{N}$ & 170 & 248 & \multirow{4}{*}{0,77} & \multirow{2}{*}{1,04} & 418 & 168 & 254 & \multirow{4}{*}{0,41} & \multirow{2}{*}{0,88} & 422 \\
\hline & $\%$ & $40,7 \%$ & $59,3 \%$ & & & 100,0 & $39,8 \%$ & $60,2 \%$ & & & 100,0 \\
\hline \multirow{2}{*}{ Sistólico aumentado } & $\mathrm{N}$ & 134 & 204 & & \multirow{2}{*}{$\begin{array}{l}\text { IC } \\
0,7-1,3\end{array}$} & 338 & 147 & 197 & & \multirow{2}{*}{$\begin{array}{l}\text { IC } \\
0,6-1,1\end{array}$} & 344 \\
\hline & $\%$ & $39,6 \%$ & $60,4 \%$ & & & 100,0 & $42,7 \%$ & $57,3 \%$ & & & 100,0 \\
\hline \multirow{2}{*}{ Total } & $\mathrm{N}$ & 304 & 452 & & & 756 & 315 & 451 & & & 766 \\
\hline & $\%$ & $40,2 \%$ & $59,8 \%$ & & & 100,0 & $41,1 \%$ & $58,9 \%$ & & & 100,0 \\
\hline \multirow{2}{*}{ Diastólico normal } & $\mathrm{N}$ & 183 & 259 & \multirow{4}{*}{0,42} & \multirow{2}{*}{1,12} & 442 & 186 & 260 & \multirow{4}{*}{0,69} & \multirow{4}{*}{$\begin{array}{l}1,05 \\
\text { IC } \\
0,7-1,4\end{array}$} & 446 \\
\hline & $\%$ & $41,4 \%$ & $58,6 \%$ & & & 100,0 & $41,7 \%$ & $58,3 \%$ & & & 100,0 \\
\hline \multirow{2}{*}{ Diastólico aumentado } & $\mathrm{N}$ & 121 & 193 & & \multirow{2}{*}{$\begin{array}{l}\text { IC } \\
0,8-1,5\end{array}$} & 314 & 129 & 191 & & & 320 \\
\hline & $\%$ & $38,5 \%$ & $61,5 \%$ & & & 100,0 & $40,3 \%$ & $59,7 \%$ & & & 100,0 \\
\hline \multirow{2}{*}{ Total } & $\mathrm{N}$ & 304 & 452 & & & 756 & 315 & 451 & & & 766 \\
\hline & $\%$ & $40,2 \%$ & $59,8 \%$ & & & 100,0 & $41,1 \%$ & $58,9 \%$ & & & 100,0 \\
\hline \multirow{2}{*}{ Pressão pulso normal } & $\mathrm{N}$ & 164 & 234 & \multirow{4}{*}{0,55} & \multirow{4}{*}{$\begin{array}{l}1,09 \\
\text { IC } \\
0,8-1,4\end{array}$} & 398 & 172 & 232 & \multirow{4}{*}{0,38} & \multirow{4}{*}{$\begin{array}{l}1,13 \\
\text { IC } \\
0,8-1,5\end{array}$} & 404 \\
\hline & $\%$ & $41,2 \%$ & $58,8 \%$ & & & 100,0 & $42,6 \%$ & $57,4 \%$ & & & 100,0 \\
\hline \multirow{2}{*}{ Pressão pulso aumentada } & $\mathrm{N}$ & 140 & 218 & & & 398 & 143 & 219 & & & 362 \\
\hline & $\%$ & $39,1 \%$ & $60,9 \%$ & & & $100,0 \%$ & $39,5 \%$ & $60,5 \%$ & & & 100,0 \\
\hline \multirow{2}{*}{ Total } & $\mathrm{N}$ & 304 & 452 & & & 756 & 315 & 451 & & & 766 \\
\hline & $\%$ & $40,2 \%$ & $59,8 \%$ & & & 100 & $41,4 \%$ & $58,9 \%$ & & & 100 \\
\hline
\end{tabular}


Distribuição dos alelos do AGT e ECA nos fenótipos idade e cor da pele

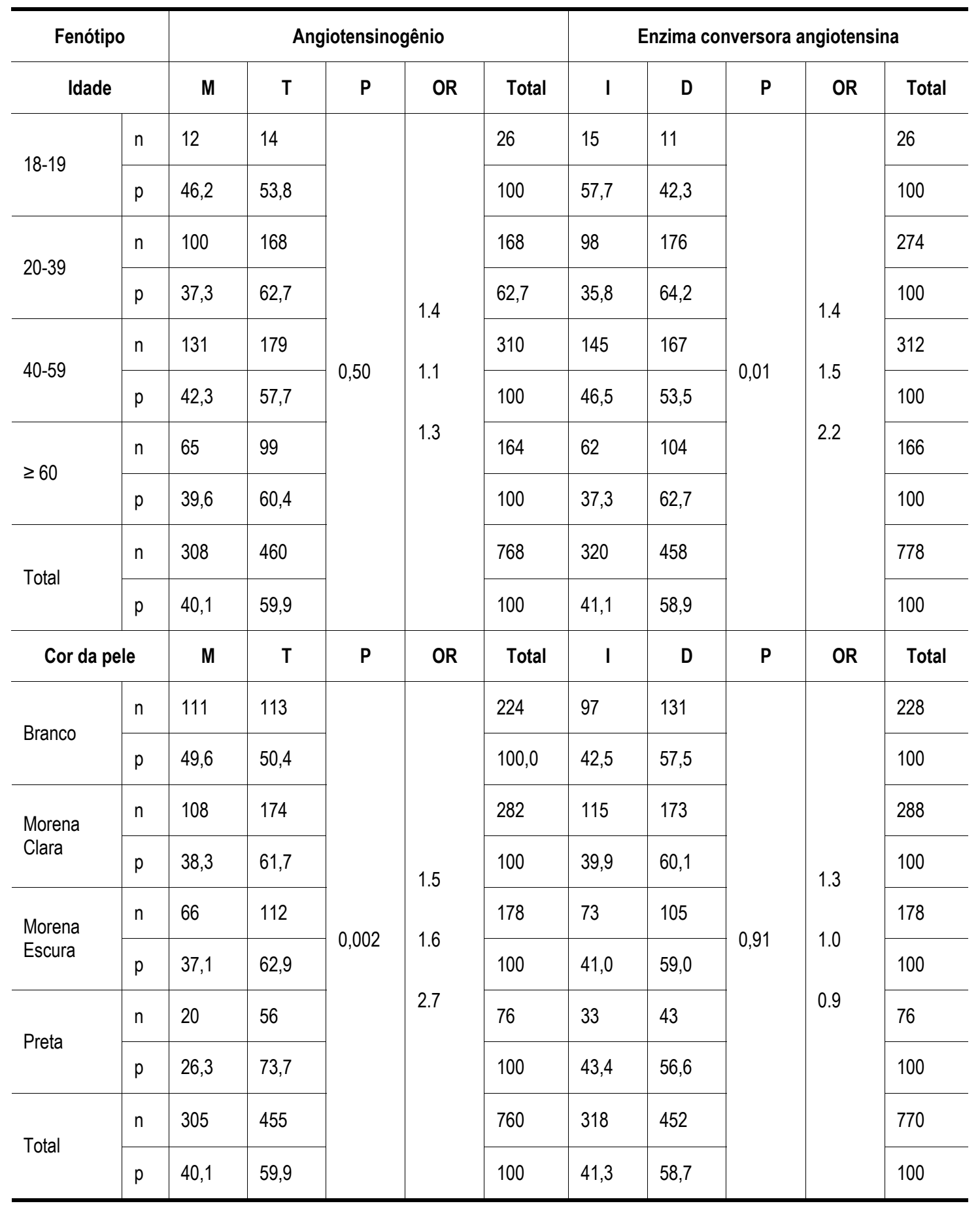




\title{
APÊNDICE II - Projeto “Corações de Ouro Preto"
}

\author{
Artigo Original
}

\section{Risco Nutricional na População Urbana de Ouro Preto, Sudeste do Brasil: Estudo de Corações de Ouro Preto}

Nutricional Risk in the Unan Population of Ouro Preto, Southeastern Region of Brazil: The Ouro Preto Heart Study

Silvia Nascimento de Freitas, Waleska Teixeira Caiaffa, Cibele Comini César, Vatéria Andrade Faria, Raimundo Marques do Nascimento, George Luiz Lins Machado Coelho

Universidade Federal de Ouro Preto, Universidade Federal de Minas Ceraise instituto de Hipertensão Arterial - Belo Horizonte - Ouro Preto, MC

Resumo

Objetivo: Estimar a prevalência do risco nutricional combinado [índice de massa corporal (IMC) e circunferência da cintura (CC)] segundo as características sócio-demográficas e sedentarismo, da população urbana residente em Ouro Preto (MG), Brasil.

Métodos: Estudo transversal foi realizado em uma amostra probabilística de 768 indivíduos com 15 ou mais anos de idade. Risco nutricion al (RN) foi definido de acordo com os critérios de dassificação do IMC e CC do National Institutes of Health, classificando-se em RN isolado (RNI) as mulheres com $\mathrm{CC} \geq 80 \mathrm{~cm}$ e homens $\mathrm{CC} \geq 94 \mathrm{~cm}$ e combinado (RNC) (CC acima e/ou MC $\geq 25 \mathrm{~kg} / \mathrm{m}^{2}$ ). Regressão logística binária e teste de Hosmer \& Lemeshow foram utilizados para construir e ajustar os modelos.

Resultados: O RNI esteve presente nas diferentes categorias de IMC tanto para mulheres quanto para homens, sendo de $19,1 \%$ e 1,4\% entre aqueles com peso normal; $91,7 \%$ e $56 \%$ com sobrepeso e $98,5 \%$ e $80 \%$ com obesidade, respectivamente. Idade e escolarid ade associaram-se de forma independente ao RNC. Mulheres e homens acima de 60 anos apresentavam, respectivamente, Odds Ratio (OR) de RNC de 9,94 e 14,35, quando comparados aos mais jovens. Para mulheres com escolaridade $\leq 4$ anos, a $O R$ foi de 1,83 quando comparadas àquelas com mais de 4 anos e, em homens de média escolaridade, de 2,55 em relação aos de alta.

Conclu são: Estes achados mostram o efeito independente da idade e escolaridade na probabilidade de ocorrência do RNC e a importância da análise conjunta do IMC e CC para a seleção de grupos em risco nutricional.

Palavras-chave: sobrepeso, obesidade, índice de massa corporal, circunferência abdominal, prevalência.

\section{Summary}

Objective: To estimate the prevalence of combined nutritional risk (body mass index (BMI) and waist circumference (WC)] according to sociodemographic and sedentarism characteristics of the urban poputation of Ouro Preto, state of Minas Cerais, Brazil.

Methods: This cross-sectional study was conducted with a probability sampling of 768 subjects aged 15 years or older. Nutritional risk (NR) was defined according to the BMt and WC dassification criteria adopted by the National institutes of Health. Isolated NR (NNR) was defined as women with WC $\geq 80 \mathrm{~cm}$ and men with WC $\geq 94 \mathrm{~cm}$, and the combined nutpitional risk (CNR) as the same WC values mentioned above and/or $B M I \geq 25 \mathrm{~kg} / \mathrm{m}^{2}$. Binary logistic regression and the Hosmer \& temeshow test were used to construct and adjust these models.

Results: $\mathbb{N}$ R was observed in several BMI categories for both women and men, with the following results: $19.1 \%$ and $1.4 \%$ among those with normal weight $91.7 \%$ and $56 \%$ in ovenweight patients, and $98.5 \%$ and $80 \%$ in obese patients, respectively. Age and level of education were independently associated with the ONR. Odds ratios (OR) for ONR in women and men over 60 years of age were 9.94 and 74.35 , respectively, when compared to younger patients. For women with $\leq 4$ years of schooling, the OR was 7.83 compared to patients with more than 4 years of school attendance, while among men with an average number of years of school attendance, the OR was 2.55 relative to those with more years of schooling.

Conclusion: These findings show that age and education have an independent effect on the probability of CNR occurrence, and also that a joint analysis of BMl and WC is important in screening groups for nutritional risk.

Key words: Overweight; obesity; body mass index; abdominal circ umference; prevalence.

Correspondêndia: George Luiz Lins Machado Coelho •

E-mail: gmcoelho@ef.ufop br

Artigo recebido em 23/01/06; revisado recebido em 29/03/06; aceito em 1/06/06. 


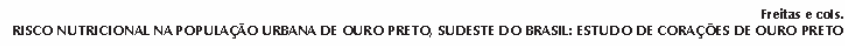

Artigo Original

combined body mass index and waist dircumference. Obes Res. 2003; 11

8. Frankenfield DC, RoweWA, Cooney RN, Smith JS, Becker D. Limits of body massindextodetect chesity and predict body oomposition. Nutrition. 2001; $17: 26-30$.

9. Bigaard J, Tjonneland A, Thomsen BL, Overad K, Heitmann BL, Sorensenet TIA. Waist circumference, BMI, sm oking, and mortal ity in middle-aged men and women. Obes Res, 2003;11/7):895-903.

10. Olinto MTA, Nacul LC, Gigante DP, Costa JSD, Menezes AMB, Macedo S. Waist circumference as a determinant of hypertension and diabetes in Brazilian women: a population-based study. Public Health Nutr. 2004, 7 (5):

11. Velásquez-Meléndez $\mathrm{C}$, Kac $\mathrm{C}$, Val ente $\mathrm{C}$, Tavares $R$, Silva CQ, Carcia ES. Evaluation of waist dircumferen oeto predictgen eral obesty and hypetension in women in great metropolitan Belo or orizonte, Brazil. Cad Saude Páblica.

12.Zhu SK, Wang Z, Hesh Ka S, Heo M, Faith MS, Heymsfield SB. Waist drcumferen ce and obesity-assod ated risk factors am ong whites in the third National Health and Nutition Examin ation Survey: dinical action thresh dds.

13. Zhu S, Heshka S, Wang Z Shen W, Allison DB, Ross R. Combination of BMI and waist circumference, and health risk for identifying cardiocasoular risk factorsin whites. ObesRes. 2004; 12: 633-45. 14. Wannamethee SC, Shaper AC, Morris RW, Whincup PH. Measures of
adiposity in the identification of metabolic abnormalitiesin elderly men. Am J Clin Nutr. 2005; 81: 131 3-21.

15. Monteiro $\mathrm{CA}$, Conde $\mathrm{WL}$, CastrolRR. Atenden dia cambiante darelação entre esodaridade e riscode obesidaden oB rasil (1975-1997). Cad Saude Pública. 2003; 19 (Supl. 1): S67-S75.

16. In stituto Brasil eiro de Ceografia e Estatística (IBCE). Pesqui sa de or çamentos familiares - POF 2002-2003. [citado 2004, Março 20]. Disponivel em: http://mww.ibge.gov.br/.

17.Freitas OC, Carvalho RF, Neves JM, Prevalencia da hiperten são arterial sistêmica na populaçãourbana de Catan duva, SP. Arq Bras Cardiol. 2001; 77:9-15.

18. In tituto Brasileirode Ceog afia eEstatistica (IBCE). Contagem populacional 996: dados agegados por setores censitários 1996 (CD-ROM). Rio de

19. Frisancho AR. Anthropometric standards for the assessment of gowth and nutritional satus. Ann Arbor: The University of Midchigan Press; 1990.

20. Clinical guidelines on the identification, evalu ation, and treatment of
overweight and obesity in adults: the evidence report. Bethesda; NIH overweight and obesity in adults: the endence report. Bethesda; $\mathrm{NIH}$

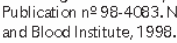

21. Cde TJ, Bellizzi MC, Flegal KM, DietzWH. Establishing a stan dard definition for child overweight and obesity worldwide: international survey. BM. 2000; 320: $1240-3$.

22. Lean $M$, Hans $T$, Morrison C. Waist dircumferen oe as a measurefor indicating need for weight manazement. BM. 1995; 311: 158-61.

23. Associaçâa Nacional de Empresas de Pesquisa. Criterrio de classificação

24. FAO/OMS. Necessidades de energia y proteinas. Cenebra: FAO/OMS, 1985. (Serie deInformes Técricos, 724 ).

25. Barnes PM, Schoenborn CA. Physical activity among adults: United States, 2000. (Advance data from vital and health statistics, no 333).

26. Henry CT. Practical sampling. Newbury Park: Jage Publication LTD, 1990.

27. Carneiro $C$, Faria AN, Ribeiro FF Filho, Cuimaräes $A$, Lerario D, Ferreira SR. Influen cia da distribui izão da gordura corporal sobre a preval en cia de hiperten são arterial eoutros fatores de risoo cardiovasaular em in dividuos
obesos. Rev Assoc Med Bras. 2003; 49 (3) : 306-11.

28. Wajchenberg BL. Suboutaneous and visoeral adiposetissue: their relation to the metab dicsyndrome. Endocr Rev. 2000; 21 (6): 697-738.

29. Scarsella C, Després PJ. Tratamiento de la obesidad: necessidad de centrar la aten ción en los pacientes de alto riesgo caracterizados por
abdominal. Cad Saúde Publica. 2003; 19 (Supl. 1): S7-S19.

30. Pi-Sunyer FX. The obesity epidemic: pathophysidogy and consequences of

31. Bertsias C, Mammas I, Linardakis M, Kafatos A. Over weight and obesity in relation to cardiovascular disease risk actors among medical sud dente.

32. Forbes $\mathrm{C}$. Longitudinal changes in adult fat-free mass: influence of body weight. AmJ Clin Nutr. 1999; 70: 1025-31.

33. Ferreira S. Prevalen dia dos fatores de risco para doen ças cardiovasculares
em Ouro Preto. Projeto Coracōes de Ouro Preto [Dissertaçäal. Ouro Preto: UniversidadeFederal de Ouro Preto; 2004.

34. Kain J, Vio F, Albala C. Obesity trends and determinant factors in Latin America. Cad SaúdePablica. 2003; 19 (supl. 1): S77-\$86.

35. Hugles VA, Frontera WR, Rouben off R, Evans WJ, Singh MAF, Longitudinal changesin body composition in older men and women: role of body weight
change and physical adtivity. Am J Clin Nutr. 2002; 76:473-81.

36. Martin I IS, Marinho SP. The potential of central obesity antropometric

37. Ministerio da Saúde. Datasus. Sistema de informą̧̧̋es sobre mortali dade. Braślia, 2000 .

38. Yamada Y, Ishizaki M, Tsuritani I. Prevention of weight gain and obesity in occupational populations: a new target of health promotion services at workstes. J Ocoup Health. 2002; 44(6): $373-84$.

39. Hu C, Sart C, Jou silahti P, Silventainen K, BarengoNC, Tu omilehtoHJ. Leisure time, occupational, and
2005; 36: 19949.

40. Ardern Cl, Janssen I, Ross R, Katzmarzyk PT. Development of health-related waist dircumference thresh dds with in BMI categories. Obes Res. 2004; 12 waist dircumfere
(7): 1094103 . 
levando em consideração a alta prevalência de sedentarismo nesta população, tanto em indivíduos com peso normal quanto naqueles com sobrepeso ou obesidade ${ }^{33}$. Resta-nos, portanto, a primeira hipótese, em que os resultados sugerem, uma vez mais, que o IMC isoladamente poderia estar sub ou superestimando a prevalência e dificultando a triagem da população em risco nutricional, se não for levada em consideração a $\mathrm{CC}^{3,7}$.

Na população estudada, mulheres com 40 anos ou mais e com baixa escolaridade apresentaram uma prevalência mais elevada do RNC quando comparadas às dos outros estratos, dados esses semelhantes aos mostrados por outros estudos nacionais ${ }^{10,15,16}$. Entre os homens, além do observado entre mulheres, também se associou à análise a inserção econômica baixa e muito baixa, cuja prevalência do RNC foi menor do que nas outras classes. Estes resultados também cão concordantes corn a litelura quant res (nsificação economica, onde se observa que os homens das classes econômicas mais elevadas apresentam maior prevalência do risco nutricional $\left.\right|^{15,3}$

A análise ajustada confirmou o papel independente da idade e escolaridade no agavamento do risco nutricional para mulheres e homens, achados estes semelhantes aos observados por outros autores $\mathrm{s}^{35,36}$. Mostrou também que, homens adultos jovens ( 20 a 39 anos) apresentaram OR elevada de RNC, dado este que pode sugerir um risco precoce elevada de RNC, dado este que pode sugerir um risco precoce
par a hipertensáo, diabetes mellitus e doen ças car diovasculares para hipertensão, diabetes mellituse doenças cardiovasculares
para os homens e, possivelmente, explicar as taxas mais para os homens e, possivelmente, explicar as taxas mais
elevadas de mortalidade por doenças do aparelho circulatório do município de Ouro Preto entre esses indivíduos em todas as faixas etárias e em relação às mulheres com menos de 50 anos ${ }^{37}$.

Em se tratando da escolaridade, a associação ocorreu de forma diferenciada para mulheres e homens. Mulheres com menor escolaridade apresentaram maior OR de RNC, enquanto que entre os homens o RNC foi maior entre os de média escolaridade. Uma possibilidade a ser investigada seria de que o gradiente dessa associação poderia estar sendo in fluen ciado pelo tipo de atividade ocupacional exercida pelos homens $\mathrm{s}^{5,838,39}$. Ou seja, os homens de classe econômica baixa ou muito baixa poderiam apresentar atividades ocupacionais pesadas estar contribuindo para a tendência de proteção en contrada neste estudo. Entretanto, os indicadores aqui utilizados não permitiram a aferição precisa da atividade física exercida, pois se considerou somente a atividade ocupacional e de lazer relatada e não a capacidade funcional dos indivíduos entrevistados; e tampouco permitiu medir a direção da

\section{Referências}

1. KatzmarzykPT, CraigCL, Bouchard $\mathrm{C}$. Under weight, over weight and obesity: relationships with mortality in the 13-year fol
Survey. Clin Epidemiol. 2001; 54:915-20.

2. Doll S, Paocaud F, Bovet P, Burnier M, Whietlishach V Body mass index, abdominal aud $F_{\text {, Bovet }}$, Burnier $M$, Wiettisbach V. Body mass index, across developing and developed countries. Intj Obes. 2002; 26: 48-57. 3. Janssen I, Katzmarzyk PT, RossR. Waist dircumferen ceandnot body massindex
explains obesity-related health risk. AmJ Clin Nutr. 2004: 79:379-84. associação.

Cabe ainda ressaltar que a utilização dos padrões de referência de adultos para a classificação da CC dos adolescentes pode ter levado a uma subestim ação sistemática da população em $\mathrm{RNC}$, pois, conforme demonstrado na literatura, a proporção de gordura corporal é dependente da idade e adolescentes tendem a apresentar uma menor proporção de gordura intra-abdominal quando comparados aos adultos ${ }^{29}$. Contudo, estudos que estabeleçam a relação aos adultos ${ }^{29}$. Contudo, estudos que estabeleçam a relação entre risco nutricional para doenças não transmissíveis são escassos neste grupo e, na ausên cia de critérios específicos,
os valores determinadospara os adultos têm sido empregados para a população jovem ${ }^{11}$.

Apesar das limitaçõesiner entes aos estudos de delineamento transversal para o estabelecimento de inferências causais, concluímos que a idade e escolaridade foram fatores independentes associados ao risco nutricional em ambos os sexos. Também o IMC sozinho não parece ter sido capaz de captar as diferentes categorias de risco nutricional, uma vez que neste estudo $17 \%$ das mulheres classificadas com peso normal pelo IMC apresentaram risco nutricional aumentado avaliado pela CC.

Portanto, estes achados, assim como os de outros autores, agregam evidências para a possivel subestimação do risco nutricional quando apenas um indicador é utilizado em uma avaliação nutricion $\mathrm{a}^{3,7,40}$, como tem ocorrido em relação ao IMC. A proposta feita por Zhu e cols. ${ }^{13}$ sobre a utilização combinada de IMC e CC no processo de identificação de fatores de risco cardiovasculares, com pontos de risco combinados específicos para mulheres e homens brancos, ajustada para co-variáveis tais como atividade física, fumo, consumo de álcool e nível educacional, encontra respaldo

Além disso, os resultados aqui encontrados possibilitam a reflexão sobre a relevância do uso combinado de IMC e CC nos serviços de saúde para o aumento da acurácia no diagnóstico do risco nutricional, além da importância de se considerarem idade e escolaridade.

\section{Agradecimentos}

Ao CNPq, Universidade Federal de Ouro Preto, Prefeitura Municipal de Ouro Preto, Unimed dos Inconfidentes, Alcan Alumínio do Brasil.

Potencial Conflito de Interesses

Declaro não haver conflitos de interesses pertinentes.

4. Misra A, Vikram NK. Clinical and pathophysiologial consequences of abdomina adiposity and abdominal adiposetisue depots. Nutrition. 2003: $19(5): 457-66$.

5. PrenticeAM, Jebb SA. Beyond body mass index. Obes Rev. 2001; 2:141-7.

6. Bray CA. Evaluation of obesity: who are the obese? Postg ad Med. 2003; 114 (6): $19-27$.

7. Ardern $\mathrm{Cl}$, Katzmarzyk PT, Jan ssen I, Ross R. Discrimination of health risk by 
Feetas e cols.
OURO PRETO

Artigo Original

\begin{tabular}{|c|c|c|c|c|}
\hline \multirow[b]{2}{*}{ MULHERES } & \multicolumn{2}{|c|}{ OR bruta } & \multicolumn{2}{|c|}{ OR ajustada } \\
\hline & OR (IC 95\%) & $\mathrm{p}^{+}$ & OR (IC 95\%) & $\mathrm{p}^{+}$ \\
\hline \multicolumn{5}{|l|}{ Idade } \\
\hline $15-19$ anos & 1,00 & & 1,00 & \\
\hline $20-39$ anos & $2,66(1,39 ; 5,10)$ & $<0,01$ & $2,41(1,24 ; 4,66)$ & $<0,01$ \\
\hline $40-59$ anos & $7,69(3,76 ; 15,70)$ & $<0,01$ & $6,04(2,81 ; 13,00)$ & $<0,01$ \\
\hline$\geq 60$ anos & $14,61(5,50 ; 38,91)$ & $<0,01$ & $9,95(3,55 ; 27,88)$ & $<0,01$ \\
\hline \multicolumn{5}{|l|}{ Escolaridade ${ }^{\alpha}$} \\
\hline$>4$ anos & 1,00 & & 1,00 & \\
\hline$\leq 4$ anos & $3,16(2,07 ; 4,78)$ & $<0,01$ & $1,74(1,06 ; 2,87)$ & 0,03 \\
\hline \multicolumn{5}{|l|}{ dasse $^{*}$} \\
\hline$A / B$ & 1,00 & & 1,00 & \\
\hline C & $1,04(0,55 ; 1,99)$ & 0,90 & $0,86(0,42 ; 1,77)$ & 0,69 \\
\hline D/E & $1,42(0,75 ; 2,68)$ & 0,28 & $1,15(0,55 ; 2,40)$ & 0,71 \\
\hline HOMENS & OR (IC 95\%) & $\mathrm{p}^{+}$ & OR (IC 95\%) & $\mathrm{p}^{+}$ \\
\hline \multicolumn{5}{|l|}{ Idade } \\
\hline $15-19$ anos & 1,00 & & 1,00 & \\
\hline $20-39$ anos & $3,64(1,63 ; 8,12)$ & $<0,01$ & $5,02(2,09 ; 12,08)$ & $<0,01$ \\
\hline $40-59$ anos & $7,54(3,26 ; 17,42)$ & $<0,01$ & $10,14(3,87 ; 26,59)$ & $<0,01$ \\
\hline$\geq 60$ anos & $12,62(4,65 ; 32,24)$ & $<0,01$ & $14,35(4,67 ; 44,08)$ & $<0,01$ \\
\hline \multicolumn{5}{|l|}{ Escolaridade } \\
\hline Alta & 1,00 & & 1,00 & \\
\hline Média & $1,12(0,63 ; 1,98)$ & 0,71 & $2,55(1,24 ; 5,23)$ & 0,01 \\
\hline Baixa & $1,80(1,08 ; 2,98)$ & 0,02 & $1,91(0,96 ; 3,78)$ & 0,06 \\
\hline \multicolumn{5}{|l|}{ Classe $^{*}$} \\
\hline$A / B$ & 1,00 & & 1,00 & \\
\hline C & $0,95(0,53 ; 1,70)$ & 0,87 & $0,88(0,43 ; 1,77)$ & 0,71 \\
\hline D/E & $0,60(0,33 ; 1,09)$ & 0,09 & $0,46(0,21 ; 1,03)$ & 0,058 \\
\hline $\begin{array}{l}\text { *Clase Economica } \\
\text { aj ustado Wald test }\end{array}$ & C: média baixa, D/E: ba & to baixa. & escolaridade media e alte & omodelc \\
\hline
\end{tabular}

demonstrada na análise do risco nutricional para as doenças não transmissíveis em decorrência de sua boa correlação com os depósitos de gordura viscer a 10,11,28 Ambos os indicadoretem sido apontados cono adequados preditores indicadorestem sido apontados como de complicaçoes metabólicas, com base no conhecimento do metabolismo dos depositos viscerais de triglicerides ${ }^{29}$. Estes possuem tumover mais acelerado do que os de outras regióes, aumentando assim a oferta de ácidos graxos lives no sistema-porta, estimulando a gliconeogênese, inibindo a depuração hepática da insulina e contribuindo para elevar a glicemia, a insulinemia e a resistência insulínica ${ }^{4,29,30}$ com conseqü ente aum ento do risco de hipertensão arterial, doenças car diovasculares e câncer ${ }^{9,31}$.

Neste estudo, de acordo com a classificação do RNI
( $C C \geq 80 \mathrm{~cm}$ em mulheres e $\geq 94 \mathrm{~cm}$ em homens) e IMC, encontramos três categorias distintas de indivíduos. As duas primeiras constituídas de indivíduos com sobrepeso central (RNI moderado) ou obesidade central (RNI elevado), mas com IMC normal/sobrepeso ou com obesidade e a última categoria, com CC normal (RNI baixo), mas com sobrepeso ou obesidade pelo IMC. Posśveis explicações para essas discordâncias poderiam ser atribuídas à distribuição desigual da gordura corporal ou da massa muscular que, por sua vez, poderia estar aumentada pelo tipo de atividade física exercida por alguns indivíduos classificados com sobrepeso ou mesmo obesos pelo ${ }^{5,8}$. Entretanto, nasegun hipótes não obsos pelo $M C$. Entretanto, na segunda hipotese, náo ha relato de risco à saude $e^{8,32}$. Contudo, e provavel que
esta aplicável para Ouro Preto, principalmente 
Artigo Original

\begin{tabular}{|c|c|c|c|c|c|c|}
\hline \multicolumn{7}{|c|}{ Categorias de risco (CO) } \\
\hline \multirow{2}{*}{ Categorias de IMC } & \multicolumn{2}{|c|}{ Baixo } & \multicolumn{2}{|c|}{ Aumentado } & \multicolumn{2}{|c|}{ Elevado } \\
\hline & n & $\%$ & n & $\%$ & n & $\%$ \\
\hline \multicolumn{7}{|l|}{ Feminino } \\
\hline Baixo peso $(n=25)$ & 24 & 96,0 & - & - & 1 & 4,0 \\
\hline Normal $(n=178)$ & 144 & 80,9 & 30 & 16,9 & 4 & 2,2 \\
\hline Sobrepeso $(n=121)$ & 10 & 8,3 & 53 & 43,8 & 58 & 47,9 \\
\hline Obesidade $(n=66)$ & 1 & 1,5 & 1 & 1,5 & 64 & 97,0 \\
\hline \multicolumn{7}{|l|}{ Masculino } \\
\hline Baixo peso $(n=24)$ & 24 & 100 & - & - & - & - \\
\hline Normal $(n=219)$ & 216 & 98,6 & 2 & 0,9 & 1 & 0,5 \\
\hline Sobrepeso $(n=109)$ & 48 & 44,0 & 52 & 47,7 & 9 & 8,3 \\
\hline Obesidade $(n=25)$ & 5 & 20,0 & 7 & 28,0 & 13 & 52,0 \\
\hline $\begin{array}{l}\text { *Baino risco CC }<80 \mathrm{~cm} \text { (m) } \\
\text { efevado } C C \geq 88 \mathrm{~cm} \text { (muther }\end{array}$ & emem); & tado ent & $a<$ & muther) & & e risco \\
\hline
\end{tabular}

\begin{tabular}{|c|c|c|c|c|c|c|}
\hline \multirow[t]{3}{*}{ Característica } & \multicolumn{3}{|c|}{ Feminino } & \multicolumn{3}{|c|}{ Masculino } \\
\hline & \multicolumn{3}{|c|}{ Risco Combinado* } & \multicolumn{3}{|c|}{ Risco Combinado* } \\
\hline & Sem \% (n) & Com \% (n) & $\mathrm{p}^{+}$ & Sem \% (n) & Com \% (n) & $\mathrm{p}^{+}$ \\
\hline \multicolumn{7}{|l|}{ Idade } \\
\hline $15-19$ an $\circ$ s & $72,9(43)$ & $27,1(16)$ & & $88,2(60)$ & $11,8(8)$ & \multirow{4}{*}{$<0,01$} \\
\hline $20-39$ an 06 & $50,9(88)$ & $49,1(85)$ & & $67,4(118)$ & $32,6(57)$ & \\
\hline $40-59$ an $\bigcirc 8$ & $25,9(29)$ & $74,1(83)$ & & $50,0(49)$ & $50,0(49)$ & \\
\hline$\geq 60$ anos & $15,2(7)$ & $84,8(39)$ & $<0,01$ & $36,8(14)$ & $63,2(24)$ & \\
\hline \multicolumn{7}{|l|}{ Escolaridade $^{\&}$} \\
\hline Baixa & $29,4(58)$ & $70,6(139)$ & & $56,6(90)$ & $43,4(69)$ & \multirow{3}{*}{0,05} \\
\hline Média & $64,9(50)$ & $35,1(27)$ & & $67,6(69)$ & $32,4(33)$ & \\
\hline Alta & $50,9(59)$ & $49,1(57)$ & $<0,01$ & $69,8(81)$ & $30,2(35)$ & \\
\hline \multicolumn{7}{|c|}{ Classe Econômica } \\
\hline$D / E$ & $39,0(73)$ & $61,0(114)$ & & $70,5(105)$ & $29,5(44)$ & \multirow{3}{*}{0,10} \\
\hline c & $46,8(72)$ & $53,2(82)$ & & $60,0(96)$ & $40,0(64)$ & \\
\hline$A / B$ & $47,9(23)$ & $52,1(25)$ & 0,28 & $58,8(40)$ & $41,2(28)$ & \\
\hline \multicolumn{7}{|l|}{ Sedentarismo } \\
\hline Não & $42,4(36)$ & $57,6(49)$ & & $64,9(111)$ & $35,1(60)$ & \multirow{2}{*}{0,61} \\
\hline Sim & $43,1(132)$ & $56,9(174)$ & 0,90 & $62,4(126)$ & $37,6(76)$ & \\
\hline \multicolumn{7}{|c|}{ 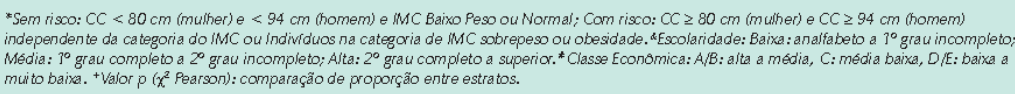 } \\
\hline
\end{tabular}


Artigo Original

\begin{tabular}{|c|c|c|c|c|c|c|c|c|c|c|c|c|c|c|c|c|}
\hline & \multicolumn{8}{|c|}{$\operatorname{IMC}(\mathrm{kg} / \mathrm{m}) * *$} & \multicolumn{8}{|c|}{$\mathrm{CC}(\mathrm{m}) * * *$} \\
\hline & \multicolumn{2}{|c|}{ BP } & \multicolumn{2}{|c|}{$\mathrm{N}$} & \multicolumn{2}{|c|}{ SP } & \multicolumn{2}{|c|}{ OB } & \multirow[t]{2}{*}{$\mathrm{p}^{+}$} & \multicolumn{2}{|c|}{$\mathrm{N}$} & \multicolumn{2}{|c|}{ SPC } & \multicolumn{2}{|c|}{$\mathrm{OC}$} & \multirow[t]{2}{*}{$\mathrm{p}^{+}$} \\
\hline & $\mathrm{n}$ & $\%$ & $\mathrm{n}$ & $\%$ & $\mathrm{n}$ & $\%$ & n & $\%$ & & $\mathrm{n}$ & $\%$ & $\mathrm{~N}$ & $\%$ & n & $\%$ & \\
\hline$\%$ Total $^{*}$ & & 6,4 & & 51,7 & & 30,0 & & 11,9 & & & 61,5 & & 19,1 & & 19,4 & \\
\hline \multicolumn{17}{|l|}{ Sexo } \\
\hline Feminino & 25 & 6,4 & 177 & 45,4 & 121 & 31,0 & 67 & 17,2 & \multirow{2}{*}{$<, 01$} & 178 & 45,8 & 85 & 21,9 & 126 & 32,4 & \multirow{2}{*}{$<, 01$} \\
\hline Masallino & 24 & 6,4 & 219 & 58,1 & 109 & 28,9 & 25 & 6,6 & & 294 & 77,6 & 62 & 16,4 & 23 & 6,1 & \\
\hline \multicolumn{17}{|l|}{ Idade } \\
\hline $15-19$ anos & 14 & 11,0 & 90 & 70,9 & 17 & 13,4 & 6 & 4,7 & \multirow{4}{*}{$<, 01$} & 112 & 87,5 & 11 & 8,6 & 5 & 3,9 & \multirow{4}{*}{$<, 01$} \\
\hline 20- 39 anos & 24 & 6,9 & 198 & 56,9 & 96 & 27,6 & 30 & 8,6 & & 239 & 68,7 & 66 & 19,0 & 43 & 12,4 & \\
\hline 40- 59 anos & 7 & 3,4 & 81 & 38,9 & 81 & 38,9 & 39 & 18,8 & & 96 & 45,9 & 45 & 21,5 & 68 & 32,5 & \\
\hline$\geq 60$ anos & 4 & 4,7 & 28 & 32,9 & 37 & 43,5 & 16 & 18,8 & & 25 & 29,8 & 25 & 29,8 & 34 & 40,5 & \\
\hline \multicolumn{17}{|l|}{ Escolaridade } \\
\hline Baixa & 16 & 4,5 & 158 & 44,5 & 127 & 35,8 & 54 & 15,2 & \multirow{3}{*}{$<, 01$} & 176 & 49,6 & 89 & 25,1 & 90 & 25,4 & \multirow{3}{*}{$<, 01$} \\
\hline Média & 17 & 9,6 & 105 & 59,0 & 37 & 20,8 & 19 & 10,7 & & 137 & 77,0 & 21 & 11,8 & 20 & 13,4 & \\
\hline Alta & 16 & 6,9 & 131 & 56,5 & 66 & 28,4 & 19 & 8,2 & & 158 & 68,4 & 34 & 14,7 & 39 & 26,2 & \\
\hline \multicolumn{17}{|l|}{ Casse $^{A}$} \\
\hline$D / E$ & 19 & 5,7 & 180 & 53,6 & 98 & 29,2 & 39 & 11,6 & \multirow{3}{*}{0,34} & 203 & 60,6 & 64 & 19,1 & 68 & 20,3 & \multirow{3}{*}{0,74} \\
\hline c & 23 & 7,3 & 156 & 49,5 & 91 & 28,9 & 45 & 14,3 & & 197 & 62,7 & 55 & 17,5 & 62 & 19,7 & \\
\hline AB & 8 & 6,8 & 59 & 50,4 & 42 & 35,9 & 8 & 6,8 & & 71 & 61,2 & 26 & 22,4 & 19 & 16,4 & \\
\hline \multicolumn{17}{|l|}{ Sedentarismo } \\
\hline Sim & 30 & 5,9 & 258 & 50,9 & 147 & 29,0 & 72 & 14,2 & \multirow{2}{*}{0,05} & 296 & 58,3 & 103 & 20,3 & 109 & 21,5 & \multirow{2}{*}{0,04} \\
\hline Não & 19 & 7,5 & 135 & 52,9 & 82 & 32,2 & 19 & 7,5 & & 173 & 67,8 & 42 & 16,5 & 40 & 15,7 & \\
\hline \multicolumn{17}{|c|}{ 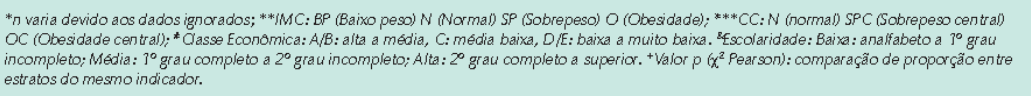 } \\
\hline
\end{tabular}

Ressalve-se que no momento da construção dos modelos multivariados optou-se por duas categorias classificatórias da escolaridade para mulheres. Mulheres de baixa escolaridade ( $\leq 4$ anos) apresentaram maior RNC quando comparadas as de melhor escolaridade, enquanto entre homens, o RNC se mostrou significativo entre aqueles com média escolaridade quando comparados aos de alta escolaridade.

Tendên cia de proteção para o RNC foi observada entre os homens das classes econômicas De E (OR: 0,46; $p=0,058$ ) quando comparados aos das classes $A$ e $B$, o que justificou a permanência da classe econômica no modelo final. Os ajustes dos modelos pelo teste de Hosmer \& Lemeshow foram de $\mathrm{p}$ $=0,90$ para as mulheres e de $p=0,47$ para os homens.

Discussão

Neste estudo, independentemente do indicador utilizado, foi observada um a alta prevalência de obesidade e sobr epeso na população acima de 15 anos em Ouro Preto. Entre mulheres o sobrepeso/obesidade foi de $48,2 \%$ e entre homens, de $35,5 \%$, quando se utilizava o IMC. Situava-se nos patamares de $54,2 \%$ e $22,4 \%$, respectivamente, quando o critério classificatório era a circunferência da cintura. Esses dados sugerem que indivíduos com IMC normal ou com sobrepeso, notadamente mulheres, podem apresentar obesidade central, indicando que car acterísticas da distribuição da gordura corpor al devem ser consideradas na avaliação do risco nutricional.

Alguns estudos têm demonstrado que o IMC pode subestimar ou superestimar o sobrepeso e a obesidade ${ }^{5,8}$, pois, apesar de estar correlacionado com excesso de gordura corporal, refletiria somente a proporção corporal, não estimando a adiposidade e distribuição de gordura corpor $a^{5}$. Por outro lado, a CC tem sido recentemente utilizada como indicador de risco à saúde $4,9,14,22,27$.

Apesar da não existência, no Brasil, de dados nacionais sobre prevalência do sobrepeso central e de obesidade central, a sua relevância epidemiológica tem sido cada vez mais 


\begin{tabular}{|c|c|c|c|c|c|c|}
\hline \multirow[t]{3}{*}{ Característica } & \multicolumn{3}{|c|}{ Feminino } & \multicolumn{3}{|c|}{ Masculino } \\
\hline & $\mathrm{n}$ & IMC $\left(\mathrm{kg} / \mathrm{m}^{2}\right)$ & $\mathrm{CC}(\mathrm{cm})$ & $\mathrm{n}$ & IMC $\left(\mathrm{kg}^{2} \mathrm{~m}^{2}\right)$ & $\mathrm{CC}(\mathrm{cm})$ \\
\hline & & Média (DP) & Média (DP) & & Média (DP) & Média (DP) \\
\hline \multicolumn{7}{|l|}{ Idade } \\
\hline 15-19 anos & 59 & $22,7(3,6)^{a}$ & $73,5(8,3)^{a}$ & 68 & $21,9(4,4)^{a}$ & $76,0(10,6)^{a}$ \\
\hline $20-39$ anos & 173 & $24,7(5,9)^{\mathrm{b}}$ & $79,7(12,9)^{b}$ & 175 & $23,2(3,9)^{b}$ & $80,7(10,6)^{b}$ \\
\hline $40-59$ ancs & 112 & $27,4(5,8)^{\circ}$ & $87,3(13,8)^{\circ}$ & 97 & $24,8(3,6)^{\mathrm{c}}$ & $89,2(11,3)^{\circ}$ \\
\hline$\geq 60$ anos & 46 & $27,9(5,0)^{c}$ & $92,9(13,5)^{d}$ & 38 & $25,1(3,5)^{\circ}$ & $90,6(11,4)^{\circ}$ \\
\hline Valor $p^{+}$ & & $<0,01$ & $<0,01$ & & $<0,01$ & $<0,01$ \\
\hline \multicolumn{7}{|l|}{ Classe ${ }^{*}$} \\
\hline$D / E$ & 187 & $25,7(6,1)$ & $83,2(14,0)$ & 149 & $23,0(3,6)$ & $80,9(10,7)^{a}$ \\
\hline c & 154 & $25,4(5,6)$ & $82,3(14,3)$ & 160 & $24,0(4,5)$ & $83,8(12,7)^{b}$ \\
\hline $\mathrm{A} / \mathrm{B}$ & 48 & $25,4(4,7)$ & $80,5(12,9)$ & 68 & $23,6(3,7)$ & $85,6(12,7)^{\mathrm{b}}$ \\
\hline Valor $p^{+}$ & & 0,83 & 0,47 & & 0,09 & 0,02 \\
\hline \multicolumn{7}{|l|}{ Escolaridade ${ }^{\&}$} \\
\hline Baixa & 196 & $26,9(6,2)^{a}$ & $86,1(14,0)^{a}$ & 159 & $24,1(3,6)$ & $84,8(11,5)$ \\
\hline Média & 77 & $23,7(5,2)^{b}$ & $77,1(13,4)^{b}$ & 101 & $23,3(4,1)$ & $80,2(11,3)$ \\
\hline Alta & 115 & $24,6(4,7)^{b}$ & $80,2(12,7)^{b}$ & 116 & $23,0(4,4)$ & $82,9(13,0)$ \\
\hline Valor $p^{+}$ & & $<0,01$ & $<0,01$ & & 0,06 & 0,10 \\
\hline \multicolumn{7}{|l|}{ Sedentarismo } \\
\hline Sim & 305 & $25,6(6,1)$ & $81,4(12,5)$ & 202 & $23,6(3,8)$ & $83,6(11,1)$ \\
\hline Não & 84 & $25,2(4,4)$ & $82,8(14,3)$ & 170 & $23,6(4,4)$ & $82,5(13,1)$ \\
\hline Valor $p^{+}$ & & 0,49 & 0,39 & & 0,98 & 0,38 \\
\hline \multicolumn{7}{|c|}{ 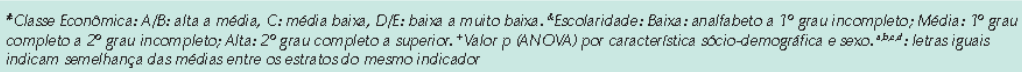 } \\
\hline
\end{tabular}

escolaridade apresentaram prevalências de aproximadamente $50 \%$ de sobrepeso central/obesidade central, sendo que este esteve presente em $40 \%$ dos indivíduos da classe alta. Em se tratando da freqüência do risco nutricional isolado associado a diferentes categorias de IMCe $O C$ (tab. 4), for am encontrados indivíduos com risco nutricional pela CC em todas as classificações do normal, participantes apresentavam medias de CC acima dos valores de normalidade, sendo $19,1 \%$ das mulheres e 1,4\% dos homens. Já para o IMC sobrepeso, o percentual de risco elevado (obesidade central) foi de $47,9 \%$ para mulheres e de 8,3\% para homens. Quando classificados como obesos, pelo IMC, observou-se que a gande maioria das mulheres neste gupo $(97 \%)$ tinha obesidade central pela CC, enquanto que grupo $(97 \%$ entre os homens este percentual foi de $52 \%$. Na categoria baixo peso, pelo $\mathrm{IMC}$, encontrou-se somente uma mulher com risco nutricional elevado, ou seja, com obesidade, e nenhum homem na categoria de RNI.

Na tabela 5 encontram-se as prevalências dos riscos nutricionais combinados (IMC e CO. Mulheres e homens apresentavam aumento significativo desses indicadores de risco com o envelhecimento e redução com o aumento da escolaridade. Naqueles com 60 anos ou mais, a prevalência do RNC chegava a $84,8 \%$ para mulheres e $63,2 \%$ para homens, e de $70,6 \%$ e $43,4 \%$ para mulheres e homens de baixa escolaridade, respectivamente. Ressalta-se que entre as mulheres foi encontrada diferença significativa $(p<$ $0,01)$ em todas as categorias de escolaridade, enquanto que  entre homens com media e alta escolaridade os RNC eram
semelhantes $(\mathrm{p}=0,53$ ). A ausência de atividade física não se associou significativamente com o RNC em ambos os sexos, assim como as categorias de classe econômica entre mulheres ip $>0,20$ ).

Resultados das análises bi e multivariada encontram-se na tabela 6 . O risco nutricion al combinado se associou significativamente com a idade e escolaridade em ambos os sexos, e com a classe econômica nos homens. O RNC elevou-se com o avancar da idade em ambos os sexos, com magnitudes mais acentuadas entre os homens, quando compados à mulheres. Quanto à escolaida comportamento diferenciado foi encontrado entre sexos. 
foram agupadas em $A$ e $B$ (alta e média), $C$ (média baixa), D e E (baixa e muito baixa). A atividade ocupacional foi categorizada em: leve (atividades executadas sentadas ou facilmente, exemplo: secretária), moderada (trabalhos que implicavam caminhar e sentar, exemplo: almoxarife) ou pesada (trabalho manual pesado, tais como: operário da construção civil). O sedentarismo foi definido neste estudo a partir do agupamento da atividade ocupacional e tempo de ativir fíc 2425 . Aques que de ative extudate, escitura estudante, escriturario, professor, ente out as, e praticavam atividade fisica de lazer com tempo semanal inferior a 150 minutos foram classificados como sedentários

Análise estatística - A análise foi ponderada ${ }^{26}$ por sexo e idade, sendo os pesos determinados pela razão entre as proporços de indivíduos no IBGE e na amostra (tabela 1). O teste qui-quadrado $\left(\chi^{2}\right)$ de Pearson foi utilizado para comparar as propor ções de in divíduos na amostra e a estim ada pelo IBGE e para comparar aqueles com RNC de acordo com as variáveis sócio-demográficas e sedentarismo. A análise de variância foi utilizada para a comparação das médias das medidas antropométricas e o teste de diferença mínima significativa de Student para comparar os grupos de pares. Regessão lóntica binária e o teste de Hogmer \& Lemeshow foram utiliza bs para co otrir e veificar o ajuse dos modes de

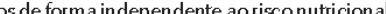
combinado (CC e IMC). O valor $p \leq 0,20$ e a plausibilidade epidemiológica e biológica foram os critérios utilizados para a inclu são das variáveis no modelo multivariado. Assumiu-se como nível de significância estatística o valor $p \leq 0,05$ para a definição do modelo final.

O projeto foi aprovado pelo Comitê de Ética em Pesquisa da Universidade Federal de Ouro Preto, sob o número $2001 / 26$.

\section{Resultados}

Comparando-se as características da amostra do estudo com in formações da população estimadas pelo IBGE na cidade, foi observada uma significativa maior proporção de mulheres $(70 \%)$ e adultos $(71,9 \%$ ). Foi então realizada a ponderação da amostra por sexo e idade, composta de 768 indivíduos, sendo $50,8 \%$ de mulheres e $49,2 \%$ de homens; $16,5 \%$ dos participantes eram da faixa etária de 15 a 19 anos, $45,3 \%$ de 20 a 39 anos, $27,2 \%$ de 40 a 59 anos e $10,9 \%$ com 60 anos ou mais. Recusas em participar da segunda fase do estudo, quando eram realizados os exames clínicos e antropométricos, após três convites sistemáticos, totalizar am $17,2 \%$.

Na tabela 2, estratificada por sexo, encontram-se as médias e os desvios-padrão dos indicadores antropométricos pelas car acterísticas sócio-demográficas e de sedentarismo. Resumidamente, entre mulheres, as médias de IMC e $O C$ variaram significativamente com a idade e a escolaridade, sendo mais elevadas naquelas com idade de 60 anos ou mais enaque com baxa escolaida. Não foram encontradas difeques sos diferenças significativas com relaçáo a classe econo sedentarismo. Entre homens, o IMC médio variou com a idade; entretanto, a CC média aumentou significativamente com o passar dos anos e com a melhoria da classe econômica.

Na tabela 3 está descrito o perfil nutricional, a partir das classificaçoes do IMC e CC de acordo com características sócio-demogáficas e de sedentarismo. Observa-se variação significativa do perfil nutricional de acordo com sexo, idade, escolaridade e sedentarismo.

Utilizando-se o IMC, a prevalência geral de baixo peso encontrada foi de $6.4 \%(n=49)$, sobrepeso de $30 \%$ in $=230$ ) e obesidade de $11.9 \%$ ( $n=92$ ). O sobrepeso e obesidade foram mais freqüentes nas mulheres, respectivamente de $31 \%$ e $17,2 \%$; nos participantes com idade $\geq 60$ anos $(43,5 \%$ e $18,8 \%)$ e naqueles com baixa escolaridade $35,8 \%$ e $15,2 \%$ ).

Quanto à prevalência geral do sobrepeso central, 19,1\% in $=146$ ) dos participantes preenchiam esse critério, assim como $19,4 \%(n=149)$ no tocante à obesidade central; em mulheres, o sobrepeso central esteve presente em $21,9 \%$ e a obesidade central em $32,4 \%$ e, em homens, ocorreu em $16,4 \%$ e $6,1 \%$, respectivamente. Esses dois indicadores também foram maiores naqueles com idades $\geq 60$ anos $(29,8 \%$ e $40,5 \%)$ e nos classificados como sedentarios $(20,3 \%$

\begin{tabular}{|lcccccc|}
\hline Sexo & Faixa etária (anos) & IBGE & $\%$ & Amostra & $\%$ & Peso \\
\hline Masculino & 15 a 19 & 2.932 & 7,21 & 41 & 4,33 & 1,6329 \\
\hline & 20 a 39 & 9.276 & 22,80 & 111 & 12,01 & 1,9082 \\
\hline & 40 a 59 & 5.390 & 13,24 & 86 & 9,31 & 1,4311 \\
\hline Feminino & 60 ou + & 1.870 & 4,59 & 41 & 4,44 & 1,0415 \\
\hline & 15 a 19 & 2.870 & 7,05 & 45 & 4,76 & 1,4563 \\
\hline & 20 a 39 & 9.763 & 24,00 & 242 & 25,87 & 0,9212 \\
\hline Total & 40 a 59 & 5.816 & 14,30 & 229 & 24,78 & 0,5799 \\
\hline
\end{tabular}

Tabela 1 - Distribuição da contagem populacional do IBCE (2000 e da amostra (2001), segundo sexo e faixa etária na cidade de Ouro Preto 
Introdução

A obesidade é uma doença crônica multifatorial car acterizada pelo excesso de tecido adiposo. Tem sido simultaneamente apontada comoum fator de risco importante para aelevação da para a levação da A reviego de indicadores antropom étricos para o seu diagnóstico e avaliação do risco nutricional para co-morbidades tem sido demonstrada por diferentes estudos ${ }^{2-4}$

Em estudos epidemiológicos, o indicador de obesidade comumente utilizado é o índice de massa corporal (IMC) por apresentar boa correlação com a gordura corporal total e ter alta aplicabilidade e baixo custo ${ }^{5}$. Entretanto, limitações desse índice na definição do sobrepeso/obesidade são evidenciadas nas diferentes categorias de sexo, idade, raça e atividade física ena avaliação do risco nutricional para co-morbidade ${ }^{3,67}$, não conseguindo tampouco diferenciar e quantificar a distribuição de gordura $a^{5,8}$.

Sabe-se que o risco de diabetes, hipertensão arterial e śndrome metabólica está associado à distribuição da gordura corporal e, mais especificamente, ao aumento da gordura centra $\mathrm{a}^{2,3,9,10}$. O método mais utilizado para avaliar a gordura central tem sido a medida da circunferência da cintura (CC), devido a sua boa correlação com a gordura visceral $\left.\right|^{3,11,12}$. Alguns autores têm demonstrado que, em indivíduos com peso normal, sobrepeso e obesidade grau I definidos pelo IMC, o risco nutricional para ocorrência de co-morbidades não transmissíveis pode ser subestimado quando há elevação da $\mathrm{CC}^{3,7,12}$.

Recentemente, tem sido proposto, para a avaliação do risco nutricional de uma população, a utilização conjunta do IMC e CC $3,7,9,13,14$ considerando que esse procedimento aumenta a acurácia do diagnóstico. Entretanto, deve-se ressaltar que a acuracia do diagnostico. Entretanto, deve-se ressaltar que
orisco nutricional pode variar segundo car acterísticas sociais, o risco nutricion al pode variar segundo car acterísticas sociais,
econômicas, demográficas e comportamentais dos diferentes econômicas, demográficas e comportamentais dos diferentes este trabalho teve como objetivo estimar a prevalência do risco nutricional combinado [índice de massa corporal (IMC) e circunferência da cintura $(\mathrm{CO}]$ segundo as características sócio-demogránicas e sedentarismo da populaça residente em Ouro Preto (MG), Regiáo Sudeste do Brasil.

\section{Métodos}

Populaçáo do estudo - O estudo foi realizado no ano de 2001 , na população com idade de 15 anos ou mais, residente nos domicilios particulares da cidade de Ouro Preto, Minas Gerais, que compreende 25.222 indivíduos.

Desenho do estudo e amostra - Estudo epidemiológico do tipo seccional foi delineado para estimar a prevalência dos fatores de risco para as doenças cardiovasculares nesta população. A amostr a de 929 domicílios foi calculada utilizando a prevalência estimada da hipertensão arterial sistêmica de $25 \%{ }^{17}$; precisão desejada de $3 \%$, nível de significância de $95 \%$ e perda estimada de $20 \%$. Os domicilios foram selecionados a partir da listarem de enderecos ditribuídos em 33 setores a patir da lista de com o Instituto Brasileiro de Geografia e Estatística (IBGE) ${ }^{18}$.
Em cada domicilio amostrado foi selecionado um indivíduo com 15 anos ou mais, cuja data de aniversário era a mais próxima à data da entrevista. No caso de recusa do indivíduo selecionado, o domicílio era descartado e substituído pela próxima casa à direita. Imóveis coletivos ou comerciais ou cujos residentes recusavam-se a participar da pesquisa eram substituídos pela próxima casa à direita.

Coleta de dados - Os in divíduos entrevistados foram agendados para a realização do exame clínicoe antropométrico no horário de 7 às 10 horas da manhã, após um jejum de 12 horas. Para aferir o peso utilizou-se a balança TANITA BF $542^{\circ}$ ajustada a cada medição, com capacidade de $136 \mathrm{~kg}$, variação de $0,2 \mathrm{~kg}$ com os indivíduos vestindo um mínimo de roupas, sem jóias e/ou bijuterias, com a bexiga vazia e em jejum.

Par a a medida da altur a utilizou-se o método preconizado por Frisancho ${ }^{19}$ por meio de um antropômetro de campo. O critério adotado para a classificação do índice de massa corporal (IMC) de adultos e de idosos foi o da Organização Mundial de Saúde adaptado pelo National institutes of Health $(\mathrm{NIH})^{20}$ onde indivíduos com $\mathrm{IMC}<18,5 \mathrm{~kg} / \mathrm{m}^{2}$ são de baixo peso, de 18,5 a $24,9 \mathrm{kgm}^{2}$ sio $\mathrm{nOmal} \geq 2$ $\mathrm{kg} / \mathrm{m}^{2}$ estão com sobrepeso e $\geq 30 \mathrm{~kg} / \mathrm{m}^{2}$ são obesos; para os adolescentes, foi adotado o padrão internacional de Cole e $\mathrm{cols}^{21}$, que classifica o IMC < percentil 5 como baixo peso, entre o percentil $\geq 85$ a $<95$, sobrepeso e no percentil $\geq$ 95, como obeso.

A circunferência da cintura $(\mathrm{CC})$ foi aferida no ponto médio entre o último arco costal e a crista ilíaca ou cintura natural com o indivíduo na posição supina. Mulheres com valores $\geq 80 \mathrm{e}<88 \mathrm{~cm}$ e homens com $\geq 94 \mathrm{e}<102 \mathrm{~cm}$ foram considerados com excesso de gordura central (sobrepeso central), portanto, com risco nutricional isolado (RNI) moderado par a morbidades não transmissíveis. Aqueles com $\mathrm{CC} \geq 88 \mathrm{~cm}$ para mulheres e $\geq 102 \mathrm{~cm}$ para homens foram considerados com obesidade central, ou com RNI elevado de acordo com os critérios propostos por Lean e cols. ${ }^{22}$. A denominação RNI foi adotada para verificação da presença do risco nas diferentes categorias de IMC.

Para a definição do risco nutricional combinado (RNC) adotaram-se os critérios de classificação da CC e IMC. Foram classificados sem risco os que apresentar am CC normal (CC $<$ $80 \mathrm{~cm}$ para mulheres $\mathrm{e}<94 \mathrm{~cm}$ para homens) e IMC baixo peso ou normal (IMC $<25 \mathrm{~kg} / \mathrm{m}^{2}$ ou menor que o percentil 85 [adolescentes]). Com risco, aqueles com RNI (CC $\geq 80 \mathrm{~cm}$ para mulheres e $\mathrm{CC} \geq 94 \mathrm{~cm}$ para homens) independente da categoria do IMC, e também aqueles com sobrepeso ou obesidade pelo IMC para a definição do modelo explicativo final na logística multivariada.

As informações sócio-demogáficas e de sedentarismo foram obtidas através de entrevistas face a face utilizando questionário estruturado e pré-codificado. A escolaridade foi agupada em baixa (analfabeto ao 10 grau incompleto), média $\left(19\right.$ grau completo a $2^{\circ}$ grau incompleto) e alta ( $\geq$ 2 으 grau completo). A classe econômica foi definida pelos critérios propostos pela Associação Nacional de Pesqui isa ${ }^{23}$ de acor empregados de instrução do chefe da família. Para a análise, as classes 
on the role of emerging risk factors such as hypertiglyceridemia, certain subclasses of LDL-c, homocysteine and lipoprotein(a) $[\mathrm{Lp}(\mathrm{a})]$ has gained substantial interest in cardiovascular research [3].

In spite that $\mathrm{Lp}(\mathrm{a})$ physiologic function has not been completely understood [4], its clinical importance in fibrinolytic and atherothrombotic processes has already been described elsewhere $[5,6]$. In fact, the mechanism by which Lp(a) contributes to atherosclerosis is poorly understood, but it appears to be related to its lipoproteic structure that includes a lipidc omponent similar to LDLand two major proteins: apolipoprotein (a) $[\mathrm{Apo}(\mathrm{a})]$ and apolipoprotein $\mathrm{B} 100$ [5]. The LDL-resembled lipid component induces accumulation of cholesterol in the atheroma [6], whereas the possible inhibitory effect of $L p(a)$ on fibrinolysis may be explained by a competitive structural similarity between Apo(a) and plasminogen, overall contributing as a prothrombotic factor in the activation of atherothrombosis [4-6]. Recent studies have showed that $\mathrm{Lp}(\mathrm{a})$ can be oxidized within the arterial walls and induce adhesion molecules upregulation on monocytes, leading to further increment of atheromatous volume [5].

Additionally, Lp(a) has been associated with high blood pressure [7], diabetes mellitus [8,9] and dyslipidemia [10,11] According to some authors obesity, another important risk factor for CVD, may also be correlated with altered Lp(a) [12-14].

The purpose of the present study is to evaluate whether the serum levels of $\mathrm{Lp}$ (a) are associated with ischemic heart disease (IHD) as well as other cardiovascular risk factors in a population-based study conducted on a local cohort of the Brazilian population.

\section{Materials and methods}

Ouro Preto is a small-sized city located in the metallurgic zone of Minas Gerais State, southeast of Brazil, and it comprises around 9287 homes and 37,603 inhabitants [15].

In a cross-sectional study, 930 homes were randomly selected out of 33 city districts on a simple sample basis. Proportionality of population density within each district was systematically considered throughout the selection process. On each sampled home, an individual aging 15 years or more whose birthday was nearby the interview date was selected to study inclusion. Participation in the study was voluntary, and a signed informed consent was obtained from all participants. Blood pressure was measured at home and sociodemographic information as gender, age, ethnicity, education and economical class were obtained upon personal intervicw. Behavior parameters as smoking, ingestion of alcoholic drinks and physical inactivity were also acquired. Subsequently, agreeable volunteers were encouraged to present themselves at the health service of Federal University of Ouro Preto (UFOP) for collection of blood samples, anthropometric measurements and recording of electrocardiograms (ECG).
Two blood pressure measurements were camied out in seated position upon interval of $3 \mathrm{~min}$, using an aneroid manometer. Blood pressure range was classified in accordance with the IV Brazilian Guidelines of Arterial Hypertension criteria [16] in normal $(<130 \mathrm{mmHg}$ and $<85 \mathrm{mmHg})$; borderline $(130-139 \mathrm{mmHg}$ and $85-89 \mathrm{mmHg})$, mild hypertension $(140-159 \mathrm{mmHg}$ and $90-99 \mathrm{mmHg})$, moderate hypertension $(160-179 \mathrm{mmHg}$ and $100-109 \mathrm{mmHg}$ and severe hypertension ( $\geq 180 \mathrm{mmHg}$ and $\geq 110 \mathrm{mmHg}$ ). Individuals with ECG parameters suggesting myocardial ischemia were additionally referred to a stress testing, aiming diagnosis confirmation. Body mass was recorded using a TANITA BF542 scale and a wall-attached stadiometer. The body mass index (BMI) was calculated in $\mathrm{kg} / \mathrm{m}^{2}$ according to the World Health Organization criteria [17]. Waist and hip circumference were measured and classified according to Han et al. [18]. Risk stratification for waist-to-hip ratio followed criteria described elsewhere [19] with abnormal values $>0.95$ in men and $>0.80$ in women. Percentage of body fat was assessed by bioelectric impedance using scales TANITA BF542 [20] and OMRON BF300 [21]. All biochemistry analyses were conducted using the analyzer AIRONE 200. Total cholesterol, HDL-e, triglyceride and glucose levels were dosed by enzymatic-colorimetric assays ( $I n$ Vitm Diagnóstica). Lipid levels were classified in accordance to the Adult Treatment Panel III of the National Cholesterol Education Program [22]. The fasting glucose levels were classified in accordance with the Brazilian Society of Diabetes criteria [23]

$\mathrm{Lp}$ (a) values were detennined using immunoturbidimetric method (In Vitro Diagnóstica) in 400 sub samples from the cross-sectional study. Serum aliquots were stored at $-80^{\circ} \mathrm{C}$ before assayed.

Analysis of variance test (ANOVA) was used to estimate statistical significance between mean values of logarithmic $\mathrm{Lp}(\mathrm{a})$ in each category of the demographic variables (sex and age), anthropometric data and body composition (BMI, percentage of body fat, waist circumference and waist-to-hip ratio), biochemistries (lipid profile and fasting glucose), plus clinical parameters (blood pressure and ischemic heart disease), using $95 \%$ confidence intervals (CI) to guide interpretation. Means of $\log \mathrm{Lp}(\mathrm{a})$ were recalculated into the original scale (mg/dL). Association between Lp(a) and independent variables was assessed using multivariate analysis. Simple linear regression was used to evaluate the correlation between $\mathrm{Lp}(\mathrm{a})$ and the Framingham risk score. The analysis was carried out using SPSS software.

The study was previously approved by the Ethics Review Board of the Federal University of Ouro Preto.

\section{Results}

The total sample $(n=400)$ was composed of $73.5 \%$ (294) women and $26.5 \%$ (106) men, with mean age of $45 \pm 17$ years. Fig. 1 shows the asymmetrical distribution of Lp(a) 


\section{Lipoprotein(a) as a risk factor associated with ischemic heart disease: Ouro Preto Study}

Ana Paula Carlos Cândido ${ }^{a}$, Silvania Ferreira ${ }^{\mathrm{a}}$, Angélica Alves Lima ${ }^{\mathrm{b}}$, Roney Luiz de Carvalho Nicolato ${ }^{\mathrm{b}}$, Sílvia Nascimento de Freitas ${ }^{\mathrm{c}}$, Paulo Brandão ${ }^{\mathrm{d}}$, Alexandre Pereira ${ }^{\mathrm{c}}$, José Eduardo Krieger ${ }^{\mathrm{c}}$, Raimundo Marques do Nascimento-Neto ${ }^{\mathrm{f}}$, George Luiz Lins Machado-Coelho ${ }^{\mathrm{a}, *}$

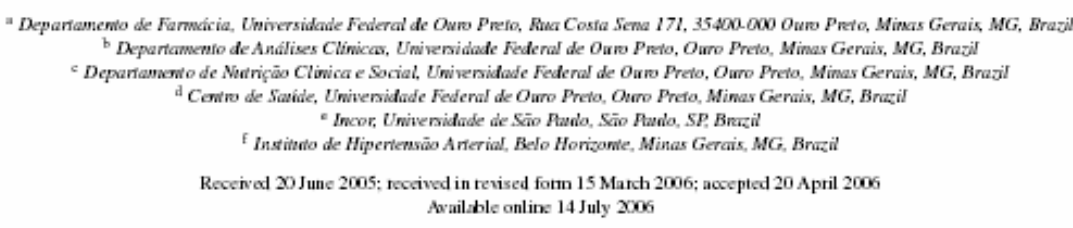

Abstract

Evidences suggest that lipoprotein(a) [Lp(a)] is an important risk factor for cardiovascular disease. However, literature has been in confirming its role as an independent risk factor for cardiovascular disease. The objective of the present study is to evalu ate the association between serum levels of $\mathrm{L}$ (a) and ischemic heart disease as well as other cardiovascular risk factors in a population-based study onducted on a local cohort of the Brazilian population.

Lpià serum levels were measured in 400 individuals selected from a larger sample of a populational survey carried out in Ouro Preto. a city in the southeast of Brazil. Lipid profile, fasting blood gluoose, anthropometric and clinical parameters were analyzed.

Lp(a) levels were significantly associated with the presence of ischemic heart disease. In relation to other cardiovascular risk factors, it was verified that L (a) levels were statistically associated with age, total cholesterol, LDL-cholesterol and percentage of body fat determined by bioelectric impodanoe. LP(a) was also highly associated with the Framingham risk soore $(p=0.003)$. In a multivariate analysis two significant interactions were revealed; one imvolving ischemic beart disease, sex and age and other associating ischemic heart disease, age and total cholesterol.

In summary, in the present amalysis Lp(a) serum levels were correlated with the occumence of ischemic heart disease and other cardiovascular risk factors

(10) 2006 Elsevier Ireland Ltd. All rights reserved.

Keymont: Lipoprotein(a); Cardionsscular rikk fastors; lschemic heart disease; Obesity

\section{Introduction}

Cardiovascular diseases (CVD) are a major cause of death in developed countries and certainly a heavy epidemiologic burden. About 17 million people die annually as a conse-

* Corresponding authar. Te1.: +55 313559 1638; fix: +55 3135591628. E-mail address: gmcoelho@ efufop.br (G.L.L. Mxchado-Coelbo). quence of cardiovascular outcomes, particularly heart attacks and stroke [1]. In Brazil, CVD constitute the most important cause of death in both genders in all regions of the country [1]. While various corventional risk factors, such as male gender, advanced age, high blood pressure, diabetes mellitus and obesity have showed to predict CV risk, not all cardiovascular events can be explained by these corventional risk factors [2]. In this purticular context, additional clarification

0021.91505 - see front matter Q 2006 Elseriat Ireland L.td. Al tights resenved doi:10.1016].athetos:letosis.2006.04.031 


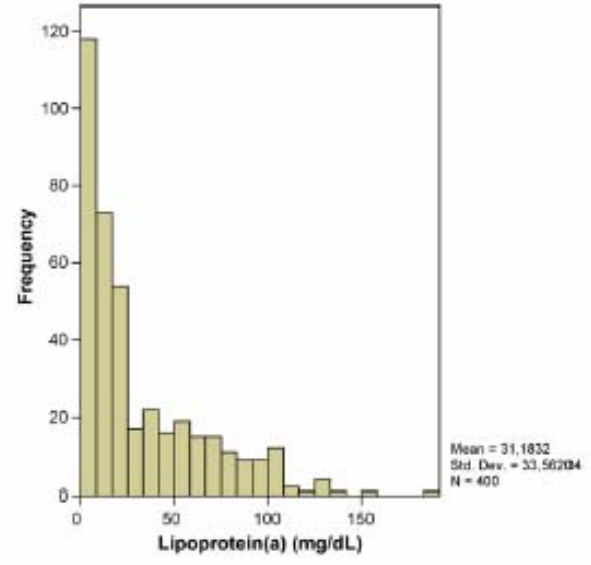

Fig. 1. Distrikuition of lipoprotein(a) concentration (mg/dL) in the 400 individuals studied.

in this population. Mean \pm standard deviation (S.D.) was $31.18 \pm 33.56 \mathrm{mg} / \mathrm{dL}$ and the median level $18.11 \mathrm{mg} / \mathrm{dL}$. The distribution of $\log$ transformed $\mathrm{Lp}$ (a) values was normal and used in all subsequent analysis. Thirty-six percent of individuals presented $L p(a)$ levels above $30 \mathrm{mg} / \mathrm{dL}$, whereas null values of $\mathrm{Lp}(\mathrm{a})$ occurred in around $15.5 \%$ of studied individuals.

Table 1 presents the univariate analysis of $\mathrm{Lp}(\mathrm{a})$ levels in comparison to demographic and behavior variables. No significant difference was found between $\mathrm{Lp}$ (a) serum levels regarding gender. Age was significantly associated with Lp(a) levels; individuals aged 60 years and older presented

Table 1

L.poprocein(a) level in accordance to demographic and behnior variables

\begin{tabular}{|c|c|c|c|}
\hline Variables & $n$ & Mean \pm S.D. & p.Valu \\
\hline Gender & & & 0.893 \\
\hline Fanule & 294 & $31.29 \pm 33.54^{*}$ & \\
\hline Male & 106 & $3088=33.79$ & \\
\hline Total & 400 & $31.18 \neq 33.5 \mathrm{Gr}^{\circ}$ & \\
\hline Age (ycars) & & & 0.041 \\
\hline $15-19$ & 34 & $2784 \pm 30.25$ & \\
\hline $20-39$ & 124 & $28.86=34.52^{2}$ & \\
\hline $40-59$ & 148 & $3006 \pm 34.22^{7}$ & \\
\hline$\geq 60$ & 94 & $37.22 \pm 32.1 d^{d}$ & \\
\hline Total & 400 & $31.18=33.56$ & \\
\hline Smoking & & & 0.274 \\
\hline Non-smoker & 228 & $33.17 \neq 34.53^{n}$ & \\
\hline Ex-smoket & 100 & $31.10 \pm 33.20$ & \\
\hline Smokat & 68 & $25.70 \pm 31.2 \%$ & \\
\hline
\end{tabular}

Sinilar supascript chataktets (a and b) indicate mo significant diffacenes within groups.
Table 2

Lipoprotein(a) levels in accordanes to biocheruistry vatiables

\begin{tabular}{llll}
\hline Vatiables & $n$ & Mann \pm S.D. & $p$-Value \\
\hline
\end{tabular}

WLefmogd

$\begin{array}{lll}\leq 129 & 348 & 28.50 \pm 31.81^{41}\end{array}$

$130-159 \quad 39 \quad 47.87 \pm 41.72$

$\begin{array}{lrr}\geq 160 & 8 & 53.52 \pm 34.94^{b} \\ \text { Tatal } & 395 & 30.92 \pm 33.54\end{array}$

Total chdestatol (mg,dL)

$<00$

$200-239$

$\geq 240$

Tatal

HDL.e (mg/dl.)

$>60$

$40-60$

$<40$

Tatal

Trighycetids (mg/AL).

$>200$

$150-199$

450

Toxal

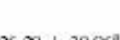

0.003

$26.29 \pm 30.06^{2}$

$40.16 \pm 39.19^{4}$

$45.52 \pm 34.50^{\circ}$

$31.18 \pm 33.56$

$33.25 \pm 34.65^{\prime \prime}$

$28.05 \pm 31.87^{4}$

$37.70 \pm 29.41^{4}$

$31.18 \pm 33.56$

$29.61 \pm 33.03^{3}$

$37.53 \pm 37.92^{4}$

$34.20 \pm 31.96^{\circ}$

$31.02 \pm 33.55$

Fusting glucose (mg/dL)

$<10$

$110-12$

$90.10 \pm 33.17$

$30.10 \pm 33.17^{7}$

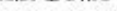

$31.18+33.56$

Tatal

$31.18 \pm 33.56$

Similar superscript ( $\mathrm{a}$ and $\mathrm{b}$ ) chuncters indicate no significant difference within groups.

higher Lp(a) levels [37.22 mg/dL. (IC 95\%. 30.65-43.80)] than individuals between ages 15 and 19 years $[27.84 \mathrm{mg} / \mathrm{dL}$. (IC 95\%, 17.29-38.40)], as well as between ages 20 and 39 years $[28.86 \mathrm{mg} / \mathrm{dL}$ (IC $95 \%, 22.73-35.0)]$. Individuals aged between 40 and 59 years presented borderline Lp(a) mean levels [30.06 mg/dL. (IC 95\%, 24.50-35.62)]. There were no significant differences in Lp(a) levels concerning smoking status.

Lp(a) was correlated to biochemical variables as described in Table 2. Univariate analysis of mean Lp(a) levels were similar in individuals with LDL-e classified as moderate $[47.87 \mathrm{mg} / \mathrm{dL}$ (IC $95 \%, 32.22-47.49$ )] and high $[53.52 \mathrm{mg} / \mathrm{dL}$ (IC 95\%, 32.87-58.18)]. Both Lp(a) levels at moderate and high LDL-c were significantly higher than in individuals with normal LDL-c [28.50 mg/dL (IC 95\%, 22.62-29.89)]. Correspondingly, in individuals with moderate and high total cholesterol the mean Lp(a) levels $[40.16 \mathrm{mg} / \mathrm{dL}$. (IC $95 \%, 32.29-48.02$ ) and $45.52 \mathrm{mg} / \mathrm{dL}$ (IC $95 \%, 32.86-58.17$ ), respectively] were significantly higher in comparison to Lp(a) in individuals within the nomal range of total cholesterol [26.29 mg/dL (IC 95\%, 22.67-29.88)]. In contrast, no significant associations were found for Lp(a) levels and HDL-c, triglycerides and fasting glucose.

As showed in Table 3, no association were observed betwoen Lp(a) levels and anthropometric parameters as 
Takle 3

\begin{tabular}{|c|c|c|c|}
\hline Variables & $n$ & Mean \pm S.D. & $p$-Valus \\
\hline \multicolumn{4}{|c|}{ Body mass index $\left(\mathrm{kg}^{\prime} / \mathrm{m}^{2}\right)$} \\
\hline$<18.5$ & 6 & $41.85 \pm 35.95$ & \multirow[t]{4}{*}{0.680} \\
\hline $18.5-24.9$ & 172 & $2901 \pm 32.49^{\circ}$ & \\
\hline $25.0-29.9$ & 130 & $32.23 \pm 32.01^{14}$ & \\
\hline$>30.0$ & 92 & $33.07 \pm 37.55^{\prime \prime}$ & \\
\hline Total & 400 & $31.18 \pm 33.56$ & \\
\hline \multicolumn{4}{|c|}{ Waist circumfertne $(\mathrm{cm})^{*}$} \\
\hline Notmal & 169 & $29.92 \pm 32.84^{\prime \prime}$ & \multirow[t]{3}{*}{0.524} \\
\hline Overwaight & 85 & $28.16 \pm 29.44^{\circ}$ & \\
\hline Cbesity & 142 & $34.85 \pm 36.24^{4}$ & \\
\hline Total & 396 & $30.93 \neq 33.47$ & \\
\hline \multicolumn{4}{|l|}{ Waist hip natio" } \\
\hline Without risk & 183 & $27.68 \pm 32.05^{4}$ & \multirow[t]{2}{*}{0.111} \\
\hline With risk & 213 & $33.72 \pm 34.45^{\circ}$ & \\
\hline Total & 396 & $30.93 \pm 33.47$ & \\
\hline \multicolumn{4}{|c|}{ Body fat by TANTTA } \\
\hline Low weight & 10 & $26.53 \pm 26.62^{a}$ & \multirow[t]{4}{*}{0.367} \\
\hline Notral & 176 & $27.85 \neq 30.53^{4}$ & \\
\hline Overweight & 98 & $31.12 \pm 33.24^{4}$ & \\
\hline Obssity & 111 & $36.33 \pm 38.34^{-3}$ & \\
\hline Total & 395 & $31.01 \pm 33.55$ & \\
\hline \multicolumn{4}{|c|}{ Body fat by CMRON $=m$} \\
\hline Low weight & 29 & $26.02 \pm 30.53^{\text {th }}$ & \multirow[t]{4}{*}{0.017} \\
\hline Nonml & 100 & $22.18 \pm 26.90^{\circ}$ & \\
\hline Onerweight & 91 & $30.54=31.58^{b}$ & \\
\hline Obesity & 163 & $37.35 \pm 37.28^{b}$ & \\
\hline Total & 383 & $30.93 \neq 33.48$ & \\
\hline
\end{tabular}

$30.93 \pm 33.48$

Similar superscript characters (a and b) indicate no significant differenee within groups. The cut off aere defined by [18], [19], [20]," [21]."

body mass index $(p=0.69)$, waist circumference $(p=0.52)$ and waist-to-hip ratio $(p=0.11)$. Inversely, $L p(a)$ levels of obese individuals [37.35 mg/dL (IC $95 \%, 31.56-43.11$ )] as determined by bioelectric impedance (OMRON) were significantly higher $(p=0.02)$ than in low and normally weight individuals $[26.02 \mathrm{mg} / \mathrm{dL}$ (IC 95\%, 14.41-37.64) and $22.18 \mathrm{mg} / \mathrm{dL}$ (IC $95 \%, 16.82-27.53$ ), respectively]. Further to these results, although obesity as measured by an alternative impedance method (TANITA scale) showed no significant differences in $L p(a)$ values $(p=0.37$ ), a consistent trend of increasing was observed with this method in obese $[36.33 \mathrm{mg} / \mathrm{dL}$ (IC $95 \%, 29.12-43.54$ ) in comparison to low weight individuals [26.53 mg/dL. (IC 95\%: 7.45-45.57)].

Regarding the clinical variables, $\mathrm{Lp}(\mathrm{a})$ levels did not alter significantly as a consequence of changes in the systolic $(p=0.38)$ and diastolic blood pressure $(p=0.81)$ as shown in Table 4. On the contrary, significantly higher levels of $L p(a)$ were found in individuals with ischemic heart disease [44.81 mg/dL. (IC 95\%, 31.61-58.02); $p=0.03]$ as compared to individuals with no elinical and electrocardiografic patterns of myocardial ischemia [29.92 mg/dL (IC $95 \%, 26.53-33.30)]$.
Table 4

Lipoprotan(a) levd in accotdanse to clinical vatiables

\begin{tabular}{lll}
\hline Vatiables & $n$ & Mean \pm S.D.
\end{tabular}

Systolic blood presame (mm

$<130 \quad 109 \quad 28.37 \pm 32.19$

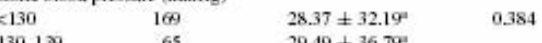

$\begin{array}{lll}130-139 & 65 & 29.49 \pm 36.79 \\ 140-159 & 78 & 3.14 \pm 33.55\end{array}$

$30.14 \pm 32.53$

$\begin{array}{lll}160-179 & 45 & 35.69 \pm 34.66\end{array}$

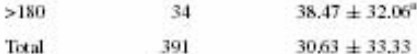

Diastolic blood pressure (minHg)

$\begin{array}{lll}<5 & 209 & 30.52 \pm 33.86\end{array}$

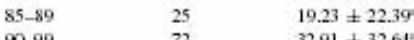

$90-99 \quad 72 \quad 32.91 \pm 32.64$

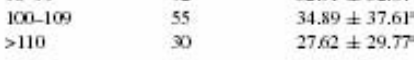

Txal $\quad 391 \quad 3063 \pm 33.33$

Eschemic heart diseuse

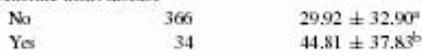

0.814

Total $\quad 400 \quad 31.18 \pm 33.56$

Similar supersctipt chanacten $(a$ and b) indicate no sigmificant difference within groups.

Fig. 2 shows that $L p(a)$ levels vary as a function of Framingham risk score $(p=0.003)$. However, $L p(a)$ was not shown to be an independent factor, because interactions were observed between ischemiaand cholesterol and age $(p=0.04)$ as well as with gender and age ( $p=0.03$ ). In non-ischemic subjects as higher are the cholesterol more elevated are the $\mathrm{Lp}$ (a) levels regardless of age. In contrast, in ischemic subjects over age of 60 years the Lp(a) decreased with the increase of cholesterol levels, whereas the same tendency was not observed in individuals between 40 and 59 years.

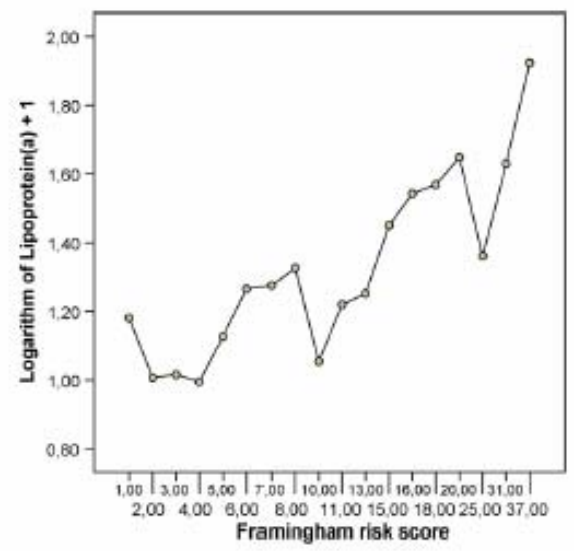

Fig. 2. Lipoprotein(a) levels and Framingham rikk. $\log L p(a)=1.078+$ Q.018; Franinghan tisk scote, $p=0.003$. 
Additionally, in non-ischemic participants Lp(a) did not vary significantly with age, although in ischemic males it was higher under 60 years and higher in females between 40 and 59 years.

\section{Discussion}

In our population cohort $\mathrm{Lp}(\mathrm{a})$ mean levels $(31.18 \pm$ 33.56) were similar to that observed in France by Boyer et al. [10]. The distribution of $\mathrm{Lp}$ (a) was asymmetrical with a high frequency of null $(15.5 \%)$ or low values, as observed by other authors $[10,13,24]$. These low values could be due to differences in methods' sensibility. Altematively, low Lp(a) values may also reflect low or absent Lp(a) synthesis by some individuals as a function of Apo(a) non-expression [25].

Our study showed that $\mathrm{Lp}(\mathrm{a})$ levels were significantly associated with age, LDL-c, total cholesterol, body fat and IHD. Leino et al. [24] also observed higher levels of Lp(a) in individuals aged 60 years or older in both sexes as compared to younger individuals. Likewise, association with lipid parameters was found by Boyer et al. [10] in a population of 1000 dyslipidemic individuals with mean age of 45 years. Unlike those observed in our study, these authors reported significant correlation between Lp(a) levels with all lipid parameters (total cholesterol, LDL-c, tryglicerides, HDLc and apoB). The discrepancies between our data and the results of these authors may be due to the low prevalence of hipertrygliceridemia and low HDL-c in our population (data not published).

Some authors suggest that the dosage of $\mathrm{Lp}(\mathrm{a})$ can be useful to evaluate the risk of coronary artery disease in diabetic patients [8,9]. Gazzaruso et al. [8], for instance, observed that higher levels of $\mathrm{Lp}$ (a) may be used as predictors of coronary artery disease (CAD) severity in type 2 diabetic patients. Habib and Aslam [9] concluded that Lp(a) levels were significantly elevated in diabetics as compared to nondiabetic; however, in agreement with our data, no correlation between $L p(a)$ and fasting glucose was verified. Nevertheless, we emphasize that only a single glucose determination was accomplished in our study. Hence, relationship between Lp(a) levels and diagnosis of diabetes may not be disegarded [23].

As also referred elsewhere [12-13], our study did not exhibit a significant association between obesity, as defined per body mass index, and Lp(a). Of particular importance in this analysis is the evidence that BMI is not a specific anthropometric measurement for determination of body fat content [26], therefore not standing as the ideal index to evaluate the association between Lp(a), obesity and CVD. The location of body fat deposits seems to be especially important to predict alterations in the lipid metabolism [27] and, consequently, on the $\mathrm{Lp}(\mathrm{a})$ levels. Different authors have observed association between obesity and $L p(a)$ only when parameters that evaluate the percentage and location of body fat content were used [13,28]. When we measured the proportion of body fat a significant association between Lp(a) and this parameter was observed; occurrence not verified, on the other hand, with other variables that indicate body fat distribution as waist circumference and waist-to-hip ratio. In general, no significant association trend was observed between all obesity-related indices and $\mathrm{Lp}(\mathrm{a})$ levels.

In spite of the various influences that the smoking habit may exert on lipid metabolism, a positive association between tobacco use and $\mathrm{Lp}(\mathrm{a})$ levels was not verified either in this study or elsewhere [29]. With respect to blood pressure, wo have not demonstrated any association between systolic of diastolic components of arterial blood pressure and Lp(a) levels. Similarly, Catalano et al. [7], examining hypertensive and non-hy pertensive individuals, did not observe differences in concentration of $\mathrm{Lp}(\mathrm{a})$. However, regardless of their results these authors suggested that high levels of $\mathrm{Lp}$ (a) could be the first pathological hint of target-organ damage.

In our cohort levels of Lp(a) were significantly higher in individuals with electrocardigraphic evidence of ischemic heart disease than in those without it. A gewall and Fagerberg [30] in a prospective study of 118 men, aged 56-77 years, observed that subjects with coronary heart disease (previous myocardial infaretion, angina, or major electrocardiographic changes) had significantly higher Lp(a) levels than subjects without known coronary heart disease. These authors concluded that $L p(a)$ was an independent predictor of major coronary events.

In spite of the association between $L p(a)$ and the Framingham risk score as reported in our cohort, our multivariate analysis found that $L p(a)$ was not considered an independent risk factor for ischemic heart disease. Inversely, recently published data [31] indicated that elevated Lp(a) increased the risk for myocardial infarction and angina, especially in men with a high LDL-c levels. Paradoxically, results published elsewhere [32] considered $\mathrm{Lp}$ (a) as an independent predictor of stroke, death from vascular disease and death from any cause in older men.

In light of our results we conclude that $L p(a)$ levels varied significantly, as a function of age, with ischemic heart disease as well as with other lipid parameters in the setting examined. Even though our findings support the relevant association of elevated Lp(a) and occurrence of myocardium ischemia, specially in older adults, additional data remain to be acquired on future studies as to clarify more comprehensively whether $\mathrm{Lp}$ (a) should play a role as a screening tool in the quotidian clinical practice.

\section{Acknowledgments}

The authors gratefully acknowledge Dr. David Brasil for his invaluable assistance in reviewing linguistic and methodological aspects of this manuscript as well as Mr. Adāo Rocha for his diligent technical assistance during achievement of the biochemical assays. This study was supported by research 
grants from UFOP and CAPES, in addition to supplementary funding from UNIMED Inconfidentes, Alcan Alumínio do Brasil and Secretaria Municipal de Saúde de Ouro Preto.

\section{References}

[1] OBAS (Organización Punamericana de la Salud). Tendencias demogrtíficas y de mottalidad en la regíńn de las Annéricse, 1980-2000. Bd Epidemiol 2002:23(3):1-4.

[2] Ammaganijn D. Batloumi M. Impacto dos fatores de risco tradicionais. Rov Soc Cardiol Estado de São Paalo 2000;10(6):686-93.

[3] Harjai KJ. Potasial newe cardionzscular tisk factors: left ventriculat hypertiophy, homocysteine, lipoptotein(a), ticlycerides, oxidative lar hypettrophy, homocysteine, lipoptotein(a), triglyeen.

[4] Koschinsly ML. Marcovina SM. Stucture-function relationships in apolipoprotein (a): irsights irto lipoprotein(a) assembly and in apolipoprotein (a): insights into lipoprotein(a)

[5] Koschinsky ML. Matcoina SM. Evaluation of lipoprotin(a) as a prothrombotic faxtor: progress from bench to bedside. Curr Opin Lipidal 2003:14(4):361-6.

[6] Angles-Cano E. Struxtural basis for the puthoptrysiology of lipopto tein (a) in the athero-thrombetic prooes. Brox J Med Biol Res 1997:30:1271-80.

[7] Catalam M, Petilli E, Carmaiga G, et al. L p (a) in hypertansive patients. J Hum Hypertens 1998:12:83-9

[8] Gazzatuso C, Bruno R, Pujia A, et al. Lipoprotein(a), apolipoprotein(a polymorphism and cotonaty athetoocletosis severity in type 2 diabstic patierts. Int J Cardiol 2006 168(3):354-8.

[9] Habib SS, Aslam M. Lipids and lipoprotein(a) concentrations in Pakistani patients aith type 2 diabstes mellitus. Diab Obes Metab 2004;6:338-43.

[10] Boyer H, Genne Л., Truffert J, et al. Lpoia) leveds in diffarent types of dysipidamia in the French population. Atherosckfosis 1990:85:61 -

[11] Wang J, Zhars C, Chen D, Liu X, Feng X. Lipoprotein (a) and its inmune complexes in dyslipidernic subjects, Clin Bioctem 2004:37:710-3.

[12] Lamon Fiun S, Wiloon P. Schacfer EJ Impat of body mess inder of

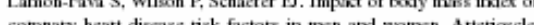
cornnaty heart discase tisk factots

[13] Chien K-L. Lee Y-T, Sung F-C, at al. Lipoprotein (a) level in the population in Taiwan: relationship to sociodemognaphic in the population in Tuiwan: relationship to sociodemognaphic and at $267-73$.

[14] Alanji A, Al-Shayji I, Kumar P. Metabolic and anthropanetric daterminants of serum Lp(a) concentrations and apo(a) polymorphism in a heal thy Anab population. Int J Obe 1999:23:855-62.

[15] IBGE (Instituto Brasileiro de Geografia e Estatística). Contagem pop ulacional: 1996.

[16] Mion Júniot D. (Cootd.). IV Dirttrizes Brasileins de Hipentaxāo Anterial. Sociodade Btrailein de Hipettereāo, Sociedade Brasilein de Curdiologia, Sociedade Btasilein de Nefrologia. hup/f publicacoes.cardiol.btfconserso/2004/Dirtriz\% 20HA\%20ENG.pdf; September 2002

[17] Warld HealthOtganizztion. WHO Expent Committee on Physical Status: the use andintapretation of anthroponetry physical status. Genevw: World Heal th Organization; 1995 [WHO Technical Report Scrie, vol. 854].

[18] Han TS, Van Leer EM, Seidell JC, Lean MEJ. Waist circunference action levek in the identification of cardiovercular risk factors: prevaknce study in a nandom sample. BMJ 1995:311:1401-5.

[19] Petein RA, Sichieti R. Matirs VMR. Raxiso cinturadquadril como preditor de hipentensāo arterial. Cad Saúde Pública 1999:15(2): 333-44.

[20] Gallaghet D, Heymsfield SB, Heo M, et al. Heal thy percentage body fat ranges: an approsich for developirng guidelines bosed on body mass index. Am J Clin Nutr 2000:72694-701.

[21] Irstruxtion manual body fat monitor Omton BF 300 , sxailable at hitp://hww.comton-healtheate.con'/ [ascessed on 2003/2003].

[22] National Irstitutes of Health Third Report of the National Cholesterol Edusation Ptogram. Expert Panel on Detection. Evaluation and Treatment of High Blood Choksterol in Adults (Adult Treatment Pand III). National Chdesteml Edusation Program. Treatment Pand III). National Cholesterol Bdusation Progeram. Health. Washington DC, US. NHI Publication. 01-3670; 2001.

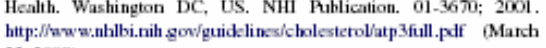
$25,2000)$.

[23] Sociedade Brasikira de Diabetes Conserso Brasikito de Conceitos - Condutas pana o Diabstes Mellitus Resomendeçāo da Sociedude Brasileina de Diabstes pata a Prática Clínica. Foderaçāo Internacional de Diabstes/Associaçăo pata a Amónica do Sul e Caribe October; 2000. http://www.anadotg.br/conserso. hitm (May 12, 2001).

[24] Leino A, Impivaata O, KaitsariM,Järvisalo J. Sesum consentratices of apolipoptotein $A-1, A$ polipoptotein B and lipoprotein(a) in a population sample. Clin Chem 1995;41:1633-6.

[25] Utermann G. Genetic architectute and evolution of the lipoprotein(a) trait. Curt Opin Lipidd 1999:10:133-41.

[26] Ftankenficld DC, Rovae WA, Coonsy RN, Smith JS, Becket D. Limits of body mass index to detest doesity and predict body composition. Nutrition 2001:17:26-33.

[27] Després JP. The insulin resistance-dyslipidemic syndtome of viscenal obesity: effect on putiants' risk. Obe Res 1998:6:8-17.

[28] Sattar N. Tan C. Han T, et al. Associatices of indices of scliposity with atherogenic lipoprotein subfiactions. Int J Obes 1998;22:432-9.

[29] SanzEJ, Cazunto AM. Bellido AL., MartinIML. Cigarette consumpticn and lipoprectin(a) concentrations. Clin Chem 1996:42:479.

[30] Agewall S, Fugetberg B. Lipoptrotein (a) was an independert predictor for majot coronary events in tested hypentensive men. Clin Cardid $2002: 25: 287-90$.

[31] Lue G, Bard JM, Anviler D, et al. Lipoprotein (a) as a predictot of ortonary heart disease the PRIME Study. Athetroscletosis 2002:163:377-84

[32] Ariyo AA, Thach C, Tracy R. L.p(a) lipoptotein, vascular disease, and mottality in the eldaty. N Engl I Med 2003;349:2108. 


\section{A comparative study of methods for diagnosis of obesity in an urban mixed-race population in Minas Gerais, Brazil}

Silvia Nascimento de Freitas ${ }^{1} * *$, Waleska Teixeira Caiaffa ${ }^{2}$, Cibele Comini César ${ }^{3}$, Ana Paula Carlos Cândido', Valéria Andrade Faria ${ }^{4}$, Raimundo Marques do Nascimento Neto ${ }^{5}$ and George Luiz Lins Machado-Coelho ${ }^{6}$

'Department of Social and Clinical Nutrition, School of Nutrition, Federal University of Ouro Preto (UFOP), University Campus, Morro do Cruzeiro, CEP 35400/000 Ouro Preto, MG, Brazil: ${ }^{2}$ Deparment of Social and Preventive Medicine, School of Medicine, Epidemiology Research Group, Urban Health Observatory of Belo Horizonte,

Federal University of Minas Gerais (UFMG), Belo Horizonte, Brazil: ${ }^{3}$ Deparment of Statistics, Exact Science Q1 Institutes, UFMG, Belo Horizonte, Brazil: ${ }^{4}$ Holder of Scientific Initiation Grant, UFOP, Ouro Preto, Brazil: ${ }^{5}$ Institute of Hypertension, UFOP, Ouro Preto, Brazil: 'Department of Pharmacy, School of Pharmacy, UFOP, Ouro Preto, Brazil

Subritted 5 July 2005: Accepted 10 May 2006

\section{Abstract}

Background: Obesity is defined as an excess of total body fat and may be assessed by different methods. The objective of the present study was to establish the discriminatory power of anthropometric data in determining obesity.

Methods: The subjects comprised 685 individuals, aged $20-79$ years, sampled from a population-based survey. The following indicators were used: body mass index (BM), waist circumference (WC) and total body fat percentage estimated with both Sirr's equation (\%BF Siri) and foot-to-foot bioelectrical impedance analysis (\%BF BIA) Sensitivity and specificity of different cut-off points for each method were determined using \%BF BIA as reference.

Results: Of 685 participants, $57.6 \%$ were aged $\geq 40$ years, $69.9 \%$ were women and $72.6 \%$ self-referred themselves as non-white. To classify obesity based on sex and age among women aged $<40$ years, the cut-off points were BMI of $26.0 \mathrm{~kg} \mathrm{~m}{ }^{2}$, WC of $84.0 \mathrm{~cm}$ and $\% \mathrm{BF}$ Siri of $34.0 \%$; in those aged $\geq 40$ years, the cut-off points were $28.0 \mathrm{kgm}^{2} 90.0 \mathrm{~cm}$ and $37.4 \%$, respectively. The cut-off points among men aged $<40$ years were BMI of $26.3 \mathrm{~kg} \mathrm{~m} 2$, WC of $86.0 \mathrm{~cm}$ and $\% \mathrm{BF}$ Siri of $22.5 \%$, and in those aged $\geq 40$ years, $26.3 \mathrm{kgm}^{2}, 89.0 \mathrm{~cm}$ and $24.5 \%$, respectively. BMI was the method with the largest area under the curve (AUC) independent of sex and sex/age, yet no differences were observed in AUC between BMI and WC $(P>0.05)$. Classifying according to skin colour did not change cut-off points in any indicator. Conclusion: BMI and WC better discriminate obesity among women and men aged $\geq 40$ years from a mixed-race population.

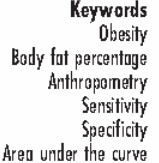

Total body fat, which is one part of body composition plays an important role in epidemiological studies because it is a known risk factor for non-communicable diseases ${ }^{1,2}$. Several different methods have been used for it assessment, among which hydrostatic weighing, dualenergy X-ray absorptiometry (DEXA), body mass index (BMI), waist circumference (WC), skinfold thickness and bioelectrical impedance stand out

Hydrostatic weighing and DEXA are considered the gold standards. However, they have the disadvantages of low applicability and high cost for population studies. On the other hand, BMI, WC, skinfold thickness and bioelectrical impedance are cheaper and quite reliable ${ }^{3}{ }^{5}$ but provide different information about body composition. BMI assesses individuals based on their total body mass; wC classifies central adiposity; and skinfold thickness estimates body fat based on the assumption that subcutaneous fat thickness comprises a constant proportion of total body fat ${ }^{3,5,6}$

Bioelectrical impedance has also been used recently to estimate body composition. It is based on the knowledge that lean body mass conducts electricity better than adipose tissue, showing an inverse relationship with body resistance under an electric current ${ }^{3}$. Two techniques are used: bipolar (conventional) and portable bioelectrical impedance analysis (BIA)

In the first method, the evaluator should be trained in order to ensure the correct placement of electrodes on the subject's feet and hands, a factor of paramount importance for accuracy and reproducibility of body component estimates ${ }^{3}$. However, the latter technique costs less, does not require much time for measurements, and recent 
studies have shown it to be valid and applicable to epidemiological investigations ${ }^{7} 9$

Although DEXA is considered the gold standard, among portable instruments the Tanita ${ }^{\circledR}$ excels in providing footto-foot BIA and has shown a high correlation with both conventional bipolar BIA and DEXA. Furthermore, the classification of body fat percentage takes into account sex and age differences ${ }^{10}$

The literature reports that body composition can be determined by several factors characterising a population such as age, sex and race, ${ }^{6,11}{ }^{13}$. Studies on body composition according to sex and age in mixed-race populations are scarce ${ }^{14} 16$. Ouro Preto City has a mixed race population, probably resulting from a high concentration of African Diaspora descendents brought to the city from the 16 th to the 18 th century, and it has a high percentage of non-white people (63.14\%) living in the urban area ${ }^{17}$. Therefore, its inhabitants present a unique opportunity to investigate indicators for the diagnosis of obesity in population groups with such characteristics.

In the light of diverse methodologies available to assess body composition and total body fat ${ }^{3,7,9}$, the objective of the present study was to verify the sensitivity, specificity and discriminatory power of anthropometric measurements obtained by different methods in determining obesity in a mixed-race population group.

\section{Materials and methods}

\section{Study population and sample}

This study included 685 participants aged $20-79$ years from a population sample of 930 residents aged 15 years or more, randomly sampled in a medium-sized town - Ouro Preto - in the Southeastern region in Brazil during 2001. I is part of a cross-sectional study aimed to investigate the prevalence of risk factors for cardiovascular disease in this population

The sampling frame was based on the following assumptions: infinite population, systemic arterial hypertension prevalence estimation at $25 \%{ }^{18}, 3 \%$ precision, $95 \%$ confidence level and estimated loss of $20 \%$

\section{Antbropometric and body composition}

\section{measurements}

The measurements were performed according to standard recommendations on subjects with an empty bladder who had fasted for $12 \mathrm{~h}$. Measurements were taken between 07.00 and 10.00 hours by the same previously trained team.

Total body fat percentage (\%BF) was measured by means of foot-to-foot BIA using Tanita ${ }^{\circledR}$ BF542 scales with an electric current of $500 \mu \mathrm{A}$ and a fixed frequency of $50 \mathrm{kHz}$, with $0.5 \%$ precision. BMI $\left(\mathrm{kgm}^{2}\right)$ was calculated as weight (in $\mathrm{kg}$ ), obtained on the scales mentioned above (which had a capacity of $136 \mathrm{~kg}$ and weight increments of $0.2 \mathrm{~kg})$, divided by the square of height $(\text { in } \mathrm{m})^{3,19}$. WC $(\mathrm{cm})$ was measured at the natural waist, which is the midpoint between the lower costal arch and the lliac crest, using a 2 non-elastic measuring tape with a precision of $0.1 \mathrm{~cm}^{19}$ Triceps, biceps, subscapular and suprailiac skinfold thickness ( $\mathrm{mm}$ ) was measured on the non-dominant side of the body by means of a CESCORF ${ }^{\circledR}$ apparatus, with a precision of $0.1 \mathrm{~mm}$. Three measurements were carried out on each skinfold, and the mean was considered for analysis ${ }^{19}$. Body density was estimated according to sex and age using the Durnin and Womersley equation. \%BF was also calculated based on body density by means of Siri's equation (referred to as \%BF Siri below). All participants $(n=685)$ who complied with all anthropometric measures were included in the analysis.

\section{Definition of obesity}

Excess body fat was defined by means of the criterion established by Gallagher et al. for African American populations ${ }^{10}$, following the recommendations of the manufacturer of the Tanita ${ }^{\circledR}$ BF542. Men and women with body fat excess were classified by age, and their \% $\mathrm{BF}$ was, respectively: $\geq 38 \%$ and $\geq 26 \%$ for age $20-30$ years; $\geq 39 \%$ and $\geq 27 \%$ for age $40-59$ years; and $\geq 41 \%$ and $\geq 29 \%$ for age $60-79$ years.

\section{Statistical analysis}

Analysis of correlation, using the Pearson chi-square test, was carried out between Tanita ${ }^{\circledR} \% \mathrm{BF}$ and the anthropometric and body composition variables. Using bioelectrical impedance measured by the Tanita ${ }^{\circledR}$ scales as the reference (referred to as \%BF BIA below), we calculated the sensitivity (probability of detecting truly obese individuals) and specificity (probability of detecting truly not obese individuals) for various obesity discriminating points by plotting on the receiver operating characteristic (ROC) curves by sex, sex and age, and sex and skin colour. Age was categorised according to the median distribution of the dataset ( $<40$ years: younger adults, $\geq 40$ years: older adults) and self-referred skin colour as white and non-white.

The areas under the curves (AUC), 95\% confidence intervals and standard errors were tested using the Wilcoxon test ${ }^{20}$. The method of Hanley and $\mathrm{McNeil}^{21}$, within the $95 \%$ confidence interval, was used to compare the areas under the ROC curves for each anthropometric variable.

The project was approved by the Institutional Review Board of the Federal University of Ouro Preto under the protocol 26/2001

\section{Results}

of 685 participants, 479 (69.9\%) were females and 206 (30.1\%) males, $57.6 \%$ were $\geq 40$ years old, and $72.6 \%$ selfreferred themselves as non-white. Table 1 describes their demographic, anthropometric and body composition characteristics by sex and age. 
A comparative study of methods for obesity diagnosis

Table 1 Demographic, anthropometric and body composition features according to sex, Ouro Preto City, Brazil

\begin{tabular}{|c|c|c|c|c|}
\hline \multirow{2}{*}{ Variable } & \multicolumn{2}{|r|}{ Females } & \multicolumn{2}{|r|}{ Males } \\
\hline & $n$ & Mean + SD & $n$ & Mean + SD \\
\hline Age (years) & 479 & $46.0+15.2$ & 206 & $42.7+15.4$ \\
\hline Height $(\mathrm{cm})$ & 479 & $157.1+7.1$ & 206 & $170.8+7.1$ \\
\hline Weight (kg) & 479 & $64.8+13.5$ & 206 & $70.7+12.7$ \\
\hline BMI $\left(\mathrm{kgm}^{-2}\right)$ & 479 & $26.3+5.3$ & 206 & $24.2+3.9$ \\
\hline \multicolumn{5}{|c|}{ Stratified by age } \\
\hline$<40$ years & 177 & $24.6+5.5$ & 97 & $23.5+4.1$ \\
\hline$\geq 40$ years & 302 & $27.4+5.0$ & 109 & $24.9+3.6$ \\
\hline$P$-value $(t$-test $)$ & & $<0.01$ & & 0.02 \\
\hline \multirow{2}{*}{\multicolumn{5}{|c|}{ Stratified by age }} \\
\hline & & & & \\
\hline$<40$ years & 177 & $32.0+8.4$ & 97 & $18.6+8.8$ \\
\hline$\geq 40$ years & 302 & $34.4+8.0$ & 109 & $21.3+6.8$ \\
\hline$P$-value ( $t$-test) & & $<0.01$ & & \\
\hline$\% \mathrm{BF}$ Siri & 474 & $35.4+5.9$ & 206 & $20.4+6.6$ \\
\hline \multicolumn{5}{|c|}{ Stratified by age } \\
\hline$<40$ years & 174 & $33.6+6.1$ & 97 & $19.6+7.3$ \\
\hline$\geq 40$ years & 300 & $36.5+5.5$ & 109 & $21.1+5.8$ \\
\hline$P$-value $(t$-test) & & $<0.01$ & & 0.11 \\
\hline WC (cm) & 475 & $85.2+13.7$ & 205 & $85.9+11.8$ \\
\hline \multicolumn{5}{|c|}{ Stratified by age } \\
\hline$<40$ years & 174 & $79.8+12.8$ & 96 & $81.7+10.8$ \\
\hline$\geq 40$ years & 301 & $88.3+13.3$ & 109 & $89.6+11.5$ \\
\hline$P$-value $(t$-test $)$ & & $<0.01$ & & $<0.01$ \\
\hline
\end{tabular}

$\mathrm{SD}$ - standard deviation; BMI - body mass index; \%BF BIA - percentage BF Sin - percentaged by foot-to-foot bioelectrical impedance analys waist circumference.

Females had the following anthropometry (mean \pm standard deviation, SD): age, $46.0 \pm 15.2$ years; height $157.1 \pm 7.1 \mathrm{~cm}$; weight, $64.8 \pm 13.5 \mathrm{~kg}$; BMI, $26.3 \pm 5.3 \mathrm{~kg} \mathrm{~m}^{2}$. Stratified by age, younger women presented significantly lower mean ВMI $\left(24.6 \mathrm{~kg} \mathrm{~m}^{2}\right)$ than older women $\left(27.4 \mathrm{~kg} \mathrm{~m}^{2}\right)$. \%BF Siri $(35.4 \pm 5.9)$ was higher than \%BF BIA $(33.5 \pm 8.2)$, especially among older females. Regarding WC, among all females the mean value $(85.2 \pm 13.7 \mathrm{~cm})$ was above normal levels, although younger subjects presented mean average WC $(79.8 \mathrm{~cm})$ near to normal limits.

Table 2 Correlation between anthropometric measurements and BF BIA according to sex, Ouro Preto City, Brazl

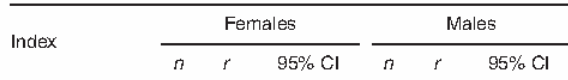

BMI $\left(\mathrm{kgm}^{-2}\right) \quad 4790.82(0.78-0.84) 206 \quad 0.90(0.87-0.93)$ Stratified by age

$\begin{array}{llllll}<40 \text { years } 177 & 0.80 & (0.74-0.85) & 97 & 0.93 & (0.90-0.95)\end{array}$ $\geq 40$ years $302 \quad 0.82(0.78-0.86) \quad 109 \quad 0.87 \quad(0.81-0.91)$ BF Siri $4740.76(0.72-0.80) 206 \quad 0.75(0.68-0.80)$ Stratified by age

$\begin{array}{lllllll}<40 \text { years } 174 & 0.79 & (0.73-0.84) & 97 & 0.79 & (0.70-0.85)\end{array}$

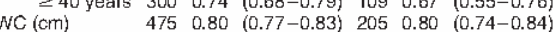
Stratified by age

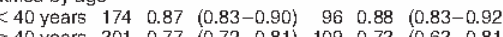
$\begin{array}{lllllll}\geq 40 \text { years } 301 & 0.77 & (0.72-0.81) & 109 & 0.73 & (0.63-0.81\end{array}$

$\mathrm{CI}$ - confidence interval; BMI - body mass indeX: \%BF Siri - percentage
total body fat estimated by Siri's equation; WC - waist circumference.
In males, anthropometry (mean \pm SD) was as follows: age, $42.7 \pm 15.4$ years; height, $170.8 \pm 7.1 \mathrm{~cm}$; weight, $70.7 \pm 12.7 \mathrm{~kg}$. ВMП $24.2 \pm 3.9 \mathrm{~kg} \mathrm{~m}^{2}$. Stratified by age men aged $<40$ years had a mean BMI of $23.5 \mathrm{~kg} \mathrm{~m}{ }^{2}$, significantly lower than that $\left(24.9 \mathrm{~kg} \mathrm{~m}^{2}\right)$ of men aged $\geq 40$ years. \%BF BIA $(20.0 \pm 7.9)$ was similar to \%BF Sirt $(20.4 \pm 6.6)$; slight but non-significant differences $(P=0.11)$ were observed when mean \%BF Siri was compared with mean \%BF BIA among younger male adults. Mean WC for all men $(85.9 \pm 11.8 \mathrm{~cm})$ was below normal levels but a significant increase with age could be observed: from $81.7 \mathrm{~cm}$ in younger males to $89.6 \mathrm{~cm}$ among older males.

Table 2 shows the correlation between anthropometric measurements and \%BF BIA, by sex and sex and age. The correlations ranged from 0.74 to 0.87 for females, and from 0.67 to 0.93 for males. BMI was the method that presented the best correlations with the reference method, except for females aged $<40$ years, whose WC correlation $(r=0.87)$ was greater than with the reference method. Nevertheless, stratifying by sex independent of age verified that the correlation found between WC and \%BF BIA showed no significant differences between sexes $(r=0.80)$

Sensitivity and specificity of several cut-off points for obesity, according to the reference method used and by sex and age, are presented in Table 3. For diagnosis of obesity, it was observed that the cut-off points showing greatest sensitivity and specificity for BMI were $27.5 \mathrm{~kg} \mathrm{~m}^{2}$ for females (sensitivity $=90.3 \%$, specificity $=82.6 \%)$ and $26.3 \mathrm{~kg} \mathrm{~m}^{2}$ for males (sensitivity $=90.5 \%$, specificity $=86.6 \%$ ). The cut-off point of $\geq 30 \mathrm{kgm}^{2}$ suggested by the World Health Organization (WHO) and the US National Institutes of

Table 3 Values of sensitivity (Sens) and specificity (Spec) of the cut-off points for obesity, according to reference method and reference standards, Ouro Preto City, Brazil

\begin{tabular}{|c|c|c|c|c|c|c|}
\hline \multirow{2}{*}{ Index } & \multicolumn{3}{|c|}{ Females } & \multicolumn{3}{|c|}{ Males } \\
\hline & $\begin{array}{l}\text { Cut-off } \\
\text { point }\end{array}$ & $\begin{array}{c}\text { Sens } \\
(\%)\end{array}$ & $\begin{array}{c}\text { Spec } \\
(\%)\end{array}$ & $\begin{array}{l}\text { Cut-off } \\
\text { point }\end{array}$ & $\begin{array}{c}\text { Sens } \\
(\%)\end{array}$ & $\begin{array}{c}\text { Spec } \\
(\%)\end{array}$ \\
\hline \multicolumn{7}{|l|}{$\mathrm{BMI}\left(\mathrm{kgm}^{-2}\right)$} \\
\hline Ouro Preto & 27.5 & 90.3 & 82.6 & 26.3 & 90.5 & 86.6 \\
\hline Reference $^{*}$ & 30.0 & 60.4 & 94.2 & 30.0 & 33.3 & 98.8 \\
\hline \multicolumn{7}{|c|}{ Stratified by age } \\
\hline$<40$ years & 26.0 & 97.9 & 88.5 & 26.3 & 95.0 & 93.5 \\
\hline$\geq 40$ years & 28.0 & 90.8 & 77.7 & 26.3 & 86.4 & 81.6 \\
\hline \multicolumn{7}{|l|}{ WC $(\mathrm{cm})$} \\
\hline Ouro Preto & 86.0 & 91.0 & 75.7 & 89.5 & 92.9 & 79.1 \\
\hline Reference $†$ & 88.0 & 82.7 & 79.5 & 102.0 & 33.3 & 98.8 \\
\hline \multicolumn{7}{|c|}{ Stratified by age } \\
\hline$<40$ years & 84.0 & 89.1 & 93.7 & 86.0 & 100 & 86.8 \\
\hline$\geq 40$ years & 90.0 & 87.4 & 75.7 & 89.0 & 100 & 65.5 \\
\hline \multicolumn{7}{|l|}{$\%$ BF Siri } \\
\hline Ouro Preto & 37.0 & 78.9 & 73.6 & 21.9 & 92.9 & 66.5 \\
\hline Reference $\neq$ & 35.0 & 92.5 & 57.8 & 25.0 & 61.9 & 86.6 \\
\hline \multicolumn{7}{|c|}{ Stratified by age } \\
\hline$<40$ years & 34.0 & 97.8 & 67.2 & 22.5 & 100 & 75.3 \\
\hline$\geq 40$ years & 37.4 & 82.8 & 67.1 & 24.5 & 68.2 & 79.3 \\
\hline
\end{tabular}

Q6 $\mathrm{M}$ WHO; †NIH; łLohman. 
Health (NIH) showed low sensitivity ( $60.4 \%$ and $33.3 \%$ for women and men, respectively) but high specificity (94.2\% for women and $98.8 \%$ for men)

Stratified by age, for young females the BMI cut-off point of $26.0 \mathrm{~kg} \mathrm{~m}^{2}$ corresponded to sensitivity $=97.9 \%$ and specificity $=88.5 \%$, and for older females the cut-of point of $28.0 \mathrm{kgm}^{2}$ had sensitivity $=90.8 \%$ and specificity $=77.7 \%$. For young and older males, the BM cut-off point of $26.3 \mathrm{~kg} \mathrm{~m}^{2}$ corresponded to sensitivity and specificity of $95.0 \%$ and $93.5 \%$, and $86.4 \%$ and $81.6 \%$ respectively.

For WC, the discriminating point for diagnosis of total body fat excess in women was $86 \mathrm{~cm}$ (sensitivity $=91.0 \%$ specificity $=75.7 \%$ ), whereas in men it was $89.5 \mathrm{~cm}$ (sensitivity $=92.9 \%$, specificity $=79.1 \%$ ). Using the values recommended by the $\mathrm{NIH}(88 \mathrm{~cm}$ and $102 \mathrm{~cm})$ sensitivity of $82.7 \%$ and $33.3 \%$, and specificity of $79.5 \%$ and $98.8 \%$, was calculated for women for men, respectively.

Stratifying by age, the WC cut-off with best discrimination for women $<40$ years was $84.0 \mathrm{~cm}$ (sensitivity $=89.1 \%$, specificity $=93.7 \%$ ) and for those aged $\geq 40$ years was $90.0 \mathrm{~cm}$ (sensitivity $=87.4 \%$ specificity $=75.7 \%$ ). For men, cut-offs of $86.0 \mathrm{~cm}$ (sensitivity $=100 \%$, specificity $=86.8 \%$ ) and $89.0 \mathrm{~cm}$ (sensitivity $=100 \%$, specificity $=65.5 \%$ ) were found respectively.

Considering \%BF Siri, the best discriminating points were $37.0 \%$ (sensitivity $=78.9 \%$, specificity $=73.6 \%$ ) for all females and $21.9 \%$ (sensitivity $=92.9 \%$ specificity $=66.5 \%$ ) for all males, which varied with age in both sexes. The cut-offs were: for women $<40$ years, $34.0 \%$ (sensitivity $=97.8 \%$, specificity $=67.2 \%$ ) and $\geq 40$ years, $37.4 \%$ (sensitivity $=82.8 \%$, specificity $=67.1 \%$ ) and for men $<40$ years, $22.5 \%$ (sensitivity $=100 \%$ specificity $=75.3 \%)$ and $\geq 40$ years, $24.5 \%$ (sensitivity $=68.2 \%$, specificity $=79.3 \%$ ). These levels were very similar to those recommended by Lohman, i.e. $35 \%$ for women and $25 \%$ for men.

Figure 1 shows the ROC curves and their respective AUC by sex using \%BF BIA as the reference method. It can be observed that AUC was larger for BMI and WC and smaller for \%BF Siri, for both sexes. Comparing the curves, in females BMI had better discrimination than WC or \%BF Sir $(P<0.05)$, while $\mathrm{WC}$ and $\% \mathrm{BF}$ Siri were quite simila $(P=0.10)$. In males BMI also showed larger AUC, and this was similar to that of WC $(P=0.31)$ and statistically different from that of $\% \mathrm{BF} \operatorname{Siri}(P=0.01)$. On the other hand, AUC for WC and \%BF Siri were similar $(P=0.11)$.

Stratifying according to age, the methods that presented greater AUC were BMI and WC independently of sex. Among females aged $<40$ years and $\geq 40$ years, it was observed that AUC for BMI was similar to that for WC $(P=0.16$ and 0.15 , respectively) but differed from AUC for \%BF Siri $(P=0.01$ for both); whereas WC was similar to \%BF Siri in AUC ( $P=0.13$ and 0.16 , respectively). On the other hand, among males aged $<40$ years, no differences

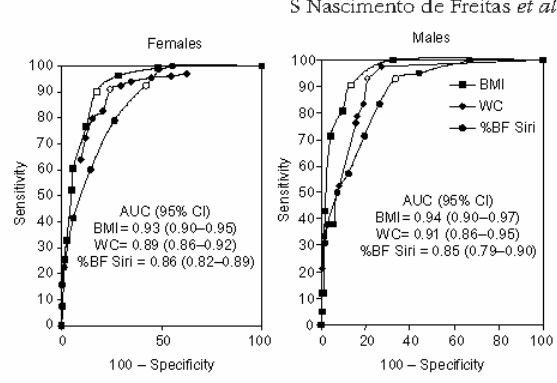

Fig. 1 Receiver operating characteristic curves of anthropometric predictors in the urban population of Ouro Preto City, Brazil aged $20-79$ years, by sex (AUC - area under the curve; $\mathrm{Cl}$ - confience: \%BF Siri - percentage total body fat estimated with Siri's equation)

were observed between AUC for BMI and WC $(P=0.88)$, $\mathrm{BMI}$ and \%BF Siri $(P=0.14)$ and $\mathrm{WC}$ and \%BF Siri $(P=0.14)$. Among males aged $\geq 40$ years, AUC for BMI was similar to that for WC $(P=0.95)$ and greater than AUC for \%BF Siri $(P=0.055)$, while AUC for WC and AUC for \%BF Siri were different $(P=0.04)$ (Figure 2).

Defining the balance points based on sensitivity and specificity, we observed similarities between cut-off points by either sex or sex and skin colour. This may be explained by the high percentage of non-whites found in this study population ( $72.6 \%$ ). Regarding morbid obesity, prevalent in $0.99 \%$ of our population, the exclusion of this group did not change any cut-off point indicators.

\section{Discussion}

In the present study, BMI, WC and \%BF using Siri's equation showed good discriminatory power for diagnosis of obesity with specific cut-off points for age and sex/age in an urban mixed-race population. Compared with the reference method (\%BF determined by foot-to-foot BIA), $\mathrm{BMI}$ and WC were the methods revealing greatest accuracy for the entire population, except for males aged $<40$ years, whose estimates did not differ regarding the method adopted. BMI and WC had similar discriminatory power, according to the ROC areas under the curve, independently of age and sex.

Age and sex are well-known and relevant factors to determine anthropometric indicator cut-off points, especially if we take into account body fat composition and distribution. Marked changes in body composition are observed in men and women as they get older, and there is a trend to increase fat mass to the detriment of lean mass $^{22} 28$ in populations of different races ${ }^{29}{ }^{31}$. Accumulation of fat particularly in the abdominal region has been observed in postmenopausal women ${ }^{6,32,33}$; hence, in our study, BMI and WC had similar discriminatory power in 


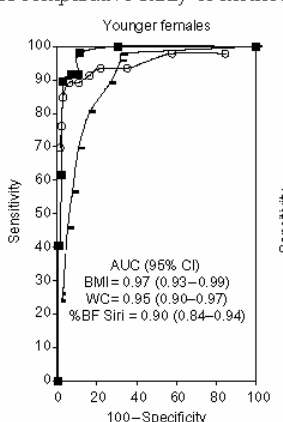

Oder females
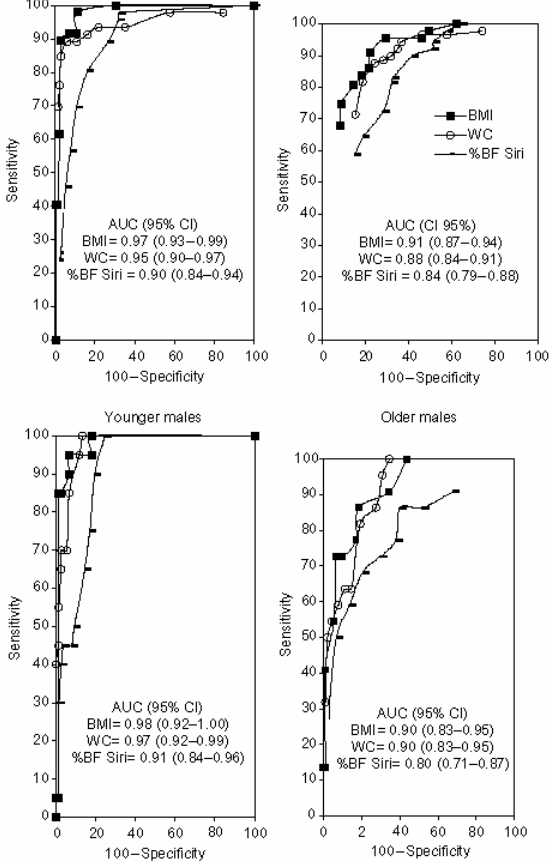

Older males

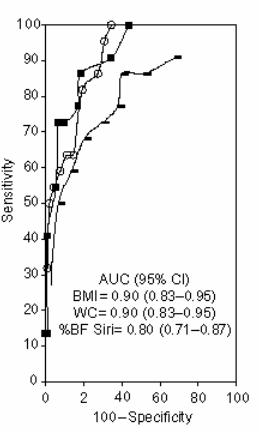

Fig. 2 Receiver operating characteristic curves of anthropometric predictors in the urban population of Ouro Preto City, Brazil aged $20-79$ years, by seX and age (AUC - area under the curve; $\mathrm{Cl}-$
confidence interval; BMI - body mass index; WC - waist circumference; \%BF Siri - percentage total body fat estimated with Siri's equation)

this population. In other words, higher BMI could be attributed to increased adiposity in the abdominal region. Nevertheless, lower estimates of BMI cut-off points compared with international standards were observed in this study, according to sex and sex/age. Similar results were reported by other authors in studies of specific population groups, in whom the cut-off points varied according to sex and age $e^{15,26,34} 36$. When the values recommended by the $\mathrm{NIH}^{37}$ and WHO were used to define obesity, we observed an increase in specificity for men and women $(98.8 \%$ and $94.2 \%$, respectively) and a significant drop in sensitivity $(33.3 \%$ and $60.4 \%$, respect ively). The rise in the number of false-negatives, i.e. obese individuals who were not considered as such, led to an underestimated rate of obesity of $57.2 \%$ and $29.9 \%$ for men and women, respectively, regardless of age. Similas underreporting of estimates was found by Frankenfield et al. ${ }^{24}$ using the same cut-off points recommended by the WHO to estimate obesity in white individuals
WC is a fat centralisation predictor, deemed a robust body adiposity indicator ${ }^{2}$, and in our study it showed good correlation with total body fat $(r \geq 0.80)$ for both sexes, except for individuals aged $\geq 40$ years $(r=0.77$ for females and $r=0.73$ for males). Similar results were obtained by Lemos-Santos et al. . $^{38}$ in a Brazilian male adult population $(r=0.83-0.89)$. Also, WC was the anthropometric variable that ranked second in discriminatory power for both sex and age; and no differences were observed in the AUC of BMI and WC. These findings may suggest that the excess of body fat could be a result of increased adiposity in the waist in our population.

Similar to BMI, WC showed a tendency to lower cut-off points compared with those recommended by the $\mathrm{NIH}^{37}$, as also observed by Taylor et al. ${ }^{39}$. We found in men that the recommended cut-off point of $102 \mathrm{~cm}$ was highly specific and not very sensitive, whereas in women the cutoff point was slightly lower than that recommended by the literature $(88 \mathrm{~cm})$, thus again leading to underreported obesity estimates.

With regard to \%BF estimated by Sirt's equation, we verified a smaller correlation $(r=0.67-0.79)$ with the foot-to-foot BIA method in both sexes and according to sex/age, when compared with BMI and WC. This estimator also presented a smaller AUC. \%BF estimated by means of skinfold thickness using the equation based on the two-body compartment model has been criticised by some authors regarding its agreement with other methods ${ }^{40,41}$, as well as for methodological suitability in its generalised use of equations for body density prediction from Caucasian and Asian populations applied to other populations ${ }^{12,41,42}$. Some authors discuss about a possible systematic underreporting of obesity. These claims could corroborate our finding of underreporting of obesity, even using a cut-off point recommended by Gallagher et al. ${ }^{10}$ for the African American population per sex and age. It is important to emphasise that our population group had ethnic characteristics and body distribution features that were distinct from those of so-called African American individuals. However, it is worth mentioning that there are no specific equations for body density prediction in Brazil, which justifies this study.

Moreover, the \%BF Siri cut-off points that maximised the combination of sensitivity and specificity for females (37.0\%) and males (21.9\%) were higher for women and lower for men, with high sensitivity and low specificity, compared with those recommended in the literature ${ }^{3}$.

Several issues related to methods to assess body composition, the standards used and the ethnic diversity of population groups studied could be discussed. Body composition assessment methods are indirect procedures that are not free from errors, but technical and operational feasibility should be a decisive factor when choosing methods in epidemiological studies. In the present study, the reference standard adopted was foot-to-foot BIA because it presents a good correlation with DEXA, the gold 
standard. Furthermore, it is considered the best reference method in nutritional epidemiology for use in populationbased studies because of its high accuracy and low $\operatorname{cost}^{4,43}$. However, limitations to its use have to be acknowledged and concern some clinical conditions of subjects such as hydration status, exercise level, physiological or pathological status. All of them can lead to an over- or underestimation of fat mass ${ }^{44,45}$. This may be a particular problem in subjects with morbid obesity ${ }^{45,46}$. In our study we tried to minimise all of these factors by the strict study protocol during data collection and in the analysis. For the latter we excluded all patients with mortid obesity ( $0.99 \%$ of our sampled population) and the cut-points did not change by age and sex.

Ethnic diversity may also be a determining factor for body composition and, naturally, for the standard used for comparisons ${ }^{12,29}$. Asian, black and Hispanic populations apparently have a higher fat deposit in the trunk than in the limbs, and more subcutaneous fat in the upper part of the body, than Caucasian individuals ${ }^{15,29,47}$. That we observed no significant differences in the cut-off points of the diverse methods used when classifying the sample according to skin colour might be explained by the high percentage of non-whites in the population of Ouro Preto $(72.6 \%)$. This fact is due to colonisation of the city during the gold extraction period, therefore hindering comparisons, but enabling an anthropometric study in a population known for its multi-race characteristic ${ }^{17,48}$. It should be mentioned that skin colour definition and race in Brazil should not be dissociated from social conditions and schooling, as appropriately reported in the literature ${ }^{14,49}$.

It must be pointed out that developing reference standards to define obesity in the field of epidemiology is still a problem. It is recommended that the cut-off point should be specific for a given population, due to variations in body composition related to age, sex, level of physical activity and ethnic group $6,12,26,29,50$. Indeed, these factors may too have influenced our results, since the reference standard used to classify \%BF BIA in the population of Ouro Preto was that proposed by Gallagher et al. ${ }^{10}$.

In conclusion, the present results suggest that the discriminatory capacity of tests for obesity yaries according to sex and age. BMI and WC had better discriminatory power for obesity among women, regardless of age, as well as among older adult males. The methods did no differ among young adult men. These findings corroborate the claim that it is necessary to use different reference standards for body fat for each sex and age $e^{6,10,34}$. Thus more accurate studies aiming to define body fat prediction formulas for multi-race populations, like that of Ouro Preto, Brazil, are required.

\section{Acknowledgements}

Sources of funding: The study was financially supported by the Federal University of Ouro Preto and Ouro Preto
City Health Department, 'Unimed dos Inconfidentes' and 'Alcan Alumínio do Brasil'. W.T.C. is the recipient of a scholarship from the Brazilian National Council for Scientific and Technological Development (CNPq).

conflict of interest declaration.

Authorship responsibilities.

Acknowledgements: We sincerely thank the sponsors of this research, the residents of Ouro Preto City, Dr Aline Cristine de Sousa Lopes and Dr Claudia Marliere for their Q3 comments.

\section{References}

1 Zhu S, Wang ZM, Shen W, Heymsfield S, Heshka S Percentage body fat ranges associated with metabolic and Nutrition Fxamination Survey (1988-1994). American and Nutrition Examination Survey (1988-1994).

Journal of Cinical Nutrition 2003; 78: 228 - 35 .
2 Mista A Vikram NK. Clinical and pathophysiologial Misra A, Vikram NK. Clinical and pathophysiologial consequences of abdominal adiposity and abdon

3 Lohman TG. Advances in Body Composition Assessment. Champaign, I: Human Kinetics Publishers, 1992.

4 Fllis KI. Selected body composition methods can be used in Fllis $\mathrm{KJ}$. Selected body composition methods can be used in 15895-95s.

5 Bray GA. Evaluation of obesity: who are the obese? Postgraduate Medicine 2003; 114: 19-27.

6 Prentice AM, Jebb SA Beyond body mass index Obesity Reviews 2001; 2: 141-7.

7 Nunez C, Gallagher D, Visser M, Pi-Sunyer FX, Wang Z, Heymsfield SB. Bioimpedance analysis: evaluation of le-toleg system based on pressure contact food-pad electrodes. $524-31$.

8 Austin MA, Heymsfield SB, Nieman DC. Body Composition Measurement in Femates with Leg-to-leg Bioelectricat Impedance Anatysis compared to DEXA. New York: Department of Health, Leisure \& Exercise Science, Obest

9 Jebb SA, Cole TJ, Doman D. Evaluation of the novel Tanita body-fat analyser to measure body composition by comparison with a four-compartment model. British fou mat of Nutrition 2000; 83: 115-22.

10 Gallagher D, Heymfield SB, Heo M, Jebb SA, Murgatroyd PR, Sakamoto $Y$. Healthy percentage body fat ranges: an approach for developing guidelines based on body mass 694-701.

11 Weinsier RL, Hunter GR, Gower BA, Schutz Y, Darnell BE, Zuckerman PA. Body fat distribution in white and black women: different patterns of intrabdominal and subcutaneous abdominal adipose tissue utilization with weight loss. American fournal of Clinical Nutrition 2001; 74 : 631-6.

12 Deurenberg P, Deurenberg-Yap M. Validity of body composition methods across ethnic population groups. Acta Diabetologica 2003; 40: $5246-9$

13 Santos IL, Albala C, Lera L, Garcia C, Arroyo P, Perez-Bravo F, et al. Anthropometric measurements in the elderly population of Santiago. Cbite. Nutrition 2004; 20:452-7.

14 Chór D, Faerstein E, Kaplan GA, Lynch JVV, Lopes CS. Association of weight change with ethnicity and life course socioeconomic position among Brazilian civil servants. international fournat of Epidemiology 2004; 33: 100-6.

15 Stanforth PR, Jackson AS, Green IS, Gagnon J, Rankinen T, Despres JP, et al. Generalized abdominal visceral fat 
A comparative study of methods for obesity diagnosis

prediction models for black and white adults aged 17-65y: the HERITAGE family study. Internationat foumal of Obesity and Related Metabolic Disorders 2004; 28: 925-32.

16 Baltrus P, Lynch JVV, Everson-Rose S, Raghunathan TE Kaplan GA. Race/ethnicity, life-course socioeconomi position, and body weight trajectories over 34 years: the 2005; 95: 1595-601.

17 Instituto Brasileiro de Geografia e Estatística. Censo Demográfico [orline], 2000. Available at http://wwww.sidra ibge.gov.br. Accessed 14 December 2005

18 Freitas OC, Carvalho RF, Neves JM. Prevalenncia da hipertensão arterial sistêmica na população urbana de Catanduva, SP. Arquivos Brasiteiros de Cardiologia 2001; 77 9-15.

19 Costa RF. Composição Corporat, 1st ed; São Paulo: Manole, 2001

20 Alonso ED, Gonzáles-Suárez R. Análisis de las curvas receiver-operating characteristic: un método útil para
evaluar procederes diagnósticos. Revista Cubana de Endocrinotogiá 2002; 13: 169-76.

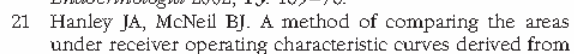
the same cases. Radiotogy 1983; 148: 839-43.

22 Hortobagyi T, Israel RG, O'Brein KF. Sensitivity and specificity of the Quetelet index to assess obesity in men and women. European foumat of Clinical Nutrition 1994; 48: 369-81.

23 Forbes $G$. Longitudinal changes in adult fat-free mass: influence of body weight. American foumat of Ctinical Nutrition 1999; 70: 1025-31.

24 Frankenfield DC, Rowe WA, Cooney RN, Smith IS, Becker D Limits of body mass index to detect obesity and predict body composition. Nutrition 2001; 17: 26-30.

25 Mei Z, Grummer-Strawn LMG, Pietrobelli A, Goulding A Goran MI, Dietz WH. Validity of body mass index compared with other body-composition screening indexes for the with other body-composition screening indexes for the American foumal of Clinical Nutrition 2002; 75:978-85.

26 Movsesyan L, Tarkó LB, Larsen PJ, Christiansen C, Svendsen OL Variations in percentage of body fat within different BMI groups in young, middle-aged and old women. Ctinical Pbysiology and Functional Imaging 2003; 23: 130-3.

27 Stewart A. Fat patterning: indicators and implications. Nutrition 2003; 19:559-60.

28 Kuk J, LeeS, Heymsfield SB, Ross R. Waist circumference and abdominal adipose tissue distribution: influence of age and $1330-4$

29 Fernández $\mathrm{JR}$, Heo M, Heymsfield SB, Pierson RN Jr, PiSunyer FX, Wang $\mathrm{ZM}$, et al. Is percentage body fat Sunyer FX, Wang ZM, et al. Is percentage body fat differentially related to body mass index in Hispanic Americans, African Americans, and European America

30 Mott JW, Wang J, Thornton JC, Allison DB, Heymsfield SB, Pierson RN Jr. Relation between body fat and age in 4 ethnic groups. American fournal of Clinical Nutrition 1999; 69: groups. A
$1007-13$.

31 Bell AC, Adair LS, Popkin BM. Ethnic differences in the association between body mass index and hypertension.

32 Pichard C, Kyle UG, Bracco D, Slosman DO, Morabia A Schutz Y. Reference values of fat-free and fat masses by bioelectrical impedance analysis in 3393 healthy subjects.

Q4 Appl Nutr Invest 2000; 16: 245-54.

33 Jackson AS, Stanforth $\mathrm{P}$, Gagnon I. The effect of sex, age, and Jackson AS, Stanforth P, Gagnon J. The effect of sex, age, and
race on estimating percentage body fat from body mass

index: the Heritage Family Study. Internationat foumat of Obesity and Related Metabolic Disorders 2002; 26: 789-96. 34 Aronne LJ, Segal KR. Adiposity and fat distribution outcome measures: assessment and clinical implications. Obesity Researcb 2002; 10(Suppl. 1): 14S-21S.

35 Sánchez-Castillo $C P$, Velázquez-Monroy $O$, Berber A, LaraEsqueda A, Tapia-Conyer R, James WP. Encuesta Nacional de Salud (ENSA) 2000 Working Group. Anthropometric cutoff points for predicting chronic diseases in the Mexican National Health Survey 2000. Obesity Researcb 2003; 11: $442-51$.

36 Pitanga FJG, Lessa I. Indicadores antropométricos de obesidade como instrumento de triagem para risco coronariano elevado em adultos na cidade de SalvadorBahia. Arquivos Brasiteiros de Cardiotogia 2005; 85: 26-31.

37 National Institutes of Health (NIH). The Practicat Guide: Identification, Evaluation, and Treatment of Overweigbt and Obesity in Adults. Bethesda, MD: NIH, 2000 .

38 Lemos-Santos MGF, Valente JG, Gonçalves-Silva RMV, Schieri R. Waist circumference and waist-to-hip ratio as predictors of serum concentration of lipids in Brazilian men. Nutrition 2004; 20: 857-62.

39 Taylor RW, Jones IE, Williams SM, Goulding A Evaluation of waist circumference, waist-to-hip ratio, and the conicity index as screening tools for high trunk fat mass, as measured by dual-energy X-ray absorptiometry, in children aged 319y. American foumat of Clinical Nutrition 2000; 72: $490-5$

40 Moreno VM, Gandoy JBG, González MIA. Medición de la grasa corporal mediante impedancia bioeléctrica, pliegues cutáneos y ecuaciones a partir de medidas antropométricas, análisis comparativo. Revista Española de Salud Pública 2001; 75: 221-36.

41 Peterson MJ, Czerwinski SA, Siervogel RM. Development and validation of skinfold-thickness prediction equations with a 4-compartment model. American fournal of Cinical

2 Wagner DR, Heyward VH. Measures of body composition in blacks and whites: a comparative review. American foumat of Cinical Nutrition 2000; 71: 1392-402.

43 Bray GA. What is the ideal body weight? foumat of

44 Nitritional Biocbemistry 1998; 9: 489-92. Marivel Gomez J, et at. ESPEN. Bioelectrical impedance analysis-part II: utilization in clinical practice. Clinicat

5 Coppini LZ, Waitzberg DL, Campos ACL. Limitations and validation of bioelectrical impedance analysis in morbidly obese patients. Current Opinion in Clinical Nutrition and

Metabolic Care 2005; 8: $329-32$.

Krupa D. Body composition measurement in severe obesity. Current Opinion in Clinical Nutrition and Metabolic Care

Gallagher D, Kuznia P, Heshka S, Albu J, Heymsfield SB, Goodpaster B, et at. Adipose tissue in muscle: a novel depot similar in size to visceral adipose tissue. American foumat of

8 Campolina A, Melo CA, Andrade MG. Escraxidão em Minas Gerais. Belo Horizonte: Secretaria do Estado da Cultura, Arquivo Pablco Mhero, COPASA MG, 1988.

Maio MC, Monteiro S, Chor D, Faerstein E, Lopes CS $\mathrm{Cor} /$ raça no Estudo Pró-Saúde: resultados comparativos de
dois métodos de autoclassificação no Rio de Janeiro, Brasil. Cadernos de Saúde Púbtica 2005: 21: 171-80.

50 Hugles VA, Frontera WR, Roubenoff R, Evans WJ, Singh MAF Hugles VA, Frontera WR, Roubenoff R, Evans WJ, Singh MA Longitud dial changes in body composition in older men and American foumat of Clinical Nutrition 2002; 76: 473-81. 
PHIV 2005_786-23:28, 14/11/2006-235245

8

Author Queries

JOB NUMBER: 2005_786

JOURNAL: PHW

Q1 Please check interpretation of affiliations $2-6$ and amend if necessary.

Q2 For completeness, please specify how height was measured and the precision.

Q3 Please expand Acknowledgements by providing copy to complete the subsections (new joumal requirements)

Q4 Please protide full journal title.

Q5 Correct interpretation of publisher's location?

Q6 Please provide a literature reference for each of the reference standards in the footnote.
S Nascimento de Freitas et al. 


\section{APÊNDICE III - Pesquisa}

\section{EQUIPE}

(Especificar o Nome, Titulação, Departamento, Instituição e a função de cada membro da equipe, exceto o bolsista)

Nome: George Luiz Lins Machado Coelho Titulação: Doutor
Departamento: Departamento de Farmácia

Função: Coordenaça geral do projeto, definir os cálculos estatísticos que seráa aplicados no conjunto de dados, orientar o bolsista nas questóes envolvendo estatística e na análise dos dados resultantes dos exames laboratoriais.

- Nome: Sivia Nascimento de Freitas

Titulação: Doutor

Departamento: Depto de Nutriçáa Clinica e Socia

Instituição: Escola de Farmácia - UFOP

Função: Coordenar as atividades de campo. avaliar o estado nutricional e o consumo alimentar dos individuos eleitos a participarem do estudo.

Titulação: Doutor

Departamento:

Função: Goordenar a avalia

Instituiçäo: Sociedade Mineira de Cirurgia Cardiovascular

- Nome: Raimundo Marques

Departamento:

Titulação: especialist

- Nome: Márcio António Moreira Galvāo

Titulação: Doutor

Departamento: Secretaria Municipal de Saúde Instituiçäo: Prefeitura Municipal de Ouro Preto

Função: Coordenar as atividades logísticas do trabalho de campo e de divulgaçāo do trabalho na comunidade de Ouro Preto.

- Nome: Roney Nicollato

Titulação: Especialista

Departamento: Departamento de Análises Clínicas Instituição: Escola de Farmácia - UFOP

Função: Coordenar as atividades de execuça dos exames laboratoriais.

- Nome: Angélica Alves Lima

Titulação: Doutora

Departamento: Departamento de Análises Olínicas

Instituicão: Escola de Farmácia - UFOP

Função: Coordenar as atividades de execuçäo dos exames laboratoriais.

- Nome: Andrěa Grabe Guimarāes

Titulação: Doutora

Tepartamento: Departamento de Farmácia

Titulação: Doutora

Funça: Coordenar e qientar os bolsistas nas atividades da atençáo farmacêutica. Elaboraça do questionârio de uso de medicamentos pela populacáo amostrada: Treinamento dos alunos de Farmácia da UFOP envolvidos n avaliaça do uso de medicament os quanto ao inquếrito domiciliar; Anâlise dos dados obtidos quanto à correlacão entre uso de medicamentos e desenvolvimento de DCV; Treinamento dos alunos em atençäo farmacëutica para hipertensos, especificamente em aferiçes da pressão arterial, tếchicas de entrevistas, estudos de casos clinicos, acompanhamento da eficácia terapëutica antihipertensiva, detecçāo de problemas reais e potenciais com o uso de medicamentos, estudos de estratégias de intervencēo lresolucāo dos problemas reais e prevencóo dos problemas medica

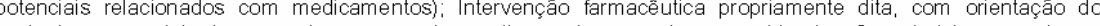
pacientes encaminhados, quanto ao uso de medicamentos que levam a hipertensáa a terial como doença

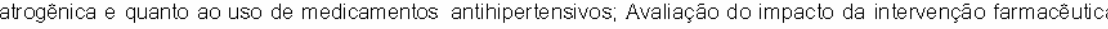
com relaçáa a morbidade; Análise do uso de produtos naturais com finalidade terapëutica versus descriçáo na iteraturacientífica

- Nome: Elza Conceição de O. Sebastiāo

Departamente: Departamento de Farmácia

Titulação: Mestre

Função: Orientar os bolsistas nas atividades de atença farmacéutica.

- Nome: Núncio Antônio Araújo Só

Instituição: Escola de Farmácia - UFOP

Departamento: Departamento de Farmácia

Função: Coordenar a assistência ambulatorial dada aos pacientes pela rede ambulatorial da SMSiOP. 
Início: Término:

QUESTIONÁRIO DA PESQUISA

ESTUDO SOBRE FATORES DERISCOPARA AS DOENÇAS CARDIOVASCULARES OURO PRETO -MG

ANEXO II: CARACTERZAÇÃO DA FAMÍLIA

IDENTIFICAÇÃO E CONTROLE

N'do questionário:

Nome do entrevistado:

Data da entrevista:

Telefone:

Seu pai tem alguma doença:

Sua mãe tem alguma doença:

\begin{tabular}{|l|l}
\hline Bairro: & Setor censitário: \\
\hline
\end{tabular}

\begin{tabular}{|c|c|c|c|c|c|c|c|c|c|c|c|c|c|c|c|c|}
\hline $\begin{array}{c}N . \\
\text { ordem }\end{array}$ & \multicolumn{3}{|c|}{ Nome } & $\begin{array}{c}\text { Condiģâao } \\
\text { Familia }\end{array}$ & Sexo & Idade & $\begin{array}{l}\text { Cor } \\
\text { pele }\end{array}$ & $\begin{array}{c}\text { Nivel } \\
\text { Instruçấo }\end{array}$ & $\begin{array}{c}\text { Data } \\
\text { Nascimento } \\
\end{array}$ & Naturalidade & Ocupaçẫo & $\begin{array}{l}\text { Pulso } \\
\text { (ppm) }\end{array}$ & $\begin{array}{l}\text { Pressão } \\
\text { Arterial }\end{array}$ & $\begin{array}{c}\text { Cido } \\
\text { Menstrual }\end{array}$ & $\begin{array}{l}\text { Plano } \\
\text { saúde }\end{array}$ & $\begin{array}{l}\text { Históría } \\
\text { Pregressa }\end{array}$ \\
\hline \multicolumn{17}{|l|}{$\begin{array}{l}\text { Selecio } \\
\text { nado }\end{array}$} \\
\hline \multicolumn{17}{|l|}{$\begin{array}{l}02 \\
03\end{array}$} \\
\hline \multicolumn{17}{|l|}{04} \\
\hline \multicolumn{17}{|l|}{05} \\
\hline \multicolumn{17}{|l|}{07} \\
\hline \multicolumn{17}{|l|}{08} \\
\hline \multicolumn{17}{|l|}{9} \\
\hline \multicolumn{17}{|l|}{10} \\
\hline \multicolumn{17}{|l|}{11} \\
\hline \multirow{2}{*}{\multicolumn{3}{|c|}{$\begin{array}{ll} & \text { Condiçāo na familia } \\
\text { 7. Chefe } & \text { 6. Pensionista } \\
\text { 2. Cônijuge } & \text { 7. Empregado doméstico } \\
\text { 3. Filho } & \text { 8. Parente do empregado } \\
\text { 4. Outro parente } & 9 \text {. Morador ausente } \\
\text { 5. Agregado } & \end{array}$}} & \multirow{2}{*}{\multicolumn{3}{|c|}{$\begin{array}{ll} & \text { CordaPele } \\
\text { 1. } & \text { Branca } \\
\text { 2. } & \text { Morena clara } \\
\text { 3. } & \text { Mcrena escura } \\
\text { 4. } & \text { Preta }\end{array}$}} & \multicolumn{5}{|c|}{ Nivel de instruçāo } & \multicolumn{4}{|c|}{ Cido Menstrual } & \multicolumn{2}{|c|}{ Plano de Saúde } \\
\hline & & & & & & $\begin{array}{l}\text { Analiab } \\
\text { 2. Sabe ele } \\
\text { Primán } \\
\text { Primári } \\
\text { Primeir } \\
\text { Primeir }\end{array}$ & $\begin{array}{l}\text { beto } \\
\text { er e esc } \\
\text { io incon } \\
\text { io comp } \\
\text { ro grau } \\
\text { ro grau }\end{array}$ & $\begin{array}{l}\text { rever } \\
\text { pleto } \\
\text { leto } \\
\text { ncompleto } \\
\text { com pleto }\end{array}$ & $\begin{array}{l}\text { 7. Segundo gr } \\
\text { 8. Segundo gr } \\
\text { 9. Técnico } \\
\text { 10. Superior in } \\
\text { 11. Superior co }\end{array}$ & $\begin{array}{l}\text { Uincompleto } \\
\text { un completio } \\
\text { iompleto } \\
\text { mpleto }\end{array}$ & $\begin{array}{l}\text { 1. Pré-puber } \\
\text { 2. Menarca } \\
\text { 3. Menstrua } \\
\text { 4. Menstrua } \\
\text { 5. Menopau }\end{array}$ & $\begin{array}{l}\text { hé }<1 \text { an } \\
\text { á regula } \\
\text { á irregu } \\
\text { a (especi }\end{array}$ & que a idade & que ocorreu) & $\begin{array}{ll}\text { 1. } & \text { SD } \\
\text { 2. } & \mathrm{UP} \\
\text { 3. } & \mathrm{PS} \\
\text { 4. } & \mathrm{AE} \\
5 . & \mathrm{OL}\end{array}$ & ED \\
\hline
\end{tabular}




\section{ANEXo III: NÍYEL SÓcIo-ECONÔMICo}

PLANO DE SAÚdE

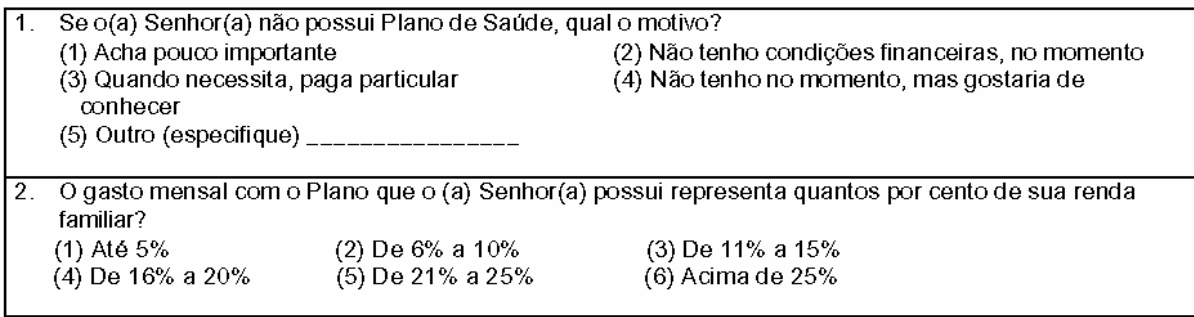

INDICADORES DE RENDA

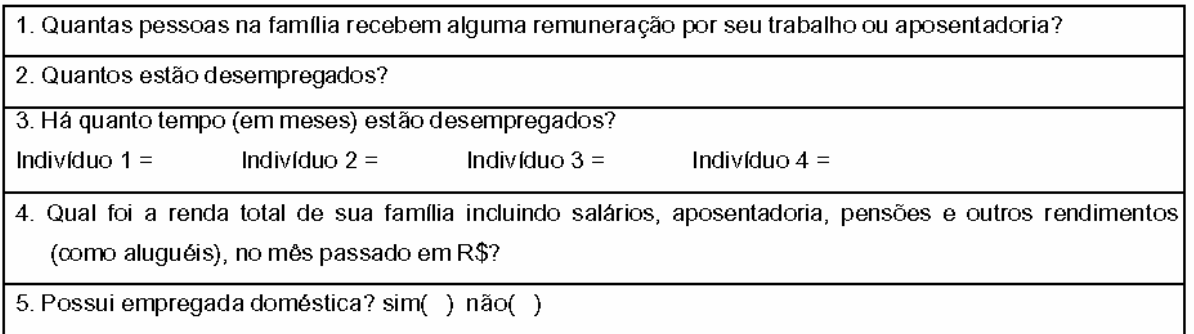

\section{EQUIPAMENTOS E ELETRODOMÉSTICOS}

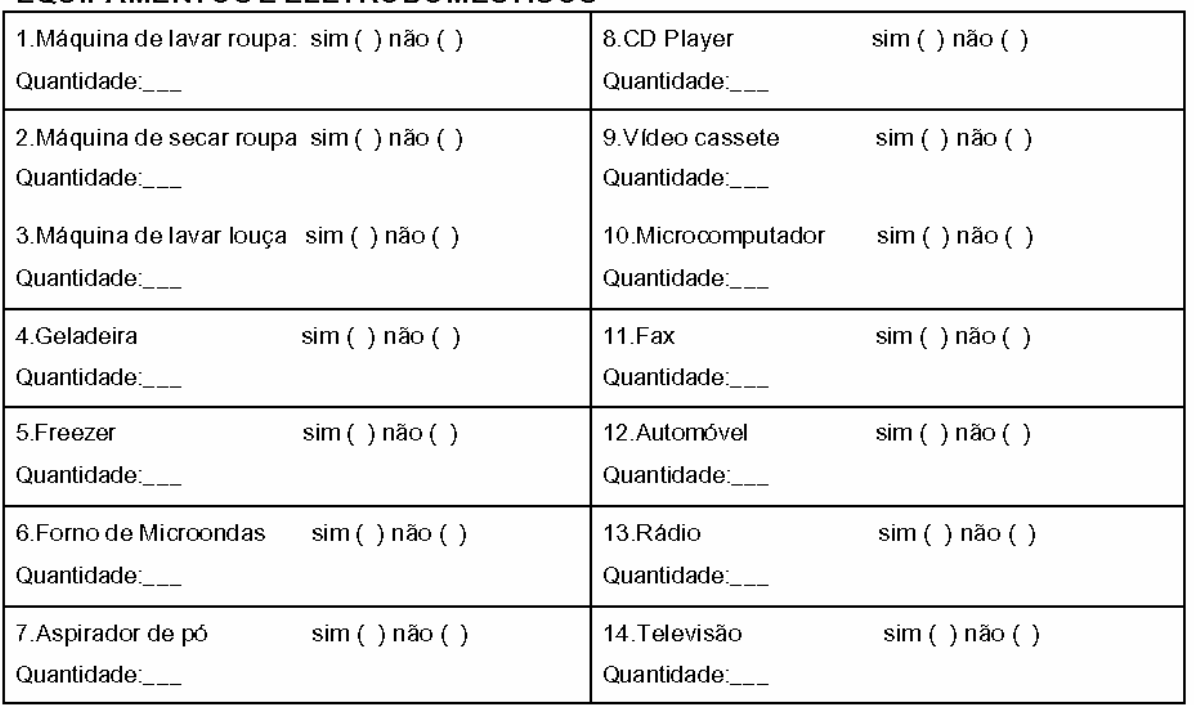


CARACTERIZAÇÃO SÓCIO-DEMOGRÁFICA (MIGRAÇÃO)

\begin{tabular}{|l|r|}
\hline $\begin{array}{l}\text { 1.A quanto tempo vocé mora em Ouro Preto? } \\
\text { 1. meses }\end{array}$ & $\begin{array}{l}\text { 2. Onde morou anteriormente? } \\
\text { 2. anos }\end{array}$ \\
$\begin{array}{l}\text { 3. sempre viveu ( ) } \\
\text { 2. outra cidade }\end{array}$ & \\
\hline
\end{tabular}

OBSERVACŌES: 


\section{QUESTIONÁRIO DA PESQUISA}

ESTUDO SOBREFATORES DE RISCOPARA AS DOENCAS CARD IOVASCULARESOUROPRETO - MG

DATA DA MEDIDA:

IDENTIFICAÇÄO E CONTROLE

\begin{tabular}{|c|c|c|c|}
\hline $\mathrm{N}^{\circ}$ do questionário: & Endere & & \\
\hline Bairro: & Setor censitário: & Ponto de referência & Telefone: \\
\hline
\end{tabular}

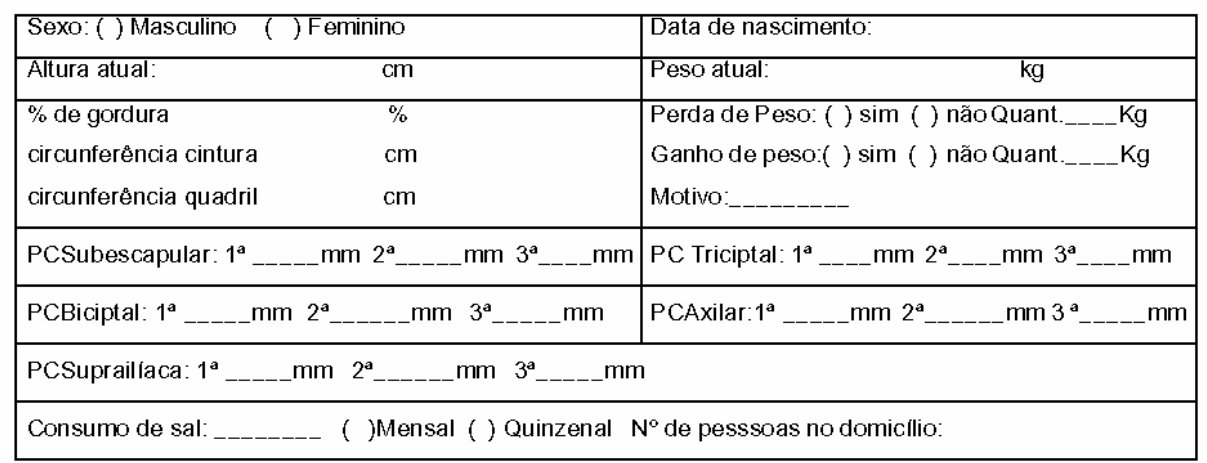

\section{DATA DA MEDIDA:}

\section{IDENTIFICAÇÃO E CONTROLE}

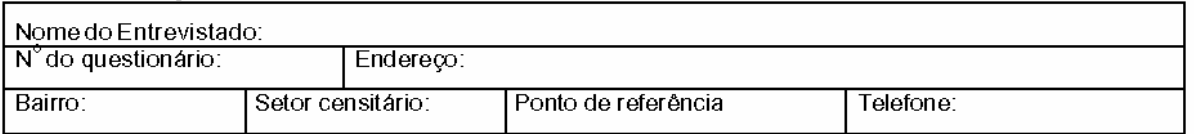

\begin{tabular}{|c|c|}
\hline Sexo: ( ) Masculino ( ) Feminino & Data de nascimento: \\
\hline Altura atual: & \begin{tabular}{|l} 
Peso atual: \\
Peso
\end{tabular} \\
\hline $\begin{array}{lc}\% \text { de gordura } & \% \\
\text { circunferência cintura } & \mathrm{cm} \\
\text { circunferência quadril } & \mathrm{cm}\end{array}$ & $\begin{array}{l}\text { Perda de Peso: ( ) sim ( )năo Quant._-_Kg } \\
\text { Ganho de peso:( ) sim ( )nâo Quant._-_-_ } \mathrm{Kg} \\
\text { Motivo: }\end{array}$ \\
\hline 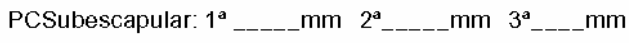 & PC Triciptal: $\mathbf{1}_{--}^{\mathbf{a}}{ }_{2-} \mathrm{mm} 2^{\mathbf{a}}$ \\
\hline 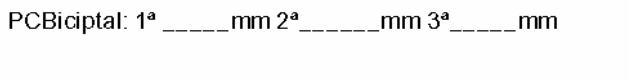 & 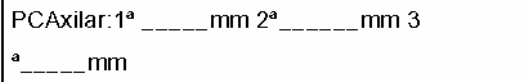 \\
\hline \multicolumn{2}{|l|}{ PCSuprailiaca: $1^{\mathrm{a}}$} \\
\hline \multicolumn{2}{|c|}{ Consumo de sal: +------ ( Mensal () Quinzenal $N^{\circ}$ de pesssoas no domicilio: } \\
\hline
\end{tabular}


Início

Término:

QUESTIONÁRIO DA PESQUISA

ESTUDO SOBRE FATORES DE RISCOPARA AS DOENCAS CARD IOVASCULARESOUROPRETO - MG ANEXO V: FREQUÉNCIA DE CONSUMO DE ALIMENTOS

IDENTIFICAÇĂO E CONTROLE

\begin{tabular}{|l|l|l|l|}
\hline$N^{\circ}$ do questionário: & \multicolumn{2}{|l|}{ Nome do entrevistado: } & Telefone: \\
\hline Data da entrewsta: & \multicolumn{2}{|l|}{ Entrevistador: } & Ponto de referéncia: \\
\hline Endereço: & Bairro: & & \\
\hline
\end{tabular}

\begin{tabular}{|c|c|c|c|c|c|c|c|}
\hline \multirow[b]{2}{*}{ PRODUTO } & \multicolumn{2}{|c|}{ QUANT. } & \multicolumn{5}{|c|}{ FREQUÊNCIA } \\
\hline & CóD. & $g$ & DIÁRIA & SEMANAL & QUINZENAL & MENSAL & $\begin{array}{l}\text { NUNCA OU } \\
\text { RARAMENTE }\end{array}$ \\
\hline \multicolumn{8}{|c|}{ 1. Arroz } \\
\hline \multicolumn{8}{|c|}{ 2. Fejjão oozido } \\
\hline \multicolumn{8}{|c|}{ 3. Tutu de feijão } \\
\hline \multicolumn{8}{|c|}{$\begin{array}{l}\text { 4. Feijoada ( ) Caseira ( ) } \\
\text { Indust. }\end{array}$} \\
\hline \multicolumn{8}{|c|}{ 5. Fejão Tropeiro } \\
\hline \multicolumn{8}{|c|}{ 6. Macarrão } \\
\hline \multicolumn{8}{|c|}{ 7. Farinha de mesa } \\
\hline \multicolumn{8}{|c|}{8 . Pão de sal } \\
\hline \multicolumn{8}{|l|}{ 9. Pão doce } \\
\hline \multicolumn{8}{|c|}{ 10.Cheep's } \\
\hline \multicolumn{8}{|c|}{ 11. Biscoito doce } \\
\hline \multicolumn{8}{|c|}{ 12. Biscoito salgado } \\
\hline \multicolumn{8}{|c|}{ 13. Bolo simples } \\
\hline \multicolumn{8}{|c|}{ 14.Bolo Recheado } \\
\hline \multicolumn{8}{|c|}{ 15.Polenta/angú } \\
\hline \multicolumn{8}{|c|}{ 16. Batata frita } \\
\hline \multicolumn{8}{|l|}{17 Batata } \\
\hline \multicolumn{8}{|l|}{ 18.Mandioca } \\
\hline \multicolumn{8}{|c|}{ 19.Milho verde } \\
\hline \multicolumn{8}{|c|}{$\begin{array}{l}\text { 20.Pipoca microondas() sal () } \\
\text { sisal }\end{array}$} \\
\hline 21.Pipoca Cas & & & & & & & \\
\hline 22. Inhamedcar & & & & & & & \\
\hline $\begin{array}{l}\text { Lentilhal ervill } \\
\text { canjiquinha }\end{array}$ & & & & & & & \\
\hline 23.Laranja & & & & & & & \\
\hline 24.Banana & & & & & & & \\
\hline 25.Mamão & & & & & & & \\
\hline 26.Maçã & & & & & & & \\
\hline 27. Melancia/m & & & & & & & \\
\hline 28.Abacaxi & & & & & & & \\
\hline 29.Abacate & & & & & & & \\
\hline 30 Manga & & & & & & & \\
\hline 31.Limão & & & & & & & \\
\hline 32.Maracujáa & & & & & & & \\
\hline 33. Jva & & & & & & & \\
\hline 34.Goiaba & & & & & & & \\
\hline 35.Pera & & & & & & & \\
\hline 36.Chiória & & & & & & & \\
\hline 37 Tomate & & & & & & & \\
\hline 38.Chuchu & & & & & & & \\
\hline 39.Abobora & & & & & & & \\
\hline 40. Abobrinha & & & & & & & \\
\hline $\begin{array}{l}\text { 41.Pepino } \\
\text { 42. Vagem }\end{array}$ & & & & & & & \\
\hline
\end{tabular}




\begin{tabular}{|c|c|c|c|c|c|c|c|}
\hline \multirow[b]{2}{*}{ PRODUTO } & \multicolumn{2}{|c|}{ QUANT. } & \multicolumn{5}{|c|}{ FREQUÊNCIA } \\
\hline & CóD. & $g$ & DIÁRIA & SEMANAL & QUINZENAL & MENSAL & $\begin{array}{l}\text { NUNCA OU } \\
\text { RARAMENTE }\end{array}$ \\
\hline \multicolumn{8}{|l|}{ 43. Broto samambaia } \\
\hline \multicolumn{8}{|l|}{ 44.Quiabo } \\
\hline \multirow{2}{*}{\multicolumn{8}{|c|}{\begin{tabular}{|l|} 
45. Alface \\
46. Couve
\end{tabular}}} \\
\hline & & & & & & & \\
\hline \multicolumn{8}{|l|}{ 47.Repolho } \\
\hline \multicolumn{8}{|l|}{ 48.Pimentăo } \\
\hline \multirow{2}{*}{\multicolumn{8}{|c|}{\begin{tabular}{|l|l|}
49. Cenoura \\
50 . Beterraba
\end{tabular}}} \\
\hline & & & & & & & \\
\hline \multicolumn{8}{|l|}{ 51. Couve-flor } \\
\hline \multicolumn{8}{|l|}{52.0 vos } \\
\hline \multicolumn{8}{|l|}{$\begin{array}{ll}\text { 53. Leite } & \text { () Integral } \\
& \text { () Semi-desnatado } \\
\text { () Desnatado }\end{array}$} \\
\hline \multirow{2}{*}{\multicolumn{8}{|c|}{ 54. logurte/coalhada }} \\
\hline & & & & & & & \\
\hline \multirow{2}{*}{\multicolumn{8}{|c|}{ 56.Requeijăo }} \\
\hline & & & & & & & \\
\hline \multirow{2}{*}{\multicolumn{8}{|c|}{ 58.V/sceras }} \\
\hline & & & & & & & \\
\hline \multicolumn{8}{|l|}{$\begin{array}{l}\text { 99. Lame de dor c osso } \\
54 . \text { Carne de boi s/osso }\end{array}$} \\
\hline \multicolumn{8}{|l|}{ 55.Carne de porco } \\
\hline \multicolumn{8}{|l|}{$\begin{array}{c}\text { 56.Frango () Peito } \\
\text { () Sobrecoxa } \\
\text { () Asa }\end{array}$} \\
\hline \multicolumn{8}{|l|}{57 . Salsicha } \\
\hline 58.Linguiça & & & & & & & \\
\hline 59.Peixe fresco & & & & & & & \\
\hline 60.Peixe enlatado & & & & & & & \\
\hline 61.Hamburguer & & & & & & & \\
\hline 62.Mortadela / Presunto & & & & & & & \\
\hline 63. Pizza & & & & & & & \\
\hline \begin{tabular}{|l|}
$64 . C a m a r a ̃ o$ \\
\end{tabular} & & & & & & & \\
\hline 65.Bacon/torresmo & & & & & & & \\
\hline 66. Sopalndustrial & & & & & & & \\
\hline \begin{tabular}{|l|}
67. Ketchup \\
\end{tabular} & & & & & & & \\
\hline 68.Molho Inglês & & & & & & & \\
\hline 69. Molho Soyo & & & & & & & \\
\hline $\begin{array}{l}\text { 70. Molho pimenta } \\
\text { 71. Caldo Knor/Arisco } \\
\text { 72. Molho p/salada } \\
\text { 73. Mostarda }\end{array}$ & & & & & & & \\
\hline 74. Maionese & & & & & & & \\
\hline 75. Salgados (kibe, pastef) Outro & & & & & & & \\
\hline Sorvete ()Fruta ()Creme & & & & & & & \\
\hline 76. Adocantes Marca: & & & & & & & \\
\hline \begin{tabular}{|l|}
77. Caramelos (balas) \\
\end{tabular} & & & & & & & \\
\hline 78.Achocolatados (po) & & & & & & & \\
\hline 79.Chocolate / bombom & & & & & & & \\
\hline 80.Ambrósia / Quindim & & & & & & & \\
\hline 81.Pudim/doce de leite & & & & & & & \\
\hline 82. Refrigerantes & & & & & & & \\
\hline 83. Café & & & & & & & \\
\hline 84. Sucos ()Natural () Indust. & & & & & & & \\
\hline 85.Mate (chás) & & & & & & & \\
\hline
\end{tabular}


No do questionário

CONSUMO FAMILIAR MENSAL OU SEMANAL

\begin{tabular}{|l|l|l|l|l|}
\hline \multicolumn{1}{|c|}{ Alimento } & \multicolumn{2}{c|}{ Quantidade } & \multicolumn{2}{c|}{ Consumo Individual } \\
\hline 1. Leite Condensado & Mensal & Semanal & SIM & NÃO \\
\hline 2. Creme de Leite & & & & \\
\hline 3. Acúcar & & & & \\
\hline 4. Óleo & & & & \\
\hline 5. Gordura & & & & \\
\hline 6. Azeite & & & & \\
\hline 7. Alho & & & & \\
\hline 8. Cebola & & & & \\
\hline 9. Pasta de alho esal & & & & \\
\hline
\end{tabular}

MUDANÇA NO HÁBITO ALIMENTAR NO ÚL TIMO ANO: () sim ( ) não

Motivo( Em caso afirmatiwo): 
Início: Término:

QUESTIONÁRIO DA PESQUISA

ESTUDO SOBRE FATORES DE RISCO PARA AS DOENÇAS CARDIOVASCULARES OURO PRETO - MG

ANEXO VI: FATORES COMPORTAMENTAIS

IDENTIFICAÇÃO E CONTROLE

\begin{tabular}{|l|l|l|l|}
\hline N do questionário: & \multicolumn{2}{|l|}{ Nome do entrevistado: } & Telefone: \\
\hline Data da entrevista: & \multicolumn{1}{|l|}{ Entrevistador: } & Sonto de referência: \\
\hline Enderego: & Bairro: & & \\
\hline
\end{tabular}

\section{TABAGISMO}

1- Você já fumou cigarros? 1) sim, regularmente (1 cigarro ou mais por dia) no passado, mas não agora

sim ocasionalmente (menos de 1 cigarro por dia) no passado mas não agora ir para 10

3) sim, e eu ainda fumo continue a entrevista

4) não, $n$ unca

ir para questão 12

2- Em média quantos cigarros wocé fuma atualmente? número dias.

número

semanas

3- Quantos dias por semana voce costuma fumar atualmente? 1) usualmente 1 dia na semana ou menos 2) usualmente de 2 a 4 dias na semana

especifique o número de dias

3) quase todos os dias da semana: 5 a 6 dias

4) todos os dias

4- Qual o número máximo de cigarros que vocẻ fumou diariamente no último ano? cigarros

5- Quantos anos você tinha quando comegou a fumar regularmente? Idade anos

$* * * 4$

6- Voce fuma charutos?

1) fumo regularmente (1 ou mais por dia)

2) กลัo

3) fumo ocasionalmente (menos que 1 por dia)

4) usava, mas agora não ir para 10

7- Quantos charutos ousimilares vocẻ fuma? Número __dias Número semanas

$+* *$

8- Voce fuma cachimbo? 1 -fumo regularmente (1 ou mais vezes ao dia)

$$
\begin{aligned}
& \text { 2- não } \\
& \text { 3- ocasionalmente (menos de } 1 \text { vez ao dia) } \\
& \text { 4- usava, mas agora não ir para } 10
\end{aligned}
$$

9-Quantas gramas (definir medida) de tabaco (cachimbo) wocê fuma? --- gramas/dia gramasisemana

$* 4 * 4$

10- Quando você parou de fumar cigarros ou similares regularmente? Indique o Ano Calendário caso seja menos de 12 meses marque uma das três opcóes abaixo

$$
\begin{aligned}
& \text { 1) menos que } 1 \text { mes } \\
& \text { 2) de } 1 \text { a } 6 \text { meses } \\
& \text { 3) } 6 \text { a } 12 \text { meses }
\end{aligned}
$$

11- Em média quantos (especifique) vocẻ fumava por dia? cigarros charutos cachimbos

12- Por quantas horas woce fica em ambiente fechado o/ pessoas que fumam cigarros ou similares por dia? 


\section{CONSUMO DE BEBIDA ALCÓOLICA}

13. Durante os últimos 12 meses com que freqüencia média vocé tem ingerido bebida alcoólica?
1) Bebe diariamente
5) Bebe de 1 a 3 vezes por mës
2) Se embriaga ao menos 1 vez por me̊s
6) Menos de 1 vez ao més.
3) Bebe de 1 a 3 vezes por semana

7) Nenhuma ir para 17

14. Para as questôes abaixo deve-se indicar o conteúdo médio de áloool (em porcentagem de volume) para cada bebida e o conteúdo médio de llquido (em dL) das unidades usadas no questionário. $O$ Centro de Dados computará o consumo de álcool para cada pessoa

Quantos copos, taças (medidas de dosimêtro= $1 / 3$ do copo americano), garrafas ou latas das seguintes bebidas voce consumiu nos últimos sete dias?

$\begin{array}{ll}\text { 1) Cerveja } & -- \text { garrafas } \\ \text { 2) Vinho branoo } & -- \text { copos } \\ \text { 3) Vinho tinto } & -- \text { copos } \\ \text { 4) Uisque } & -- \text { (dosimetro) } \\ \text { 5) Cacha ça } & -- \text { (dosimétro) } \\ \text { 6) Vodka } & --- \text { (dosimétro) } \\ \text { 7) Licores } & -- \text { (dosimétro) } \\ \text { 8) Outras } & -- \text { (dosimétro) (especifique) }\end{array}$

$\begin{array}{lll}\text { 15. Voce tem sentido a necessidade de beber menos? } & \text { 1) Sim } & \text { 2) Não }\end{array}$

16. Al guma vez bebeu pela manhã para acalmar-se ou eliminar ressaca por ter bebido na noite anterior ? 1)Sim 2)Não

\section{ATIVIDADE FÍSICA (Leia as opções para o entrevistado) (marque somente uma opção)}

17. Qual o grau de atividade fisica que woce exerce durante suas atividades diárias

1) Vocẻ tem que estar sentado para exercer suas atividades? Você não caminha muito enquanto trabalha? Ex: relojoeiro, radialista, costureira, trabalhador de escritório, salgadeira

2) Vocé caminha bastante enquanto trabalha mas não tem que levar nem carregar coisas pesadas? Ex: empregado do comércio, trabalho em indústria ou em escritório, professor, laboratório

3) Voce caminha e move muitas coisas ou sobe e desce escada ou ladeira?

Ex: carpinteiro, trabalhador da agricultura, mecãnica, ou in dustria pesada

4) Sua atividade requer grande esforco fisico, como por exemplo mover ou levantar coisas pesadas ou cortar sacudir objetos pesados?

Ex: construção civil, trabalho agrícola pesado ou de in dustria

18. Qual a atividade fisica que wocê pratica durante suas horas livres ou de lazer

1) Em seu tempo livre, woce ve televisão ou faz coisas que não requerem atividade fisica

2) Em seu tempo livre voce realiza e pratica atividades fisicas leves tais como passear pelas ruas olhando vitrines ou indo a parques de diversão, etc

3) Em seu tempo livre vocé pratica esportes ou realiza ginástica.

19. Quanto tempo duram esses episódios de atividade fisica? minutos

20. Quantas dias da semana vocé pratica alguma atividade fisica? dias

21. Alguma vez tentou melhorar sua atividade fisica durante as hor as de lazer?
1) Nunca
2) Há mais de 6 meses
3) Entre 1 a 6 meses
4) Durante o último més

22. Aumentou sua atividade fisica durante seu tempo livre nos últimos 6 meses?
1) Muito
2) Um pouco
3) Não mudou
4) Diminuiu um pouco
5) Diminuiu muito 
No do questionário

\section{ANEXO VII: AVALIAÇÃO DO USO DE MEDICAMENTOS}

Usa algum medicamento, chá, planta medicinal, garrafada de origem natural? não sim

Lembrar de questionar sobre: Terapia hormonal (anticoncepcional, menopausa, tiré6ide,...), AINES (AAS, diclofenaco,...), Corticóide, Medicamento para pressão alta e para colesterol alto.

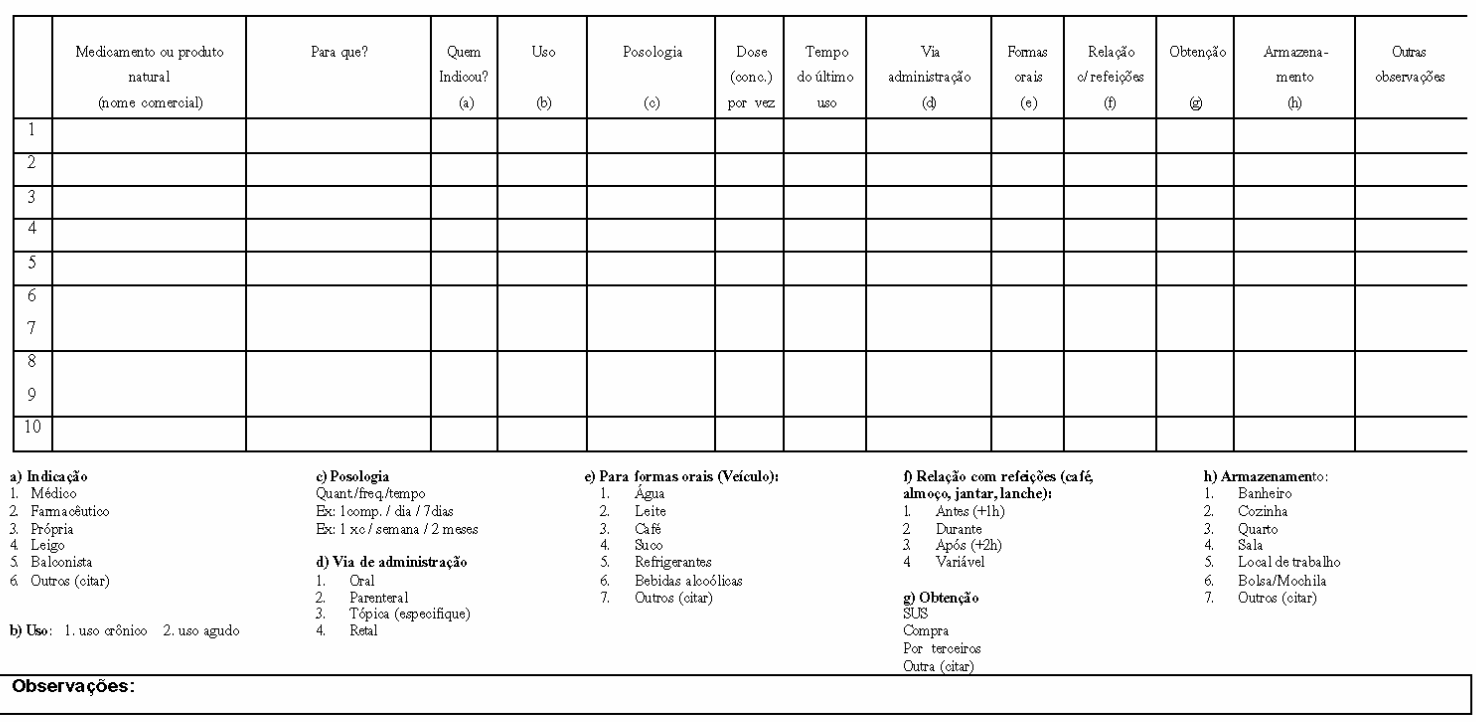




\section{ANEXO VIII: TERMO DE CONSENTIMENTO PÓS-INFORMAÇÃO}

UNIVERSIDADE FEDERAL DE OURO PRETO

SECRETARIA MUNICIPAL DE SAÚDE

FUNDAÇÃO CASA DO COR AÇÃO

UNIVERSIDADE DE SÃO PAULO

\section{DADOS DE IDENTIFICAÇÃO DO SUJEITO DA PESQUISA OU RESPONSÁVEL LEGAL} NOME DO PACIENTE

DOCUMENTO DE IDENTIDADE $\mathrm{N}^{\circ}$ ÓRGÃO EXPEDIDOR:

SEXO: $M() F()$ DATA NASCIMENTO

RESPONSÁVEL LEGAL

NATUREZA ( grau de parentesco, tutor, curador etc.)

DOCUMENTO DE IDENTIDADE: ÓRGÃO EXPEDIDOR

SEXO: $M() F()$

DATANASCIMENTO

ENDEREÇO

BAIRRO CIDADE

TELEFONE: DDD (31)

DADOS SOBRE A PESQUISA CIENTÍFICA

TÍTULO DO PROTOCOLO DE PESQUISA: CORAÇÕES DE OURO PRE TO

\section{Coordenacão do Estudo:}

George Luiz Lins Machado Coelho (DEFARUFOP) Raimundo Marques do Nascimento Neto (FCC)

Silvia Nascimento de Freitas (DENCS/UFOP)

\section{Pesquisadores Participantes do Estudo:}

Andréa Grabe Guimarães (DEFAR/UFOP) Angélica Alves Lima (DEACL/UFOP) José Eduardo Krieger (HCFMUSP) Roney Nicolato (DEACL/UFOP)

AVALIAÇÃO DO RISCO DA PESOUISA:
() SEM RISCO
(X) RISCO MÍNIMO
() RISCO MÉDIO

( ) RISCO MAIOR

DURAÇÃO DA PESQUISA: Quatro anos 


\section{REGISTRO DAS EXPLICAÇÕES DO PESQUISADOR AO PACIENTE OU SEU REPRESENTANTE}

\section{LEGAL SOBRE A PESQUISA}

A pesquisa que o senhor(a) está sendo convidado(a) a participar tem como objetivos: (1) determinar a prevaléncia das doenças cardiovasculares ao nlvel de setores censitarios da cidade de Ouro Preto, (2) identificar os fatores biológicos, ambientais e socio-economico que fazem com que um individuo tenha mais ou menos chance de apresentar uma doença do coração, e (3) avaliar o impacto das medidas de prevenção sobre as taxas de prevaléncia das doenças cardiovasculares em Ouro Preto.

Nesta pesquisa cada participante devera responder a um questionário, que sera aplicado pela equipe que está visitando a sua casa. E posteriormente, em data marcada pela equipe de entrevistadores, 0 senhor(a) deverá comparecer à Escola de Farmácia para se submeter a um eletrocardiograma, a mediçăo antropométrica e a coleta de uma amostra de sangue no Laboratório Piloto de Análises Clínicas (LAPACfEF/UFOP). No sangue coletado serão realizadas provas bioquimicas e genéticas. Para a prova genética, uma amostra de seu sangue sera enviada ao Laboratório de Genética e Cardiologia Molecular do Incor, em São Paulo para a extração de DNA (material genético). A partir da análise dos dados acima coletados é que pesquisaremos caracteristicas que podem influenciar no desenvolvimento das doenças do coraçăo.

Em nenhum momento desse estudo, as pessoas que estarăo trabalhando oom seu material saberão que ele é seu, garantindo o sigilo de seus dados. Sua participação ou não neste estudo não influenciara de nenhuma forma o tipo e a qualidade do atendimento médico que vocé está ou poderá está recebendo no futuro Vocé poderá solicitar aos pesquisadores o seu desligamento do estudo a qualquer momento É através deste tipo de pesquisa que esperamos poder aumentar o nosso conhecimento sobre os riscos de desenvolver doenças do coração (pressão alta, colesterol alto, obesidade etc.) e os beneficios do tratamento que vocé recebe ou poderá vir a receber.

Sua participacão poderá ajudar outras pessoas que tenham doencas como essas Ainda com sua participacão neste estudo vocể estará realizando uma série de exames e consulta médica qué poderão identificar alteraçōes que, tratadas, irăo diminuir a chance de vocẻ desenvolver essas doenças.

Caso você queira se informar de mais detalhes sobre a pesquisa agora, ou no futuro, poderá entrar em contato com o Prof George Luiz Lins. Machado Coeho (Escola de Farmácia/UFOP- Tel: 35591638) Prof $^{a}$ Silvia Nascimento de Freitas (Escola de Nutricão- Tel: 35591822). Dr. Núncio de Araújo Sol (Secretaria Municipal de SaúdefPMOP - Tel: 35593280) e Prof. Jose Eduardo Krieger (Laboratório de Genética e Cardiologia Molecular do Instituto do Coraçăo/HC/FMUSP- Tel: $0 \times \times 11-30667544)$. Dr Raimundo Marques do Nascimento Neto e Dr. Charles Simão Filho (Fundação Casa do Coração- Tel: 32746839 ). Obrigadol

ESCLARECIMENTOS DADOS PELO PESQUISADOR SOBRE GARANTIAS DO SUJEITO DA PESQUISA

- Acesso, a qualquer tempo, às informaçós sobre procedimentos, riscos e beneficios relacionados à pesquisa, inclusive para dirimir eventuais dúvidas

- Liberdade de retirar seu consentimento a qualquer momento e de deixar de participar do estudo. sem que isso traga prejulzo à comunidade da assistência

- Salvaguarda da confidencialidade, sigilo e privacidade.

- Disponibilidade de assisténcia no Servico Municipal de Saúde, por eventuais danos à saúde, decorrentes da pesquisa.

- Viabilidade de indenizaçăo por eventuais danos à saúde decorrentes da pesquisa.

CONSENTIMENTO PÓSESCLARECIDO

Declaro que, apos convenientemente esclarecido pelo pesquisador e ter entendido o que me foi explicado consinto em participar do presente Protocolo de Pesquisa

Ouro Preto,

de 2001 
ANEXO IX: ORIENTAÇÕES GERAIS DO MANUAL DE INSTRUÇÕES Pi ENTREVISTADOR

Na administração dos questionários deve -se seguir algumas regras gerais:

deve -se usar as mesmas palavras do questionário;

> se a pessoa entrevistada năo responde ou der a impressăo de năo haver entendido da primeira vez deve-se repetir as perguntas da mesma forma;

> se a pessoa entrevistada náo responde ou náo entende, deve-se formular a pergunta uma terceira vez usando outras palavras com o mesmo significado das perguntas originais;

$>$ deve -se anotar as perguntas sem realizar nenhuma interpretação;

> não se deve exercer nenhuma influencia sobre as respostas;

$>$ deve-se formular todas as perguntas e anotar todas as respostas a menos que indique 0 contrário.

\section{Objetivo do Estudo}

Identificar os fatores de risco para doenças cardiovasculares no Município de Ouro Preto, MG, atravếs da aplicaçăo de questionário domiciliar, por amostragem.

\section{Aspectos Éticos da Pesquisa}

1. Apresentar-se ao informante, devidamente documentado, inclusive usando um crachá próprio, citando as instituiçóes que estáo envolvidas na realizaçáo do estudo em questáo: UFOP, PMOP, SMC, sua profissão e o lugar onde estuda.

2. Explicar aos familiares os objetivos da pesquisa e solicitar sua permissão para realizar a entrevista.

3. Assegurar aós entrevistados o SIGILO SOBRE AS INFORMAÇÕES FORNECIDAS e sua utilização exclusivamente voltada para a finalidade do estudo das condições de saúde e nutrição das familias entrevistadas.

4. Somente ao final da entrevista, orientar as famílias, quando necessário, sobre o manejo de situações comuns incluídas no questionário, tais como adequada utilização dos alimentos, valor nutricional dos mesmos, entre outras.

5. Aconselhar a procura de um centro de saúde, não só em caso de enfermidades, mas de forma regular para o monitoramento do crescimento e vacinaçáo de rotina.

6. Encontrando-se indivíduos com problemas de saúde ou nutrição, estes devem ser orientados para o im ediato encaminhamento ao serviço de saúde. 
INSTRUÇÖES GERAIS:

1. Formular as perguntas exatamente como estão escritas, sem enunciar as alternativas de respostas. Caso necessário, repetir a pergunta de maneira sucinta conforme instruçóes e, em último caso, enunciar todas as opçóes. TOMAR CUIDADO PARA NÃO INDUZIR AS RESPOSTAS.

2. Considerar como "unidade familiar" aquela constituída por todos que fazem regularmente as refeiçōes juntos. Empregadas domésticas não devem ser consideradas como da mesma familia, mesmo que morem no emprego. Portanto, caso seja encontrada uma empregada doméstica que tenha filhos, deve-se preencher outro questionário, mesmo que ela more e faça suas refeiçôes com a familia. Suas refeiçóes podem entrar no item "acréscimos à renda familiar".

3. Sempre que houver dúvida, escrever por extenso a resposta do informante e deixar para o supervisor decidir ao final do dia.

4. Quando uma resposta de um inform ante parecer pouco confiável, anotá-la e fazer comentários.

5. NÃO DEIXE RESPOSTAS EM BRANCO. Quando o informante não souber responder utilize a resposta "ignorado" e codifique com o " 9 " ou " 99 ", somente em último caso. Aproveite mesmo as informaçóes aproximadas. Ex.: renda mensal entre 100 e 200 reais, anotar 150 reais. Quando a pergunta não se aplica àquele caso ou houver instrucões para pular de uma pergunta para outra mais adiante, utilizar a resposta "náo se aplica" e codificar com o "8" ou "88". ATENÇÃO: O tópico 2 - Caracterização dos Moradores - possui códigos especificos para suas opçóes de resposta.

6. NÃO TENTE FAZER CONTAS DURANTE A ENTREVISTA, pois este procedimento pode conduzir a erros. No momento da codificaçăo realizar as conversóes dos valores informados para os valores pedidos pelo questionário.

7. Ao final do dia não esquecer de REVISAR AS INFORMAÇÕES COLHIDAS para identificar possiveis erros e proceder à codificação das perguntas.

Anotar cada domićlio visitado no "Relatório Diário de Campo", assim como a situaçăo dọ questionários, agendando possiveis retornos. Nos casos em que năo encontrar o informante adequado passar imediatamente à casa seguinte, obedecendo as características de renda e nivel educacional.. Incluir no relatório as perdas de domicílio e o motivo da perda (recusa, casa desocupada, abandonada, etc.). Observe o exemplo a seguir:

\begin{tabular}{|l|l|l|}
\hline Data & Endereço do domicílio & Situação do questionário \\
\hline $22 / 03$ & Av. Francisco Salles 206/301. Floresta & Completo \\
\hline $22 / 03$ & R. Bernardo Guimarăes 123 & Perda - casa abandonada \\
\hline $22 / 03$ & Av. Assis Chateaubriant 219 - Florestas & $\begin{array}{l}\text { Incom pleto - Voltar para completá -lo em } \\
25 / 03 \text { à tarde }\end{array}$ \\
\hline $23 / 03$ & R. São Bartolomeu, 507 Céu Azula & Perda - recusa \\
\hline
\end{tabular}

9. $O$ indivíduo a ser entrevistado deverá ter idade de 15 anos ou mais. 
ANEXO X: INSTRUÇÕES ESPECÍFICAS: AVALIAÇÃO NUTRICIONAL

\section{Identificaçăo e Controle}

A unidade de pesquisa é a familia, entendida como o grupo de indivíduos que dividem a mesma estratégia de sobrevivência, ou seja, dividem um mesmo orçamento e preparam suas refeiçóes juntos.

1. Data: Anotar a data da entrevista

2. $N$ de questionários: Caso haja mais de uma familia no mesmo domicilio, numerar de 1 a $n$. Havendo apenas uma família, marque com um traço (-).

\section{Antropometria}

Serão tomados o peso e a estatura dos indivíduos com 15 anos ou mais que compóe a amostra

PESO

Preparação do Material: Será utilizada balança eletrônica digital com antropômetro, com capacidade para $136 \mathrm{~kg}$ e divisão de $50 \mathrm{~g}$, funcionando à base de bateria. As baterias deverão ser desconectadas ao final do dia de trabalho. Ao ligar a balança, esperar que fique zerada para iniciar a pesagem.

Técnica de Pesagem dos adultos: Pesá-los com roupas leves, descalços, sem adornos, carteiras, seguindo os mesmos cuidados descritos na aferiçăo anterior.

Percentual de gordura: Apertar SET, selecionar o número do paciente e se o mesmo é adulto ou criança (até 18 anos incompletos se considerará CRIANÇA), escolher o sexo. Registrar a altura do paciente, esperar a balança zerar. Posicionar o paciente com os calcanhares na parte metálica da balança e esperar para a leitura do peso e posteriormente do \% de gordura. OBS: Antes de medir $\% \%$ de gordura solicitar ao paciente o esvaziamento da bexiga.

\section{ESTATURA}

Preparaçăo do Material: A mediçăo da estatura se fará por mejo do antropồmetro acopladọ à balança. No caso da medição de adultos talvez se faça necessário o uso de um banquinho para que o entrevistador possa realizar a leitura.

Técnica de Medição: Retirar os sapatos e meias do indivíduo e colocá-la de pé (1), com os pés unidos pelos calcanhares sobre uma folha de papel em branco. Delimitar os pés do indivíduo com uma caneta, fazendo uma plataforma no papel. Posicionar o indivíduo encostada no antropômetro com os pés encaixados dentro da plataforma desenhada. Enquanto um entrevistador pressiona os pés do indivíduo junto ao chão para que estes não se desloquem da plataforma, o outro coloca a mão sob o queixo do indivíduo e posiciona a sua cabeça de maneira que a base do queixo forme um ângulo de $90^{\circ} \mathrm{com}$ a régua do antropômetro onde o indivíduo está encostada. Assegurar-se de que as nádegas, os ombros e a parte posterior da cabeça estão tocando a régua, estando os braços soltos ao longo do corpo (1). Deslizar lentamente o "esquadro" sobre a superfície plana até tocar a cabeça do indivíduo. Pedir ao indivíduo que se retire com cuidado do local onde está encostada $O$ esquadro deve permanecer imóvel quando o individuo se deslocar. Se o esquadro se elevar, deve-se medir o indivíduo novamente. Ler em voz alta a medida encontrada na parte inferior onde o esquadro toca a régua e anotar o valor encontrado imediatamente.

Obs. Para a medição de adultos o procedimento é o mesmo com exceção do desenho dos pés na folha de papel. 


\section{ANEXO XI: INSTRUÇÕES ESPECIFICAS: AVALIAÇÃO DO CONSUMO ALIMENTAR}

\section{Identificaçăo e Controle}

A unidade de pesquisa é a fam ilia, entendida como o grupo de indivíduos que dividem a mesma estratégia de sobrevivência, ou seja, dividem um mesmo orçamento e preparam suas refeiçóes juntos.

1. Data: Anotar a data da entrevista

2. $N$ de ordem: Esta numeraçáo será feita pelo coordenador, correspondendo à seqüência de domicílios já visitados.

3. $\mathrm{N}$ de questionários: Caso haja mais de uma familia no mesmo domicilio, numerar de 1 a $\mathrm{n}$. Havendo apenas uma família, marque com um traço $(-)$.

\section{Freqüência semi-quantitativa de consumo de alimentos}

A freqüência de consumo a ser observada refere -se ao período do mês anterior ao da entrevista. A quantidade a ser anotada refere-se à porçáo média habitualmente consumida por refeição no mesmo período.

Quando um alimento fizer parte no registro fotográfico ("book") anotar o código correspondente à porção e o número de porçóes consumidas por refeição na coluna apropriada .

No levantamento de consumo de bebidas como café, chás e sucos perguntar sobre a quantidade de açúcar utilizada para adoçar e incluir tudo na linha correspondente a este último. Caso a bebida tenha sido adoçada na preparação, anotar a quantidade total utilizada, o volume final e o volume ingerido pelo indivíduo para estimar a porçăo individual de açúcar. Verificar, ainda, se este nầo está sendo utilizado em preparaçôes năo muito usuais como em frutas, água com açúcar, entre outras.

Atentar para o fab de que a freqüência a ser levantada é aquela em que o alimento é consumido e não comprado ou preparado.

Prestar atenção para não induzir uma resposta sobre uma freqüência determinada de consumo. Após insistir com o indivíduo sobre a tentativa de aproximação do intervalo de tempo de consumo dos alimentos, listar as opcóes de freqüência para que ele escolha uma delas.

Caso o entrevistador náo entenda o significado da palavra "freqüência", a pergunta sobre pode ser formulada da seguinte maneira: de quan to em quanto tempo o alimento " $X$ " é consumido.

Tomar cuidado para năo fazer perguntas fora do contexto sócio-econồmico em que vivem as familias de uma determ inada região para evitar constrangimentos e possiveis respostas falsas. Ex.: perguntar sobre o consumo de alimentos de alto custo (presunto, apresuntado, requeijão cremoso, etc.) em fam ilias de baixa renda.

No grupo das carnes (carne de boi, frango, peixe, carne de porco) poderá ser necessário anotar a freqüência de consumo em termos de $n^{\circ}$ de vezes por mês, principalmente na população de baixa renda. 
ANEXO XII: INSTRUÇÕES ESPECIFICAS: CARACTERIZAÇÃO DA FAMÍLIA

\section{Identificaçăo e Controle}

A unidade de pesquisa é a fam flia, entendida como o grupo de indivíduos que dividem a mesma estratégia de sobrevivência, ou seja, dividem um mesmo orçamento e preparam suas refeições juntos.

1. Data: Anotar a data da entrevista

2. $N$ de ordem: Esta numeraçáo será feita pelo coordenador, correspondendo à seqüência de domicílios já visitados.

3. $N$ de questionários: Caso haja mais de uma familia no mesmo domicilio, numerar de 1 a $\mathbf{n}$. Havendo apenas uma família, marque com um traço $(-)$.

\section{Caracterização da família}

Nome: anotar o nome de cada membro (não necessita ser o nome completo); sempre que possivel, o respondente deve ser a pessoa mais diretamente relacionada com o abastecimento de alimentos.

Condição na família: anotar na frente de cada nome segundo o código correspondente.

Sexo : feminino ( $F)$ ou masculino (M).

Idade: anotar a idade, em anos, de cada membro com mais de 1 ano; no caso do indivíduo ser menor de um ano, anotar quantos meses de vida.

UF : anotar com a sigla correspondente o Estado de origem

Nivel de instruçăo: anotar segundo os estratos pré-estabelecidos.

Ocupaçăo: esta informação corresponde à atividade atual que cada indivíduo executa (nâo confundir com profissão).

Atencão: A partir deste momento, cada indivíduo está relacionado com um número de ordem (número do canto esquerdo da tabela "CARACTERIZAÇÃO DA FAMÍLIA"), desta maneira, em todo o decorrer do questionário náo será mais especificado o nome de cada indivíduo e estes serão referidos somente pelos seus números de ordem, por isso é importante o entrevistador náo confundir ou alterar estes números. 


\section{ANEXO XIII: INSTRUÇÕES ESPECÍFICAS: NIVH SÓcIO-ECONÔMICo}

\section{Identificação e Controle}

A unidade de pesquisa é a familia, entendida como o grupo de indivíduos que dividem a mesma estratégia de sobrevivência,ou seja, dividem um mesmo orçamento e preparam suas refeicóes juntos.

1. Data: Anotar a data da entrevista

2. $\mathrm{N}^{\circ}$ de ordem: Esta numeração será feita pelo coordenador, correspondendo à sequiencia de domicllios já visitados.

3. $\mathrm{N}^{\circ}$ de questionários: Caso haja mais de uma familia no mesmo domicilio, numerar de 1 a $\mathrm{n}$. Havendo apenas uma familia, marque com um traço (--)

\section{Indicadores de renda}

1. Quantas pessoas na familia recebem alguma remuneração por seu trabalho ou aposentadoria? Anotar o número de pessoas.

2. Quantos estăo desempregados? Anotar o número de pessoas.

3. Há quanto tempo? Anotar o tempo, em meses, para cada individuo desempregado (note que neste caso năo é necessário identificar cada desempregado).

4. Qual foi a renda total de sua familia, incluindo salários, aposentadoria, pensões e outros rendimentos como aluguéis, no més passado, em R\$. Anotar o valor total declarado.

5. Empregada doméstica: Empregada doméstica: considerar apenas os empregados mensalistas, isto é, aqueles que trabalham pelo menos 5 dias por semana, durmam ou năo no emprego. Não esquecer de incluir babas, motoristas, cozinheiras, copeiras, caso atendam o quesito acima

\section{Equipamentos e eletrodomésticos}

No levantamento de aparelhos eletrodomésticos devemos considerar:

Năo considerar o bem alugado em carater eventual, emprestado para outro domiclio há mais de 6 meses quebrado há mais de 6 meses e bem de propriedade de empregados ou pensionistas.

Considerar:

- Televisores: somente os coloridos

- Rádio considerar qualquer tipo de rádio do domicilio, mesmo que esteja incorporado a outro equipamento de som ou televisor, etc. Não considerar o rádio do carro.

Automóvel: Năo considerar os velculos utilizados para a atividade profissional ( táxis, Vans para frete) velculos de uso misto ( lazer e profissional) não devem ser considerados.

- Aspirador de po: Considerar mesmo que seja portátil e também máquina de limpar a vapor (tipo Vaporeto).

Máquina de lawar: perguntar sobre a existência da máquina de lavar mas quando mencionado espontaneamente o Tanquinho, ele deve ser considerado.

- Videocassete: considerar qualquer tipo de videocassete

\section{Caracterização sócio-demográfica}

1. MIGRAÇÄO

1.1 Há quanto tempo vocẻ mora Belo Horizonte? Refere-se ao tempo em que a "mãe" está morando no municipio. Assinalar apenas uma alternativa e anotar o tempo em meses caso seja menor que 12 meses e emanos quando for superior a esse perlodo.

1.2 Onde morou anteriormente? Registrar o nome de outro municipio quando se tratar do estado de Minas Gerais e quando for originário de outro estado anotar o nome do mesmo. 


\section{ANEXO XIV: ORIENTAÇÕES: TÉCNICA DE AFERIÇÃO DA PRESSÃO ARTERIAL}

1. Deve-se orientar a pessoa que evite as seguintes atividades, pelo menos uma hora antes de medir a pressão arterial: realizar exercicios extenuantes, fumar, tomar medicamentos que afetem a pressão arterial, comer ou beber qualquer coisa que não seja agua. Além disso, a pressão arterial pode ser afetada pela bexiga cheia, devendose orientar a pessoa a este respeito

2. A pessoa deve tirar casaco, etc, que esteja vestindo. Deve levantar a manga da camisa para que o antebraço fique exposto e se possa colocar a correia do aparelho para medir a pressão arterial. A manga năo deverá apertar o braço nem se deve colocar a correia em cima da roupa. Se a roupa dificultar para a medição, devese pedir a pessoa que a tire e coloque uma camisa de manga curta.

3. O exame deve ser realizado num recinto tranqüilo ou silencioso com a temperatura controlada.

4. O aparelho usado deve ter $12-12,5 \mathrm{~cm}$ de largura, o suficiente para cobrir no minimo $2 / 3$ do antebraço.

5. A pressão arterial deve ser medida depois de um descanso de pelo menos 5 minutos, sentado usando o braço direito, exceto quando houver deformidade. Ao estar sentado, o braço da pessoa deve estar apoiado sobre a mesa de tal maneira que fossa anticubital fique no mesmo nivel do coraçăo. Para consegui - bo, devese modificar a posição da pessoa na cadeira, ou entăo pode-se levantar ou abaixar o braço sobre o apoio comodo. A pessoa, objeto da mediçăo, deve estar sempre comoda.

6. Deve-se colocar bem a correia para evitar que se mova. Os tubos de brracha devem estar em forma simétrica a cada lado da fossa cubital (para que a parte central da bolsa de borracha ou tubo, cubra a artéria braquial). A borda inferior da correia deve estar dois a três centímetros acima da fossa cubital, para deixar espaço suficiente para o estetoscópio. A borda superior da correia não pode estar limitada pela roupa

7. O observador deve estar numa posição cômoda em relação a mesa onde se realiza o exame. Uma vez transcorridos os cinco minutos nesta posicão (periodo durante o qual pode se explicar o processo da afericão à pessoa examinada). Deve -se estabelecer um nfwel máximo de insuflação Trata-se do nlvel em que deve chegar a pressăo na mesma medição da pressão arterial.

O examinador

A) toma o pulso radial da pessoacomos dedo da mão esquerda

B) infla a correia até o desaparecimento do pulso radial e anota o walor mais próximo que seja múltiplo de 2 e soma 30 a esta cifra (esta soma se chama nvel de insuflaçáo máxima)

8- A seguir o examinador volta a correia e espera durante pelo menos 30 segundos, ou levanta o braço da pessoa durante 5 segundos, para deixar que o sangue volte as veias do antebraço. Depois, o examinador localiza o pulso braquial da pessoa e coloca a campanula do estetoscópio imediatamente abaixo da correia no ponto de pulsação maxima. Se não for possivel sentir e localizar o pulso, deve-se colocar a campanula do estetoscópio em cima da parte superior do braço dentro do tendão do músculo do b/ceps. A campanula do estetoscopio não deve tocar a correia, a borracha ou a roupa. O examinador infla a correia rapidamente até chegar a uma pressão equivalente ao nfwel de insuflacão maxima. Deste ponto o examinador comeca a reduzir a pressăo em $2 \mathrm{mmHg}$ por segundo de forma constante até registrar o nivel de pres são sistolica e diastólica da fase 5 , para logo eswaziar rapidamente a correia. Os valores da pressão arterial devem ser anotados.

9. O examinador volta a conectar a correia e o esfignomanômetro, levanta o braco da pessoa durante 5 segundos ou espera 30 segundos no máximo e logo volta a repetir a medição exatamente da mesma maneira anterior. Se o examinador tiver dificuldades para ouvir o som, deve esvaziar completamente a correia e esperar 30 segundos no mínimo antes de tomar a mediçăo seguinte

10- O examinador anota os valores de ambas medições. 


\section{ANEXO XV: INSTRUÇÕES DO QUESTIONÁRIODE MEDICAMENTOS}

- Geralmente as pessoas esquecem ou minimizam o uso de medicamentos, no entanto estes costumam guardar os fármacos mesmo depois do uso portanto, é importante que o entrevistador confira o local de amazenamento dos fármacos, se possivel.

- É de fundamental importância que os estudantes de farmácia, no momento da verificação do armazenamento confiram o estado de conservação e a data de validade dos medicamentos.

- No preenchimento do questionário devem ser consideradas todas as substâncias que o paciente considera como medicamento. Ex.: berinjela utilizada para controlar os níveis de colesterol, chá de boldo para ressaca, etc.

É importante salientar que chás, alimentos e outros que são utilizados sem fins terapêuticos não devem ser incluídos.

\begin{tabular}{|c|c|c|c|c|c|c|c|c|c|c|c|}
\hline Medicamento & Para que? & $\begin{array}{c}\text { Quem } \\
\text { indicou? }\end{array}$ & Freqüencia & Posologia & $\begin{array}{c}\text { Ultimo } \\
\text { uso }\end{array}$ & Via & Vefculo & $\begin{array}{c}\text { Relaçãó } \\
\text { Refeiçöes }\end{array}$ & Dose & Obtençäo & $\begin{array}{c}\text { Armaze- } \\
\text { namento }\end{array}$ \\
\hline Diazepan & F/dormir & 1 & 1 & $1 /$ dia/lano & 0 & 1 & 1 & 3 & $10 \mathrm{mg}$ & 2 & Quarto \\
\hline $\begin{array}{c}\text { Chá } \\
\text { Camomila }\end{array}$ & Acalmar & 4 & 2 & $1 /$ dia/1dia & $2 \mathrm{~m}$ & 1 & 1 & 4 & - & 3 & $\begin{array}{c}\text { Sem } \\
\text { Estoque }\end{array}$ \\
\hline Omeprazol & Queimação & 1 & 1 & $1 /$ dia/1m & $6 \mathrm{~m}$ & 1 & 1 & 2 & $10 \mathrm{mg}$ & 2 & Quarto \\
\hline Omeprazol & Queimaçăo & 3 & 1 & $1 / \mathrm{sem} / 6 \mathrm{~m}$ & $2 \mathrm{~d}$ & 1 & 1 & 2 & $10 \mathrm{mg}$ & 2 & Quarto \\
\hline
\end{tabular}

Na coluna "Para que?" - deve ser transcrito as informações do próprio paciente, năo importando a verdadeira indicação do fármaco.

Na coluna "Último uso" - se o tratamento é crônico colocar 0.

Na coluna "Relação com Refeições" - Qualquer tipo de refeição incluindo leite, suco, café, etc. A opção "variável" indica que o medicamento é tomado quando aparecem os sintomas, não mantendo hora fixa.

Na coluna "dose" - caso o medicamento não traga a dose indicada na embalagem basta no item medicamento discriminar sua apresentação e depois será consultada a sua dose.

O caso do omeprazol mereceu duas classificações devido a uma indicação de úlcera péptica que a paciente tratou. No intuito de evitar recidivas a paciente continuou tomando o medicamento só que este apresentava nova posologia e nova indicação. 